

\section{Language and the Making of Modern India}

Through an examination of the creation of the first linguistically organized province in India, Odisha, Pritipuspa Mishra explores the ways regional languages came to serve as the most acceptable registers of difference in post-colonial India. She argues that rather than disrupting the rise and spread of all-India nationalism, regional linguistic nationalism enabled and deepened the reach of nationalism in provincial India. Yet this positive narrative of the resolution of Indian multilingualism ignores the cost of linguistic division. Examining the case of the Adivasis of Odisha, Mishra shows how regional languages in India have come to occupy a curiously hegemonic position. Her study pushes us to rethink our understanding of the vernacular in India as a powerless medium and acknowledges the institutional power of language, contributing to global debates about linguistic justice and the governance of multilingualism. This title is also available as Open Access.

Pritipuspa Mishra is a Lecturer in History at the University of Southampton. 


\section{Language and the Making of Modern India}

Nationalism and the Vernacular in Colonial Odisha, 1803-1956

Pritipuspa Mishra

University of Southampton 


\section{CAMBRIDGE \\ UNIVERSITY PRESS}

University Printing House, Cambridge CB2 8BS, United Kingdom

One Liberty Plaza, 20th Floor, New York, NY 10006, USA

477 Williamstown Road, Port Melbourne, VIC 3207, Australia

314-321, 3rd Floor, Plot 3, Splendor Forum, Jasola District Centre, New Delhi - 110025, India

79 Anson Road, \#06-04/06, Singapore 079906

Cambridge University Press is part of the University of Cambridge.

It furthers the University's mission by disseminating knowledge in the pursuit of education, learning, and research at the highest international levels of excellence.

www.cambridge.org

Information on this title: www.cambridge.org/9781108425735

DOI: $10.1017 / 9781108591263$

(C) Pritipuspa Mishra 2020

This work is in copyright. It is subject to statutory exceptions and to the provisions of relevant licensing agreements; with the exception of the Creative Commons version the link for which is provided below, no reproduction of any part of this work may take place without the written permission of Cambridge University Press.

An online version of this work is published at doi.org/10.1017/9781108591263 under a Creative Commons Open Access license CC-BY-NC 4.0 which permits re-use, distribution and reproduction in any medium for non-commercial purposes providing appropriate credit to the original work is given and any changes made are indicated. To view a copy of this license visit https://creative commons.org/licenses/by-nc/4.0

All versions of this work may contain content reproduced under license from third parties.

Permission to reproduce this third-party content must be obtained from these third-parties directly.

When citing this work, please include a reference to the DOI 10.1017/ 9781108591263

First published 2020

Printed in the United Kingdom by TJ International Ltd, Padstow Cornwall A catalogue record for this publication is available from the British Library.

ISBN 978-1-108-42573-5 Hardback

Cambridge University Press has no responsibility for the persistence or accuracy of URLs for external or third-party internet websites referred to in this publication and does not guarantee that any content on such websites is, or will remain, accurate or appropriate. 
For my parents Puspamitra and Amarnath Mishra In love and gratitude 


\section{Contents}

List of Maps

Acknowledgments

page viii

ix

Introduction: Nation in the Vernacular 1

1 How the Vernacular Became Regional 31

2 Vernacular Publics: A Modern Odia Readership Imagined

3 The Odia Political Subject and the Rise of the Odia Movement

4 Odisha as Vernacular Homeland

5 The Invisible Minority: History and the Problem of the Adivasi

6 The Genius of India: Linguistic Difference, Regionalism, and the Indian Nation

Postscript

Bibliography

Index 


\section{Maps}

1. Political map of India ca. 1908.

page xii

2. Political map of India ca. 1956.

3. Political map of India 2018.

4. 1870 map of Orissa Division of Bengal Presidency and associated princely states.

5. 1905 map of Orissa Division of the Bengal Presidency.

6. 1912 map of the new province of Bihar and Orissa.

7. 1936 map of the newly formed Orissa Province. 


\section{Acknowledgments}

I have carried the early versions of this book with me as I have moved across the world and made my home in many different localities. And through these journeys, this book has been fed by numerous conversations and friendships. The book began its life as a $\mathrm{PhD}$ dissertation at the University of Minnesota. Under Ajay Skaria's guidance, an incredible mix of kindness and intellectual challenge, I learned to hone in on my central conceptual concerns for this project. Simona Sawhney's generous mentorship pushed me to find my academic voice. Her insightful yet cryptic questions have often shown me the promise of my own work when I failed to see it myself. I am also indebted to the Qadri Ismail, John Mowwit, Tom Wolfe, Fleur D'Souza, Anindita Mukhopadhyay Dilip Menon, and Barbara Welke for their liberal sharing of their time and expertise.

I have been fortunate to receive funding at critical points in developing, researching, and completing this book. Funding from the American Institute of Indian Studies, the University of Minnesota, and Texas A\&M University supported archival research for the book. Funding from Princeton University in the form of a Fung Global Fellowship and the generous research leave from the University of Southampton have allowed me space to write the book.

My research on the history of Odisha took me to a number of archives and libraries. I am deeply grateful to the staff at the Odisha State Archives for their warm welcome and extremely helpful investigative tips that helped me explore the archive. I also received valuable help from the staff of the Madras State Archives, the Nehru Memorial Museum, the National Archives, Utkal Sahitya Samaj Library, Kedarnath Gabesana Sansad, Odisha State Museum, and the British Library.

Over the years, friends and colleagues have had an enormous impact on the final shape of the book. At Minnesota, N'Jai-An Patters, Papori Bora, Emily Rook-Koepsel, Aditi Chandra, Julietta Singh, Sarah Crabtree, Katie Levin, and Nadim Asrar sustained the early development of this project with great friendships and intellectual camaraderie. At College 
Station, Lisa Ramos, Molly Warsh, Jason Parker, Rebecca Schloss, Leah Devun, Jayson Brewster-Jones, and Olga Dror helped me tease out the new current shape of the book. At Princeton, I was fortunate to be involved in intense and insightful discussions about language and authority with Michael Gordin, Brigitte Rath, Ying Ying Tan, Helder Descutter, David Kiwawa, Beate Witzler, Adam Clulow, Rosina Lozano, and Michael Laffan. This book bears many imprints of their impact on my thinking. At Southampton, I have had brilliant colleagues, including Ian Talbot, Stephanie Jones, Jesse Ransley, Eleanor Jones, John McAleer, Joan Tumblety, Nick Karn, Christer Petley, David Brown, Justine Puzzo, Sarah Hayden, and Sophie Holmes Elliot, who have all provided a rigorous intellectual climate for the final development of the book. Conversations with colleagues in India, including Sowmya Dechamma, Asha Sarangi, Kailashchandra Das, and Veena Naregal, have helped me clarify the political stakes of my work. I would like to thank Lucy Rhymer of Cambridge University Press for her expert shepherding of this manuscript into the finished book. I am grateful to the anonymous readers for their insightful and productive engagement with my work.

Finally, I have been blessed with the support of a wonderful family. My parents, Amarnath and Puspamitra Mishra, have been central to the research enterprise involved in this project. They have enthusiastically accompanied me in my meandering journey through many Indian archives. As I continued to read and analyse Oriya documents, my parents exposed me to the complex texture of nineteenth-century Oriya prose. Irrespective of its outcome, this project has enabled me to catch a glimpse into the intellectual lives of my parents. It is not often that children have that privilege. I thank them for allowing me in. Swapnapushpa Mishra and Deepak Konale have provided much needed motivation and perspective to an otherwise obsessive process. The late $\mathrm{K}$. G. S Mani, R. Asha, and G. Nithya entered my life at a crucial point of this project and joined the rest of my family in cheering me on. I thank them for their unquestioning acceptance and love. This book would not have been possible without the love and unwavering support from Bharath and Riya as they have shared me with this project over the last few years. 


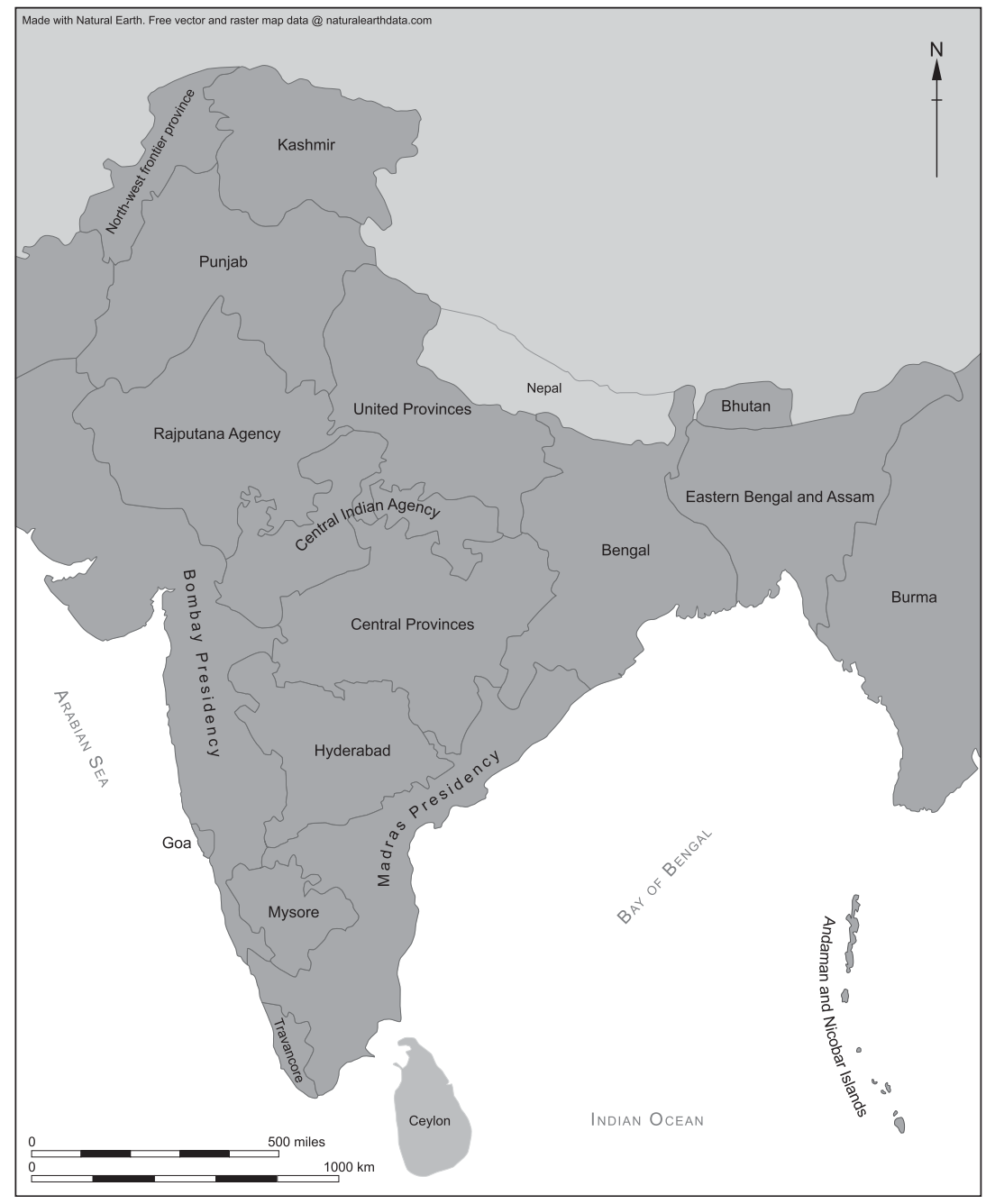

Map 1. Political map of India ca. 1908. 


\title{
Introduction
}

\author{
Nation in the Vernacular
}

Thou art the ruler of the minds of all people, Dispenser of India's destiny.

Thy name rouses the hearts of Punjab, Sindhu, Gujarat and Maratha, Of the Dravida, Utkala and Bengal;

It echoes in the hills of the Vindhyas and Himalayas, mingles in the music of Yamuna and Ganga and is chanted by the waves of the Indian Ocean.

They pray for thy blessings and sing thy praise.

The saving of all people waits in thy hand,

Thou dispenser of India's destiny. Victory, victory, victory to thee.

In the National Anthem, India is portrayed as a collection of images, some geographical and some linguistic. Written by Rabindranath Tagore in 1911, this poem staked out linguistic regions long before they were officially formed. By juxtaposing language-based regions such as Punjab, Gujarat, Maratha, Utkala, and Banga with geographical features of the Indian landscape such as the mountains of Vindhyas and Himalayas, the Ganga and Yamuna rivers, and the Indian Ocean, the anthem endows these linguistic regions with a naturalness that can be belied by an attention to the history of how they came to be formed in modern India. Just as mountains, rivers, and oceans were seen as primeval features of the national landscape, so, too, were the territorial domains of these languages. Akhil Gupta has argued that in invoking these linguistic regions, the National Anthem also referenced the speakers, their culture, and social life. ${ }^{1}$ In marking these fragments of the nation, the Anthem was therefore a site where difference in India was incorporated and domesticated even as such difference was assigned roles in the fortunes of the nation.

${ }^{1}$ Akhil Gupta, "The Song of the Non Aligned World: Transnational Identities and Reinscription of Space in Late Capitalism", Cultural Anthropology 7, no. 1 (1992): 63-79. 
This neat schema produced a linguistically diverse but, at heart, a united India. What this neatness veils is the truly messy nature of the making of India, particularly from the linguistic and regional angles. Many tensions came to bear on this process: tensions between regional cultural nationalism and Indian unitary nationalism, tensions arising from claims and counterclaims for territory between regions, tensions between regional minorities and the majority linguistic groups and, finally, tensions between the adivasi and the caste Hindu, IndoEuropean language-speaking elites.

The province of Odisha serves as a particularly good site to see how these tensions and their resolution founded the Indian nation. Formed in 1936 as a linguistically defined province, Odisha constitutes a majority Hindu population with a large minority community of adivasis. The movement for the formation of a separate province of Odisha began in the mid-1860s amidst debates about the relative underdevelopment of the Odia language. This movement to amalgamate Odia-speaking areas from the Bengal and Madras Presidencies as well as the Central Provinces ran parallel to the increasingly popular Indian anticolonial movement. Therefore, the modern regional community of Odisha had to be imagined even as the Indian national community was being configured in the political, cultural, and literary spheres.

By tracking the history of Odia linguistic politics and situating it in the broader frame of colonialism and Indian nationalism, this book analyses two interlinking tensions that bear upon the making of regions in India. One, that contrary to governing anxiety about multilingualism often signaled by the refrain "our language problem," regional linguistic politics functioned to strengthen the hold of Indian nationalism. The goal of rescuing regional "mother tongues" from colonial neglect became fundamental to the deepening of Indian nationalism - the aspirations toward distinct regional self and shared national community went hand in hand. Two, that this celebratory narrative needs to be interrupted by a more cautionary approach to linguistic politics that illustrates how being placed within the logic of the nation made regional formations on linguistic basis into sites of hegemonic power, where those who did not fit into the neat linguistic framework of India were absorbed into regional communities as second-class citizens. Thus, not only are regional languages written into the making of the Indian nation, but also written in are the exclusions inevitably involved in the reification of regional Indian languages.

To do this, we need to uncover the labors performed by major Indian languages in the making of modern India, supported by a 


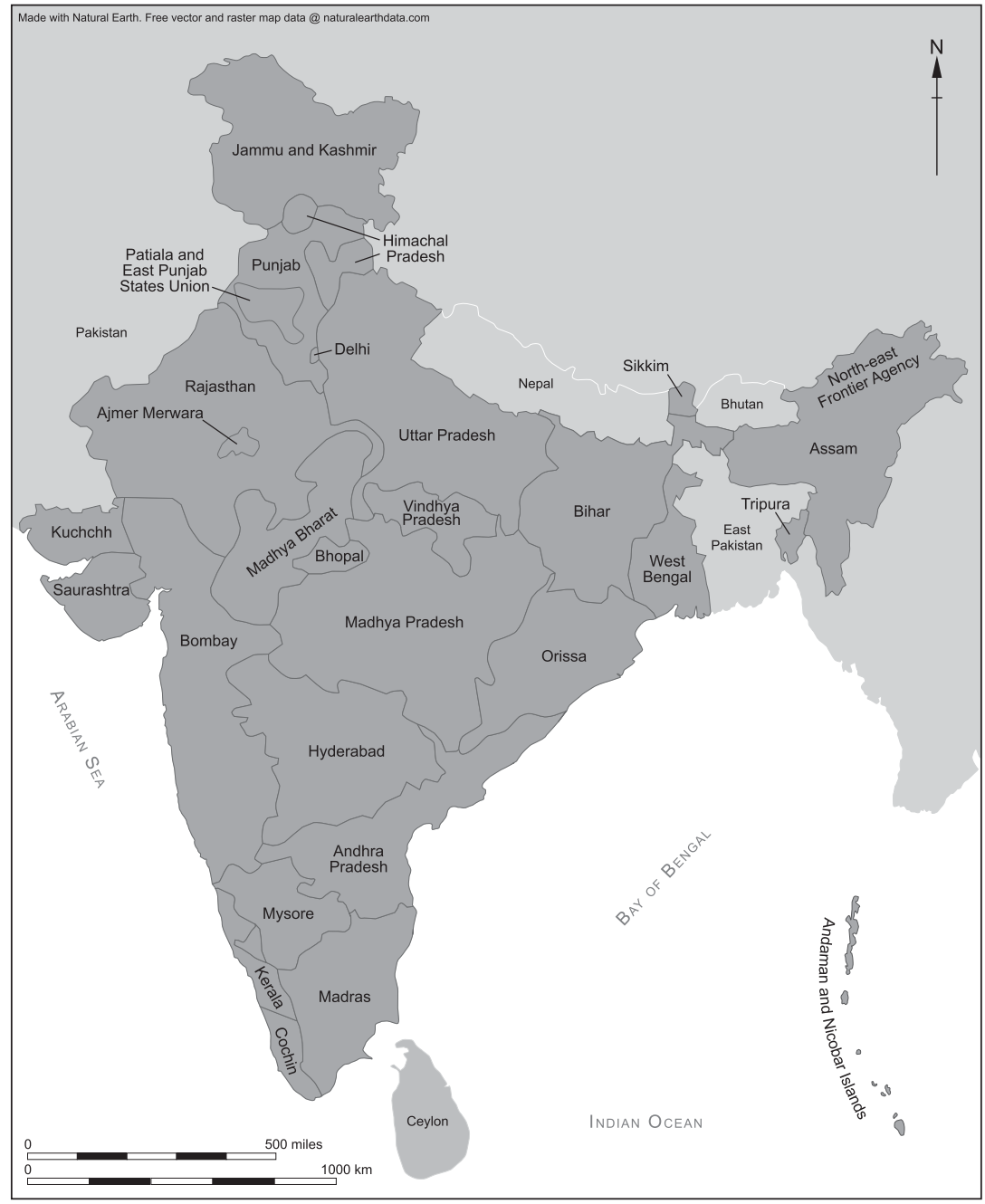

Map 2. Political map of India ca. 1956.

better understanding of the term "vernacular" as it is applied to these languages. Through a history of the making of Odisha, this book proposes that we should supplement our histories of how language produces community with more critical histories of how language is used to mark territory and bolster regional political power. 


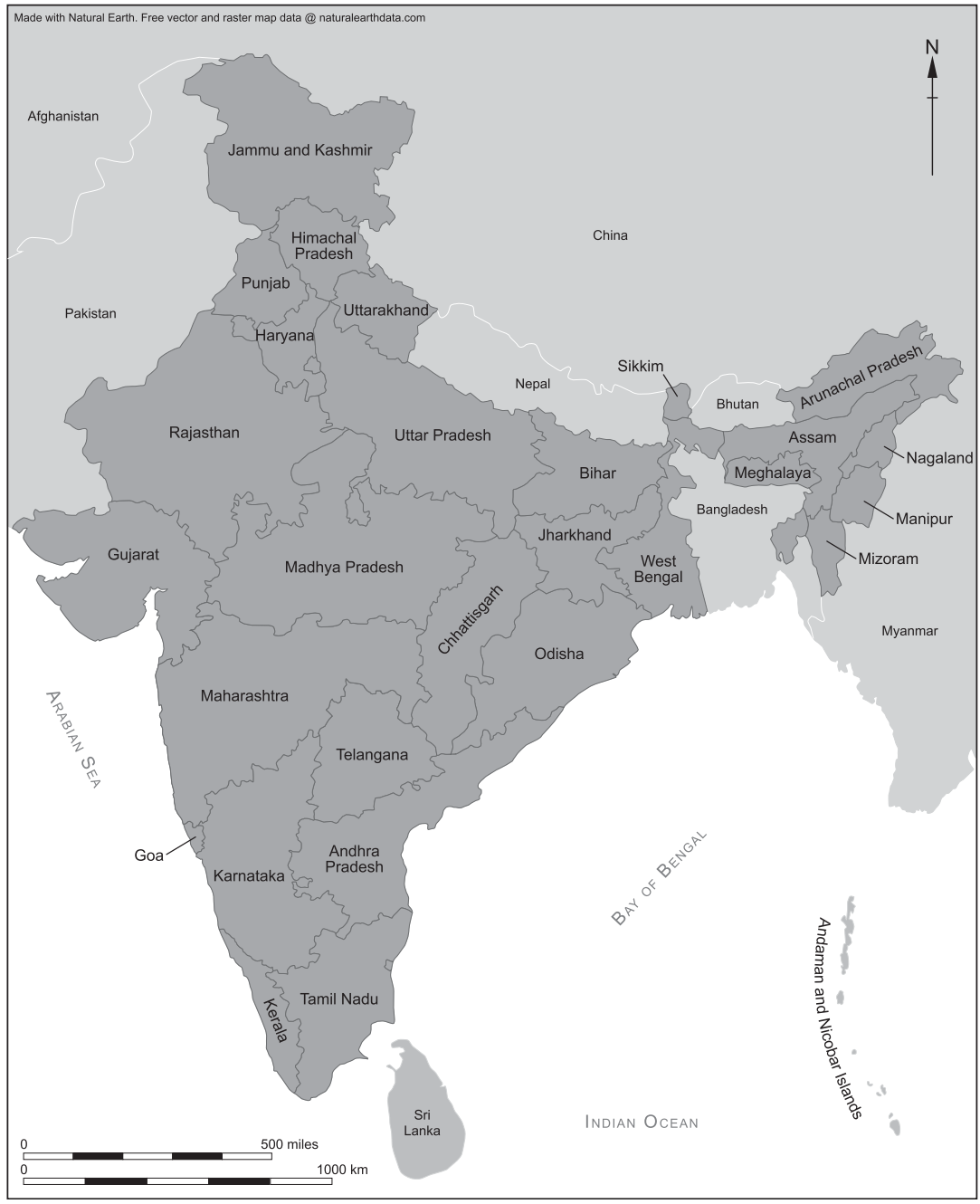

Map 3. Political map of India 2018.

Any attempt to destabilize the sort of naturalized primeval linguistic argument that the National Anthem makes would require us to think about the formation of the linguistic region in a nonpositivist manner. This history will approach these questions by thinking about the contretemps of power, affect, and politics connected to major Indian languages that contribute to the making of regional and national community in India. 


\section{Rethinking "Vernacular": Language and its Sublimation in the Construction of Regional Territory}

Often, in histories of linguistic nationalism in India, an invocation of the term "vernacular" carries with it a suggestion of powerlessness. ${ }^{2}$ This connotation of vernacular as powerless draws from the two dominant paradigms for the understanding of this term in contemporary Indian scholarship. ${ }^{3}$ In scholarship on early modern literary history of India, the vernacular is understood as a diminutive and local counterpart of more dominant cosmopolitan or classical languages such as Sanskrit or Latin. ${ }^{4}$ Then again, in the study of linguistic politics of the nineteenth and twentieth centuries, the term vernacular is used to mark the subalternity of Indian languages and their speakers in relation to the colonizing English language and its speakers. ${ }^{5}$ Comparing vernacular languages to "civilizing" languages such as Sanskrit or "colonizing" languages, like English has defined contemporary Indian life in the nineteenth and twentieth centuries as less than either their own past or the colonized present. In this framework, the major Indian vernaculars appear besieged by a sense of decline from the classical past and inadequacy in relation to the present. ${ }^{6}$ Although current scholars of regional vernacular languages explore the politicization of language in deeply nuanced ways, an a priori assumption about the powerlessness of the vernacular in general prevents

${ }^{2}$ I employ the term "nationalism" in the sense that Sumathi Ramaswamy uses it to understand linguistic politics in colonial Tamil Nadu. Ramaswamy explicitly configured linguistic politics in colonial India within the conceptual framework of nationalism and illustrated that even though such politics does not neatly map onto Western understanding of nationalism, linguistic politics could be understood as "nationalism but different." Sumathi Ramaswamy, Passions of the Tongue: Language Devotion in Tamil India, 18911970 (Berkeley, CA: University of California Press, 1997).

${ }^{3}$ An example of such a discussion would be Rama Sundari Mantena's essay on colonial Telegu, in which she makes explicit reference to both paradigms in explaining her use of the term "vernacular." See Rama Sundari Mantena, "Vernacular Futures: Colonial Philology and the Idea of History in Nineteenth-Century South India", Indian Economic E Social History Review 42, no. 4 (2005): 513-34.

${ }^{4}$ The most prominent example of this school of thought is Sheldon Pollock's definition of the vernacular in Sheldon I. Pollock, The Language of the Gods in the World of Men: Sanskrit, Culture, and Power in Premodern India (Berkeley, CA: University of California Press, 2009).

${ }^{5}$ The most authoritative statement of this paradigm can be found in Ranajit Guha's discussion of historiography in the vernacular in Ranajit Guha, "The Authority of the Vernacular Pasts", Meanjin 51, no. 2 (1992): 299-302.

${ }^{6}$ In his article on colonial translation, Michael Dodson has illustrated how colonial philologists imbued the Indian vernaculars with qualities of inadequacy and degeneration in relation to both English and Sanskrit. Through a brief reading of contemporary English discussions about the connections between language and civilization, Dodson demonstrated how such ascriptions reflected not just on the status of the vernacular itself but also involved a judgment on the civilizational status of the people who spoke it. See Michael. S. Dodson, "Translating Science, Translating Empire: The Power of Language in Colonial North India", Comparative Studies in Society and History 47, no. 4 (2005): 809-35. 
them from asking more exacting questions about the representative power of the vernacular. ${ }^{7}$

Even as scholars historicize the making of vernacular mother tongues in India, there is little attention paid to the hegemonic power of language in the formation of modern Indian territorial and political alignments. ${ }^{8} \mathrm{My}$ reading of political rhetoric on community, history, and territory in the movement for the creation of a separate state of Odisha suggests that the vernacular became powerful precisely due to prevailing assumptions about its indigeneity and its ability to represent and speak for hitherto unrepresented groups along with elite groups. ${ }^{9}$ The capacity of the vernacular to act as a broad-based site of representation is, as I shall illustrate, the product of justificatory strategies employed by movements for Odia linguistic regionalism in negotiations for territorial entitlements of new linguistic provinces. These justificatory strategies, in turn, hinged on arguing for the primacy of language as a basis of community while ensuring that such a claim did not exclude non-Odia speakers from definitions of the Odia community.

${ }^{7}$ Even as I question this investment for the purposes of understanding the role of vernacular languages in colonial and postcolonial Indian polity, I do recognize the political and ethical stakes in this stressing of powerlessness. As Gayatri Chakravorty Spivak mentions in her discussion of strategic essentialism, even though essentialism in academic writing can be ethically suspect, the strategic deployment of essentialism by groups such as the Subaltern Studies Collective to interrogate the structures of colonial power can serve a radical purpose. See Gayatri Chakravorty Spivak, Donna Landry, and Gerald M. MacLean, The Spivak Reader (New York: Routledge, 1996).

${ }^{8}$ Research on the politics of language has traced how the evocation of Indian vernacular languages as the locus of regional community in nineteenth and early twentieth century enabled the emergence of the earliest forms of anticolonial political radicalism in different parts of India. For instance, Farina Mir has illustrated how the colonial government's negligence of Punjabi in favor of Urdu sparked the emergence of an autonomous Punjabi public sphere in which more complex cultural negotiation between the Hindu and Muslim Punjabi-speaking public was possible. See Farina Mir, The Social Space of Language: Vernacular Culture in British Colonial Punjab (Berkeley, CA: University of California Press, 2010) . In her study of the politics of mother tongue in colonial Andhra Pradesh, Lisa Mitchell has illustrated how language emerged as a foundational category in the reorganization of South Indian public life. See Lisa Mitchell, Language, Emotion and Politics in South India: The Making of a Mother-Tongue (Bloomington, IN: Indiana University Press, 2009).

${ }^{9}$ Like other major languages in India, literature in Odia emerged in the sixteenth century as part of radical critique of caste discrimination. This history of Odia as a non-elite language accessible to lower caste, adivasi and Muslim populations of the Odia-speaking areas was often referred to in the rhetoric of the movement for the formation of a separate province of Orissa. For the connections between early Odia literature and social critique, see Satya P. Mohanty, "Alternative Modernities and Medieval Indian Literature: The Oriya Lakshmi Purana as Radical Pedagogy", in Colonialism, Modernity, and Literature: A View from India (New York: Palgrave Macmillan, 2011), pp. 3-21. The vision of early Odia literature as fundamentally populist has spilled into academic writings on the Odia literary history. See Mayadhar Mansingh, History of Oriya Literature (New Delh:, Sahitya Academy 1978), pp. 9-12, where he describes early Odia literature as "essentially proletarian." 
The case of Odisha illustrates how this move was enacted through what I call the "sublimation" of language as the basis of regional territorial divisions. The changing definitions of Odia community and territorial limits of the proposed province illustrate how the foundational nature of language was sublimated through a shift in the definition of regional community from one based on shared language to one based on shared space even as the salience of language in the definition of regional community was maintained. At stake in this sublimation of shared language to shared space was the attempt of Odia leadership to claim tracts of land populated by a sizable non-Odia-speaking adivasi population. The history of the institutional life of the Odia language is also, then, a history of boundary formation in the new state of Odisha. Through a focus on the history of the demarcation of territorial limits of the emergent Odia province in the 1920s and 30s, this book reveals that when it came to the regional organization of Indian territory, the vernacular was anything but powerless. ${ }^{10}$

To truly understand the role of major vernacular languages in the shaping of modern India, we need to revise and expand our assumptions about the implications of the term "vernacular" in nineteenth and twentieth century political and official rhetoric. ${ }^{11}$ While existing definitions of the term take into account the history of linguistic and literary development in early modern India as well as account for the status of the vernacular as the language of the oppressed, these paradigms cannot be borrowed and deployed in the study of regional linguistic politics in nineteenth- and twentieth-century India. Even as Sheldon Pollock's definition of the vernacular acknowledges the institutional status of the literary vernaculars in early modern India as fundamental to the emergence of regional polities, his notion of vernacular as a language of place cannot be directly applied to the modern period where the place-ness of

10 This argument applies to the politics of language beyond the case of Odisha. As an edited volume on language and politics in India indicates, scholars are noting that dominant languages in Indian do play a role in extending regimes of power and authority. See Asha Sarangi (ed.), Language and Politics in India (New Delhi: Oxford University Press, 2009). My understanding of the power of language is drawn from the discussion on language and power in Martin Pütz, Joshua Fishmann, and Joanne Van Neff Aertselaer, "Along the Routes to Power": Explorations of Empowerment through Language (Berlin: de Gruyter Mouton, 2006). In the context of language, Joshua Fishman defines power in this volume as "control over scarce resources" (p. 5).

11 "Vernacular" here denotes the major literary vernaculars of India that came to serve as the basis of the linguistic reorganization of Indian territory. As Sheldon Pollock notes, these languages are not the same as those that are deemed vernacular in sociolinguistics. These are standardized, literary, and historically powerful languages that often formed the basis of premodern regional polities; Pollock, The Language of the Gods in the World of Men, p. 24. 
language itself is being rigorously contested by the colonial state and various nonofficial pressure groups. Furthermore, even as languages like Odia, Telegu, Kannada, and Marathi functioned at a disadvantage in the linguistic economy of colonial India, these languages came to command profound institutional power as the colonial and postcolonial Indian state reconfigured Indian territory along linguistic lines.

Existing definitions of the term draw on either the translation of relevant Indian words or by reference to the Western origin of the term through a search for its etymological roots. In the first paradigm, best exemplified by Sheldon Pollock's famous treatment of the vernacular millennium, the meaning of the term is founded on Indian words pertaining to languages that are first called vernacular in the late eighteenth century by colonial philologists. Pollock has defined his use of the term by drawing on early references to the word desi or of place, which he notes has served as a "conceptual counterpart" to the cosmopolitan in Indian languages at the beginning of the vernacular millennium. ${ }^{12}$ Through a discussion of early modern literary history, Pollock illustrates how the use of the term desi was embedded in contemporary efforts among local elites to demarcate their regional worlds from the broader cosmopolitan world in which languages such as Sanskrit and Persian operated. ${ }^{13}$ Through a discussion of how translations of the Mahabharata into various Indian languages are deployed in the process of linking language, space, and political order, Pollock illustrates how the desi languages of India were being used to establish the spatial boundaries of regional political praxis. Even as he rightly hesitates to provide a definitive explanation of the term vernacular, Pollock insists on the relational nature of the vernacular. Ultimately, he argues that a vernacular language can only be vernacular in relation to a cosmopolitan language. ${ }^{14}$ Therefore, in this framework, vernacular or desi languages were self-consciously local languages of place defined in opposition to cosmopolitan languages that transcended the local. As such, vernacular languages are understood as less than-in scope as well as power-cosmopolitan languages. And a fundamental feature of the vernacular is its "emplacement" in the local.

The second paradigm emerged from the postcolonial epistemological critique of imperial knowledge by the subaltern studies school of Indian historiography. In an effort to unravel the orientalist depictions of Indian languages as languages that are unable to sustain the progress of modernity, this paradigm made much of the nonmodernity of Indian languages. Rather than being a weakness, the nonmodernity of the Indian vernacular had the ability to house voices and ways of thinking that would have been

12 Ibid, p. $22 . \quad{ }^{13}$ Ibid, pp. 380-97. ${ }^{14}$ Ibid, p. 388. 
drowned out by the increasing influence of colonial modernity. This paradigm takes the nonmodernity of these languages for granted-as though they escaped imperial intervention through the introduction of colonial philology or even European standards of literary criticism. ${ }^{15}$ In some ways, these languages were able to sustain older traditions and idioms. However, that was not the vernacular that came to be empowered in colonial and postcolonial India.

In the second paradigm, best exemplified by Ranajit Guha's plea for the recognition of the authority of vernacular pasts, the etymology of the term is traced to its Latin root-verna or slave. Guha's influential treatment of the term is an exposition of both the Latin root of the word and its English use in the nineteenth century. Guha argues that the modern Indian understanding of the vernacular draws from the English use of the term, which is hinged on the indigeneity of the vernacular even as it remains marked by a trace of enslavement left behind by its Latin origins. In the Indian context, Guha poses, the "vernacular" became a pejorative term that served as a "distancing and supremacist sign which marked out its referents, indigenous languages and cultures, as categorically inferior to those of the West or of England in particular." As such this ascription of inferiority allowed it to uphold "in every invocation, the power, value and status of white civilization." 16 For Guha, every invocation of the term vernacular was an instance of the epistemological violence perpetrated by colonial disciplinary knowledge. An example of the postcolonial critique of colonialism and its instrumental knowledge of the colonized, Guha's reading of the vernacular is very influential in contemporary postcolonial scholarship on Indian vernacular languages, historiography, and linguistic politics. As an important volume of essays on regional historiography in India reveals, histories written in the vernacular are seen as representative of an authentic subaltern voice. ${ }^{17}$

15 The impact of colonialism on the languages of the colonized has been extensively studied. See Bernard Cohn, Colonialism and its Forms of Knowledge (Princeton, NJ: Princeton University Press, 1996); Monica Heller and Bonnie McElhinny, Language, Capitalism, Colonialism: Toward a Critical History (Toronto: University of Toronto Press, 2017); Judith. T. Irvine, "Subjected Words: African Linguistics and the Colonial Encounter", Language and Communication 28, no. 4 (2008): 323-43; Judith T. Irvine, "The Family Romance of Colonial Linguistics", Pragmatics. Quarterly Publication of the International Pragmatics Association (IPrA) 5, no. 2 (1995): 139-53; Joseph Errington, Linguistics in a Colonial World: A Story of Language, Meaning, and Power (New York: John Wiley \& Sons, 2008); Michael J. Franklin, "Orientalist fones”: Sir William fones, Poet, Lawyer, and Linguist, 1746-1794 (Oxford: Oxford University Press, 2011). Javed Majeed, Colonialism and Knowledge in Grierson's Linguistic Survey of India (New Delhi: Routledge, 2018).

${ }^{16}$ Guha, "Authority of Vernacular Pasts", pp. 299-300.

${ }^{17}$ Aquil Raziuddin and Partha Chatterjee (eds.), History in the Vernacular (Hyderabad: Orient Blackswan, 2010). 
In contrast to Pollock and Guha, this treatment of the institutional life of the vernacular in the making of modern Indian regional territory points to an expansion of our understanding of the term "vernacular," which would compensate for some of the intellectual pitfalls inherent in the central implications of these two paradigms - that the vernacular is local, powerless, and indigenous. Rather than taking these three features of vernacular languages for granted, one can trace how major Indian regional vernacular languages came to claim a status of indigeneity and radical, representative powerlessness. Attention to the emerging official recognition of these languages as the basis of regional territory can reveal that these languages were not always indigenous to the territory that they claimed. As the case of Odia will reveal, in the movement for the creation of Odisha, arguments about the powerlessness of the Odia language and its people in relation to other groups was coupled with a systematic production of a historiographical orthodoxy portraying the history of Odia as an ancient, independent, Indo-European vernacular that was indigenous to the areas being claimed as Odisha. This seemingly contradictory narrative about the status of the vernacular as both powerless and linguistically singular was driven by an equally paradoxical imperative to appear as minority in a bid to become the majority group in the proposed province. This deployment of a minority discourse rooted in liberal narratives of emancipation, the rhetoric of state protection of minority rights and the threat of homelessness, effectively produced Oriya as a historically independent vernacular of the region fallen on hard times. ${ }^{18}$

By focusing on the institutional life of language, I seek to elaborate on the repressive power of the vernacular. My argument here hinges on recognizing the dual lives of the regional vernaculars in India-the quotidian and the institutional. Therefore, it is not my contention that the major Indian vernaculars function only as powerful classificatory tools of colonial and postcolonial governmentality. Rather, I pose that we need to recognize that even as vernacular language use enables the kind of radical politics being valorized by Ranajit Guha, Partha Chatterjee, and others, it does so in parallel to its life as a hegemonic, institutional marker of identity recognized by the postcolonial Indian state. By "institutional," I mean the ability of language to demarcate regional boundaries and hence determine individual access to provincial state resources through

${ }^{18}$ My definition of liberal discourse of minority rights is borrowed from Amir R. Mufti, Enlightenment in the Colony (Princeton, NJ: Princeton University Press, 2007) p. 2. Mufti argues that liberal thought on the "question of minority existence" displays certain central tropes. They include, "assimilation, emancipation, separatism, conversion, the language of state protection and minority rights, uprooting, exile, and homelessness." 
the ascription of regional domicile. ${ }^{19}$ Accordingly, this discussion does not privilege the institutional life of language. Rather, it is a critique of its overriding influence in the understanding and definition of modern India. ${ }^{20}$ It questions the authority of the vernacular by drawing attention to the complex nature of this authority.

The authority of the major Indian vernacular languages draws from their ability to do two things in India. First, as Ranajit Guha has suggested, their authority draws from their ability to represent the subaltern voice. In an ethical economy of ideas, the vernacular has authority precisely because it is powerless. Second, and this is my contention, the vernacular Indian languages have a peculiar ability to exercise their institutional authority through their sublimation.

The term "sublimation" carries obvious psychoanalytical connotations. In Freud's use, "sublimation" denotes the process of turning socially unacceptable hidden desires into more visible socially productive actions. ${ }^{21}$ However, for Freud, this sublimation, which produces the most essential elements of "civilized" society from poetry to scientific invention, is a source of resentment, of discontent, and this resentment renders the process of sublimation always potentially reversible. In Civilization and its Discontents, Freud notes that "sublimation is a vicissitude which has been forced upon the instincts entirely by civilization." Sublimation allows the individual to adapt to society and to reconcile her impulses with that of society. ${ }^{22}$

${ }^{19}$ In his path-breaking book on regimes of governance by high modernist states, James Scott has remarked on the institutional role of language as a means for the state to render its citizens "legible" or "visible." See James C. Scott, Seeing Like a State: How Certain Schemes to Improve the Human Condition Have Failed (New Haven, CT: Yale University Press, 1999), pp. 72-3. As the colonial shift from Persian to Bengali, Hindi, and Odia as the official languages of the Bengal Presidency in the 1830s illustrates, even the colonial government, in its unprecedented effort to "see" its subjects, recognized that the institution of official languages was an important means of categorizing and ruling people. See Farina Mir, "Imperial Policy, Provincial Practices: Colonial Language Policy in Nineteenth-century India", Indian Economic E Social History Review 43, no. 4 (2006): 395-427.

${ }^{20}$ David Washbrook noted that "new ideology (of modern linguistic ethnicity) dictated that territorial space itself must be culturally (or at least linguistically) homogenous" and thus India became a "a society of language jatis much as it has previously been one of the caste jatis competing for honor and status within a continuing multi-jati social order"; quoted in Asha Sarangi, Language and Politics in India, p. 6.

${ }^{21}$ Freud's discussions about sublimation are scattered and fractured. The clearest articulation of the idea is in his Civilization and its Discontents, in The Standard Edition, Vol. 21 (London: Hogarth, 1956-74), p. 97.

22 In his reading of Freud's understanding of sublimation, Eckart Goebel suggests: "Freud's concept of sublimation likewise covers both dimensions. It encompasses the individual balance between self-preservation and the demands of the drives, encountered in technical literature as 'neutralization', and also posits the necessary renunciation of the drives for the benefit of the society in which the individual lives, later given the term 
Despite what seems like taking liberties with Freud's formulation, this notion of sublimation can be borrowed in a limited way to explain the transference of regional political allegiance from language to territory as regional political parties were under pressure to fall in line with broader majoritarian nationalism. In my use of the term, I seek to draw out two important moves that sublimation of language involves. The first is the repression of the increasingly unpopular drive to demand rights for a collective based of an exclusive linguistic definition of community. The move to territory enabled the Odia regional movement to continue to desire an Odia province without making a case for the exclusion of nonOdia speaking people from their imagination of regional cultural and political community. This move allowed the Odia elite to claim adivasi communities as Odia because they inhabited land that the movement claimed to be Odisha. Second, drawing on Freud's argument about discontent, I suggest that this sublimation was forced-instrumentally brought about to enable the Odia movement to adapt to Indian nationalism and to reconcile its exclusive linguistic politics with contemporary demands to imagine a universal Indian citizen. This "false sublimation," as Nietzsche called sublimation that was based on only weakening of drives, was always precarious and essentially easy to undermine once political circumstances demanded it. ${ }^{23}$ In the case of Odisha, the reversal of this sublimation of language by reference to territory would take place once the new province of Odisha was formed and the question of the allocation of state resources to "genuine" Odias was raised in discussions about the limits of domicile within the new province. Ultimately, I use sublimation as a means to uncover the process that Ayesha Jalal commends researchers to question - the given-ness of language as a category of analysis. Can we take the territorial domain of language for granted? ${ }^{24}$

This is particularly evident in the process through which these vernacular languages become officially recognized as regional languages and come to be the basis of the territorial realignment of Indian regions in the nineteenth and twentieth centuries. The conflation of language and territory is fundamental to this process. The history of the "landing" of the vernacular languages in India illustrates how they emerge as the most powerful representative category in postcolonial India that determines political and territorial alignments to the exclusion of other categories

'adaptation'." Freud himself refers once to sublimation as an "art". Whoever masters this art is capable either of directing uneconomical instinctual impulses towards a higher purpose with greater social value or of neutralizing them; ultimately, he is able to adapt himself completely. See Eckart Goebel, Beyond Discontent: Sublimation from Goethe to Lacan (London: Continuum, 2012).

${ }^{23}$ Ibid, pp. 63-106. ${ }^{24}$ Quoted in Asha Sarangi, Language and Politics in India, p. 6. 
such as class or caste. ${ }^{25}$ In her book on Telegu linguistic politics, Lisa Mitchell has illustrated how language came to be a foundational category in India. ${ }^{26}$ However, a reading of political rhetoric of the period shows that language could only serve as a foundational category being bypassed while maintaining its salience in defining regional territory. That is, the reason language can trump other registers of difference is because it can be used as a basis of territorial divisions and then neatly sublimated in ways that religion, caste, and class cannot. The capacity of language to be "landed" and its ability to be sublimated through a reference to it as simply a feature of territory and not as the predominant determinant of the scope of regional spaces allows it to not obfuscate other ways of being in the same land. This sets the regional vernacular languages apart in their capacity to serve as a foundational representational category.

In this way, the major vernacular languages of India are simultaneously able to define Indian regions as exclusive cultural spaces while enabling the inclusion of people who do not belong. However, this sublimation is the product of elite efforts to define Indian territory and community and often involves the imposition of a certain vernacular language on areas in which they are not spoken. This is particularly true of the areas inhabited by adivasi populations. The history of regionalization of vernacular languages reveals that they are local as well as translocal, elite, and fundamentally powerful.

The example of the formation of the territorial linguistic province of Odisha in 1936 is a particularly good instance for illustrating how the major regional vernaculars of India became powerful, translocal languages with clearly demarcated territorial domains. As one of the earliest linguistic state movements, beginning in the last decade of the nineteenth century and culminating in 1936 with the formation of a new state of Odisha, this movement necessarily involved complex justificatory strategies that would lay the groundwork for subsequent redistribution of Indian provinces along linguistic lines. As Odisha was to be culled from three different British provinces (Bihar and Orissa, Bengal Presidency, and Madras Presidency), the movement fell into a strangely dislocated discussion about reorganizing provinces where leaders representing different vernaculars were vying to lay claim to the same territories as

25 Theorists argue that language is unlike other registers of difference in a multicultural society because of the "fact that language is the medium in which most social interaction takes place, the fact that most people can speak only one or several languages, the fact that learning new languages is very difficult for most adults, and the fact that translation is expensive, inconvenient, and always imperfect." Alan Patten, "Political Theory and Language Policy" Political Theory 29, no. 5 (2001), 692.

${ }^{26}$ Lisa Mitchell, Language, Emotion, and Politics in South India. 
Bengali speaking, Hindi speaking, or Telegu speaking. ${ }^{27}$ This competition for territory led to further debates about which linguistic community would gain control over lands where none of these languages was spoken as the mother tongue. The Odia, Telegu, and Bihari claims to tribal areas that lay in the intersection of Odia-, Telegu-, and Hindi-speaking areas proved to be particularly contested. ${ }^{28}$

More importantly, the disaffiliation of Odia linguistic regionalism from language resulted in the creation of a land-based vernacular that was always posed as though it was set to include other Indians who had made Odisha their home, but which politically allowed for the remaking of adivasis who lived in the middle of the Oriya language tracts and did not speak Odia into members of the 'natural' Odia community by dint of their landed vernacular. This book traces the history of the effort among the Oriya-speaking elite to situate the adivasi communities of the proposed province within the Odia-speaking community despite the linguistic, social, cultural and economic differences between the Odia-speaking people and their adivasi neighbors to expose the emerging ability of vernacular languages to speak for communities that were not necessarily allied to those vernaculars.

\section{Nation in the Vernacular}

As this book is about the making of a linguistic region, the question of language needs to be complemented by the question of how the region has been understood as a category in early Indian nationalism. For this, again, the National Anthem is a good starting point. The Anthem defined India as a collective of linguistic regions such as Punjab, Sindh, Orissa, Gujarat, and Bengal. By choosing this song as the National Anthem of the Indian republic, the Constituent Assembly in 1950 acknowledged the

${ }^{27}$ For a detailed history of border disputes in Orissa before and after 1947, see Nivedita Mohanty, Oriya Nationalism: Quest for a United Odisha, 1866-1936 (Bhubaneswar: Prafulla, 2005).

${ }^{28}$ Public and official debates about this matter began as early as 1903 when the Bengal government started to consider plans for the territorial reorganization of the Bengal Presidency. Even as fervent opposition in the Madras legislature forced the Indian government to abandon these plans, the issue was raised again in the Montague Chelmsford reforms. Subsequent government established commissions such as the Phillip Duff Commission (1924) and the Orissa Boundary Commission (1931) surveyed the population of the Oriya-speaking Ganjam district to ascertain whether the Ganjam district should be detached from the Madras Presidency. See Report of the Enquiry into the Attitude of the Oriya-Speaking Population of the Madras Presidency towards Amalgamation with Other Oriya-Speaking Tracts, Orissa State Archives, Bihar and Orissa Secretariat Papers, B\&O Doc 11216. Also Report of the Orissa Committee, British Library India Office Records, L/PJ/9/54. 
constitutive nature of regional linguistic states in the normative understanding of the Indian Union. However, it was in the decades between 1911, when Tagore wrote the poem, and its adoption as the Indian National Anthem in 1950 that the linguistic regions it mentioned assumed this political and cultural significance for an independent India. In 1911, the precise linguistic nature of these areas was not considered their most dominant feature. At the national level, these areas were seen as merely geographical units not yet marked by the various meanings that the term "linguistic region" would evoke half a century later during the linguistic reorganization of the Indian provinces. ${ }^{29}$ Indeed, for Tagore, areas such as Punjab, Sindh, and Odisha merely denoted parts of India. As actual efforts by the colonial government for the linguistic reorganization of British Indian provinces had not yet begun in 1911, Odisha and Sindh would not become separate provinces until a quarter of a century later. Furthermore, the Indian National Congress, the most influential allIndia nationalist party, had not yet rethought its understanding of India as a federation of linguistic provinces. Therefore, when Tagore described India as constituted by these parts in 1911, he was referencing them simply as locales of the nation - the nation in the vernacular.

By 1950, the Constituent Assembly, with its concerns about issues of citizenship, federation, domicile, rights, franchise, and electoral constituencies, understood regions like Odisha and Sindh as more than just parts of the Indian nation. Regions were not merely considered as geographic areas but linguistic units; rather than just being part of the nation, the region and its language came to mark Indian citizenship and democracy. By the 1950s, the Indian citizen was imagined not only as Indian but also as a member of a particular region and a speaker of a particular language. Hence, by this time, both the Indian nation and the universal Indian citizen came to be marked by linguistic difference.

This transformation of the region from simply a geographical category to a linguistic and constitutional category is the focus of this book. I trace this transformation by investigating the formation of Odisha, a province in eastern India, as a linguistic, historical, cultural, and geographical region. Through this history of the formation of Odisha, I illustrate how

29 The linguistic reorganization of the Indian provinces took place 1956 to 1970 s. While the linguistic reorganization of the Indian provinces had begun in 1936 with the formation of Sindh and Odisha, the new postcolonial Indian state finally faced the questions of regional linguistic loyalties in 1956 when the new states of Maharashtra, Karnataka, Kerala, and Andhra Pradesh were formed. This moment in the history of the infant postcolonial state was one of great national anxiety as the Indian leadership saw the pressing need for the creation of linguistic provinces as a divisive move that would eventually jeopardize the basic unity of the Indian republic. 
the idea of a linguistic region emerged both within the area that would eventually become Odisha and, at the national level, in the Indian National Congress. ${ }^{30}$ In particular, I look at the changing relationship between the Indian National Congress, as a representative of the all-India nationalist attitude towards regional politics, and the Utkal Sammillani, a regional political organization that represented all the Odia-speaking areas established in 1903.

The relationship between regional linguistic politics and nationalism in 1903 was not the same as the comfort with the multilingual nature of India reflected in the Constituent Assembly's choice of the Indian National Anthem in 1950. In the late nineteenth and early twentieth century, anticolonial nationalism led by the Indian National Congress was accompanied by movements in various parts of the country for the creation of linguistically homogenous administrative provinces like Odisha, Sindh, and Andhra Pradesh. ${ }^{31}$ In its early years, the Indian National Congress remained indifferent to such movements and focused on creating a common national platform for anticolonial politics. However, even decades after the Congress officially acknowledged the demands of these regional linguistic movements and acquiesced to the reorganization of the Indian provinces on linguistic lines in 1920, the national leadership remained apprehensive of the divisive potential of the regional linguistic politics.

The early engagement of the Indian National Congress with the question of linguistic difference and regional politics based on language in the late nineteenth and early twentieth century was marked by an anxiety about the divisiveness of such regional politics. ${ }^{32}$ This anxiety drew from pressure on the Congress to present to the colonial government the most representative and "authoritative statement" of the needs and desires of

${ }^{30}$ Odisha, in its present-day form, came into existence in 1936. Like other provinces in India, it is a linguistically organized province. That is, a majority of the population of Odisha speak the Odia language and these speakers of the Odia language are also called Odia. Prior to 1936, areas in which a majority of the people spoke Odia were scattered in three different British provinces. Hence, when I mention Odisha in a pre-1936 context, I mean the Odia-speaking regions. It is not my intention to naturalize a place that did not exist before 1936 .

${ }^{31}$ Such movements were particularly lively in the areas that eventually became Sindh, Andhra Pradesh, and Orissa. For a history of the movement for the creation of Sind and Andhra Pradesh, see Sarah F. D. Ansari, Sufi Saints and State Power: The Pirs of Sind, 1843-1947, Cambridge South Asian Studies; 50 (Cambridge: Cambridge University Press, 1992); Allen Keith Jones, Politics in Sindh, 1907-1940: Muslim Identity and the Demand for Pakistan (Karachi: Oxford University Press, 2002); G. V. Subba Rao and Movement Andhra Pradesh Committee of History of Andhra, History of Andhra Movement (Hyderabad: Committee of History of Andhra Movement, 1982).

32 Henceforth, the Indian National Congress will be called simply Congress. 
the Indian people. ${ }^{33}$ The success of the Congress as an all-Indian organization set up to negotiate political, legal, and constitutional reforms with the colonial state was contingent on its ability to present itself as the sole, most authoritative representative of all non-European inhabitants of British India. Hence, unity became the most central objective of the early Indian National Congress in the nineteenth century. To that end, as Gordon Johnson put it: "It was no good speaking to England with a babble of tongues." ${ }^{34}$ As national unity and establishing its own status as the most representative Indian organization became the Congress' primary objective, the early Congress became very selective in its choice of issues. The deciding factor in the choice of Congress agenda of the nineteenth century was whether the issue would help unite the people of India or prove divisive. ${ }^{35}$ Furthermore, it was essential at this stage to discuss only those issues that could evoke a consensus among the various members of the Congress. Hence, in 1888, Ananda Charlu-one of the early leaders of the Congress-noted in a speech to the delegates at Allahabad: "If we all agreed on any matter, then we will submit the universal view to government; but if we cannot come to a substantial agreement among ourselves then we drop the subject till we can." ${ }^{36}$

This stand precluded the Congress from discussing any issues that could cause divisions within the organization's ranks. Also excluded from the Congress platform was any politics that was "provincial" rather than "national" - any politics that did not pertain to the whole of India. In effect, this effort to make the Congress an all-India organization resulted in the marginalization of more provincial and local brands of politics. In particular, the emerging regional linguistic identity politics in areas including the Orissa division of the Bengal Presidency or the Teleguspeaking area of the Madras Presidency threatened the effort to produce national unity within Congress. Hence the question of politics associated with vernacular languages was studiously avoided in Congress meetings at the time. In terms of regional politics, the Congress' avoidance of regional issues resulted in the continued influence of regional political

${ }^{33}$ See Gordon Johnson, Provincial Politics and Indian Nationalism; Bombay and the Indian National Congress, 1880 to 1915 (Cambridge: Cambridge University Press, 1973). Johnson describes the political expediency of the early Congress claim about its representative status. He notes: "In order to influence English political parties it was essential to draw up a single all-India programme. There was no point in having several bodies working in London all claiming to represent Indian interests. As an English sympathizer wrote to Pherozeshah Mehta, 'Nothing would more strengthen the hands of your friends in this country than to have an authoritative statement which would show to all the world what people of India want ... To set the constituencies in motion will not be difficult as soon as we know for certain what the people of Indian wish for'," p.13.

${ }^{34}$ Ibid, p. $35 .{ }^{35}$ Ibid, pp. 36-7. ${ }^{36}$ Ibid, p. 35. 
organizations that represented regional demands to the colonial government. Even as this effort to avoid any involvement in regional/provincial politics ensured that Congress remained a purely national entity, the lack of a Congress presence in the provinces severely curtailed the efforts of Congress to build a popular following. ${ }^{37}$

This avoidance of regional politics was sorely tested during the partition of the Bengal Presidency (1903-12) and raised serious questions about the representative nature of the organization. The governmental proposal to partition the highly politicized Bengal Presidency into a Hindu majority province of West Bengal and a Muslim majority province of East Bengal occasioned the first direct opposition to the colonial government by Congress. ${ }^{38}$ The Risley Circular that first proposed this partition in 1903 was received with great consternation by the members of Congress at the annual meeting in Madras. ${ }^{39}$ Congress opposition used the rhetoric of linguistic affinity to argue against the partition of Bengal on religious lines. Hence, the accusation that the British were separating "Hindu Bengali brothers" from their "Muslim Bengali brothers" came to dominate the rhetoric of the anti-partition movement. Here, the Congress rhetoric posed that the linguistic community centred on the Bengali language trumped the sway of Hindu or Muslim religious community allegiance.

This vocabulary of dissent represents a very crucial paradox in the Congress attitude towards regional linguistic politics. As a national organization, it was invested in ensuring that this kind of division between Hindus and Muslims should not be validated. Paradoxically, while avoiding such a religious division, the Congress was invoking a different kind of internally differentiated nation - an India constituted by linguistic groups whose unity was being consistently articulated by regional political movements. ${ }^{40}$ As a consequence of the antipartition agitation in 19031908, the Congress had to acknowledge the importance of regional linguistic identity politics at the beginning of the twentieth century. However, even as this recognition marked the politics of the Congress in the early twentieth century, it was not extended to other regional linguistic politics in India. Congress ambivalence towards such politics is evident in the coupling of the denunciation of the partition of Bengal

37 Ibid, pp. 35-6.

38 For details, see Sumit Sarkar, The Swadeshi Movement in Bengal, 1903-1908 (New Delhi: People's Publishing House, 1973).

39 For Risley's statement about the reorganization of the Bengal Presidency, see Two Bachelor of Arts, The Oriya Movement: Being a Demand for a United Orissa ([S.1.]: H. H. Panda, 1919). Appendix A.

40 See A. M. Zaidi (ed.), Inc the Glorious Tradition, Volume One: 1885-1920, five vols. (New Delhi: Indian Institute of Applied Political Research, 1987), p. 238. 
with the criticism of the proposed partition of the Madras Presidency that would have allowed the unification of all Odia-speaking people under a single administration. Criticizing all government efforts to rearrange provincial boundaries the Congress resolved in Madras in 1903:

[T] his Congress views with deep concern the present policy of the Government of India in breaking up territorial divisions which have been of long standing and are closely united by ethnological, legislative, social and administrative regulations and deprecates the separation from Bengal of Dacca, Mymensingh, Chittagong Divisions and portions of Chotanagpur Division, and also the separation of the district of Ganjam and the agency tracts of the Ganjam and Vizagapatnam Districts from the Madras Presidency. ${ }^{41}$

In this critique of colonial policy, regional communities, and, by extension, the "region" in 1903 seems to be the product of the conflation of two different types of category. Region is a territorial unit "united" by "ethnological" and "social" bonds. But it is also united by "administrative" and "legislative" regulations. Thus, a region is both a social category that draws on native ethnic, social, and cultural commonalities and a geopolitical category that is founded on colonial administrative borders. The conflation of these two types of definition of region does not allow for the possibility that there may be a contradiction between them. This ignores the possibility that colonial regions may not necessarily be culturally, social, or ethnically homogenous. By espousing this dual definition of the region in 1903, Congress was able to illustrate that there was no contradiction between their disavowal of the Odia claim that the administrative boundaries were not "natural" and the avowal of the Bengali claim that the division of Bengal was dividing a region united by ethnological and social bonds.

Hence, even as Congress acknowledged the significance of the linguistic bond among the Bengali-speaking people, it was unable to uphold the broader demand for the creation of linguistic provinces being raised across British India. However, by raising the question of the "ethnological" and the "social" in the definition of the regional community, Congress rhetoric of this period inadvertently opened the door for future regional demands based on ethnic or linguistic homogeneity.

Historically, while these movements for the creation of linguistic provinces mobilized people around particular languages, the leaders of the Indian National Congress were attempting to inspire people of various provinces to transcend their regional differences and come together as a unified national community. In the minds of Congress leaders, the project of these regional linguistic identity movements was fundamentally at odds with their own project of producing a common Indian national identity.

41 Ibid, p. 238. 
Even as late as 1952, five years after the independence of India, Jawaharlal Nehru, Prime Minister of Independent India from 19481964, argued that:

I have been overburdened with the thought that we must give the topmost priority to the development of a sense of unity in India because these are critical days. Any decision that might come in the way of that unity should be delayed till we have laid a strong foundation for it. The idea of linguistic provinces will intensify provincial feelings and that, undoubtedly, will weaken the concept of a unified India. ${ }^{42}$

Despite these anxieties about divisiveness of the linguistic identity politics in the provinces, India remains, seven decades later, a federation of mostly linguistic regions. Paradoxically, also continuing is the divisive politics that had made Nehru so anxious in 1950. The Cauvery water dispute between Karnataka and Tamil Nadu, the campaign by the Shiv Sena in Bombay to oust the Bihari "outsiders" from the city and similar attacks on Tamil speakers in the slums of Bangalore illustrate the continued use of regional "nationalist" rhetoric to argue local political, economic, and infrastructural difference between various Indian provinces. The relationship between the region and the nation remain, as ever, deeply fraught on many different registers.

This book poses the following question: What does this coexistence of profound linguistic difference and unitary nationalism reveal about the nature of the Indian nation and the relationship between the region and the nation? Is the region merely a subnation? Despite recent efforts by a new generation of scholars to decenter the nation from historical narratives of the late nineteenth- and early twentieth-century India, the idea of subnationalism continues to function as the dominant framework of analysis for studies of regional politics. ${ }^{43}$ Studies of regional politics, prominently

${ }^{42}$ Robert D. King, Nehru and the Language Politics of India (Delhi: Oxford University Press, 1997), p. 15.

${ }^{43}$ For a definition of subnational understanding of regional politics, see Sanjib Baruah, India against Itself: Assam and the Politics of Nationality, Critical Histories (Philadelphia: University of Pennsylvania Press, 1999). Some recent revisionist histories are Farina Mir, "Imperial Policy, Provincial Practices: Colonial Language Policy in Nineteenth-Century India", Indian Economic and Social History Review 43, no. 4 (2006); Sumathi Ramaswamy, Passions of the Tongue : Language Devotion in Tamil India, 1891-1970, Studies on the History of Society and Culture 29 (Berkeley, CA: University of California Press, 1997); Prachi Deshpande, Creative Pasts : Historical Memory and Identity in Western India, 1700-1960, Cultures of History (New York: Columbia University Press, 2007); Yasmin Saikia, Fragmented Memories : Struggling to Be Tai-Ahom in India (Durham, NC: Duke University Press, 2004); Lisa Mitchell, "Parallel Languages, Parallel Cultures: Language as a New Foundation for Reorganization of Knowledge and Practice in Southern India", Indian Economic and Social History Review 42, no. 4 (2005); Mridu Rai, Hindu Rulers, Muslim Subjects: Islam, Community, and the History of Kashmir (London: C. Hurst, 2003); Chitralekha Zutshi, Languages of Belonging : Islam, Regional Identity, and the Making of Kashmir (London: C. Hurst, 2004). 
Sanjib Baruah's India against Itself, define regional politics as subnationalism - a regional iteration of all India nationalism. Baruah defines subnationalism as a "pattern of politicization and mobilization" at the regional level, which "coexist with and are occasionally in tension with the panIndian national community, are best located in the intellectual universe of nations and nationalism." ${ }^{44}$ Hence, according to Baruah, the prefix "sub" in subnationalism points to both the subordinate status of regionalism and its coexistence with all-India nationalism. However, he notes that: "[W] hile the qualifier helps to make a distinction between regional and pan-Indian national projects, the distinction should only be seen as provisional." ${ }^{45}$ In this study on Assamese "subnationalism," Baruah argues for the recuperation of the initial utopian thrust in the formulation of the Indian Federation; that India is an egalitarian union of various identities. ${ }^{46} \mathrm{He}$ demands that the Indian Federation create institutional space for the articulation of and engagement with subnational dissent; thus resolving the separatist crisis in the northeastern province of Assam.

Such arguments are often invested in the federal nature of the Indian nation-state and use the term subnationalism to provide for both regional political particularity and the inherent integrity of the Indian Union, despite regional difference. The notion of the subnational presumes that the nation is reproduced on a smaller scale in the subnation/region, and that the subnation is structurally similar to the nation. The limitations of such a definition lie in the absence of clear argument about why such subnational politics does not eventually overwhelm Indian national efforts at maintaining unity and secede from the Indian nation.

Studies of regional history have branched out into the cultural history of the nineteenth and twentieth centuries of various regions in India. While there is an increasing attention given to the particularity of regional cultural politics, such histories remain within the problematic of subnationalism. Scholars of regional history, including Sumathi Ramaswamy, Lisa Mitchell, Yasmeen Saikia, Veena Naregal, Mridu Rai, Chitralekha Zutshi, Prachi Deshpande, and Farina Mir, have illustrated that cultural history of the nineteenth and twentieth centuries in Tamil Nadu, Andhra Pradesh, Assam, Kashmir, and Maharastra respectively are integrally linked with the creation of a regional political identity that was used to negotiate with the colonial state on issues of local concern. ${ }^{47}$ These

${ }^{44}$ Baruah, India against Itself: Assam and the Politics of Nationality, p. $5 .{ }^{45}$ Ibid, p. 5.

46 Assamese is the name for both the language spoken in the northeast Indian province of Assam and the people of that province.

47 These studies vary in their methodological and thematic focus. Sumathi Ramaswamy and Lisa Mitchell investigate the relationship between cultural politics focused on mother 
studies use the history of regional language, literature, print culture, religious institutions, and princely states to point out that identity politics in the various provinces of India emerged in response to colonialism and the administrative structures of the colonial state. Ultimately, these studies have attempted to prove through detailed cultural histories that not all politics in modern India was national. Cultural movements of the Indian provinces were fundamentally political. The histories of politics of Indian nationalism have to take into account these particular regional political movements that were not always animated by the need to create and sustain a homogenous Indian national community. As a result these studies have drawn attention to the relationship between regional, cultural, and political movements and all-India nationalism.

For instance, Prachi Deshpande shows through a reading of history writing in the province of Maharastra how particular narratives of the Maharastrian past were used to justify the separate identity of the Maharastrian people while illustrating the significance of Maharastra in the broader Indian community of linguistic provinces. She argues that the region cannot be seen as a "subset of nationalism with differing local flavors." Rather, region as a category developed in conjunction with nationalism. However, this formulation of the region as something that develops in conjunction with nationalism remains bound within the problematic of subnationalism. That is, even as her discussion of Maratha historiography points beyond it, her explicit formulation of the region and the nation remains within the problematic of subnationalism. Studies like Deshpande's reading of history in Maharastra argue that regionalism is separate but subsumed within nationalism. What remains unclear is how such a relationship is sustained over time.

Hence, even as the scholarship on regional history has illustrated the particularity of regional politics and its simultaneity with nationalism,

tongues, Tamil and Telegu respectively, and the social movements in nineteenth- and twentieth-century Tamil Nadu and Andhra Pradesh. See Ramaswamy, Passions of the Tongue: Language Devotion in Tamil India, 1891-1970; Mitchell, "Parallel Languages, Parallel Cultures: Language as a New Foundation for Reorganization of Knowledge and Practice in Southern India." Saikai and Deshpande investigate how the formation of historical memory of the region Assam and Maharastra enabled and informed the emerging relationship between the regional and the pan-Indian nation. See Saikia, Fragmented Memories: Struggling to Be Tai-Ahom in India; Deshpande, Creative Pasts: Historical Memory and Identity in Western India, 1700-1960. Chitralekha Zutshi and Mridu Rai investigate the relationship between religious politics in Kashmir and the situation of Kashmir within the Indian nation. Both argue that "Kashmiriyat" is a term coined to think about religious secularism that enables Kashmir to fit into the normative idea of the Indian nation. Zutshi, Languages of Belonging: Islam, Regional Identity, and the Making of Kashmir; Rai, Hindu Rulers, Muslim Subjects: Islam, Community, and the History of Kashmir. 
what remains relatively unstudied is the nature of the relationship between regional politics and nationalism. How do particular regional identity politics and the nationalist project for the creation of a united India come to be resolved even as the distinction between them remains fundamental to political discourse in India? This relationship can be best understood by tracing the formulation of region as a category in nationalist thought in the early twentieth century. To this end, I focus on the period when a tactical resolution between the demands of the region and the nation occurs in India. My contention is that at the root of this resolution is the need (both at the regional and at the national level) to imagine a new citizen of emergent India.

Through detailed studies of cultural and intellectual engagement of regional political, literary, and historical organizations in early twentiethcentury Odisha, this book traces the resolution of regional and national interests. I argue here that in the period between 1900 and 1920, the emergence of the idea of a universal and politicized Indian citizen occasioned this resolution of the tension between the region and the nation. As the meanings of politics, statehood, rule, and subjecthood changed due to the colonial state's efforts to introduce franchise in India, both the Indian National Congress and the major regional political organization in Odisha, the Utkal Sammillani, were forced to elaborate a clear relationship between Odisha as a region and the broader Indian nation in order to define the universal Indian citizen.

The case of Odisha is particularly instructive in this investigation of the relationship between the region and the nation because of the simultaneous development of both Odisha as a region and India as a nation in the late nineteenth and early twentieth centuries. This simultaneous emergence of Odisha and India as modern political and cultural categories marked Odia political life in the early twentieth century with conflicts between regional and national objectives. Hence, in this period, reflections on the engagement of regional political interests with the homogenizing tendencies of emergent Indian nationalism provide a very productive site for the investigation of the emerging political thought about the relationship between linguistic regions and Indian nationalism.

Historians of Odisha have read the early twentieth century, particularly the period between 1900 and 1920, as a period marked by a shift from insular Odia parochialism to a more politically "legitimate" participation in cosmopolitan Indian nationalism. Some have argued that even as the Odia political leadership was invested in regional interests, they did not necessarily oppose the gradual establishment of all-India nationalism that the region and nation coexisted peacefully in the minds of early Odia 
politicians. ${ }^{48}$ Both these readings of early twentieth-century Odia politics are invested in the primary legitimacy of Indian nationalism and serve as explanations for regional difference that effectively efface regional specificity. I argue that regional politics in early twentieth-century Odisha should not be read as a mere preparatory phase in the emergence of unitary Indian nationalism. Rather, regional definitions of culture, heritage, history, and political life enable the formation of the Indian nation and are fundamentally constitutive of it.

At the core of my argument about the relationship between the Odia linguistic region and the Indian nation is the story of the making of the Indian citizen. As the last section reveals, in the 1910 s the need to politicize larger sections of the Indian population came to occupy a central position in public discussions about politics. Compelled by divergent motives, both the colonial government and the anticolonial nationalist parties in India were involved in the project of thinking about Indian self-determination through the construction of a universal Indian citizen. Linguistic difference and its fervent articulation by various regional public associations threatened to disrupt this project. However, rather than efface this linguistic difference by arguing for the dominance of a single national language, the leaders of the Indian National Congress chose to work linguistic difference into the very fabric of the Indian nation. Hence the 1910s saw the emergence of a paradoxical figure of the universal Indian citizen who was marked by particular regional linguistic difference.

\section{On Categories - Region, Space, Territory}

As the confusion about categories in the 1903 Indian National Congress description of regional community suggests, the "region" as a category is somewhat hard to situate. In the 1903 definition of a region, it was both a space in which a socially and ethnically homogenous community lived and a geopolitical territory under a single administration. In this framework, it could be defined by the people who lived in the region or by the boundaries of the region. Therefore, the question arises: Is region a spatial category or a territorial category? That is, if as Henri Lefebvre argues,

${ }^{48}$ Bishnu Narayan Mohapatra, The Politics of Oriya Nationalism, 1903-1936 (Oxford: Oxford University, 1990); Pritish Acharya, National Movement and Politics in Orissa, 1920-29, Sage Series in Modern Indian History 11 (New Delhi: Sage, 2008). Jayanta Sengupta's recent book explores this theme through a nuanced narrative that elides these tropes by thinking the relationship between region and nation via the issue of development: Jayanta Sengupta, At the Margins: Discourses of Development, Democracy and Regionalism in Orissa (New Delhi: Oxford University Press, 2015). 
geographical space is fundamentally social, then should we study the history of the making of the linguistic region in India as a purely social process of definition of space through lived experience, capitalist development, and social imagination? In other words, should we see the places that are the product of this social production (Odisha, Maharashtra, or Andhra Pradesh, for example) as the 'locus of 'imaginaries,' as 'institutionalizations,' as configurations of 'social relations,' as 'material practices,' as forms of 'power,' and as elements in 'discourse'?" 49 Or should we track this history of the making of the linguistic region in India as a history of territorial formations with a focus on the processes of boundary making and territorial division of the British presidency provinces of Bengal and Madras?

Thinking of the making of Odisha simply as a process of boundary making and the apportioning of Indian territory to particular linguistic groups runs the risk of falling into what John Agnew has called the "territorial trap." 50 By trap, Agnew meant that often when we see territories we make false assumptions that they are "internally homogenous, externally bounded political communities that exercise uniform sovereignty across their domain." ${ }^{51}$ Geographers and scholars of international law have suggested that we apply the spatial turn to our understanding of territory and recognize that, like space, territory is also a product of social debates and discourse. In his study of the formation of regions, Swedish geographer Anssi Paasi has argued that regions are "institutionalized" over time through a four-stage process that is not necessarily incremental or developmental. ${ }^{52}$ The four stages in which the region takes territorial shape, symbolic shape, institutional shape, and established shape produced by state power can be historically contingent and needs to be studied in order to establish the historical and sociological formation of the region. Passi's formulation allows us to combine the history of spatial imaginaries that produce both the territorial scale of the region and the identity of the inhabitants of the region with the history of territorial boundary formation, which are a result of the state supported

${ }^{49}$ David Harvey, Fustice, Nature and the Geography of Difference (Cambridge: Blackwell Publishers, 1996), p. 294.

50 John Agnew, "The Territorial Trap: The Geographical Assumptions of International Relations Theory", Review of International Political Economy 1 (1994): 53-80. For a recent rethinking of Agnew's argument, see Ayelet Banai and Margaret Moore, "Introduction: Theories of Territory Beyond Westphalia", International Theory 6, no. 1 (2014): 98-104.

${ }^{51}$ Ibid, 99.

52 Anssi Paasi, "Constructing Territories, Boundaries and Regional Identities", in T. Forsberg (ed.), Contested Territory: Border Disputes at the Edge of Former Soviet Empire (Aldershot: Edward Elgar, 1996), pp. 42-61. For a discussion of how conceptualization of region had changed over the last few years, see Anssi Paasi and Jonathan Metzger, "Foregrounding the Region", Regional Studies 51, no. 1 (2017): 19-30. 
institutionalization of the regional spatial imaginaries. Simply put, for the purposes of our reading of the history of the making of Odisha, region is both a spatial and a territorial category.

In this history of Odisha, we will explore how the region of Odisha is formed through interventions from the colonial state, the regional elite, and the emergent nation-state of India. For the colonial state, administrative and educational imperatives caused the state to divide India into monolingual language zones where a single language could be used to mediate the individual's relationship with the state. This was a shift away from the more multilingual reality of precolonial Indian states. The production of exclusive linguistic zones in turn led to identity politics in areas such as Odisha where access to administration and education through Odia was seen as an essential factor in enabling the Odia community to engage with the development practices of the colonial state. In the nineteenth and twentieth centuries, we see the emergence of the Odia movement for state formation that uses a range of spatial imaginaries to produce an argument for a "natural" Odisha, which was much larger than the "artificial" Odisha acknowledged by the colonial state in the shape of the Orissa division of the Bengal Presidency. In the early twentieth century, these spatial imaginaries of Odia space had to take into account the increasingly dominant demand for national unity from the Indian National Congress. For the Indian National Congress and, subsequently, the newly postcolonial state, the linguistic region became the only acceptable form of regional space. This choice was founded on the need to consolidate the "geopower" of the new nation-state by using the neat linguistic divisions of Indian territory to simplify and domesticate the overwhelming range of social, class, caste, religious, ethnic, and linguistic diversity amongst the Indian population.

\section{Shape of the Book}

This book is written as a linguistic history of both modern India and that of Odisha. Apart from the introduction and the postscript, it consists of six chapters. When taken together, the first and last chapters present a global, national, and local history of how language came to be the foundation of Indian territorial divisions. This story is told through a history of colonial language policy, local debates about boundaries between languages and their territories, and national-level discussions about regional linguistic identity and the formation of linguistics states.

At the core of this book, however, is the history of the making of Odisha as a discrete, linguistically organized territory within India during the period from 1866 to 1936 . The origins of Odisha are examined 
with a dual focus on the cultural politics of language and the spatial production of Odisha as a territorial category. These chapters chronicle the development of Odia cultural identity, its subsequent politicization, and its ultimate culmination in the establishment of the province of Odisha. Just as the national level discussion indexes the operations of elite power and nonelite exclusion in the neat linguistic division of India, the chapters on Odisha produce a critique of elitism in the linguistic, cultural, and political constitution of the province through an attention to how the adivasi or tribal populations of the state were absorbed into the regional community.

Chapter 1 describes the growing imperative in nineteenth-century India to carve out geographically distinct social-linguistic zones where only one Indian language could officiate. By doing a transnational history of the shifting understanding of the sociopolitical role of popular mother tongues, I show how the use of "vernacular" as a common epithet for some Indian languages came to imbue these tongues with meanings that drew from European debates on language and freedom. In the late eighteenth and early nineteenth century, British debates about juridical and political language as well as education focused on the use of common speech as the most effective means of deterring elite exploitation of the masses. At the same time, the English colonization of the British Isles led to a radical shift in the status of English from vernacular to cosmopolitan, from local to translocal. The idea of colonized vernaculars, which needed to be cultivated into modern tongues as part of the broader civilizational mission, came to determine the relationship between the English and the Irish or the Welsh. Once Britain colonized India, major Indian languages came to be called vernacular. The "vernacular" in its Indian career was an underdeveloped mother tongue whose recuperation and use in education, revenue, and judicial administration was thought to be crucial to liberal governance. Through a history of successive colonial policy decisions to use vernaculars in education and governance in India as well as the concomitant local debates about boundaries between the geographical domains of Indian languages like the Odia/Bengali debate of the $1860 \mathrm{~s}$ and 1870 s, I illustrate the peculiar politics of colonial vernacularization. The very processes of insistent localization and denigration of Indian languages created the conditions of possibility of the simultaneous empowerment of these languages as languages of state. To be vernacular was to be both popular and elite in regional India.

The language debate of the $1860 \mathrm{~s}$ and 1870 s had a significant impact on the development of literature, literary criticism, and pedagogy in the Odia language. In Chapter 2, I describe how anxieties about the quality of "traditional" Odia literature served as a site for imagining a cohesive Odia 
public who would become the consumers and beneficiaries of a new, modernized Odia-language canon. A renewed public controversy about the Odia language was initiated in the 1890s with the publication of a serialized critique of the works of Upendra Bhanja, a very popular precolonial Odia poet. The critic argued that Bhanja's writing was not true poetry, that it did not speak to the contemporary era, and that it featured embarrassingly detailed discussions of obscene material. These claims sparked responses and counterresponses in all the major newspapers in the Odia-speaking areas. I argue that the central theme in these discussions was a concern for linguistic community building that presupposed a new kind of readership of literature in the Odia language. This turn-ofthe-century literary debate played an important role in the ongoing consolidation of an Odia-centric public sphere. Such consolidation came at the cost of the suppression of competing non-elite counter publics that were either contemporary phenomena or had preexisted the emergent mainstream Odia public sphere. Through a reading of contentious discussions about literary realism and prevailing critiques of literature produced in counterpublic spaces such as travelling theatres and millenarian cults, I argue that the vernacularity of Odia was established through radical exclusion of the non-elite.

The developing idea of a social identity based on the Odia language became politicized during the first decade of the twentieth century. In 1903 an organization called the Utkal Sammillani was created to lobby for the amalgamation of all Odia-speaking areas under a single provincial administration. The Sammillani quickly came to serve as the most prominent pan-Odia site for presenting Odia interests to the colonial authorities. In Chapter 3, I show that debates within and about the Sammillani frequently turned to discussions about the meaning of politics, citizenship, and the status of the Odia constituency in relation to the colonial state. I describe the ways in which the demand for an Odia province reconfigured nineteenth-century Odia cultural activism into a clearly articulated argument for the political representation of the Odia people as a unified constituency. By including a brief discussion of emergence of colonial franchise and the changing attitudes of the Indian national Congress towards linguistic politics during this period, I show that the politicization of the Odia public into a liberal representative category is part of a larger narrative of the politicization of the Indian masses.

As the Utkal Sammillani and similar organizations began to lobby for the formal political amalgamation of Odia-speaking areas, the prospect of a concrete territorial entity - a new province of Odisha - became an increasingly central concern. In Chapter 4, I analyze the development of Odisha as a newly imagined territorial entity. By the late 1910s, the 
leaders of the movement had begun to call this proposed province "Natural Orissa," presenting it as a historical reality that had been lost during centuries of colonial rule. This perspective was backed up by new histories of "ancient" Odisha that were written by Odia advocates. Drawing on the Odia leadership's portrayals of their desired motherland and sketches of Odisha in the rhetoric of nationalist leaders such as Gandhi, I illustrate the emergence of a shared discourse about the underlying qualities of this imagined province. Odisha was conceptualized as a fundamentally religious land. In contrast to other Hindu religious centers, however, Odisha was seen as being marked by a propensity to absorb lower-caste people, tribal groups, and even Muslims into the Hindu fold albeit without undermining the purported differences between such minority groups and the upper-caste, Odia-speaking population. By analyzing this religious outlook and other projected aspects of "Natural Orissa," I show how the province came to be seen as a fundamentally local and yet simultaneously cosmopolitan Indian space. Such an imagined territory exerted a great appeal for both local and national leaders.

In Chapter 5, I discuss the more problematic ramifications of imagining "Natural Orissa" as a homogenous historical homeland. By 1924, the colonial government had begun earnestly discussing the formation of a separate province of Odisha, and, in 1931, the Orissa Boundary Commission was established to delineate the territorial scope of the new province. The formation of a geographical Odisha involved several contradictions that had to be resolved. Perhaps the most significance was the presence of the many "tribal" (non-Odia-speaking, adivasi) communities, whose members comprised almost one-fourth of the population of the proposed Odisha province. Through a reading of memoranda sent by various public organizations to the Orissa Boundary Commission I trace the developing justifications for the inclusion of adivasi communities into Odisha. Unsurprisingly, these justifications were largely based on claims about the exceptional ability of the "ancient" Odia community to absorb non-Odia populations into its fold. Couched in religious rhetoric, the memoranda display a paternalist civilizing discourse in which Odia-speaking people were presented as benevolent civilizers of the tribal communities. Such discourse was largely successful, as the diverse inhabitants of the region were subsumed into the emerging Odia political identity without being offered social parity.

Taking its title from Bhimrao Ramji Ambedkar's puzzling claim that the "Genius of India is to divide," Chapter 6 tracks the career of linguistic difference in the making of modern India. I show how the effacement of adivasi pasts in the imagination of Odisha was mirrored in the way linguistic difference was managed through the language based division of Indian 
territory. I analyze writings on multilingualism by three influential leaders of the Indian nationalist movement - Mohandas Karamchand Gandhi, Jawaharlal Nehru, and Bhimrao Ramji Ambedkar. Representing three radically different perspectives on the question of language and nation, these writings allow me to track the passions, ideologies and anxieties inherent in imagining a nation with multiple mother tongues. Gandhi posed a nonliberal, affect-based argument for a multilingual nation-state. Building upon Gandhi's espousal of multiple languages on the Indian National Congress platform, Nehru forged an uncomfortable compromise with multilingualism based on an acknowledgement of the centrality of linguistic identity to liberal representation in India and a severely truncated notion of linguistic difference that only acknowledged fourteen major Indian languages. Ambedkar, as a representative of the non-elite lowercaste population in India, remained skeptical of the efficacy of using regional languages in state institutions. Even as he acknowledged that Indian territory had to be organized linguistically due to the influence of various language-based political movements in provincial India, Ambedkar called attention to the dangers of handing over institutional power to regional elites. However, in spite of his skepticism, he was unable to provide a sustained critique of linguistic provinces from the adivasi perspective. The chapter ends with a short discussion of the adivasi critique of linguistic provinces through a reading of speeches given by Jaipal Singh, the leader of the movement for the formation of the adivasi majority province of Jharkhand. The effacement of adivasi difference became established in both the imagination of modern Indian citizens and in the physical, territorial divisions of the emerging Indian nation. As vernacular languages became the foundational category for understanding representation and subjectivity in India, the concomitant exclusion of aboriginal peoples and the downplaying of alternative political possibilities were institutionalized into the very definition of the modern Indian community.

In the postscript, I remark on the tenacity of the narratives of regional linguistic identity that were produced in the early twentieth century and the way in which elite justifications for a homogenous, Odia-speaking community came to transcend the sites of their production to take a central place in the nation's imagination. Through a discussion of contemporary adivasi activism, I show how the Odia appropriation of adivasi pasts remains the central problematic through which the struggles between the Odia mainstream majority and the adivasi minority are enacted. 


\section{How the Vernacular Became Regional}

In 1903, Gopal Candra Praharaj, compiler of the most extensive Odia lexicon of the early twentieth century, published a collection of episodic fiction called Bhagawat Tungire Sandhya (Evenings in the Bhagawat Hut). It was a satirical piece featuring conversations between three ubiquitous figures of nineteenth-century Odisha: a classically educated Sanskrit teacher whose "professed aim in life" was "to transform Odia into Sanskrit" and who did not "feel good unless he introduced a few pure Sanskrit words into his Odia speech"; the English-educated village schoolmaster who had an "unnatural hatred for the Odia language and believed that it is impossible to express thoughts without peppering his Odia with choice English words"; ${ }^{2}$ and, finally, the law clerk who was so "well versed in the loopholes of law that even when he spoke to his children at home some legal language slipped in."3

Even as this satire lampooned elite Odia society of the nineteenth century, the linguistic characterization of the central protagonists invoked some reigning anxieties about the Odia language and its boundaries. While it is not surprising that these anxieties focused in part on the obliterating threat of English, Praharaj's reference to Sanskrit is revealing. The threat of Sanskrit had to do with a worry about what the "purification" (read Sanskritization) of Odia speech would do to the singularity of Odia within the spectrum of Indo-European languages. Therefore, at stake here is Praharaj's investment in the identity of Odia and its relationship with its peers. The jettisoning of Odia by more vehicular languages such as English or even the ritually vehicular Sanskrit and with the more institutionally influential language of law also poses the question of what

${ }^{1}$ Gauranga Charan Dash (ed.), Praharaj Granthabali Vol. 1 (Cuttack: Vidyapuri, 2005), p. 8 .

2 Ibid, p. 9. The Odia word for "unnatural" in the original text was bijatiya. By connecting the use of one's mother tongue with the term fati, Praharaj was invoking both the notion of a physiological connection (Jati as species) and a sociological connection (Jati as community). A bijatiya hatred of Odia, therefore, was an alienation of both visceral and social connections with Odia.

${ }^{3}$ Ibid, p. 9. 
the proper place of Odia is, where is it at home? ${ }^{4}$ Not only the identity but also the locality of language is invoked here. In different ways, both English and Sanskrit are languages that come from elsewhere - from England or from the past. They are outsiders. How is the relationship of a local language like Odia properly established with languages such as English and Sanskrit? Should we draw inspiration from English as the language of modernity, capital, and empire or should we return to our classical Sanskrit roots to establish our non-Western cultural antiquity and sophistication ${ }^{5}$ Praharaj's lampooning of adulteration suggests that neither of these options is welcome as neither allows Odia to be itself.

Elsewhere, in the preface of his quadrilingual Odia lexicon, Praharaj drew attention to the singularity of Odia in relation to neighboring languages such as Bengali and Telegu. ${ }^{6}$ In his preface, Praharaj set out the features of Odia that separated it from Bengali even as the two languages effectively shared a single root language. In this chapter, I seek to establish why the discrete selfhood of Odia mattered so much. Why was it important to ensure that the discreteness and singularity of the Odia language had to be proved, acknowledged, and practiced?

This investment in the discrete selfhood of the Odia language was founded on the categorical logic of colonial thought on Indian languages. By the end of the nineteenth century, major Indian languages had come to be seen as parallel to one another with progressive histories of their own. ${ }^{7}$ This historicization of Indian languages both required and produced boundaries between languages such as Odia and Bengali or Telegu and Tamil. Once they were posed as objects to be historicized, the limits of the languages had to be established, their specific origins had to be traced from the point in time when they diverged from commonly spoken

4 The term "vehicular" is often used to denote languages that travel, languages that carry ideas across boundaries. In other words, languages that are cosmopolitan.

${ }^{5}$ For the conflation of English and modernity, see Javed Majeed, "Modernity's Script and a Tom Thumb Performance: English Linguistic Modernity and Persian/Urdu Lexicography in Nineteenth Century India", in Michael. S. Dodson and Brian A. Hatcher (eds.), Trans-Colonial Modernities in South Asia (New Delhi: Routledge, 2012), pp. 95-115. For the social life of English, see Veena Naregal, Language, Politics, Elite and the Public Sphere: Western India Under Colonialism (London: Anthem Press, 2002) and Shefali Chandra, The Sexual Life of English: Languages of Caste and Desire in Colonial India (Durham, NC: Duke University Press, 2012). On Sanskrit in modern India, see Simona Sawhney, The Modernity of Sanskrit (Minneapolis: University of Minnesota Press, 2009).

${ }^{6}$ Gopal Chandra Praharaj, Purnachandra Ordiā bhāshākosha (A Lexicon of the Oriya Language) (Cuttack: Utkal Sahitya Press, 1931), pp. i-xii, 1-32.

${ }^{7}$ Research on Telegu best illustrates this trend towards the analysis of how languages were historicized in nineteenth-century India. See Rama Sundari Mantena, "Vernacular Futures, Colonial Philology and the Idea of History in Nineteenth-Century South India", Indian Economic \& Social History Review 42, no. 4 (2005): 513-34. 
regional prakrits. ${ }^{8}$ Each language had to have its own moment of origin, script, vocabulary, grammatical structure, and literary culture that was distinct from those of its neighbors. Key to this emphasis on the boundaries between languages were discussions about the discrete limits of the domain of major Indian languages - both demographic and territorial.

To prove this discreteness of Odia, Praharaj orchestrated a curious tension in the preface of his lexicon. Praharaj argued that Odia has been a discrete, standardized language since the seventh century and has been devoid of any dialects. At the same time, he argued for a lexicon that takes into account all the variations of the language in his contemporary period. This avowal of the standard language and a deep investment in the everyday lexical messiness seems to pull the reader towards opposite poles. I would suggest that Praharaj's preface is not necessarily bipolar. Indeed, it is the object of his study that carries the tension within it - the vernacular. Praharaj's 1937 lexicon was the culmination of a century-long process of making the notion of the vernacular indigenous to India. The tensions that inform the lexicon give us a glimpse of how the vernacular as an idea performed contradictory labors in colonial and, ultimately, postcolonial India. This chapter contextualizes the tension in Praharaj's take on Odia in the longer history of what I like to call the politics of colonial vernacularization. I will do this through a history of how the term vernacular came to make its home in India and came to determine the career of language-based politics in the nineteenth and early twentieth centuries.

The term has conventionally been understood through Ranajit Guha's really perceptive take on the term. As Ranajit Guha has long since argued, the term "vernacular" did tremendous ideological work in colonial as well postcolonial India. ${ }^{9}$ Although I differ from his take on the vernacular in significant ways, I would agree with Guha's foundational claim that the term signaled entirely different meanings across the colony-metropole divide. For instance, even a cursory review of textual databases from the eighteenth and nineteenth centuries illustrates how the term vernacular denoted local, sometimes vulgar language in England in the former and came to be overwhelmingly used only to denote Indian languages in the latter. At first glance, it almost appears that England lost the use of the word once the empire was firmly ensconced in India.

${ }^{8}$ This moment of divergence and regional languages such as Odia or Telegu is itself an issue of great debate. Right from the relationship between Sanskrit and the various prakrits to the question of the relationship between older regional prakrits and the modern regional languages in India, the connections have been debated since the emergence of colonial comparative philology in the nineteenth century. For the relationship between Sanskrit and prakrit, see Sawhney, Modernity of Sanskrit, pp. 5-7. Madhav M. Deshpande, Sanskrit and Prakrit: Sociolinguistic Issues (Delhi: Motilal Banarasidass, 1993).

9 Ranajit Guha, "The Authority of Vernacular Pasts", Meanjin 51, no. 2 (1992): 299. 
Guha argues that in its new Indian career, the term carried the taint of slavery - drawing from its etymological root verna or slave. Consequently, vernacular served as a mark of colonial difference - constantly referencing the purported inferiority of Indian languages in relation to English and other Western tongues. Thus, marked with difference, the Indian vernaculars carried within them the possibility of radical politics. Ultimately, in Guha's framework, these vernaculars could serve as the medium for a multipronged critique of oppression - both colonial and within the native community.

I would like to suggest that perhaps the term vernacular was much more loaded with imperial import than Guha suggests. And that perhaps some of this excess baggage would eventually undermine the vernacular's radical potential. In the first half of the chapter, I will introduce the possibility of a more complicated understanding of the term vernacular and its implications for Indian linguistic politics than those provided by the existing frameworks. Then I track the multiple strands of meaning that should populate our understanding of the term in the context of colonial India. Finally, I will show how these meanings come to determine colonial policy towards Indian languages. Successive governmental language policies that often drew from an ideological investment in this new understanding of the vernacular have resulted in bestowing these languages with very discrete geographical domains and demographic constituencies.

Then, in the second half of the chapter, I will illustrate the native appropriation of the colonial descriptions and disciplinary interventions in struggles to demarcate the territorial and demographic domains of Indian vernacular languages. I will sketch the local consequences of this new discreteness of linguistic domains, in particular, how the boundaries between Odia and Bengali and their territorial domains came into question in the latter half of the nineteenth century. In tracking this history of how the term vernacular came to be ascribed to Indian languages, this chapter illustrates how some Indian languages came to be, first, vernacular and then developed to become regional.

\section{Vernacular Imported}

In 1837, the government of the Bengal Presidency passed Act no. 29 to change the language of revenue and business administration from Persian to the languages vernacular to the Presidency - Odia, Bengali, and Hindustani. At first glance, this seems like a curious move to make. As some of the responses from district-level officials about the feasibility of a shift away from Persian suggest, the change was slated to be cumbersome, expensive, and fraught with unforeseen challenges. By the early 
nineteenth century, Persian had already had a long history of serving as the official language of the vast swathes of Indian territory under British control. This meant that there was already a well-established vocabulary of legal and revenue terms that the local languages like Odia did not have at this point. Also, as Persian served as the lingua franca of the northern Indian officialdom, newly minted colonial officials need only learn a single official language in any detail. ${ }^{10}$ This could have led to greater mobility and flexibility of governmental functionaries across British India. Why then was it essential that the change to the local languages be made at this moment?

In her treatment of this Act, Farina Mir has rightly argued that the colonial government's primary concern was to ensure "just" governance. ${ }^{11}$ This poses the question as to how justice in governance came to be linked with the use of the vernacular in British India. We should not take the conflation of just governance with the use of the vernacular for granted. Even though this seems commonsensical to us, this conflation had to be debated and negotiated in metropolitan Britain just as it was debated amongst the officialdom of the Bengal Presidency. The connection between just governance and the use of the vernacular may seem further commonsensical to us given the linking of self-determination with use of mother tongues since the Wilsonian moment in the early twentieth century. The assumption that the change from Persian to vernacular languages in colonial India was in the interest of just governance surely had to be based on linguistic activism in metropolitan Britain from the late eighteenth century on. This move is an important indicator of the impact of metropolitan understanding of the salience of popular language to proper governance on language policy of the colonial government. Act no. 29 of 1837 is an important chapter in the history of how language and justice in governance - and by extension in the exercise of self-determination - came to be linked in the British Empire.

This conflation of just governance and the local or vernacular language reveals one of the primary burdens that the term vernacular bore on its journey to India - the idea that the vernacular was the best language of governance. As a letter sent to the court of directors of the East India Company by the Governor of Bengal in July 1836 noted, the introduction of the vernacular into the two departments was to be carried out "in order

${ }^{10}$ For a precolonial history of Persian, see Muzaffar Alam, The Languages of Political Islam c. 1200-1800 (Chicago, IL: Chicago University Press, 2004), pp. 115-40.

${ }^{11}$ See Farina Mir, "Imperial Policy, Provincial Practices Colonial Language Policy in Nineteenth-century India", Indian Economic \& Social History Review (43) (4) (2006): 395-427. And, for a longer treatment of the Act, see Farina Mir, The Social Space of Language: Vernacular Culture in British Colonial Punjab (Berkeley, CA: University of California Press, 2010). 
that the people may enjoy 'the inestimable advantages of having the public's business transacted in a manner which secures their confidence, because it is plainly intelligible to them'." "This is a particularly colonial formulation of state policy of language. The emphasis on public confidence suggests that the concern here is for ease of governance of a nonnative power over the Indian public as well as the need to establish local legitimacy of East India Company rule. The emphasis on intelligibility marks out the limits of this governmental concern about language. This move is not a governmental acknowledgement of linguistic affect held by the public, local linguistic identity politics, or any notion of ethnic particularity of the governed. This is not a move driven by the need to acknowledge difference among the people of the Bengal Presidency. Rather, this is singularly about the clarity of governance. Therefore, essentially, unlike twenty-first century notions of linguistic justice, which couple intelligibility of governance with the question of dignity (drawn from the idea of linguistic identity of the governed), the conflation of intelligibility and good governance is about the clarity of communication between the ruler and ruled. ${ }^{13}$

The linking of public confidence with intelligibility of governance suggests that the Company was drawing on debates in eighteenth-century England about the language of administration. The question of public confidence and intelligibility of governmental language had become a particularly fraught debate in late eighteenth-century England. In the 1790s, the passing of the Seditious Meetings and Treasonable Practices bills in England occasioned a debate about the need to use accessible language in order to reduce the opacity of governance. This debate, which was essentially about parliamentary reforms that would sustain a new sort of British government that was accessible to non-elite members of English society, resurrected a Lockean understanding of pure language or plain speech and set in motion some very important political, philological, and literary movements in England. ${ }^{14}$ Taking up Locke's suspicion of the way in which language can sometimes obfuscate the truth, one of the important radicals, John Horne Tooke, wrote the Diversions of Purley, in which he argued that it is important to understand the etymological makeup of words to reintroduce the common people to responsible

12 Papers regarding the enactment of Government of India Act 29 of 1837 authorizing the replacement of Persian by the vernacular languages in the Courts of Justice and the Revenue Department, Vol. 1, IOR/F/4/1684/67992, June 1835-December 1837.

${ }^{13}$ See Philippe Van Parijs, Linguistic Fustice for Europe and for the World (London: Oxford University Press, 2011). Helder De Schutter and David Robichaud (eds.), Linguistic fustice: Van Parijs and His Critics (London: Routledge, 2017).

14 For an detailed discussion of the impact of the sedition laws of the 1790s on philology, literature, radicalism, and constitutional reform, see Susan Manly, Language, Custom and Nation in the 1790s (Aldershot: Ashgate, 2007). 
government. ${ }^{15}$ He suggested that this was possible only by revealing to them the meaning of terms used to govern them. The influence of Tooke's arguments about simple language during this period is evident in Samuel Taylor Coleridge's critique of the treason trials of late 1795. The Seditious Meetings and Treasonable Practices bills were passed as a measure to protect the person of the king in response to an attack on his procession in October $1795 .^{16}$ The implementation of the bills enabled the English state to bring to trial a number of radical intellectuals, including John Horne Tooke and Thomas Hardy, who were arguing for parliamentary reforms. To counter the language of the sedition bills, Coleridge did an etymological analysis of one of the catchwords of the English state's rhetoric about the bill - "majesty." By arguing that, contrary to the English state's use of the word in the phrase "the person of the majesty," which was under threat from the treasonous masses, the word majesty meant the people rather than the king. Hence, an act of parliament that sought to gag the people's democratic voice, that curtailed the majesty of the people was, in itself, an act of treason. The English state, rather than the radical English people, was the perpetrator of the treason.

In this debate, popular access to an understanding of law was central to the possibility of proper governance. And this proper governance was portrayed as a specifically English thing to do. William Jones, who was then one of the most important Indological scholars of classical Indian languages, found himself engaged in this debate when he wrote a pamphlet entitled "Dialogue Between a Scholar and a Peasant", in which he posed a critique of prevailing elitist ideologies

${ }^{15}$ Hans Arsleff, The Study of Language in England (1780-1860) (Princeton, NJ: Princeton University Press, 1967), pp. 44-114. For a discussion about the relationship between Tooke's thoughts on language and those of Locke, see Paul Lamarre, "John Horne Tooke and the Grammar of Political Experience", Philological Quarterly (77) (1998): 187-207. Lamarre quotes Locke to show how he was suspicious of the ways in which a multiplicity of words for common ideas produces confusion and discord among men. "Men, when they come to examine them, find their simple Ideas all generally to agree, though in discourse with one another, they perhaps confound one another with different Names" (Lamarre, 187). On Tooke's influence on important literary and political thinkers of the late eighteenth and early nineteenth centuries, see Andrew R. Cooper, “'Monumental Inscriptions': Language, Rights, the Nation in Coleridge and Horne Tooke", ELH (66)(1999): 87-110. Bauman and Briggs elaborate a reading of what they call Locke's "anti-rhetorical rhetoric", which illustrates how Locke laid out a radical politics of language in "attempts to shape which ways of speaking would afford access to power, how privileged discursive practices would be learned and how one would learn them" ( Richard Bauman and Charles S. Briggs, Language Ideologies and the Politics of Inequality (Cambridge: Cambridge University Press, 2002), pp. $\mathrm{x}$ and 19-70).

${ }^{16}$ For more details about the controversy and the question of treason in this period, see John Barrell, Imagining the King's Death: Figurative Treason, Fantasies of Regicide, 1793-1796 (Oxford: Oxford University Press, 2000), pp. 554-62. 
of language by explaining parliamentary governance in simple and accessible language. ${ }^{17}$

Prominent among such ideologues was James Harris. Harris drew on a different reading from that of Locke to suggest that there were two layers of linguistic existence - the rational language and a more affect-based language of sensory experience. And Harris's affect-based language, which drew from sensory experience, was always tied to the local and was unable to transcend its fleshy life to do the political work. The radicals would respond to ideologies such as Harris's to argue that this is what buttressed the elitist power structure in Britain. And perhaps there should be greater attention to using plain speech. And by staking the Lockean investment in recuperating a pure language that could reveal important truths, radical philology of this kind called for an attention to etymology. This lead to the valorization of the vernacular as natural language not yet hijacked by those in power.

While the influence of Tooke waxed and waned in the ensuing years, the cultural politics of language remained an important matter of literary, philological, and political debates. The impact of these discussions was far reaching. Tooke's materialist understanding of language influenced early Romantic literary concerns with individual agency and the human relationship with the natural world. The investment of the Romantic poets in these questions was in itself a product of an engagement with the legacy of the French Revolution and the imperative to think about individual political agency in Britain where the non-elite had very little political sovereignty. ${ }^{18}$ The continental influence on the philosophy of language in English Romantic poetry is particularly evident in William Wordsworth's thoughts on language. Wordsworth's notion of language was founded on borrowings from the language-oriented philosophy of Locke and Condillac. He based his understanding on the principle of linguistic relativity, which makes three basic assumptions. First, that words are an expression of our private ideas of what we encounter in the world. This assumption drew heavily from Locke's critique of language as nomenclature. That is, for Locke, words did not necessarily mean things, rather, they expressed our abstract ideas about things. This understanding of words had become increasingly popular across Europe and we find resonances of it in the thoughts of Condillac and Humboldt. The second assumption was that, as ideas were intensely private, they could only be

${ }^{17}$ William Jones, Principles of Government in a Dialogue between a Scholar and a Peasant (London: Society for Constitutional Information, 1783).

${ }^{18}$ For a discussion of Coleridge's understanding of agency and the impulses behind his thinking about agency, see Steven E. Cole, "Coleridge, Language and the Production of Agency”, Modern Philology (88) (1990): 109-25. 
expressed through the "sad incompetence of human speech."19 This assumption was based on an understanding shared by Locke, Condillac, Herder, and Humboldt that "every individual has his own language." 20 However, language is fundamentally a social thing. This leads to the third assumption, that language is a "social institution" that "embodies the communally shared universe of knowledge and feeling." 21 Hence, language in the moment of Wordsworth was understood as something both intimately personal and communally shared. Thus, the community that shared this language also shared a degree of intimacy through language.

This understanding of a private language that is intimate to a people's collective thought drew on a much deeper history in the career of Middle English of the early modern period. Vernacular came to mean a very specific thing when literary figures of this period sought to separate it from Latin as well as from French. In this period, vernacularization involved the mapping of spoken language on to the written language of the middle elite and in doing so the language sought to rise beyond its vernacularity to take up a position as a national mother tongue that was always in competition with both other mother tongues and vehicular languages. In this period, the status of English as a vernacular was founded on the notion that it was the common tongue commonly spoken by the lower classes, as well as between the common people and the elite who had access to other classical languages as well. ${ }^{22}$ Also part of this vernacularization was a stronger investment in the idea of it as a mother tongue, which established a visceral connection between the speakers and the language. ${ }^{23}$ Across Europe, the idea of the genius of language also emerged in this period. In his history of Italian, Paola Gambarota shows how the concern with the genius of language came to dominate European discussions about common tongue in the early modern period. ${ }^{24}$

19 Hans Aarsleff, "Wordsworth, Language and Romanticism", in From Locke to Sassure: Essays On the Study of Language and Intellectual History (Minneapolis: University of Minnesota, 1983), p. 375.

20 Ibid. ${ }^{21}$ Ibid.

22 Jocelyn Wogan-Browne and Ian Richard Johnson, The Idea of the Vernacular: An Anthology of Middle English Literary Theory, 1280-1520 (University Park, PA: Penn State University Press, 1999).

23 Margaret. W. Furgusson, Dido's Daughters: Literacy, Gender and Empire in Early Modern England and France (Chicago, IL: University of Chicago Press, 2003), pp. 83-134.

24 Paola Gambarota, Irresistible Signs: The Genius of Language and Italian National Identity (Toronto: University of Toronto Press, 2011). He argues that "the building blocks of linguistic nationalism were long in the making, starting with seventeenth-century discussions of vernaculars that began consistently to link the genius of language to the genius of the nation" (p. 13). 
Another factor that informed the idea of the vernacular in eighteenthand nineteenth-century England was the linguistic experience of internal colonialism, which pitted English in an adversarial relationship with colonized languages such as Irish and Welsh. In this context, English had come to serve as the vehicular language or a language that travelled beyond the local confines of the community that initially spoke it and was also able to connect various language groups together by serving as a common tongue. While early modern textual evidence suggests that the English government sought to force the Irish to use the English language, by the nineteenth century we find that that relationship with Irish had become far more complex. Rather than being the only viable language of use that sought to obliterate other languages, English had come to occupy a very different position in the hierarchy of languages - it had become the worldly vehicular language that could connect the far reaches of the empire in which specific vernaculars were spoken. For instance, in the case of Irish and its relationship to English rule in the nineteenth century, we find discussions of Irish as vernacular where it denoted the local language and it also meant, very emphatically so, the language that was owned by the people. ${ }^{25}$ It was described as the language that was best used to impart religious scripture as well as education. ${ }^{26}$ In discussions of language planning, Irish was described as a language that could not be separated from the Irish population. At the same time, there was also a constant concern about how the Irish language did not have the ability to carry what the colonizing elite wanted to teach the colonized. The Irish language needed improvement. And this ideology established a culture of improvement of the colonized vernacular in relation to Irish. Furthermore, with the growing popularity of comparative philology and the increasing acceptance of an evolutionary historicist understanding of the relationship between languages of the world, the comparison between an inadequate colonized vernacular and a much more successful and wellendowed vehicular English had been set up by this time. ${ }^{27}$

${ }^{25}$ In 1787, we find arguments about teaching in Irish. A 1787 pamphlet writer argued: "No, my lord, the natives of Ireland must ever be instructed in their vernacular tongue ... No change could be lasting, which took place in contradiction to the passions of the people, who in all nations have been more affected by changes in local manners and customs, but particularly in language". Tony Crowley, Politics of Language in Ireland, 1366-1922: Source Book (London: Routledge, 2000), p. 126.

${ }^{26}$ J. S. Taylor, "Reasons for Giving Moral Instruction of the Native Irish Through the Medium of their vernacular language, 1817", in Crowley, Politics of Language, pp. 146-7.

${ }^{27}$ One of the first language-mapping projects in India was Robert Needham Cust's Language Map of India, which dealt with revenue collection. See Judith T. Irvine, "Language Fields: Robert Needham Cust's Language Map of South Asia, 1878", in Cynthia Talbot, Knowing India: Colonial and Modern Constructions of the Past (New Delhi: 
By the 1830s when the question of language became very fraught in India due to the Orientalist-Anglicist debate, we find that this shift in English from vernacular in England to vehicular in the empire was entirely in place. For instance, if we read Thomas Babbington Macaulay's Indian and British writings together we find that he placed English where the English would have placed Greek and Roman in the Renaissance in the spectrum of languages. In the Minute on Indian Education, Macaulay argued that:

The first instance to which I refer is the great revival of letters among the Western nations at the close of the fifteenth and the beginning of the sixteenth century. At that time almost everything that was worth reading was contained in the writings of the ancient Greeks and Romans. Had our ancestors acted as the Committee of Public Instruction has hitherto noted, had they neglected the language of Thucydides and Plato, and the language of Cicero and Tacitus, had they confined their attention to the old dialects of our own island, had they printed nothing and taught nothing at the universities but chronicles in Anglo-Saxon and romances in Norman French, -would England ever have been what she now is? What the Greek and Latin were to the contemporaries of More and Ascham, our tongue is to the people of India. The literature of England is now more valuable than that of classical antiquity. I doubt whether the Sanscrit [sic] literature be as valuable as that of our Saxon and Norman progenitors.

In Macaulay's characterization of languages, we find that there is composite understanding of language that is deeply implicated in the experience of colonialism and the politics of knowledge and power. Macaulay's understanding of language in this passage seems to be borrowed from a number of sources. Language here is primarily a custodian of knowledge and textual reserves of any particular community. In this we see resonances of Wordsworth's two-tier understanding of languages as the individual's ideas borne out of his/her responses to the natural world, which then get bolstered by a public consensus within the individual's immediate community. Language then bears the knowledge of both the individual's immediate experience and the shared knowledge of the community. This connection between nature, the individual, and the community could allow language to be the custodian of scientific knowledge. At the same time Macaulay's critique of Indian languages carries a whiff of Harris' understanding of the differing abilities of different languages; that some languages are too earthy to reflect complex and abstract thought. Macaulay's description of Sanskrit, in particular, is intriguing. While he acknowledges that there is knowledge in Sanskrit, he notes how this knowledge is misleading. But his comparison of

Yoda Press, 2011). Joseph Errington, Linguistics in a Colonial World: A Story of Language, Meaning, and Power (Chichester: John Wiley \& Sons, 2008). 
English, European classical languages, and Sanskrit suggests that this condition of inadequacy is not absolute for Indian vernacular languages. Anglo-Saxon and its contemporaries grew into English. This opens up the possibility for the future development of the Indian vernaculars through the influence of English. And that is precisely what Macaulay hoped that his "brown sahibs" could achieve. They could serve to filter Western knowledge that resided in English into the Indian vernaculars. In arguing for the creation of a new class of Indian men who were Indian in "blood and colour" but English in "tastes, manners and distinction," Macaulay was not just arguing for the creation of a class of intermediaries for the administration of the Indian empire, he was also hoping to create a class of people across India who were tasked to reform, modernize, and empower Indian vernaculars to become languages that could do what English was able to do due to centuries of influence from Greek and Latin.

This brief discussion of ideologies of language in the late eighteenth and early nineteenth centuries that the idea of the vernacular had come to acquire a range of meanings in the imperial metropole. It invoked the idea of the mother tongue, a common tongue that connected the nation across classes and natural or pure language. It was also applied to the language of the colonized that was lacking in knowledge and the equipment for carrying such knowledge. The colonized vernacular was a fit subject for reform. And despite its deficiencies the only language through which the colonized could be spoken to because it was their mother tongue and its use would fit with English notions of efficacious rule. And finally, as Robert Yelle has argued, the vernacular was seen as having the ability to confound attempts of local religious orthodoxy to beguile the common people through the use of opaque "classical" languages such as Sanskrit and Persian. ${ }^{28}$

\section{Colonial Vernacularization of India}

In late eighteenth-century colonial India, William Jones, as well as his contemporaries who worked on Indian languages, started by looking at Sanskrit and Arabic as a means to gain access into understanding the Indian population and Indian legal systems. ${ }^{29}$ Jones himself started studying Sanskrit because he served as a judge in Calcutta and he needed

${ }^{28}$ Robert A. Yelle, The Language of Disenchantment: Protestant Literalism and Colonial Discourse in British India (New York: Oxford University Press, 2012).

29 See Bernard Cohn's famous essay on the language of command: Bernard S. Cohn, Colonialism and its Forms of Knowledge: The British in India (Princeton, NJ: Princeton University Press, 1996); Thomas R. Trautmann, Languages and Nations: the Dravidian Proof in Colonial Madras (New Delhi: Yoda Press, 2006). 
to understand Hindu law. Unlike Macaulay after him, Jones believed that an understanding of Persian and Sanskrit was key to a more nuanced understanding of Indian society to enable imperial rule. ${ }^{30}$ Much of the early study of India languages was for such reasons. For instance, taking a different approach, Nathaniel Halhed wrote his grammar of the Bengali language to produce a language that would be intelligible to both the colonizer and the colonized so that the newly colonized Bengalis could be incorporated into the British empire as "more than subjects but less than citizens." ${ }^{31}$ Understanding, codifying, and teaching Indian languages became central to the imperial project in the late eighteenth and early nineteenth centuries.

The consequence of Jones' and his contemporary's investment in an understanding of language as the route to accessing some sort of primeval truth about India was that the early linguistic Indology ascribed to languages such as Sanskrit and Persian the capacity for holding some foundational truths about the Indian people. In the meanwhile, the launching of comparative linguistics and new ideas about the Indo-European language family, which connected Indian languages with European languages, also situated Indo-European vernaculars in a genetic and gendered relationship with Sanskrit, which, in turn, came to be understood as the mother of Indian languages. ${ }^{32}$ Thus was put in place a hierarchy of languages in which the classical Sanskrit or Persian was followed by the more lumpen Indian vernacular languages. The vernaculars were often thought of a vulgarized, bastardized version of the classical.

This hierarchy is visible in the first of the three crucial moments when colonial policy about Indian languages was determined in India. It is attested in the evidence that we garner from the Orientalist and Anglicist debate on education of the 1830s, which was concerned with choosing the medium of higher education in India between English and Indian classical languages, i.e., Sanskrit and Persian. The Anglicists argued that using English would allow Indians access to a large body of literature that came from the West. They were adamant that Indian languages did not have the ability to represent modern thoughts and neither did they have a sizable textual tradition that would be useful for

${ }^{30}$ Hans Aarsleff, The Study of Language in England, 1780-1860 (Princeton, NJ: Princeton University Press, 1967), p. 122.

${ }^{31}$ For a nuanced reading of Halhed's grammar, see Henry Schwarz, "Laissez-Faire Linguistics: Grammar and the Codes of Empire", Critical Enquiry, 23 (1997): 509-35.

32 Sumathi Ramaswamy, "Sanskrit for the Nation", Modern Asian Studies 33, no. 02 (1999): 339-81. Judith T. Irvine, "The Family Romance of Colonial Linguistics: Gender and Family in Nineteenth-Century Representations of African Languages", Pragmatics 5, no. 2 (2009). Errington, Linguistics in a Colonial World. 
modern life. Thus, such tongues were unable to render Indians into productive subjects of the British Empire. The Orientalists held that the Indian populace did not desire Western knowledge and that there was much to be learnt from a classical Indian education. In a move that was reminiscent of Wordsworth's linguistic assumptions, they also argued that Sanskrit and Persian literature was important to the people of India because poetry in these languages was the "source of national imagery and the expression of national feeling." ${ }^{33}$ While there are differences between the two sides, what is striking is that both sides maintained a consistent narrative of linguistic lack when it came to Indian vernaculars. Even someone like John Stuart Mill, who wrote about this debate and responded to some of the more vociferous Anglicist arguments, posed that the study of Indian classical languages was important precisely because it would enable the colonial state to improve Indian vernacular languages. This narrative of linguistic lack about the Indian vernaculars continued and we see this in discussions about Urdu in Delhi College, which talk about how Urdu is a language that is unprepared to speak modern thoughts and hence a new lexicon needs to be introduced into that language.

Despite the resolution of the Orientalist-Anglicist debate with the introduction of English as the language of higher education, the colonial state in the same period also invested in recognizing the vernaculars of Indian for administrative reasons. With the passing of the Act of 1837, the language of revenue and judicial administration in the Bengal presidency was changed from Persian to Hindustani, Bengali, and Odia. As I have discussed earlier, the justification for this change was that in judicial and revenue administration, justice could not possibly be served if the people who were being judged or accessed by the state were unable to understand the language of the state and language of law. This was a very clear reference back to the 1790s' moment in British politics. In the process involved in getting this Act passed, the government of Bengal asked its district-level officials to report on what languages were used in their districts and asked for their opinions about the possible drawbacks of these languages and what could be done to rectify these. A number of conclusions can be drawn from a reading of the correspondence that followed. First, we see that this call for district-level responses resulted in a very careful mapping of the languages of the Bengal Presidency. And we should note here that the Act was applied to other British provinces

${ }^{33}$ Lynn Zastoupil, and Martin Moir, The Great Indian Education Debate: Documents Relating to the Orientalist-Anglicist Controversy, 1781-1843 (London: Psychology Press, 1999): p. 23. 
immediately after and this meant that there was meticulous linguistic surveying occurring across India, although this was by no means the first linguistic mapping of India by the colonial government. This new mapping, however, was the first time the mapping was coupled with administrative changes. The correspondence, which runs into 430 manuscripts of district reports, reveals a discussion of how these languages were unable to serve as judicial languages because of their difficult script, lack of standardization, or lack of a judicial lexicon. The pervasive disdain for these languages within the ranks of low level colonial officials also comes through in the correspondence.

In twenty years' time, the linguistic mapping of colonial administration was mirrored in a linguistic mapping of colonial education with the institution of the Wood's Despatch of 1854, which stipulated that all primary education and some secondary education should be conducted in the medium of the local vernacular. ${ }^{34}$ The ideological investment in teaching in the people's own language that comes through in the discussions about the Wood's Despatch echoes back to the experience of Irish in India.

The rigorous linguistic mapping of colonial India that ensued due to the institution of the Wood's Despatch forced colonial officials to draw discrete geographical boundaries between language zones. In the border zones of language, the question of the official language of instruction often became the subject of vigorous debates. For instance, the question of language in the Midnapore district of the Bengal Presidency had to be resolved between colonial officials as many people of the district were bilingual with an ability to speak both Odia and Bengali. As residents selfidentified as either Odia speaking or Bengali speaking, it became difficult for officials to stipulate a clear choice for the language of instruction. ${ }^{35}$ The question of the Midnapore district would become a point of contention later in the century, when members of the Odia intelligentsia would cite the example of the falling number of Odia speakers in the district as an instance of Odia-speaking people identifying as Bengali speaking due to governmental neglect of the Odia language. However, it was not just a question of the choice between major vernaculars in border areas of language zones in India that threw up problems for officials instituting the recommendations of the Wood's Despatch. In Chittagong, officials became concerned about what would be the language of instruction as

${ }^{34}$ Robin James. Moore, "The Composition of Wood's Education Despatch", English Historical Review 80, no. 314 (1965): 70-85.

${ }^{35}$ A collection of despatches from the Home Department on the subject of Education in India 1854-1868 (Calcutta: Office of Superintendent of Government Printing, 1870), p. 49. 
the vernacular of the area was an adivasi language known as Chakma. Officials recommended a choice between Bengali, the dominant language of neighboring areas, or English, which was the most developed language in India. The protectionist language of the discussion about this choice throws into clear relief the limits of the government's stipulation that the language of instruction should be in the vernacular of the area. ${ }^{36}$ Not every vernacular qualified as the language of instruction. These choices effectively put in place a hierarchy of languages in India. First English, then some of the major native languages including Tamil, Bengali, or Odia and, finally, at the bottom of the hierarchy were adivasi languages such as Munda, Ho, Chakma, and Gond. Earlier efforts for administration and proselytization did not make such distinctions as the impetus was on reaching the local population rather than a centralized effort to categorize the populations in unilingual language groups that could be educated in a uniform manner. Boundaries and minorities had to be rationalized into discrete monolingual zones.

By the end of the 1850s, when we look at how the colonial government works, we see that Indian languages have come to have discrete boundaries with discrete groups of speakers whose interests are staked with these languages. To be vernacular is now to be local to a particular part of India in contrast to the vehicular and far-reaching English. This understanding of Indian languages had already existed since the precolonial times. While there is no word for the vernacular as such in Indian languages, Sheldon Pollock has illustrated how these languages were thought of as local or desi in relation to the more cosmopolitan or marga language of Sanskrit. However, the locality of these languages, their territorial domains, had never before been so discretely marked and intensely contested (as it came to be later).

Now people had to speak, be adjudicated, and be taught in their own languages. Due to the influence of Romantic notions of natural language that informed British linguistic liberalism, vernacular has now become emphatically indigenous - not just to the locality or place but to the people themselves. And through the narrative of linguistic lack that pervaded early Indological and official discussion, vernacular now had also become, to some extent, powerless. It had become a vulnerable, abject object of native protectionism and activism.

However, this claim of powerlessness emerges through the very process that empowers these languages as languages of education and state by making them into languages that allow access to colonial boons. Therefore, written into the claim of the "enslavement" of the vernacular

${ }^{36}$ Ibid, p. 86. 
is already tremendous political power - which will be harnessed by local regional elites to buttress anticolonial politics and regional hegemony over internal minorities. This is the new politics of vernacularization of colonial India. ${ }^{37}$

The institutional process of colonial vernacularization gradually transformed the people of India into a collection of monolingual subjects in the eyes of the colonial state. This institutional monolingualism emerged with the growth of colonial governmentality in India in the last 250 years. The writings of early philologists including William Jones and administrators such as Thomas Macaulay suggest that languages in India were classified into classical languages (Sanskrit and Persian) and vernaculars (prakrit languages and the languages of the indigenous peoples of India). From comments such as "some languages not vernacular among them," we can infer that in the late eighteenth and early nineteenth centuries, "vernacular" simply meant language commonly spoken by the people. ${ }^{38}$ However, the shift in the relationship between language, place, and people had already begun with this usage. As Sheldon Pollock has argued, in the precolonial period, language was not linked to people but to place. In Europe, by way of contrast: "Origins of languages and people, morphing into chronologies and histories of kingdoms-and-peoples, can fairly be called an obsession [...] in the first half of the vernacular millennium." ${ }^{39}$ The history of colonial and comparative philology in India suggests that a trace of this European legacy carried into colonial linguistic policy. Using the example of C. P. Brown, a scholar of nineteenth-century Telegu, Rama Sundari Mantena has illustrated how colonial philology saw languages as having "progressive histories" that would foreshadow later debates

37 This narrative of vernacularization in the nineteenth century that I am trying to establish produces these boundaries between Indian languages and between their domains and produces their own regional basis, but does not, however, suggest that there is no geographical life of the major Indian languages before colonialism. As the work of Sheldon Pollock illustrates, there is no term to denote the many meanings that the term vernacular carries in Indian languages. Through his study of the vernacular millennium as he calls it, Pollock illustrates that two kinds of language exist and they have a certain kind of relationship between them, which is both spatial and ideological; that is, the language of the path or marga, like Sanskrit, and the language of place or desi, like Odia. Desi is not thought of as a mother tongue. There are no words for the idea of a mother tongue. There probably does not exist the same kind of affective relations with language. While relationship between language and early modern polity exists, these discrete boundaries did not exist, the boundaries are much more fuzzy and the discreteness is new.

${ }^{38}$ L. Zastoupil and M. Moir (eds.),The Great Education Debate: Documents Relating to the Orientalist-Anglicist Controversy, 1781-1843 (London: Routledge, 1999), p. 236.

39 Sheldon Pollock, "Cosmopolitan and Vernacular in History", Public Culture 12, no. 3 (2000): 612 . 
about modernization of Indian languages. ${ }^{40}$ In later years, regional linguistic activism would conflate the progress of the speakers with the progress of the language. For instance, in the late 1930s Tamil nationalists argued that the prosperity of Mother Tamil or Tamiltay would entail the prosperity of Tamil speakers - "If Tamiltay prospers, so will Tamilians and so will Tamilnadu" - language, people, and place now shared a common destiny. ${ }^{41}$

\section{Tower of Babel: Language Policy and Affect in Colonial Odisha}

In Odisha, language and community came to be coupled in a public debate in the 1860s when the Odia-speaking elite organized a campaign against proposals for the removal of Odia as a language of instruction in schools of the Odisha division of the Bengal Presidency. This drew the colonial government and the Odia elite into a debate about the viability of Odia as an official language, as questions were raised about the scope of existing Odia literature, the ability of the impoverished Odia-speaking people to finance the production of new literature in Odia, and the efficacy of granting state patronage to a language that was not equipped to serve as an official language due to the paucity of educated Odiaspeaking people. This section will trace the shift in the understanding of language as an instrumental medium of communication to an object of affect - a mother tongue - as the Odia-language press engaged with the proposal to replace Odia with Bengali. This engagement, I will argue, is marked not only by the avowal of Odia as a mother tongue but also by an effort to question the hierarchical relationship between Odia and Bengali - where Bengali is understood as a more developed language. By lobbying for the continued use of Odia as a language of instruction in the schools of the Odisha division of the Bengal Presidency, the Odia elite effectively convinced the colonial state that the Odia language had a separate, inviolable geographical domain of its own.

While the formation of a discrete geographical domain of Odia was a colonial phenomenon, it would be incorrect to say that this was the first instance of vernacularization in Odisha. In sixteenth-century Odisha, under the influence of devotional Vaisnavism, the earliest Odia translations of the Mahabharata, Bhagavad Gita and Ramayana were produced.

${ }^{40}$ Rama Sundari Mantena, "Vernacular Futures: Colonial Philology and the Idea of History in Nineteenth Century South India", Indian Economic and Social History Review 42 (2005): 513-34.

${ }^{41}$ Quoted in Sumathi Ramaswamy, "En/Gendering Language: The Poetics of Tamil Identity", Comparative Studies in Society and History 35 (1993): 691-2. 
The term "translation" can only be used loosely in relation to these texts because even though the broad plot of these texts were based on the Sanskrit originals, their content departed sharply from the actual stories in the original texts. The Odia Mahabharata, written by a peasant poet Sarala Das, located the epic entirely in Odisha. These localized religious texts became extremely popular in rural Odisha. Instrumental in this process was the Bhagabat Ghara, a communally held hut present within most villages in Odisha, where these texts were read out loud to a devotional audience. Reports of the presence of such Bhagabat Gharas can be obtained as late as the last decade of the nineteenth century. ${ }^{42}$ It could be argued that this auditory literacy in medieval Odia religious texts shared by people across Odia-speaking areas, greater use of Odia in court proceedings and royal inscriptions, and a significant increase in the production of literature in Odia could have already created a sense of regional belonging based on language as early as the sixteenth century. Furthermore, the subsequent growth of Odia literature and folk traditions could only have added to this sense of belonging to one community. However, the capitulation of the last centralized Odia empire to the Mughal empire in the late sixteenth century, the emergence of smaller states all over Odisha, and Mughal and Maratha influence on Odia language, literature, and cultural life must have shaped the ways in which definitions of Odia-ness changed over time. It is evident that the provenance of Odia identity can be traced to a much earlier time. A straightforward linear history of Odia identity from its point of origin in the medieval period to its modern articulation in the nineteenth century could potentially simplify and distort a remarkably complex and internally differentiated process. Hence, even as I concede that the origins of Odia linguistic identity do lie in the precolonial period, in this chapter, I do not wish to identify some line of descent from precolonial times. My effort here is to treat particular moments in colonial history of the Odia language in their complexity rather than produce a linear narrative of the development of Odia linguistic politics. This politics is neither simply precolonial nor simply colonial. Furthermore, the danger of such a history is also that it would present Odia identity as a concept with a singular normative meaning commonly held by all Odia-speaking people.

Therefore, I do not argue that Odia as a language of affect emerged in this period. Surely, an affective relationship with language is not a modern phenomenon and a history of this affect may involve a much more

${ }^{42}$ A discussion of Bhagabat Ghara is found in the 1893 travel memoir Orisara Chitra. Also see Bana Bihari Shukla, Bhagabata Ghara and Village Panchayat in Mediaeval Orissa, 1510-1803 AD, 1st ed. (Cuttack: Bharati Publications, 1986). 
complex reading of nineteenth-century texts as well as those from earlier times. Such a reading is outside the scope of this project. Rather, I argue here that the transformation lay in the public, collective articulation of the Odia language as a "mother tongue," which could not be replaced by another more developed language. This articulation and the ultimate acknowledgement by the colonial state of the Odia right to "learn in their own language" gestured at the transformation of the colonial state's linguistic understanding of India. In future, the colonial state understood India as a collection of discrete linguistic areas. The eventual product of this new understanding of this vernacular geography of India was Grierson's multi-volume magnum opus - the Linguistic Survey of India, which was published between 1903 and $1927 .{ }^{43}$ The survey mapped the linguistic geography of India and effectively granted each major language its own geographical domain. The Odia-Bengali debate of the 1860s represents the moment when this transformation of British understanding of India was underway. Concomitant to this process was the emergence of identity politics focused on languages as the boundaries of linguistic domains came to be contested. Successive government initiatives such as the establishment of the 101 Hardinge vernacular schools in the Bengal Presidency and the Wood's Despatch on education of 1854, which advocated the use of vernacular languages as the language of instruction in primary educational institutions throughout India, made the question of language in the Odia-speaking areas an important policy issue for the government. ${ }^{44}$ What should the language of instruction in the schools of the Odia-speaking areas be? Is there an adequate supply of appropriate Odia literature and trained Odia teachers to cater to the needs of these schools and their students?

The problem with ascertaining the language of instruction in the Odiaspeaking areas arose from the minority linguistic status of Odia speakers in the larger provinces of British India. In the case of areas where a majority of the population spoke Odia, the use of the vernacular was only partial. Odia was officially designated the language of instruction in

43 George Abraham Grierson and India Linguistic Survey, Linguistic Survey of India (Calcutta: Government of India, Central Publication Branch, 1903). In his new book, Javed Majeed has showed how Grierson's survey became the focus of interregional linguistic politics as many linguistic movements deployed the findings of the survey as alibis for their territorial demands. See Javed Majeed, Nation and Region in Grierson's Linguistic Survey of India (New Delhi: Routledge, 2018).

${ }^{44}$ In 1844, Lord Hardinge decreed the establishment of 101 vernacular schools in the Bengal Presidency. Eight of these 101 were establish in the Orissa division. For details, see Bharati Mohapatra, Going to School in the Raj: Primary Education in India (1803-1903) with Focus on Orissa (Bhubaneswar: V. B. Shastry, 2003), pp. 63-72. For more details on the Wood's Despatch, see Mir, "Imperial Policy, Provincial Practices". 
the Orissa division of the Bengal Presidency. However, in Odia-speaking areas in the Central Provinces and Madras Presidency the language of instruction remained Hindi and Telugu, respectively. Hence, the subsequent Odia-language movement of the 1860 s, which was organized to oppose proposals to substitute Bengali for Odia, developed mostly in the Orissa division of the Bengal Presidency. ${ }^{45}$

By the late 1860s, Cuttack, the capital of the Orissa division, could boast of a fairly vocal albeit limited public sphere comprising of discussion clubs such as the Cuttack Debating Society and newspapers (for example, Utkal Dipika). ${ }^{46}$ As a response to the mismanagement of the famine relief efforts by the government in 1866, Utkal Dipika, a weekly newspaper, was floated to apprise the government of the needs of the people of Orissa division. A secondary object of the newspaper was to work for the development of the Odia language. The Utkal Dipika provided the site where the notion of the economic, social and cultural interests of a community came to be conflated with the Odia language. The newspaper, edited by Gourishankar Rai, frequently carried articles and received letters about the economic condition of the people of Odisha, famine relief efforts by the government, and other governmental policies pertaining to Odisha. ${ }^{47}$ In the late 1860 s, the newspaper spearheaded the campaign against the proposal to replace Odia with Bengali in the Orissa division.

The debate about Odia and Bengali had been brewing for some time among colonial officials. As early as 1841, the Commissioner of Orissa was petitioned by the Sudder Board of Revenue that Odia be replaced by Bengali as language of governmental activity. ${ }^{48}$ Reasons given by these early proposals were twofold: one, that there was very little difference between the two languages and the use of Bengali in the Orissa division

45 This, however, does not mean that similar debate did not occur in other Odia-speaking areas in the Central Provinces and the Madras Presidency in the subsequent period. In fact, the first political movement for the separation of an Odia-speaking area occurred in the Sambalpur district of the Central Provinces. In Sambalpur, where a majority spoke Odia, the government of the Central provinces was attempting to substitute Hindi for Odia as the language of instruction. This led to a rather public debate in both Orissa division and Sambalpur. After much debate, the Central Provinces government rescinded the order and transferred the Sambalpur district and its associated princely states to the Bengal Presidency. For more details, see Nivedita Mohanty, Oriya Nationalism: Quest for a United Orissa, 1866-1956 (Bhubaneswar: Prafulla, 2005), pp. 63-81.

46 For a detailed list of other newspapers and the general state of newspaper media in the late nineteenth century, see Ibid, pp. 55-60.

47 For a cross-section of articles published in Utkal Dipika, see Sudhakar Patnaik, Sambadapatraru Odisara Katha, Vol. 1 (1886-1881) (Cuttack: Grantha Mandir, 1971).

48 S. C. Patra, Formation of the Province of Orissa: The Success of the First Linguistic Movement in India (Calcutta: Punthi Pustak, 1979), p. 101. The events preceding this report are noted in Panchanan Mohanty, "British Language Policy in Nineteenth Century India and the Oriya Language Movement”, Language Policy 1 (2002). 
would be in the interest of administrative economy; and, two, the lack of properly educated Odia-speaking officials made it difficult to find appropriate personnel. Thus, these proposals argued that using Bengali in the Orissa division made sound administrative sense.

Similar proposals were being made for the changes in the language of instruction in schools of the Orissa division. ${ }^{49}$ The lack of qualified Odia school teachers and proper textbooks in Odia often formed the grounds for such proposals. Even as late as 1860, there were only seven Odia teachers in the entire Orissa division. As a result, most of the teaching posts in urban as well as remote rural areas were manned by Bengalispeaking teachers who, owing to their inability to teach in Odia, failed to enforce the provisions of the Wood's Despatch on education. Education in these areas could not be conducted in the officially recognized vernacular language - Odia. In 1864-65, both the Inspector and Deputy Inspector of Schools in Odisha recommended that Bengali be made the only language of instruction in the schools of Orissa division. ${ }^{50}$ This sparked the Odia-language movement in earnest.

As a response to such proposals, the Utkal Bhasha Uddhipani Sabha (Association for the Development of Odia Language) was organized in 1867. Headed by both domiciled Bengalis and Odia members, this organization aimed at the development of the Odia language, encouragement of the involvement of common people (sarbasadharana) in this project, the replacement of the mixed languages used in government offices with pure Odia, and to ensure that only linguistically qualified officials be able to work as revenue officials in Odisha. ${ }^{51}$ The last of these aims perhaps points to the need for a larger number of educated Odia-speaking government officials to man the junior positions in the revenue department that had a major impact on the lives of the Odia populace. ${ }^{52}$

49 The fact that such proposals were being made in official circles is evidenced in the rebuttal issued by E. Roer, the first Inspector of Schools for Orissa, who said: "The Ooriah language cannot be considered as a dialect of Bengalee, though nearly related to it; but it is a language of its own which has its own grammatical forms, idioms and signs for the letters and mostly translations from Puranas, the Hitopadeshas, Baratrishasinghasana etc.", in Patra, "Formation of the Province of Orissa", p. 102.

${ }^{50}$ Mohanty, "British Language Policy in Nineteenth Century India", 62.

51 "Utkala Bhasha Uddhipani Sabha", Utkal Dipika, May 26, 1867, reprinted in Appendix 2 of Mahanti, Odia Bhasha Andolana, p. 121.

${ }^{52}$ In his report on education in 1867-68, the Inspector of schools noted that there was a need for a surveyor school in Cuttack as there was a lack of Odia-speaking amins. See Instruction Bengal Dept. of Public, "General Report on Public Instruction in the Lower Provinces of the Bengal Presidency", in General Report on Public Instruction in the Lower Provinces of the Bengal Presidency (Calcutta: Printed [for the Government] at the Alipore Jail Press, 1867-68), pp. 58-9. 
However, even as this organization was striving towards strengthening the position of Odia in governmental and educational institutions, the leaders used the development of Bengali as a template for future efforts to achieve their goals. The career of Bengali under colonial rule was seen as an exemplar of the manner in which a native population had been able to preserve, modernize, and develop an Indian vernacular. The influence of the Bengali model is apparent from the proceedings of the first meeting of the Sabha. Rangalal Bandyopadhyay, the president of the session noted that: "If we investigate the rise to favor of our Bengali language in such a short time then we will find that printing presses and organizations for religious propaganda are responsible." ${ }^{53}$ Hence Bandyopadhyay argued that, as religious texts had been so successful in the spread and development of Bengali, the old Odia religious texts should be reprinted. It was to be the responsibility of the Sabha to unearth the background of the authors of these classical texts and enable the dissemination of the texts through publication.

Paradoxically, even as the Sabha was established for the development of the Odia language in a climate where Odia was being displaced by Bengali based on claims that Odia was merely a dialect of Bengali, Bandyopadhyay reiterated such claims rather than questioning them. $\mathrm{He}$ argued that the difference between Odia and Bengali was not any more pronounced than the distinction between regional variations of Bengali. This inability to break away from the foundational claim against the establishment of Odia reveals how entrenched this idea was among the educated elite.

However, the argument against Odia was not always based on the similarity between Odia and Bengali. The most influential statement in favor of Bengali was a speech made by Rajendralal Mitra at the Cuttack Debating Society in 1868, where he argued for the removal of Odia from the schools of the Orissa division on the grounds that the Odia-speaking population was numerically too small to support the production of new Odia school textbooks. ${ }^{54}$ Mitra was well known both in the Orissa division as well as in Calcutta. An active member of the Asiatic Society of Bengal, Mitra had strong links in Odisha due to his research on Odisha

53 “Atirikta", Utkal Dipika, May 26, 1867, reprinted in Appendix 2 of Mahanti, Odia Bhasha Andolana, p. 200.

54 The Cuttack Debating Society was an organization of students and teachers at the Cuttack High School. It was held in the building of the printing press of the Odia weekly Utkal Dipika. In its early years, it remained one of the more popular forums for public discussion in Odisha where Odia intellectuals, government officials and visiting scholars discussed a variety of issues. For details, see Nataban Samantaraya, Odia Sahityara Itihasa (1803-1920), (Bhubaneswar: Granthalaya, 1974). 
antiquities. In 1875 he published Antiquities of Orissa. ${ }^{55} \mathrm{He}$ was also very vocal in the debate about vernacular education in Calcutta. ${ }^{56}$

In his speech Mitra argued that the lack of an adequate number of people who speak the Odia language could render the survival of Odia as an independent language impossible. He noted:

Any well wisher of Utkal will first introduce Bengali and replace Oriya. As per the Famine Commissioner the total population of Utkal is twenty lakhs now. If we discount the women and the children, it is possible that only ten to twelve lakh people know how to read and write. But can this small number of people maintain a language? Nobody can be successful in writing new books here. Bengal is a vast country and has progressed so much because its population is large. If Bengali is introduced in Utkal then Bengali books will be read here. And the Oriya people will get good books easily. ${ }^{57}$

Thus, for Mitra, not unlike the colonial government, the lack of textbooks was the central problem that informed the deliberations about the status of Odia in the schools of the Orissa division. However, Mitra introduced a revealing dimension to the debate by raising the question of population and the economics of textbook production. In this remarkably practical allusion to liberal economic practice, Mitra argued that a language could only be supported if there were a market for its consumption. The number of Odia-speaking people was an important concern as they constituted the market for Odia texts. Unfortunately, argued Mitra, the famine of 1866 had severely depleted the Odia population. Elsewhere, Mitra elaborated this claim by arguing that it would be unreasonable to expect support from any other linguistic group (the Bengalis, for example). Furthermore, he contended that it would be unfair for the government to devote its own resources to the development of texts in the Odia language. This, he warned, would mean that the government would be supporting a project that would separate the Odias from the Bengalis, effectively implying that in so doing the government would be practicing a policy of divide and rule. ${ }^{58}$ Such a policy, Mitra cautioned, would complicate governance as it will mean raising "a tower of Babel to disunite and disperse the native races." ${ }^{59}$ In the absence of state support, the

55 Rajendralala Mitra, The Antiquities of Orissa By Rajendralala Mitra, ... These Are Some of the Relics of the Past, Weeping over a Lost Civilisation and an Extinguished Grandeur.... Published under Orders of the Government of India (Calcutta: Wyman \& Co., 1875); Rajendralala Mitra and Jogeshur Mitter, Speeches by Raja Rajendralala Mitra (Calcutta: S. K. Lahiri, 1892).

${ }^{56}$ Mitra and Mitter, Speeches by Raja Rajendralala Mitra.

57 Quoted in Mohanty, "British Language Policy in Nineteenth Century India", 66-7.

58 The Honourary Secretaries, "Remarks on Mr Beames 'Notes on the Relation of the Uriya to the Other Modern Aryan Languages'. " Proceedings of the Asiatic Society of Bengal (1870), 211.

59 Ibid, 211. 
development of Odia language would be ultimately the concern of the Odia-speaking people alone. However, Mitra pointed out, a majority of the Odias were desperately poor. Could they possibly afford to sponsor the production of new Odia texts?

Mitra had another argument against the use of Odia in the schools of the Orissa division. He noted that the new governmental desire to promote the use of vernacular languages in primary as well as higher education would be very difficult to execute in the case of Odia. In a language that did not have adequate textbooks for primary education, textbooks for college-level education would require huge investment of time and money. Mitra argued: "To suppose that such a thing is possible for a poor community of $2^{1 / 2}$ millions of Uriyas to accomplish, is to suppose an impossibility." ${ }^{\circ 0}$ Consequently, the Odia-speaking people would be reduced to primary- and secondary-level education and left unprepared for college education, which is conducted in English and Bengali. In such a circumstance, there will not be a quantum body of highly educated Odia people. The result, Mitra warned, would be the creation of a generation of unimaginative clerks - "bad substitutes of Babbage's calculating machines!" ${ }^{61}$ This definitely would not serve the long-term interests of the Odia people.

Mitra's arguments had two major implications for the future articulations of Odia linguistic politics. First, by connecting the fortunes of the Odia language with the numerical strength of the Odia-speaking population, Mitra unwittingly sparked the earliest Odia discussions on the need to lobby for the amalgamation of the Odia-speaking tracts in the Bengal Presidency, Madras Presidency and the Central Provinces under a single administration. The response in the Odia press to Mitra's claims focused on refuting his argument about the lack of an adequate number of Odiaspeaking people and establishing that Bengali was textually rich because of a long history of patronage from the colonial state. In a two part article entitled "Odia Bhasha Unnati Prati Byaghat" (Obstacles to the Development of the Odia Language) published in Utkal Dipika, the author argued that the primary obstacle to the development of the Odia language was the territorial dispersal of the Odia-speaking people had led to a lack of state support and patronage as Odia was a language spoken by a minority in different British provinces. ${ }^{62}$ As such a language, Odia did not have access to patronage from the colonial state in the form of grants for schools, textbook publication, and college-level classes conducted in the vernacular. Such a situation, the author argued, was responsible for

${ }^{60}$ Ibid, $211 . \quad{ }^{61}$ Ibid, 214.

${ }^{62}$ Utkal Dipika, October 3, 1871, in Patnaik, Sambadapatraru Odisara Katha, p. 244. 
the present state of the Odia language. The author countered Mitra's claim about the more advanced state of the Bengali language by pointing out that as the dominant language of the huge Bengal Presidency, Bengali had been benefiting from state patronage for many years. If Odia were to have access to such help from the colonial state then, over time, Odia, too, would be able to support a vernacular educational system. The article writer argued that Mitra's accounting of the Odia population was wrong because he had not counted the Odia-speaking people in provinces other than the Bengal Presidency. If all Odia speakers in different British provinces were counted, then it would be evident that Odia was a language spoken by a large number of people and the colonial government would definitely support the development of the Odia language. The article ended with a proposal to organize the Odia people to agitate for the amalgamation of the Odia-speaking tracts.

The other implication of Mitra's arguments against the use of Odia, particularly his contention that governmental support to the Odia claim would create divisions among the "native peoples of India", raised the question of divisiveness of such regional claims. The specter of divisiveness of regional politics would mark both discussions about regional identity politics within Odisha and non-Odia attitudes towards such politics as Odia regional linguistic politics came to dominate the Odia public sphere over the following decades. Even emphatic calls to the Odia-speaking people to protect and maintain the particularity and identity of the Odia community often punctuated their argument with qualifications about how such a move would not threaten the intrinsic unity of India. In fact, such qualifications often ended with the claim that such regional efforts actually strengthened the unity of the Indian community. ${ }^{63}$

We return for a moment to the article "Obstacles to the Development of the Odia Language", and its argument with Mitra's thesis about the future status of the Odia language. It appears that the author of the article and Mitra were speaking at cross-purposes. Mitra's concern was to speed up the development of the education of the Odia people and to ensure that they catch up with the more advanced regions of British India. Fundamental to his argument is the assumption that the Bengali and Odia languages are interchangeable because they are merely languages of instruction or means of communication. The author of the article, however, while refuting only the superstructure of Mitra's argument by taking up the question of population, did not bother to address this idea of interchangeability. On the contrary, the article begins with

${ }^{63}$ I will discuss this point further in Chapter 2. 
the question of the development of the Odia language and the possible obstacles to it. This reveals an investment in the Odia language that Mitra did not have. It is evident from this that, unlike Mitra, the question of replacing Odia does not even arise for the article writer. The fundamental disagreement between Mitra and the author of the article draws from the difference in their attitude towards language.

In the Odia press during this period, the question of language came to stand for the question of the development of the Odia-speaking community. If Odia did not survive and thrive then the Odia community would gradually melt away. Reference to Odia as "mother tongue" or "mother" abounded in newspaper articles addressing the debate. ${ }^{64}$

Finally, in 1869-70, the office of the Governor of Bengal Presidency addressed this issue by requesting statements from the Inspector of Schools in Odisha, Commissioner of Orissa, and the Director of Public Instruction for the Lower Provinces of the Bengal Presidency, describing their views on the matter of replacing Odia with Bengali. Both the Inspector of Schools and the Commissioner advised against such a move even though the Commissioner pointed out that it was difficult to obtain qualified Odia-speaking teachers for the schools of Odisha division. ${ }^{65}$ The Director of Public Instruction differed from the Inspector of Schools and the Commissioner by advocating a policy of noninterference. He suggested]: "[I]n the main it must be left to settle

${ }^{64}$ A number of articles appeared in Uktal Dipika in 1870 and 1871 addressing these issues. For details, see Patnaik, Sambadapatraru Odisara Katha.

${ }^{65}$ Instruction Bengal Dept. of Public, "General Report on Public Instruction in the Lower Provinces of the Bengal Presidency", General Report on Public Instruction in the Lower Provinces of the Bengal Presidency (1869-1870). Furthermore, Inspector of Schools Martin, who took over in 1868-69, wrote in his first report that: "In Orissa there are but sixty four schools attended by 3787 students, and in Chotanagpore but thirty-four schools with 1599 students. I do not think either of these Provinces has had fair play, for an inspector has nearly sufficient work in Bengal without either of them, and is naturally more inclined to push on work where he sees immediate results than to set about new work, where, as a matter of necessity, it must take years before a harvest can be reaped. I do not myself see any reason why the province of Orissa should not be in ten years as far advanced as the Bengal districts under me now are, but at first it will be an uphill and discouraging work; I think, however, I see my way before me. I have been working with a fixed plan for the last few months and I mean to go on pushing, provided I am supported, as I expect to be, by the higher authorities." Bengal Dept. of Public Instruction, "General Report on Public Instruction in the Lower Provinces of the Bengal Presidency", General Report on Public Instruction in the Lower Provinces of the Bengal Presidency (1868-9). To this end, he made the following proposals: "[A] normal School, in which both Pandits and Gurus may be trained, should be opened in Cuttack. The study of surveying should be taught in Orissa. There are no amins there. The study of Oriya should as speedily as possible supersede the study of Bengali in what are called the vernacular schools of Orissa." 
itself, and the policy of Government should be to wait." ${ }^{\prime 66}$ Instead of taking a "decisive step" in either direction, he recommended that Odia be used in elementary education because there were adequate textbooks for lower levels of education. On the subject of higher education, he maintained that the government should "leave it to the people themselves to develop a higher literature in Odia if they really desire it." ${ }^{\prime 67}$ Furthermore, in order to ensure a steady supply of textbooks in Odia, he advised that a committee be set up for "supervising the preparation of any Odia school books that are really required"68 (emphasis added). However, the actual production of these textbooks should be the responsibility of the Odia people.

The director based his comments on the principle that diversity of language caused impediments to the spread of enlightenment in India. He argued:

Diversity of speech is a great evil; it obstructs intercourse and offers a serious obstacle to the advance of civilization. Whenever possible, it must clearly be desirable to remove this barrier between neighbouring populations; and till it is proved that the barrier is of sufficient strength to with stand the pressure which the progress of enlightenment may naturally bring to bear upon it, the expediency would seem at least doubtful of adopting any measures that would make it less easy of removal hereafter, and tend to give permanence to the mischievous separation which it causes. The immediate difficulty is to decide whether it is hopeless to look for the removal of this separating barrier between Bengal and Orissa. ${ }^{69}$

This statement echoes Rajendralal Mitra's anxiety about the erection of a tower of Babel that could lead to discord among the population of British India. However, the Director departs from Mitra's stand by pointing to the danger posed by linguistic diversity to the colonial civilizational mission. The Director's argument functioned at a practical as well as abstract level. On a practical level, he was referring to the obstacles posed by the use of different languages of instruction in the education of the masses. Such diversity of language, he argued, was not conducive to economic or administrative expediency in the management of public instruction. Hence, it would hamper the spread of mass education in Odisha. On a more abstract level, both Mitra and the Director were arguing on behalf of a universality of human life, which was the foundation of community allegiance for Mitra and essential to the progress of enlightenment for the Director. As both these positions spoke to the

${ }^{66}$ Instruction Bengal Dept. of Public, "General Report on Public Instruction in the Lower Provinces of the Bengal Presidency", General Report on Public Instruction in the Lower Provinces of the Bengal Presidency (1869-70), p. 60.

${ }^{67}$ Ibid, p. $62 .{ }^{68}$ Ibid, p. $60 .{ }^{69}$ Ibid, p. 61. 
civilizing mission of British colonialism, they were very powerful arguments against the acknowledgment of diversity between Odia and Bengali.

Despite such arguments, the colonial government ultimately upheld the claims of the Odia-speaking people for the use of Odia in the schools of the Orissa division. In a response to the Director of the Department of Public Instruction, a memo from the Office of the Lieutenant Governor of Bengal decreed that "all schools in the province of Orissa up to the Zillah schools (of which there are only two) the Uriya language should be the language of instruction and in the Zillah and high school it should be optional." 70 In order to promote the publication of textbooks in Odia, the memo declared that "a committee for the purpose of considering and reporting on original works and translations in the Uriya language, with a view to assist the committee of the School Book Society in deciding on the application made to them for publication of Uriya school books, has been recently appointed."71

Countering the Director's proposal for the policy of nonintervention, the memo noted:

Your proposal, therefore, to continue the study of Uriya in elementary schools, and not beyond, is, in the Lieutenant-Governor's opinion, not only against the wishes of the natives of Orissa, but is opposed to the policy which he considers the Government is bound on every consideration to follow, viz. that our chief care should be to give to the Uriyas an opportunity of learning their own language, and that the means for this end should be extensively supplied. ${ }^{72}$ (emphasis addded)

The Lieutenant Governor's comments reveal that economic and administrative expediency was overshadowed by the government's ideological commitment to provide access to education in the people's own language. In addition, this decision was influenced by concern about public opinion. This was despite the consensus among all parties involved in this decision that the introduction of Odia at the level of higher education and the extension of the use of Odia in lower-level schools was a rather expensive and long-winded process. Such an ideological stand probably drew from the earlier concerns about "just" and "liberal" governance

70 Ibid, p. 65 . The option in this case would be between taking classes in Bengali or Odia at the zilla and high school level.

71 Ibid, p. 65. Textbooks in vernacular languages of the Bengal Presidencies were produced under the auspices of the School Book Society. Long before this memo, the Calcutta School Book Society was responsible for the publication of vernacular textbooks. For a history of the School Book Society, see Mohanty, "British Language Policy in Nineteenth Century India".

72 Bengal Dept. of Public, "General Report on Public Instruction in the Lower Provinces of the Bengal Presidency”, p. 64. 
through popularly intelligible languages that emerged in the discussions about the institution of Act 29 of 1837.

Similar to this concern about just and intelligible governance, the attention to public opinion while deciding matters of government policy indicated in the reference to the "wishes of the natives of Odisha" drew partly from the colonial government's professed desire to establish liberal governance in India. The reference to "learning their own language" signalled a departure from this earlier more limited concern about just governance. To state that the government was prepared to go to great lengths to ensure that the people had an opportunity to learn their own language was to acknowledge that Indian vernaculars were not interchangeable. Bengali could not replace Odia because the Odia language was not simply a medium of communication: It was a mother tongue particular to the speakers of the Odia language. Also, inherent in this statement is the idea of a community or people who "own" a particular language. Without overdetermining the productive force of colonial rule, it should be noted here that a new idea of language was emerging in India. The right of the people to learn their own language, to have their own language, trumped administrative as well as economic imperatives of rule. While it can be argued that this concern with language for its own sake rather than as a means of communication as in the case of Mitra, the Director of Public Instruction, or even Act no. 29 of 1837, drew from ongoing research and interest in Indian languages among Orientalists and philologists, its emergence in policy discussions marks a dramatically new approach to vernacular languages in government circles. Vernacular language was now seen as something that rallied public opinion. To put it differently, this statement reveals the colonial government's acknowledgement of linguistic identity politics.

Thus, by the end of the decade of the 1860s, a new understanding of language as unique to each community rather than simply a means of communication was emerging among colonial officials and the Odiaspeaking elite. The increasing investment in the future of the language and the identification of this future with the possibilities of development of the speakers of Odia laid the foundation for Odia cultural politics of the subsequent years. In the years to come, forums for the discussion of Odia language and literature came to house the earliest articulations of the political demand for the creation of a separate administrative state of Odisha and broader discussions of anticolonialism and all-India nationalism.

A more immediate consequence of the 1860s' debate was the growing anxiety among the Odia elite about the lack of appropriate Odia texts that could be used as textbooks in the schools of the Orissa division. This 
anxiety organized early Odia efforts to mobilize the educated elite in the interests of the Odia language. In the years after the government decision to retain the use of Odia in schools, essayists and newspaper editors called for a greater production of new Odia literature and recuperation of older Odia texts that could serve as textbooks for young children. The emergence of modern Odia literature in the late nineteenth and early twentieth centuries can be traced back to this question of textbooks.

\section{On Boundaries Between Languages: Colonial Philology and the Question of Linguistic Differentiation in Oriya Swatantra Bhasa Nahe}

The Ooriah of this district, whether it may originally have been, is not but a dialect of Bengalee, from which it differs chiefly in pronunciations and in its written character ... I would submit as a measure of general policy, it is desirable that the Ooriah should cease to exist as a separate language within the British territories. ${ }^{73}$

Collector of Cuttack, the capital of the Orissa division of the Bengal Presidency, 1854

Another factor that precipitated a change in the understanding of language in Odisha and India was the establishment of clear boundaries between Indian languages as a result of colonial philological efforts to map the linguistic geography of India. ${ }^{74}$ As the boundaries between languages came to be defined through philological study of grammatical structure and origins of words, the question of actual geographical domains of these languages came to be raised. In a time in which this increased academic and governmental attention to language was accompanied by discussion among vernacular language-speaking elites about the status and function of their language in community life, this question of differentiation between languages and the demarcation of their geographical domains came to be the site of contestation between groups engaged in debates on language.

73 Quoted in Patra, "Formation of the Province of Orissa", p. 101. The term "Ooriah" is a corrupted form of Odia and was often used in official correspondence.

74 In his essay entitled " The Two Histories of Literary Culture in Bengal," Sudipta Kaviraj discussed the porous boundaries between precolonial Odia and Bengali (Pollock, Literary Cultures in History: Reconstructions from South Asia (Berkeley, CA: University of California Press, 2003)). He argues that the notion of bounded territorial domains of sovereignty was in itself a new concept in colonial India. In precolonial India, sovereignty, be it of rulers or of their sponsored language was marked by porous and indeterminate boundaries. Hence the domains of neighboring languages, including Odia and Bengali, often bled into one another. The idea of mapping India introduced by the colonial state affected the formation of discrete spheres of influence of languages such as Odia and Bengali. 
In Odisha, too, apart from the an increased attention the ability of Odia language and literature to sustain primary and higher level vernacular education, the most important feature of the Odia-Bengali debate of the 1860s was the question of the relationship between Odia and Bengali. Advocates for the use of Bengali in Odisha argued that Odia was merely a dialect of Bengali and need not be used separately in Odisha schools and state institutions. Proponents of the independence of Odia as a language argued that the similarities between Odia and Bengali were due to the common origin of the two languages. A highlight of this debate was the publication of a Bengali monograph titled Uriya Swadheen Bhasha Naye (Odia Is Not an Independent Language) written by Kantichandra Bhattacharya, a Bengali school teacher from the Odia-speaking district of Balasore. $^{75}$

Through a reading of this text, published in 1870 , this section illustrates how an academic question about a linguistic difference between Odia and Bengali came to be put in service of proposals to remove Odia from schools. Often such arguments invoked the social, religious, political, and migratory history of the Odia-speaking people to make the case for the derivative and subordinate nature of the Odia language. That is, by historicizing the development of the Odia language against the backdrop of social, cultural, and political changes in Odia-speaking areas in the longue durée, these arguments produced a cultural life history of the Odia language and established a link between the fortunes of a language and its speakers.

Hence, in this section, I will argue that another element in the emergent understanding of language in Odisha was the conflation of the history of the Odia language with the history of the Odia-speaking people. As a consequence, arguments about the lowly origins (read aboriginal) of the Odia language caused great anxiety within the Odia-speaking elite about the nature of the Odia population. In particular, I will reveal in this section how discussions about the history and development of the Odia language came to be embedded in a colonial history of race in India. ${ }^{76}$

Furthermore, a reading of Bhattacharya's text also reveals an additional reason for Odia elite anxiety about the lack of texts in Odia. The need for an Odia textual tradition that would illustrate the uniqueness of Odia was

${ }^{75}$ Kantichandra Bhattacharya, "Odiya Swatantra Bhasa Nuhe”, in Odiya Bhasa Andolana, Bansidhar Mohanty (ed.) (Cuttack: Friends Publishers, 1989). This is an Odia translation of the original Bengali text. I regret that I was unable to locate the Bengali original.

${ }^{76} \mathrm{I}$ will discuss later in the section how colonial philology and colonial understanding of race were very closely allied in discussions about languages and the peoples of India. For details, see Thomas R. Trautmann, The Aryan Debate, Oxford in India Readings. Debates in Indian History and Society (New Delhi: Oxford University Press, 2005). 
dearly felt as philological arguments in this debate on linguistic difference were based on evidence from Odia and Bengali texts. Odia texts that provided such evidence were often translations of Bengali or English texts in the first place. In these translations, the similarity of content often extended to a similarity of style, idiom, and Sanskrit-derived vocabulary as the translators strove to stay true to the Bengali and English originals. ${ }^{77}$ Consequently, critics such as Kantichandra could argue that the few recently published Odia texts contained language that was, indeed, very similar to the Bengali originals.

The context for Bhattacharya's discussion was the ongoing discussion among colonial philologists about the origins, classification, and interrelationships between various vernacular languages. In the nineteenth century, the problem of differentiating between major Indian languages had become a very vexed question for colonial philologists and linguists. Ever since William Carey of the Serampore Mission began philological research on Indian languages in the second decade of the nineteenth century, colonial philologists had been attempting to map the diversity, development, and identity of various north Indian languages. ${ }^{78}$ The fact that in northern India most of these languages came from the same root language (Sanskrit, or its colloquial form, prakrit) and often shared a significant number of words made the differentiation between languages a rather tricky problem for philologists.

While these discussions among colonial philologists formed the broad context for Bhattacharya's arguments, his chief interlocutor among colonial philologists was John Beames. Beames, a noted linguist and long-time senior colonial official in Odisha, wrote extensively about the philology of the Odia language and its relationship with other north Indian languages. ${ }^{79}$ In some ways, Bhattacharya's arguments were based on Beames' discussions about Indian vernaculars and the idea of dialects. However, by putting the arguments about the derivative nature of the Odia language in the service of the move for the substitution of Odia with Bengali in Odia schools,

${ }^{77}$ Such arguments about the need to develop an original modern Odia textual tradition by avoiding translations from Bengali and Odia appeared repeatedly in the Odia-language press until as late as the 1890 s.

78 A short history of colonial philology can be found in the preface to the 1971 reprint of the Outlines of Indian Philology, written by Suniti Kumar Chatterjee. See John Beames, Suniti Kumar Chatterii, and George Abraham Sir Grierson, Outlines of Indian Philology, and Other Philological Papers (Calcutta: Indian Studies: Past \& Present, 1971), pp. iii-vi.

${ }^{79}$ Among the most notable of his works are the following: John Beames, A Comparative Grammar of the Modern Aryan Languages of India (New Delhi: Munshiram Manoharlal, 1966) and Beames, Chatterii, and Grierson, Outlines of Indian Philology, and Other Philological Papers, as at n79. 
Bhattacharya departed from Beames' philological ideas in crucial ways. Hence, we should make a brief foray into Beames' discussions about north Indian languages in order to understand the politics of Bhattacharya's discussion of Odia as a dialect.

John Beames addressed the problem of classification of Indian languages in his 1867 text Outlines of Indian Philology. He wrote this as a preliminary statement about the norms of philological study of the north Indian languages. ${ }^{80}$ These norms formed the basis of his subsequent three-volume work titled Comparative Grammars of the Modern Aryan languages of India. In his chapter entitled "On Dialects" in the Outlines, Beames attempted to treat the commonly held standards that were used to determine whether a language was dialect of another language or an independent language in its own rights. Here, Beames attacked the commonly held test to ascertain whether a language was dialect or an independent language based on the rule of "mutual intelligibility." According to this rule, if the speakers of two different languages could understand one another then the two tongues were dialects of the same language. Beames argued that such a test was unsuitable for Indian languages because many languages either shared similar words (for example, Hindi and Bengali) or the same grammatical structure (for instance, Hindi and Punjabi). Beames warned that these pitfalls could result in a misclassification of Indian languages. These pitfalls, he argued, could be counteracted by supplementing the rule of "mutual intelligibility" with another set of parameters. To this end he noted that:

1. The test of mutual intelligibility is a very unsafe one, as it depends on the intelligence of individuals, the savage and the peasant will exaggerate it; and the man of education will make too light of it.

2. By taking into consideration certain influences which have operated on the people, the mutual intelligibility test may however be brought to bear to this extent that, that it may be fairly said of two forms of speech that if they are not mutually intelligible, they ought to be, and in fact they may often be so much alike, that the student who is master of one would almost, if not altogether, understand the other, though two natives could not.

${ }^{80}$ In his introduction, Beames maintained that: "The following pages are a compilation from the best and the most accessible books on the science of language, supplemented by facts derived from personal observations. They do not pretend to be anything more than the outline for the use of those who having no knowledge of linguistic science, which to record and preserve dialects of obscure and uncivilized tribes with whom they may come into contact; or any of the countless peculiarities of leading Indian languages which may be spoken in their neighbourhood." See the preface to Beames, Chatterji, and Grierson, Outlines of Indian Philology. 
3. These influences are, geographical position, civilization, political, and physical accidents, religion, difference of pronunciation, education. ${ }^{81}$ Hence, Beames called for a juxtaposition of observations of contemporary speech patterns, vocabulary and sociocultural contexts along with the study of the historical context for the development of languages in India. Interestingly, despite his efforts to propose a multipronged approach the study of language differentiation, the overall consequence of such efforts was an increased attention to the search for material that would serve as evidence in the linguistic study of languages. Invariably, apart from ethnographic observation of common speech, the primary source of evidence for linguistic analysis came to be textual. This is evidenced by the subsequent efforts by Kantichandra Bhattacharya's efforts to illustrate the similarity of Odia and Bengali through the use of evidence from school texts in both languages. This privileging of textual language as evidence might explain the Odia anxiety about the lack of a modern Odia textual tradition.

Eventually, Beames observed that even though a system of classification of Indian languages would be useful, a much more detailed and comprehensive study of all Indian languages had to be carried out before any binding set of criteria for classification could be set forth. A proper systematic classification was essential, Beames argued, because it would make learning Indian languages much easier for non-native students. If it were established that several tongues were merely dialects of one major language then the student of Indian languages would have only one language to master. This would make apprehending the complex linguistic variety of India far easier because: "[I]t is less difficult to learn one language than twenty." ${ }^{\prime 2}$ However, Beames warned "the consciousness that proving these forms of speech to be dialects rather than languages, be an advantage ought not to lead any one to enter in the study of them with even the wish to obtain this result." ${ }^{83}$ Instead, he suggested that such classification be deferred until most Indian languages have been systematically and intensively studied. ${ }^{84}$

It is this uncertainty about the actual boundaries between Indian languages that opened the door for Kantichandra Bhattacharya's stipulation that Odia is a dialect of Bengali in the Uriya Swatantra Bhasha Naye (Odia Is Not an Independent Language). However, Bhattacharya's arguments did not betray any such uncertainty. His argument was simply this - given the geographical contiguity between Odia- and Bengalispeaking areas, it could be inferred that Odia was actually a dialect of Bengali that had been corrupted by influences from non Indo-European

${ }^{81}$ Ibid, p. 53-4. $\quad{ }^{82}$ Ibid, p. $52 . \quad{ }^{83}$ Ibid, p. $53 . \quad{ }^{84}$ Ibid, p. 53. 
languages spoken in the Odia-speaking areas. ${ }^{85} \mathrm{He}$ based his argument on a set of parameters for "language differentiation," which he borrowed from contemporary research on Indian philology. Hence, in his introduction, he noted that:

Linguistic experts have said that large seas, very tall mountain ranges, impenetrable forests, colonization by a powerful and intellectually evolved community, development of daily practices, religious knowledge and education can cause the differentiation between one regional language and another. ${ }^{86}$

This set of parameters, almost identical to Beames' supplementary parameters, seems to be an effort to make a scientific and systematic argument about the derivative nature of the Odia language. Nowhere in his text does Bhattacharya mention the concept of "mutual intelligibility." Instead, he makes a conscious effort to base his observation on concrete textual and historical evidence. Hence, it can be safely said that he was making an effort to move away from such commonsensical distinctions between languages and establish his argument on what contemporary philologists such as John Beames considered more firm evidentiary footing. However, Bhattacharya went beyond Beames' scheme by classifying these factors of language differentiation into natural (rivers, mountain ranges, forests) and artificial (colonization, migration, education, etc.).

His argument is an interesting play on the role of natural and artificial factors for language differentiation where the natural is ultimately privileged. He argued that, it has been historically impossible for man to reorient natural boundaries. In the matter of Odia and Bengali, he noted: " $[\mathrm{A}]$ ccording to natural divisions (this entire area covering Odisha and Bengal) should be a place (stana) with one language. ${ }^{87} \mathrm{He}$ also noted that the case for the existence of a single language is strengthened because people in both areas have similar religious and daily lives.

His subsequent argument reveals that he did not consider other more historically contingent factors such as migration and colonization as

${ }^{85}$ It should be noted here that colonial philologists believed that the languages spoken in India could be divided into three major categories-Indo-European, Turanian, and Semetic. Major Indian languages such as Hindi, Marathi, Bengali, and Odia were derived from Sanskrit or its more popularly spoken form, prakrit. These languages were part of the Indo-European group. The Turanian languages were spoken by communities such as the Hos and Santhals of Odisha. By the end of the nineteenth century, colonial linguists had come to a consensus about the mixed roots of Odia, which derived mostly from prakrit but also from the various Turanian languages spoken in the Odia-speaking areas. For a more detailed discussion, see Ibid, pp. 1-15.

${ }^{86}$ Bhattacharya, "Odiya Swatantra Bhasa Nuhe." This is an Odia translation of the original Bengali text published in 1870 . The author regrets to note that she has been unable to obtain the original Bengali edition and is forced to depend on the translated version.

${ }^{87}$ Ibid, p. 158. 
having as much credence in the creation of separate languages as natural boundaries and religion. In his effort to explain why Odia sounded so different from Bengali even though it was a dialect, Bhattacharya gave a historical account of the progressive bastardization of Bengali in the Odia areas over a long period of time. He claimed that as one moves away from the site where Bengali in its purest form is spoken - Calcutta - it becomes increasingly distorted due to assimilation with other tongues. By using the tropes of purity/pollution, Bhattacharya argued that: "As faults arising from contact with undesirables results in a deterioration of character, so does such contact in the case of language lead to the deterioration of language." 88

In the case of Odia and Bengali, he noted, the undesirable element was the tribal population of the Odia-speaking areas. In Bhattacharya's scenario, the Aryan advent into India was accompanied by the introduction of Sanskrit into India. Gradually, a number of spoken languages sprang from Sanskrit. Bengali was one of these languages. According to him, the Aryan advent ultimately produced Bengali as a root language or Mula Bhasha. This root language, in its migration away from its site of origin, interacted with languages spoken by tribal populations of various areas and produced a number of dialects. In the case of Odisha, this mixing produced what was commonly known as Odia. This mixing, he pointed out, resulted in the transformation of Bengali into "a rude, harsh, impure, colloquial and lowly dialect." In his later chapters, he analyzed the language used in school textbooks and popular works of literature to establish that in its refined, written form, the Odia language is, indeed almost identical to Bengali.

Bhattacharya's narrative reveals that he understood the influence of tribal language only as the introduction of easily removable extraneous impurities rather than fundamentally constitutive of the Odia language. This attitude was at odds with the prevailing understanding of the role of tribal language in the emergence of Indian vernaculars. In colonial philology, the study of the antecedents of Indian vernaculars was closely tied to the theory that the population of northern India was the product of the assimilation of invading Indo-European Aryans and preexisting aboriginal peoples of India. This racial assimilation led to the mingling of languages spoken by the two groups and spawned the earliest versions of a majority of the languages spoken in northern India. As John Beames statements in the Outlines of Indian Philology reveal, colonial philologists agreed that even though the aboriginal peoples were eventually enslaved and colonized by the invading Aryans, they left their mark on the resultant Aryan-dominated

${ }^{88}$ Ibid, p. 159. 
culture of India. ${ }^{89}$ In terms of language, this meant that many aspects of modern Indian languages could be traced back to the various languages spoken by the aboriginal people, collectively called the Turanian family of languages. Hence, according to contemporary theorists the original aboriginal languages were fundamentally constitutive of the modern Indian vernaculars. In both his books, the Outlines of Indian Philology as well as Comparative Grammars of Modern Indian Languages, Beames painstakingly proved that Odia drew heavily from tribal languages. ${ }^{90}$

Bhattacharya, however, dedicated the second half of his text to prove that this influence of tribal language was a colloquial, easily removable impurity that only slightly mars the purer, more refined textual language in Odia school textbooks. To this end, he analyzed the words used in Odia school textbooks, biographies, dictionaries, and folk songs in order to establish that the language used in these texts was the same as Bengali, barring a slight difference in diction. He argued that, with the increasing development of education in the whole of Bengal, the "dialects" that had resulted due to the distorting influence of "uncivilized races" would gradually be straightened out. Therefore, it would be a fallacy to think that Odia is a separate language when, through education, the distortion of language can be removed. In conclusion, Bhattacharya called for concerted efforts to "purify the lowly corrupted language of the southern region (Southern region of the Bengal Presidency, namely Orissa Division)." 91

Bhattacharya's claims about the derivative origins of the Odia language excited strong responses from various quarters. Professional philologists such as John Beames and Richard Temple attacked his lack of methodological rigor and claimed that the text was based on an inadequate knowledge of the Odia language. ${ }^{92}$ Both Beames, in his speech at the Asiatic society 1871, and Richard Temple, in his critique in the Calcutta Review, wondered why the author had chosen only words of Sanskrit origin used in Bengali and Odia to make his case. Beames questioned Bhattacharya's methodology by asking why he did not account for spoken language in his thesis:

In plain English, such Sanskrit words, as were used by the Uriyas and Bengalis twenty-five centuries ago, have since then undergone the usual fate of words, and have been corrupted, abraded and distorted, till they often bear no resemblance at

${ }^{89}$ See John Beames, “On the Distribution of Indian Languages”, in Beames, Chatterji, and Grierson, Outlines of Indian Philology, pp. 24-5.

${ }^{90}$ For more details, see Ibid. ${ }^{91}$ Bhattacharya, "Odiya Swatantra Bhasa Nuhe", p. 207.

92 See John Beames, "On the Relation of the Uriyas to Other Modern Aryan Languages", Proceedings of the Asiatic Society of Bengal (1870), pp. 192-201; Richard Temple, "Review", reprinted in Appendix 2 of Mahanti, Odia Bhasha Andolana, p. 215. 
all to the original word. As it is these corrupted, or as they are called Tadbhava words, that are the real living words of the language, the words that have worn into their present shape by long use in the mouth of the people. These words our fastidious writers reject, and when by going back to the Sanskrit for their words, they have composed a work to their taste, lo! They say Uriya and Bengali are one language; for proof read such and such works, I would suggest rather, let them take a chása of Dacca and a chása of Gumsar, and then see how much they understand of one another's talk. ${ }^{93}$

However, in spite of such critiques, Bhattacharya's thesis found supporters among those who had been arguing for the removal of Odia from the schools of the Orissa division. Most notably, Rajendralal Mitra in the same meeting of the Asiatic Society of Bengal responded to John Beames's critique of Bhattacharya's failure to realize that spoken language is the true language rather than the language of written text - by arguing that: "[L] ocal peculiarities of pronunciation do not constitute language and therefore no notice should be taken of them in deciding the questions of linguistic classification." Furthermore, proponents of the use of Bengali in Odisha drew on the arguments made by Bhattacharya to draft a petition to remove Odia from the schools of the Odisha division. The "secret" petition was circulated all over Odisha and Bengal and attracted a number of signatories. Even though the petition did not result in any change in government policy, it drew the attention of the Odia language press back to the Odia-Bengali debate. ${ }^{94}$

Articles appeared in the Odia press that criticized Bhattacharya's argument about the derivative nature of the Odia language. For instance, a review article published in Utkal Dipika built on the point made by Beames and Temple and queried Bhattacharya on his methods of proving the similarity between Bengali and Odia by drawing on words with Sanskrit roots. The article inquired why Bengali should be considered an independent language if the occurrence of common Sanskrit words in Odia and Bengali makes Odia a dialect of Bengali. Would not Bengali then be considered a dialect of Hindi on the same grounds? The article introduced a new dimension to the critique of Bhattacharya's thesis by raising the question of independent tribal languages in the area where he argued only Bengali was spoken due to the absence of any geographical barriers:

In the area where the author argues that only one language - the Bengali languageis spoken; why do aboriginal groups such as Garo, Santhal, Khond, Suanga, Sabara

93 The term chasa in both instances denotes the cultivator caste of Odisha and Bengal. Ghumsar is an Odia-speaking area.

${ }^{94}$ For contemporary newspaper articles that discussed the secret petition, see Mahanti, Odia Bhasha Andolana, Appendix 2, pp. 155-220. 
etc. speak different languages? Perhaps, in order to respond to this question, the author will take assistance from Hunter and argue that all these languages have a singular root but he will not be able to deny that these languages are separate. ${ }^{95}$

In this oblique reference to the existing research on the tribal provenance of the Odia language, the article questioned the basic premise of Bhattacharya's argument that the Odisha-Bengal area could not possibly have more than one language. By raising the question of tribal or adivasi languages in the Odia-speaking areas, the article was making a case for the particularity of this area. More significantly, it should be noted that it is the adivasi presence in the Odia-speaking areas that enables the author to counter Bhattacharya's argument about the derivative nature of the Odia language. In other discussions of the Odia language, including Beames' reading of it, it is the adivasi provenance of the Odia language that distinguished it from other languages of Sanskrit origin. Thus, in a context in which the distinction of Odia from other languages was in question, it became necessary for the proponents of the independence of the Odia language to draw attention to its adivasi roots. At the same time, this avowal of the adivasi provenance of the Odia language, which suggested a deeper racial and historical relationship between the upper-class and upper-caste Odia elite and the adivasi population of the Odiaspeaking areas, led to anxieties about the possibility of the "lowly" ancestry of the Odia-speaking elite.

In the future, such use of the adivasi population to make arguments about regional particularity would necessitate new definitions of the Odia community that would include the adivasi element through recourse to the origin myths of the dominant Odia Hindu deity Jaganath. Through the use of these myths, the Odia elite would eventually portray the adivasi population as actors in the history of the formation of the mainstream Odia community. Hence, due to this presence of the adivasi element within the Odia population, the community had to be defined as more than just a linguistic one. Rather, it was also a religious community held together by a common allegiance to the Jaganath cult. Thus, the category Odia could never be a purely linguistic identity. It was always marked by an idea of religious brotherhood based on allegiance to the Jaganath cult.

There were two major consequences of Bhattacharya's argument and the accompanying debate about the roots of the Odia language, on the development of Odia cultural politics over the next few decades. The long-term result of Bhattacharya's argument was the foregrounding of

95 Unknown, "Uriya Swatantra Bhasha Nahi”, in Ibid, p. 200. This was a review of Bhattacharya's book. 
what could be called the "adivasi specter" in Odia cultural politics. Colonial philology in the nineteenth century had established both the adivasi provenance of the north Indian vernaculars and - by the very nature of their retrograde study of languages in India, which traced particular languages spoken by modern communities to their earliest antecedents - the dominant mode of historicizing linguistic communities through the histories of the emergence of languages spoken by them. That is, histories of linguistic communities like the Odia community came to be located in the complex history of the emergence of the Odia language, which was understood as a product of the interaction between aboriginal tribes and the invading Aryans in the first millennium $\mathrm{AD}$. Hence the ancient history of the Odia-speaking community became the history of the Odia language and the speakers of the antecedents of ancient Odia.

Kantichandra Bhattacharya brought this mode of historicizing the Odia community to the attention of the Odia public sphere by basing his argument on this primal linguistic history of the interaction of aboriginal speech with Aryan prakrit. The Odia vernacular press had to argue for the constitutive role played by aboriginal languages in the emergence of the Odia language in order to counter Bhattacharya's claims about the derivative nature of Odia, which was based on an understanding that these adivasi influences were merely superficial impurities that made Odia appear different from Bengali. While this avowal of tribal influence reenforced the uniqueness of Odia culture, it also laid the history of Odisha open to comments like that made by W. W. Hunter in his History of Odisha, in which he described Odisha as a primal, uncivilized land that still has evidence of primeval life extinct elsewhere. ${ }^{96}$ This led to the persistent Odia dilemma centred on how to represent the adivasi legacy in Odia social, religious, and cultural life. The "adivasi specter" haunted both the descriptions of Odisha history and the definitions of the Odia community. Interestingly, this very anxiety produced the dominant understanding of the Odia community as a community of equals based on a religious affinity to the Hindu deity Jaganath, who was said to have roots in adivasi religious practices.

The more immediate consequence of Bhattacharya's text was the reenforcement of the prevailing Odia anxiety about the lack of appropriate Odia texts that could be used as school textbooks. Bhattacharya's text argued that none of the existing literature in Odia - whether it was school textbook or folk tales - was either unique to Odisha or uniquely Odia. Whether or not his claims were true, the publication of his text drew media attention to the fact that there was very little modern Odia

${ }^{96}$ A detailed account of Hunter's argument will appear in Chapter 4. 
literature being produced in Odisha at that time. In the subsequent period, the anxiety about the lack of texts that emerged from the seemingly innocuous question of textbooks impelled of the most productive, contested and influential debates on Odia literature. The next chapter will discuss this literary debate of the 1890 s, which dealt with the efficacy of traditional Odia literature and its relevance to the modern life of the language. However, before we move on to the literary debate of the 1890 s, I would like to end the chapter with a short discussion of Gopal Chandra Praharaj's Odia Lexicon to illustrate how the modern role of Odia as a vernacular came to be ultimately elaborated.

\section{The Dual Life of the Vernacular: Odia in Praharaj's Lexicon}

In the early twentieth century, Gopal Chandra Praharaj became reputed as a proponent for the use of "chaste, idiomatic and homely language in preference to polished, labored and Sanskritized style." ${ }^{97}$ Given his reputation, he was encouraged by his supporters to put together a lexicon of Odia that would be truer to the common usage of Odia than existing dictionaries of the language that were often put together by Baptist missionaries. These, he complained, tracked a language that could "neither be called Odia nor Sanskrit, and was neither the language of the book nor of the hut." ${ }^{98}$ The lexicon evolved from a simple Odia-to-Odia dictionary into something much bigger. Praharaj hoped to produce a dictionary in which "one can find out the meanings of classical words, the vocabulary of the mass, the court language and even the language used by educated people at home, not to speak of the dialectical and provincial words used in the outlying Odia speaking parts." ${ }^{99}$ In this concluding section of the chapter, I would like to discuss two major themes that emerge from a reading of the preface of his lexicon published between 1935 and 1937.

How did he justify the structure of his lexicon? And how did he characterize the object of his study - the Odia language?

Praharaj justified his choice of languages for the quadrilingual lexicon by arguing for a cosmopolitan approach to language:

My humble efforts at making the Odia language known, appreciated and admired not only by the sister nations in India but by the civilized world of letters, by linking it with the medium of thought of the civilized world (namely English), with the lingua franca of India (namely Hindi) and with one of the most advanced sister

\footnotetext{
97 Gopal Chandra Praharaj, The Odia Language and Lexicon (Vizianagaram: International Faculty of Andhra Research University of India, 1937): p. 4

98 Ibid, p. $4 .{ }_{99}^{9}$ Ibid, p. 5.
} 
languages (namely Bengali), deserve encouragement and support from every true patriot. ${ }^{100}$

Praharaj's efforts were driven by a cosmopolitan impulse to situate Odia in a relational nexus with other vehicular languages. To be vernacular to Odisha, Odia needed to sustain its locality and particularity through a constantly pitched differential relationship with vehicular languages like English and Hindi and more developed languages such as Bengali. There is also a comparative element to his approach, which seeks to illustrate the borrowings from and distinction between these languages. The cosmopolitanism and the comparative approach both support Praharaj's efforts to carve out a space for Odia in the world republic of letters. This approach is borne out by his complaint that his contemporary writers had become too parochial in their efforts and did not incorporate cosmopolitan ideas in their writings.

He drew the mandate for his lexical project from S.W. Fallon's introduction to the Hindustani-English dictionary, which defined what a vernacular dictionary should do. Fallon's introduction was a treatise on hence how we should locate the scope and limits of a vernacular. In a departure from earlier efforts of language collection that focused on textual forms of Indian languages, Fallon argued that the wealth of a language was in the spoken language as "living dialects are the feeders of language." An attention to spoken colloquialism, vulgarisms, and idiomatic speech could enable a lexicographer to capture the ways in which the "paramount dialect of national speech" gains in "copiousness, flexibility and expression": ${ }^{101}$

The integrity of the language, the demands of the philologists, the sociologist and the philosopher, the perfect knowledge of and mastery over language which would be impossible if any part would be kept back, the insight into the minds of the people which is obtained to this very class of words, and above all the absolute importance of this knowledge to the judicial and executive officer most emphatically call for the insertions of words which are conventionally branded as abusive, indelicate, slang or obscene. In the various equivalent expressions used by the illiterate classes and in the rustic, provincial or dialectical varieties of words the student may grasp at a glance the root source and history of words and thus acquire a ready mastery over the popular language and the motley rustic speech. They are also instructive to the philologist. A great many Prakrit forms are still present in the rustic language. ${ }^{102}$ (emphasis added)

${ }^{100}$ Gopal Chandra Praharāja, A Lexicon of the Oriya Language (Cuttack: Utkal Sahitya Press, 1931), p. xii.

${ }^{101}$ For a detailed treatment of Fallon, see Walter Hakala, Negotiating Languages: Urdu, Hindi, and the Definition of Modern South Asia (New York: Columbia University Press, 2016).

102 Ibid, p. vi. 
Fallon's description of the lexicographer's task illustrates the multifaceted labors performed by the vernacular in colonial India. The audience of a vernacular lexicon ranges from the philosopher to the judicial official. And for all of these audiences, popular language is crucial. As the integrity of language drew from both elite as well as rustic speech, mastery over it is possible only through an attention to popular language. Therefore, disciplinary knowledge (of philologists, sociologists, and philosophers) required attention to "motley rustic speech." The rustic tongue was seen as a museum of language that gives easy access to the old form of language that may have passed out of textual usage. Here, another mastery that Fallon alludes to, that of the judicial and executive office, also required a broader approach to the limits of language. All these forms of mastery over language have in common the impulse to gain insight into the minds of the people.

The parallels between Fallon's position and the position of policymakers in the early nineteenth century when the first big vernacular shift happened is quite striking. Both are driven by the need for scholarly and administrative access. However, Praharaj builds upon and transforms this lexical mandate. While he agrees that rustic speech needs to be seen as wealth rather than as pollution, he does not approach this wealth as a resource for understanding the past of the language. Rather, the incorporation of the spoken tongue is an effort to think of Odia as a rich language that could be seen as developed precisely because it has multiple means of expressing the same ideas.

"The richness of the vocabulary" Praharaj argued "is the index by which the vastness of a vernacular can be gauged. The Sanskrit, the German, the English, and the Latin languages are counted as advanced languages as one word or idea can be expressed in various forms through the medium of synonyms." This reference to richness of vocabulary was not just a slavish imitation of more powerful languages. He used the narrative of richness to produce an optimistic reading of the peculiar historical experience of the Odia language. The Odia-speaking areas had been under some sort of colonial rule since the Mughal acquisition of Odisha in 1592. The Mughals brought with them Arabic and Persian. The Maratha presence in Odisha in the eighteenth century contributed to an influence of Marathi on Odia and, finally, the European presence in coastal Odisha from the seventeenth century onwards meant that English, French, and Dutch also influenced Odia. Rather than viewing this history as a history of disempowerment and the erosion of Odia purity, Praharaj posed the history of external influences as a productive force in the making of modern Odia. Hence, for Praharaj, the wealth of the Odia language was a product of contact and growth rather than the survival of 
older forms of the language. His was an argument about radical transformation rather that preservation of older forms.

And yet we find a parallel thread of a more conservative argument about Odia. In his efforts to locate the object of his study, Praharaj argues that unlike other sister languages such as Bengali, Hindi, and Marathi, Odia was established as a distinct vernacular in the seventh century AD. Odia was unique in that it did not have any dialects and "the grammatical framework or the trunk of the Odia language remains constant." 103

Odia was also unique among northern Indian languages because it has preserved the Sanskritic phonetic values attached to the different letters. What accounts for this conservatism in defining language when Praharaj spends so much energy building a more expansive scope for his lexicon? In this radical and conservative description of the Odia language, we find the two contradictory labors performed by the vernacular in nineteenthand twentieth-century India. The vernacular had to serve as a populist mode of expression that could make the state accessible to the citizen/ subject. In this role, the vernacular could grow and mutate endlessly to represent the changing everyday life of the people who spoke it. It was fundamentally a democratic object continually being reconstituted by popular usage. By the same token, and precisely due to the state's use of the vernacular as the means of reaching the broadest spectrum of people, the vernacular was also a "language of command." And, as a language of command in a profoundly multilingual country, the vernacular needed to be standardized and its boundaries clearly demarcated so that it could be separated from other languages. In the next chapter, we will see the impact of this contradictory role of Odia as a modern vernacular on the production of modern Odia literature.

103 Ibid, p. xii. 


\section{Vernacular Publics: A Modern Odia Readership Imagined}

In the winter of 1891, in the capital of the princely state of Majurbhanj set deep in the hills of the Eastern Ghats, a series of articles critiquing the work of an early modern Odia poet were published. ${ }^{1}$ The poet in question was Upendra Bhanja. With an entire era of the Odia literary canon named after him, Bhanja was an immensely popular poet among the common people of Odisha. Bhanja's modern critic, Lala Ramnarayan Rai, was arguing that his poetry failed to meet the standards of true poetry. His poems were unnecessarily obscene, grammatically incorrect, and used very verbose and convoluted language. An instance of Rai's critique of Bhanja's epic Vaidehisa Bilasa, which was based on the Ramayana, follows.

Lala quotes one of the episodes immediately following Sita's kidnapping where Rama laments to his younger brother, Lakhman:

Now that Sita is gone, who will I conduct the business of love with?

Whose gold like form will rub against my touch stone of a body?

Outraged, Lala remarked: "Dear Readers! What is the justification of this animal like, undignified description of Mahapurush Rama's emotions? ... Isn't Ramachandra our ideal man? ... If this epic is an ideal epic or if the hero of this epic serves as an aspirational ideal for our youth then it would not be too much to say that Odisha's progress is impossible! Be that as it may, we put this in front of our dear readers to evaluate the merits of our argument." 2

Lala's outraged comment points to the nineteenth-century entanglements between regional literature, aspirations for community progress and an emergent notion of responsible readership that presupposes a discerning Odia public. Not alone in his critique of early modern Odia literature, Lala sparked a rather acrimonious and public debate about the

\footnotetext{
${ }^{1}$ A very early version of this chapter appeared in Contemporary South Asia in 2012. See Pritipuspa Mishra, "Fashioning Readers: Canon, Criticism and Pedagogy in the Emergence of Modern Oriya Literature", Contemporary South Asia 20, no. 1 (2012): $135-148$.

2 Lala Ramnarayan Rai, "Kabi Upendra Bhanja”, Utkal Prabha, December 1891.
} 
value of "traditional" Odia literature for contemporary Odia public life with these essays. This chapter traces how the prevailing anxieties about the inadequacy of existing Odia literature for modern educational needs and the allied anxiety about an inadequate literary legacy for community building led to the imagination of a new kind of "responsible" Odia literary public consisting of producers, consumers, and beneficiaries of a modern Odia literary canon. As my discussion of Odia literary criticism in the late nineteenth century will reveal, at stake in this fashioning of a new literary republic was the imagination of a homologous Odia political public consisting of citizens (readers) and representatives (literary critics). Defined in opposition to their more dominant Bengali neighbors, this imagined community of Odia readers served as the earliest iteration of a modern Odia political community that would later serve as the civic constituency of the movement for the formation of a separate linguistic province of Odisha. By unpacking the impulses and arguments that informed the imagining of a new Odia literary public, we can explore the formation of the political constituency of the Odia language that would later define the limits of regional community in Odisha.

But first, a few words on my approach to reading of the debate on literary criticism that forms the core of the chapter. In framing what is essentially another Indian debate about tradition and modernity in literature and literary criticism during the colonial period, I seek to move away from discursive frameworks of critical impasse or alternative modernities and explore the inaugural aspect of the debate. ${ }^{3}$ Building upon Milind Wakankar's suggestion that doing so allows us to explore hitherto neglected issues of responsibility and historical origin, I ask how Indian writers managed to bring the "burden of their own literary pasts" to bear upon their apprehension of their role at a time of unprecedented social and political change ${ }^{4}$ I suggest that notion of the inaugural invokes the first moment of the establishment of what is hoped to be a long-lasting tradition. The literary critical debates of the 1890s in Odisha express this hope that a new weighty tradition will arise from new projects of literary production.

${ }^{3}$ For a discussion of the tradition/modernity debate as a moment of critical impasse, see Sudhir Chandra, The Oppressive Present: Literature and Social Consciousness in Colonial India (New Delhi: Oxford University Press, 1992). For a discussion of the resolution of the tradition/modernity debate in the formulation of an alternative modernity, see Vasudha Dalmia, The Nationalization of Hindu Traditions: Bharatendru Harischandra and Nineteenth Century Banares (New Delhi: Oxford University Press, 1996).

${ }^{4}$ Milind Wakankar, "The Moment of Criticism in Indian Nationalist Thought: Ramchandra Shukla and the Poetics of a Hindi Responsibility", South Atlantic Quarterly 101, no. 4 (2003): 987-1014. 
In moving away from discursive frameworks of critical impasse and alternative modernities, this reading of a late nineteenth-century literary debate illuminates a crucial aspect of the postcolonial predicament of regional Indian literature. Not focusing on the tradition/modernity dilemma and drawing more attention to the inaugural nature of this debate allow us to dwell more closely on the question of "timeliness" of literature. Anxieties about literary and political zeitgeist of Odia literature and its eventual resolution in this literary debate illustrates how the concerns and preoccupations of nineteenth-century Indian critics in the age of colonialism echo contemporary anxieties about the place of local literature in the global market place. The postcolonialist backlash against Pascale Casanova's thesis on the world republic of letters that divides the literary world into a few metropolitan centers and many provincial peripheries suggests that we have come back full circle to the kinds of question that were being raised by Odia critics in the $1890 \mathrm{~s}^{5}$ Faced with oppressive traditions, Western as well as Indian, these critics were poised to suggest the foundations for a new literary tradition that situated local Odia everyday life within broader political and social concerns in India and beyond. The resolution of this debate and the subsequent literature produced in response to it suggest to us the possibilities of recuperating and interrogating this representative function of regional literature in contemporary India.

By interrogating the representative function of regional literature and how it was managed by literary critics in the late nineteenth and early twentieth century, we could arrive at a clearer sense of how Odia as a modern vernacular was produced in this period. The vernacularity of the language in this case was invoked when Odia was presented as the essential medium through which the story of the community could be told. However, as the subsequent discussion of the debate on the remit of literature illustrates, the nature of the story was policed by an emergent infrastructure of literary criticism. In laying out the limits of inclusion into the Odia literary canon and excluding certain elements that did not fit the liberal agenda of the emergent Odia middle class, early twentieth-century literary critics produced a vernacular literature that claimed to represent the entire Odia public even as it excluded or ignored more popular forms of literary expression.

What does it mean to speak of a vernacular Odia public in this selfconsciously inaugural moment in the history of modern Odia literature?

\footnotetext{
5 See Pascale Casanova, The World Republic of Letters (Cambridge, MA: Harvard University Press, 2004); Amir Mufti, "Orientalism and the Institution of World Literatures", Critical Enquiry 36 (2010): 458-493; Christie McDonald and Susan Rubin Suleiman, French Global: A New Approach to Literary History (New York: Columbia University Press, 2010).
} 
Any invocation of an "Odia public" necessarily refers to our understanding of publics articulated within the Habermasian framework of the public sphere. ${ }^{6}$ However, as Albert Welter has noted in his study of emergent public spheres in China, the Habermasian public sphere is rooted in his analysis of eighteenth-century Europe and as such may not apply to readings of non-Western public spheres. Welter argues that the public sphere modeled on eighteenth-century European discourse and politics presupposes a number of conditions that were not necessarily present in non-Western or colonized spaces such as India and China. Preconditions such as "participatory democracy, the role of public opinion, attitude towards citizen activism ... lack of regard for status among participants, the domains of common ground over which private citizens could exercise authority and ever expanding notions of inclusivity," had not yet emerged in the Odia-speaking areas of the Bengal Presidency, Madras Presidency, and the Central Provinces. ${ }^{7}$ Apart from the absence of participatory democracy, social parity, and citizen activism, the very possibility of a "common ground" where Odias could engage in discussions was undermined by the administrative fracture of Odia-speaking areas. So then, what kind of public and by extension public sphere could emerge in nineteenth-century Odisha? Here I draw on Rajeev Bhargava's discussion of the specific nature of the literary public sphere in India. In his reading of Habermas' notion of the public sphere, Bhargava argues that in colonial India, unlike in the liberal public sphere, the literary public sphere was not open to everyone. ${ }^{8}$ Bhargava's discussion served as an introduction to a volume of essays that explored an Indian approach to Habermas' arguments about the public sphere. These essays argue that, in colonial India, the public sphere was not a singular space. It served as a site for contestation between groups that brought avowedly private matters to bear on public discussions. Hence, the publicness of public life itself was always under question. It also created a public sphere that was not simply liberal. Rather, it had to make space for discussions about religion and affect. Therefore, the public sphere in India was both narrower (in terms of membership) and wider (in terms of concepts and texts) than the Habermasian public sphere.

${ }^{6}$ In his definition of the public sphere, Habermas notes that: "[T]he bourgeois public sphere may be conceived above all as the sphere of private people come together as a public." See Jurgen Habermas, The Structural Transformation of the Public Sphere: An Enquiry into the Category of Bourgeois Society (Cambridge: Polity Press, 1989), p. 27.

7 Albert Welter, "The Sphere of Privilege: The Administration of Buddhism (and Religion) in China", in Albert Welter and Jeffrey Newmark, eds., Religion, Culture and the Public Sphere in China and fapan (London: Palgrave Macmillan, 2017), p. 22.

${ }^{8}$ See Rajiv Bhargava, "Introduction", in Rajeev Bhargava and Helmut Reifeld, Civil Society, Public Sphere and Citizenship: Dialogues and Perceptions (New Delhi: Sage 2005), pp. 13-58. 
The public at issue in this chapter is akin to what Habermas has called a "public-at-large." Public spheres, according to Habermas, are always outward facing and are inherently not imagined as enclosed enclaves limited to their empirical numbers. No matter how small or fledgling a public sphere, as Nancy Fraser has described Habermas' formulation: " $[\mathrm{I}]$ ts members understand themselves as part of potentially a wider public that indeterminately, empirically counterfactual body we call 'a public-at large'." Discussions about the duties of the Odia readership in the late nineteenth century was founded on such an imagination of a wider public that went beyond the actual, limited urban Odia public sphere. This inauguration of an idea of a public was already, at its very inception, a flawed notion that elided actual fractures in the way public life was lived in colonial Odisha. It sought to represent all Odia-speaking people even though, at least at its inception, it only consisted of urban educated Odia elite. ${ }^{10}$ It was an imagined rather than real public that served as the foundation of an equally imagined notion of an Odia liberal political constituency. This chapter is an account of how an Odia public was imagined within literary debates about the status and function of the reader.

In what follows, I will introduce the context for the literary debates of the 1890 s by tracing the history of print culture in Odisha that developed around the rise of the Odia school textbook market. I will illustrate how the need for textbook-worthy literature led to public debate about the "quality" of existing Odia literary texts. Through a focus on this debate and its eventual resolution in the writings of Biswanath Kara, one of the most influential literary critics and editors of the late nineteenth and early twentieth century, I will illustrate how these canon debates were inaugural in their vision of a new Odia literary public. However, as the final discussion of the relationship between the emergent field of literary criticism and popular forms of literary expressions will reveal, the radical potential of this new literary public is limited by the exclusion of contemporary nonliberal, nonmodern literature of the late nineteenth century.

\section{Textbook Anxieties: Odia Literary Culture Circa 1891}

As we have seen in the last chapter, the anxiety about the appropriateness of early modern Odia literature as material for school textbooks had its

${ }^{9}$ Nancy Fraser, "Rethinking the Public Sphere: A Contribution to the Critique of Actually Existing Democracy", Social Text, no. 25/26 (1990): 67.

${ }^{10}$ For a detailed discussion of social structures of class and caste in nineteenth-century Odisha in urban and rural areas, see Jayanta Sengupta, At the Margins: Discourses of Development, Democracy and Regionalism in Orissa (New Delhi: Oxford University Press, 2015), pp. 12-83. 
origins in earlier debates about the use of Odia as a language of instruction in schools of the Odisha division of Bengal Presidency. In 1864-65, when the Inspector of Schools in Odisha recommended that Odia be replaced with Bengali as the language of instruction in Odisha Division schools, he cited the lack of appropriate Odia school textbooks and qualified Odia teachers as justification for the change. ${ }^{11}$ With only seven qualified Odia teachers in the whole of the Division in as late as 1860, the remaining Bengali teachers in the Odisha schools were unable to enforce the provisions of the Wood's Despatch for educational instruction to be carried out in the native vernacular. ${ }^{12}$ Bengali, with a large number of trained teachers and a flourishing textbook industry, was a much better choice.

This proposal led to a lively debate in Odia urban centers where organizations such as the Utkal Bhasha Uddhipani Sabha were set up to refute the government's claims. ${ }^{13}$ Support for the proposal came from Bengali intellectuals such as Rajendralal Mitra, who argued that, as Odia was very similar to Bengali, the use of Odia in Odisha schools did not make financial sense. In fact, Mitra argued, using Bengali instead of Odia was in the interest of the Odia people as it would allow them to participate in the much more advanced cultural life of Bengal. As a result of this controversy and the eventual decision of the colonial government to retain Odia as the language of instruction, the Odia urban elite intelligentsia focused its energies on producing new Odia textbooks.

The emergence of a commercial Odia textbook market transformed the political economy of Odia literary production. Print had come to Odisha late and haltingly. The first printing press in Odisha was set up by missionaries in 1838. The Orissa Mission Press established in 1838 was set up in Cuttack to keep up with the increased demands for Odia tracts that could be circulated by missionaries in Odisha. Prior to this,

${ }^{11}$ Panchanan Mohanty, "British Language Policy in Nineteenth Century India and the Odia Language Movement”, Language Policy 1 (2002): 62.

12 Wood's Despatch on Indian education of 1854 had a profound impact on how statesponsored education was delivered in colonial India. One of the most important stipulations of the despatch was that education at the primary and secondary level should be delivered in the "vernacular" language of the area. For details about the history of the dispatch, see R. J. Moore, "The Composition of 'Wood's Education Despatch", English Historical Review 80, no. 314 (January, 1965): 70-85.

${ }^{13}$ It is a matter of scholarly consensus that this language debate of the 1860 s marked the beginning of the formation of an Odia public sphere. See Nivedita Mohanty, "Odia Nationalism: Quest for a United Odisha, 1866-1936”, South Asian Studies, no. 13 (1982). See also P. K. Mishra, The Political History of Orissa, 1900-1936(Calcutta: Oriental Publishers \& Distributors, 1979), Atul Chandra Pradhan, The Nationalist Movement in a Regional Setting, 1920-34: The Rise of Congress to Power in Orissa (Cuttack: Amar Prakashan, 1992). 
some Odia language texts, including an Odia translation of the Bible and an Odia grammar, were published in the Serampore Mission near Calcutta and brought to Odisha. ${ }^{14}$ However, this was a cumbersome exercise as the number of Odia tracts and books being printed had risen over the years. The activities of the Press expanded rapidly. In the first year of its establishment, Odisha missionaries were able to distribute 50,000 tracts. ${ }^{15}$ A year later in 1839, the Orissa Tract Society was set up by the General Baptist Society to stimulate the publication of a greater number of Odia texts produced in Cuttack. As a result, 429,500 texts were circulated by the missionaries in $1839 .{ }^{16}$ In this period, the Press produced texts such as The Wonderful Advantages of a Pilgrimage to fagarnath, which provided an account of the evils of pilgrimage to Puri, new editions of the Bible, an Odia dictionary and school textbooks for the government vernacular schools. By 1858, the Press employed eighteen people and had printed a total of 952,700 books of which 34,750 were educational texts. ${ }^{17}$

Despite the establishment of this new press, textual culture in Odisha was dominated by the circulation of palm leaf manuscripts in the midnineteenth century. The production of Odia palm leaf texts was driven by private patronage of literary scribes who wrote on palm leaf manuscripts. While original authors depended upon patronage from princely state rulers, the actual reproduction of the texts was carried out by scribes of variable skill who produced illustrated palm leaf manuscripts as temporary wage laborers working for very meagre wages. ${ }^{18}$ While these palm leaf manuscripts were often commissioned and owned by affluent Odias, some were housed in communal huts in the villages of Odisha called Bhagawat Ghara or Bhagawat Tungi. These huts served as village libraries and as the site for village panchayats. They were also a site for a shared aural literary sphere as the village community gathered there to

${ }^{14}$ Graham W. Shaw, "The Cuttack Mission Press and Early Oriya Printing”, British Library Fournal (1977): 29-43.

${ }^{15}$ Ibid, 37. ${ }^{16}$ Ibid, $37 .{ }^{17}$ Ibid, 35.

18 J. P. Das and Joanna Williams have traced a number of scribes in the Ganjam District of Orissa who worked in the nineteenth century. Their research reveals that these scribes often worked as temporary wage laborers in the households of affluent landowners. They describe the life of a celebrated scribe, Raghunath Prusti, who would work on the outer veranda of a rich landowner's house for meagre pay and food for the day. However, while Prusti was a talented and professional scribe, Das and Williams have found evidence of a number of other scribes whose work reveals that they were amateurs at the craft. Be they professional or amateur, the life of the scribe was not financially secure and often ended in utter poverty. J. P. Das, Palm-Leaf Miniatures: The Art of Raghunath Prusti of Odisha (New Delhi: Abhinav Publications, 1991); and for details on the production and patronage for original literature in Oriya during this period, see B. C. Majumdar, Typical Selections from Odia Literature, Vol 2. (Calcutta: University of Calcutta, 1923). 
listen to readings of the Odia Bhagawat written by the medieval bhakti poet, Jaganath Das. ${ }^{19}$

This loosely organized, informal literary sphere in Odia came to be coupled with a new print-centered, urban literary sphere in the late nineteenth century with the rise of printing presses in Odisha. Even though the printing industry was minute in comparison with that of Bengal (seventeen in Odisha as opposed to forty-three in Bengal in 1900), the urban centers of the Odia-speaking areas could boast of at least one prominent publishing house. Cuttack had two major publishing houses - the Odisha Mission Press (established 1838) and the Cuttack Printing Company (established 1866). Balasore had the Utkal Printing Company (established 1868). The Sambalpur District was served by the Jagannath Ballabh Press in Bamanda, which was moved from Cuttack to Deogarh in 1889. Almost half of these presses were established by native princes.

The first native-owned printing press was established in Cuttack in July 1865, nearly thirty years after the establishment of the Cuttack Mission Press by missionaries in 1838. Coined as the Cuttack Printing Company, the new Press was to play an essential role in Odia language publishing for the next sixty years. It published one of the most influential and longest running Odia newspapers of the nineteenth and early twentieth centuries, Utkal Dipika. The manner in which the Cuttack Printing Press was floated reveals broader trends in how early printing in Odisha was started and funded. A clerk in the Cuttack Collectorate, Gaurishankar Rai, initially sought to establish a press in Cuttack. With the support of prominent local figures including Bichitrananda Das, Jagamohan Roy, the Raja of Dhenkanal, and the Collector of Cuttack, T. E. Ravenshaw, Rai collected a seed fund of Rs 7,500 to start the Press. ${ }^{20}$ Initial funding for the Press was gathered by selling capital shares, which were purchased by princely state rulers such as the rajas of Talcher, Badamba, Nayagarh, Athgarh, and Narasignghapur. A number of zamindars also bought shares in the venture. While the Press was funded by zamindars and princely state rulers, the editorial control of Utkal Dipika

19 The presence of Bhagawat Ghara and their role in rural Odia society has been mentioned in district gazetteers, travel narratives, and contemporary literature. Soma Chand's Odisara Chitra is an Odia translation of Jatindra Mohan Singh's 1903 travel narrative in the Bengali-titled Odisyar Chitra. References can also be found in Gopal Chandra Praharaj's fictional essays on the Bhagawat Tungi written in the early twentieth century. See Soma Chand, Odisara Chitra (Cuttack: Arjya Prakashan, 2006), B. D. Panda, History of Library Development (New Delhi: Anmol Publications, 1992), and Gauranga Charan Das, ed., Praharaj Granthabali: Ramya Rachana Prathama Khanda (Cuttack: Vidyapuri, 2005).

${ }^{20}$ Sachidananda Mohanty, Periodical Press and Colonial Modernity: Odisha 1866-1936 (New Delhi: Oxford University Press, 2016), pp. 27-30. 
remained in the hands of Gaurishankar Rai until he retired in 1917. The newspaper continued in publication until 1936. The case of the Cuttack Printing Company suggests that early native-run Odia printing was heavily dependent on financial patronage from the minuscule Odia upper class but was often actually run by the emergent college educated middle-class elite. The Utkal Printing Company in Balasore was set up in 1868 using a very similar method of sourcing capital. The Press was started by Fakir Mohan Senapati who, along with Jayakrushna Chowdhury and Babu Radhanath Roy, formed an association to run a funding campaign that would sell capital shares for the press to investors. They organized a number of meetings at which they delivered speeches claiming that the Press would publish religious material at cheap rates, which would be easier to read than palm leaf manuscripts and that the Press would also produce educational material for children. ${ }^{21}$ Information on who bought these shares has not survived but, given the method of collection adopted, it may be possible that the Press could have had a wider range of supporters. The Balasore Press published the second most important newspaper of this period, Balasore Sambadabahika, in July 1869. Twenty years later, the weekly newspaper Sambalpur Hiteisini was brought out by the Jaganathballabh Press in Deogarh, the royal seat of the Raja of Bamanda Basudeva Sudhaladev. Even though the newspaper was edited by Nilamani Bidyarantna, it was funded entirely by the Raja of Bamanda. These three newspapers, Utkal Dipika, Balasore Sambadabahika, and Sambalpur Hiteisini, served as the three major nineteenth-century Odia newspapers. Apart from these major newspapers, a number of minor newspapers and journals appeared between 1866 and 1900: Cuttack Chronicle (1871), Utkal Darpana (1873), Utkala Putra (1873), Utkal Darpan (1873), Utkal Madhupa (1878), Mayurbhanja Fortnightly (1879), Purshottam Patrika (1882), Utkala Samaskaraka (1883), Prajabandhu (1882), Sebaka (1883), Pradipa (1885), Odia o Nabasambada (1888), Utkal Prabha (1891), Ganjam News (1896), and Ganjam Hitabadini (1899). Most of these newspapers were published in Cuttack and Balasore and many of them were monthlies and weeklies with small readerships. In the twentieth century, this newspaper industry became much more established with new major newspapers being published such as Asha, Sahakar, Samaja, Nababharata, and Prajabandhu. All these newspapers eventually became dailies by the 1930s and 1940s.

A number of public associations also emerged in the Odia urban centres in the late nineteenth century. In 1866, Utkal Bhasha Unnati Bidhayini Sabha was established in Balasore to discuss and lobby for the

21 Ibid, p. 30. 
status of the Odia language. After a number of false starts, the Cuttack Debating Society was set up in 1869. The Cuttack Young Men's Association, which catered mostly to school students, was set up in the same year. Associations more focused on specific agendas were also established in this period. For instance, the "Temperance and Suppression of Bribery Association" was established in 1884 and in 1888 the "Orissa Islamic Association" was also established in Cuttack.

Much of the discussions in these newspapers, journals, and associations focused on arguing against the imposition of Bengali in Odisha or on matters of neglect by the colonial state.

In his magisterial history of Odia literature, Natabar Samantaray has argued that the fledgling Odia public sphere was very limited in its scale both geographically and demographically. Geographically, most of the printing presses, newspapers, and public associations were located in Cuttack and Balasore with a few scattered in Puri, Sambalpur, and Ganjam. ${ }^{22}$ Demographically, the Odia public sphere of this period was supported mostly by a miniscule middle class.

And at the center of this emerging print industry was the textbook market. Even as the introduction of the printing press changed the way literary production took place in Odisha, it was the emergence of a commercial textbook market that finally shifted the emphasis from palm leaf manuscripts to printed books. The business conducted by the Cuttack Printing Company illustrates how important the textbook industry was to the survival of these incipient presses that would later play an important role in the growth of modern Odia literary production. The Cuttack Printing Company figured prominently in the canon debate of the 1890 s as it published the literary journal Indradhanu, which supported the use of early modern Odia literature in school textbooks. In its early years, this Press struggled to survive and depended on the publication of government forms and school textbooks. The third annual report of the Press reveals that out of a total of 18,200 books published in the Press, 12,500 were school textbooks. These books were self-published by the authors and the Press was only responsible for the printing. While this protected the Press financially, the printing of textbooks allowed another layer of protection as the timely sale of these texts was assured from year to year. In comparison, the Press published very few general books and reserved its meagre financial support to very select publications such as reprints of early modern poetry in Odia and books of social use such as Kangalinka fati Karana, which detailed methods of caste reentry for those

${ }^{22}$ Natabar Samantraya, Odiya Sahityara Itihas (1803-1920) (Bhubaneswar: Granthalaya, 1974), pp. 167-169. 
who had lost their caste status during the 1866 Odisha famine. ${ }^{23}$ This trend of increased production of Odia school textbooks is also revealed in the spike in the number of Odia books sold by the Calcutta School Book Society, which rose from 767 books in 1857 to 14,459 in $1868 .^{24}$

In this way, the writing, production and sale of school textbooks became big business in late nineteenth-century Odisha. While this increase in itself contributed to the formation of a new print-centered Odia literary public sphere, the question of patronage for textbook writing and printing also introduced public contestation between rival groups and helped mark out the limits of this literary public sphere.

This process is particularly evident in the literary life of Radhanath Ray, the first Inspector of Schools of Odisha and a prominent textbook writer who was later slated as one of the three founders of modern Odia literature. Born into a middle-class family of Balasore, Ray was brought up to become an official in the British government. His early education tracks the trajectory of the development of school education in Odisha. $\mathrm{He}$ began his schooling at home under a tutor before joining the new school at Soro, which had been set up with his father's support. Subsequently, he moved to the new Balasore High School and joined its faculty after graduating. He passed the entrance exam for Calcutta University in 1868. After university, he taught in various schools of Odisha and was eventually appointed as the Deputy Inspector of Schools in 1872. As he progressed through his school education and early teaching career, Ray met and befriended some of the most influential figures in the emergent Odia literary sphere, including Fakir Mohan Senapati and Baikuntha Nath De in Balasore, and Madhusudan Rao in Puri. In the years from 1868 until his death in 1908, Ray wrote a number of Odia textbooks, epics, and essays.

While much of his nontextbook writing was sponsored by princely state rulers, the publication, and sale of his Odia textbooks caused considerable controversy. Like a number of inspectors of schools in the Bengal Presidency, Ray began writing Odia textbooks to earn additional income. Even as his books were essential to the development of modern textbook literature in Odia, his contemporaries claimed that he enjoyed an undue advantage as a textbook writer. Gobinda Chandra Rath, a contemporary textbook writer, filed a complaint against Ray claiming he was involved in nepotism and favoritism. Even though his complaint was dismissed, it is possible that as Inspector of Schools and a close friend of De Press'

${ }^{23}$ See Third Annual Report of the Cuttack Printing Company (Cuttack: Cuttack Printing Company, 1869).

${ }^{24}$ Natabar Samantraya, Odiya Sahityara Itihas (1803-1920), p. 122. 
Baikuntha Nath De, who published a large number of school textbooks in Odia, Ray was in a position to influence the production, publication, and sale of textbooks. As a result of considerable controversy in the Odia press, Ray had to stop writing textbooks. However, his stint as textbook writer earned him many detractors, who would later question the efficacy of his literary work during the canon debate of the 1890s when Ray's "modern" poetry was pitted against Upendra Bhanja's "traditional" epics. ${ }^{25}$

Controversy about textbooks was not limited to the economics of their production and sale. As more and more Odia writers came to be employed in textbook writing, the content of the books came up for debate. Early Odia textbooks were written by missionaries such as Amos Sutton who wrote them for use in the English Charity School (established 1823) in Cuttack. With their overwhelmingly religious stance, these early books were not appropriate for secular education. ${ }^{26}$ Furthermore, as the missionaries were first introduced to Bengali before writing these textbooks, the language of the books borrowed heavily from Bengali idioms and vocabulary. ${ }^{27}$ In 1841, the Vernacular School Book Society hired vernacular translators to translate school books into local languages in India. Amos Sutton was appointed as the Odia translator. However, even these books remained fairly Bengal centric in their references. ${ }^{28}$ After 1869 , due to the government's decision to uphold the use of Odia in Odisha schools and allow the market to take over the production of textbooks in Odia, a number of important literary figures, including Radhanath Ray, Fakir Mohan Senapati, and Madhududan Roy, began writing textbooks. In fact, one of the earliest "modern" Odia poetry anthologies, Kabitabali, was written by Radhanath Ray and Madhusudan Roy as a school textbook. These three men were later named as the makers of modern Odia literature in the Odia literary canon. ${ }^{29}$ This canonization of early Odia textbook writers points to a connection between efforts to produce Odia textbooks in the late nineteenth century and the development of new Odia literature of the nineteenth and twentieth centuries. The connection was not merely based on the pioneering contribution of the earliest writers of Odia texts, rather the very process of producing Odia textbooks involved an anxious reappraisal

${ }^{25}$ Ibid, p. $92 . \quad{ }^{26}$ Ibid, pp. 98, $99 . \quad{ }^{27}$ Ibid, pp. 99-102.

${ }^{28}$ Ibid, pp. 108-9. Samantaray quotes from a few of the books to illustrate how the books refer to life in Bengal rather than that of Odisha.

29 This view is a dominant one in the history of Odia literature. Even the official history of Odia literature sponsored by the Sahitya Academy names these three as the makers of modern Odia literature. See Mayadhar Mansinha, History of Odia Literature (New Delhi: Sahitya Akademi, 1962). 
of the traditional Odia literary canon, which focused on rethinking the actual parameters of ascertaining the value of literary texts.

At the root of this reappraisal was the question of whether older Odia texts could be used as school textbooks. Contemporary Odia press repeatedly featured arguments that the traditional poetry written by seventeenth- and eighteenth-century poets such as Dinakrishna, Upendra Bhanja, and Brajanath Badajena should be reprinted and used as school textbooks. In an article published in 1868 in Utkal Dipika, the author argued that the recuperation and reprinting of older Odia literature should have greater priority than the writing of new texts. Even as such arguments favoring the use of early modern texts were being floated, there was a growing concern that these texts may not be appropriate for school children. The matter became the focus of public debate when the issue was raised at the 1878 meeting of the Utkal Sabha, an organization that sprung from the Utkal Bhashauddipani Sabha mentioned earlier. The keynote speaker at the Sabha, Pyarimohan Acharya, pointed out: "[T]here are no assets in Odia language from the ancient age that can be useful to us in our efforts to advance the Odia language. ${ }^{30}$ Elsewhere, Acharya noted in his 1873 article, "Ganjam Sambalpur O Utkal Pustak," published in Utkal Putra that:

We have no expectations from the ancient Odia texts. The glitter of Upendra, the antics of Dinakrushna and the love-play of Abhimanyu are not appropriate to our interests. Therefore, we are ashamed of presenting such obscene texts as school textbooks into the hands of innocent little boys. ${ }^{31}$

The following excerpts from prose translations of poems by Upendra Bhanja could help explain Archarya's anxieties about the appropriateness of early Odia literature for school textbooks:

No joy indeed is comparable to the joy

Derived from dipping the nails into the beloved's person,

From painting her breasts with drawings

And from beholding through sheer happy chance

The lusty pair of her breasts in the morning when she upraiseth

her arms to remove langour. from Rasikaharabalee ${ }^{32}$

How tightly hath she tied the knot of her sari with its comely border!!

Like the entrenching of her conscience doth it appear to be

${ }^{30}$ Purnachandra Mishra (ed.), Utkala Dipikare Bhanja Prasanga (Berhampur: Royal Book House, 1996), p. 6.

${ }^{31}$ Pyarimohan Acharjya, "Ganjam, Sambalpur O Utkal Pustak", in Sudhakar Patnaik, Sambadapatraru Odisara Katha, Vol. 1 (1856-1886) (Cuttack: Grantha Mandir), pp. 677-80.

32 Bichhanda Charan Patnaik, Kabisamrat Upendra Bhanja Souvenier (Cuttack: Chattrabandhu Pustakalaya, 1950), p. 7. 
This knot is the thunder to the mountain of the staidness of the heart of poets,

A chain to bind the elephant of a lovemad heart

And an eddy in the river of charms capable of setting at naught all similies.

Verily her waist is a mesh laid by lovegod to catch the bird of the eye therein.

The knot of the sari on her waist both the eye and the mind have made their abode of. from Labanyabatee ${ }^{33}$

These textbook anxieties formed the immediate context of the canon debate that began in 1891 with the publication of Lala Ramnarayan Rai's critique of Bhanja's Vaidehisa Bilasa. What should be noted in this brief history of the emerging Odia literary public sphere is the pervading sense of domination by the shadow of Bengali and the need for an independent canon that could serve both as a basis for modern textbooks as well as evidence of the autonomous life of Odia in the past, present, and future. However, as newspaper articles of the late nineteenth century reveal, this desire for autonomy was coupled with an aspiration to emulate the "development" of Bengali in the colonial period. ${ }^{34}$ The subsequent debates and discussions about tradition and modernity in Odia literature should be read with this paradoxical desire in mind. In fact, the roots of the arguments of both sides of the debate about Bhanja can be traced back to this dilemma. The reluctance of the Odia literati to countenance any critique of "classical" Odia literature drew from their need to prove that, like Bengali and English, Odia too had an impressive classical literary tradition. The critics of this tradition were driven by a need to approximate the norms of emergent Bengali civility, which they read as evidence of the more developed status of Bengali and its peoples. ${ }^{35}$

\section{Desa-Kala-Patra: Zeitgeist and Sentimentality in Early Odia Literary Criticism}

We return for a moment to the spark that led to the canon debate of the 1890s - Lala Ramnarayan Rai's essays on Upendra Bhanja published in Utkal Prabha. In his essays, Rai espouses a revelatory tone. In exploring

${ }^{33}$ Ibid, p. $48 . \quad{ }^{34}$ See Patnaik, Sambadapatraru Odisara Katha, p. 576.

${ }^{35}$ Of course, this Bengali civility was not necessarily an unalloyed social construct. In his essay on the making of the "Bengali Baboo," Anindyo Roy has traced how the notion of civility itself is not entirely accessible to the urban Bengali middle class despite its concerted efforts to espouse Western education, language, and lifestyle. See Anindyo Roy, "Subject to Civility: The Story of the Indian Baboo", Colby Quarterly 37, no. 2 (2001): 113-24. 
Bhanja's poetry, which he claims has often elided critical attention due to the overly sentimental attitude of the Odia readership, Lal "discovers" serious flaws in the poetry of Bhanja. ${ }^{36}$ The contretemps of his prose, as he oscillated between scathing critique and a sense of sentimental disappointment, points to how Rai saw his role as a literary critic. Reminiscent of Matthew Arnold's call for a "disinterested" critic who "could see the object as in itself it really is" and avoid getting embroiled in "ulterior" or "political" motives, Rai's tonal contretemps suggest an attempt to remove himself from the affect community that held Bhanja dear and yet to speak for the interests of that community. ${ }^{37}$ A reading of the essays reveal that at the crux of his critique is a dilemma about the opposing pulls of sentiment and the need for a more critical approach to literary tradition. Subsequent discussions on the merits of Bhanja's poetry among the Odia literati reveal that this dilemma was grounded on an anxiety about the appropriateness of "traditional" Odia literature to the contemporary social, political, and cultural realities faced by the Odia literati - something that they came to call desa-kala-patra (place-time-character) and we recognize from readings of the history of literary criticism as something akin to zeitgeist. Mention of desa-kala-patra also emerges in the counterclaims from advocates of early modern Odia literature that older texts need to be studied within their original context. Through a brief description of the debate on Bhanja and the subsequent resolution of the debate in the writings of a prominent editor and literary critic of the time, Biswanath Kara, I will reveal how these anxieties about context and timeliness came to produce a new orthodoxy of Odia literary production.

These discussions in Odisha are not unique in the history of modern literature. As Michel Foucault notes in his essay on the spatial turn in twentieth-century disciplinary knowledge: "The great obsession of the nineteenth century was, as we know, history: with its themes of development and of suspension, of crisis, and cycle, themes of the everaccumulating past, with its great preponderance of dead men and the menacing glaciation of the world." 38 Throughout the nineteenth century, the question of zeitgeist or temporal context had circulated in discussions about the social life of literature in England. The concern with time took different forms in English literary discussions. It was cited as the

${ }^{36}$ Lala Ramnarayan Rai, "Kabi Upendra Bhanja”, Utkal Prabha, December 1981, 2.

${ }^{37}$ Here I must confess that Arnold's litany of critical sins also includes "practical." See Stephan Collini, Arnold: Culture and Anarchy and Other Writings (Cambridge, Cambridge University Press, 2010), p. xvi. I think this is where the Odia and English literary concerns diverge. The practical value of literature is of utmost importance to the members of both sides of the debate on the value of ancient Odia literature.

38 See Michel Foucault, “Of Other Spaces”, Diacritics 16, no. 1 (1986): 22. 
prevailing zeitgeist, spirit of the age, plastic stress, Time-spirit, stream, tendency, river of time etc. ${ }^{39}$ However, these notions of temporal context, with its allied themes of the legacy of past authors and the contemporary function of literature, was not always internally consistent. ${ }^{40}$ For instance, Matthew Arnold, who popularized the use of the term zeitgeist, reinterpreted its meaning many times over his long career as a literary and social critic. In his discussion of the term and its function in Arnold's oeuvre, Frazer Neiman has illustrated how Arnold's definition of the term shifted from zeitgeist as a confining, local and parochial notion of temporal context that needed to be transcended by the poet and the critic to zeitgeist as a temporally translocal and eternal force that should guide the craft of the poet and the critic. In early Arnoldian thought, we see that he uses zeitgeist to mean the "spirit" that marks the thought or feeling of a certain age. ${ }^{41}$ It is something that the creative intellect needs to escape in order to produce art that can be eternally valid. In later texts by Arnold, the term is used to mean something similar to Goethe's "time-spirit," which denotes "an agent of necessary change in the realm of the intellect." 42 This shift in the understanding of zeitgeist is mirrored in the tension in Arnold's thought between the particular intellectual and political commitments of the critic and the need for a more general outlook in literary criticism. ${ }^{43}$ This comes through in both his formulation of a "disinterested" critic who was not to speak from any specific political position prevalent at the time as well as the idea of the "prose of the center" where, paradoxically, centrality consisted of the "widest possible position" in intellectual thought. What is of interest to us here is not the complex nuances of Arnoldian thought. Rather, we should note how the idea of temporal context influenced his understanding of the role of the critic and poet, and of criticism. Also, we should take from this discussion an understanding that even in the English literary sphere, which in Odisha was considered as a stable field of ideas that should be emulated, the standards for judging traditional literature, timely literature, and eternal literature were constantly shifting and were a source of much controversy. ${ }^{44}$

${ }^{39}$ For a detailed discussion of the various iterations of zeitgeist in literary discussions, see Frazer Neiman, "The Zeitgeist of Matthew Arnold”, PMLA 72, no. 5 (1957): 977-96.

40 For the inconsistences of this term and the pitfalls of using it as a fundamental literary concept, see Denise Gigante, "Zeitgeist”, European Romantic Review 18, no. 2 (2007): $265-72$.

41 Neiman, "The Zeitgeist of Matthew Arnold", 977. ${ }^{42}$ Ibid, 982.

43 For a detailed treatment of this tension, see Collini, "The Literary Critic", in Arnold: A Critical Portrait, 46-68.

${ }^{44}$ In the beginning of his essay, Neiman gives an account of the public response to Arnold's critique of the contemporary zeitgeist. 
Controversy on Odia literary tradition had been simmering long before the publication of Rai's essay. The earliest mention of Bhanja's poetry can be found in a Bengali journal article written by Rangalal Bandyopadhyay in $1864 .{ }^{45} \mathrm{At}$ this time Bandhopadhyay, an important figure on the Bengali literary scene, was involved in a rather acrimonious critique of contemporary Bengali literature. In the preface to his 1858 epic Padmini Upakhyan, Bandyopadhyay explained that he had borrowed many "pleasing sentiments" from English literature to introduce English literary tropes to those who could not read English and to ensure that "the immodest and contemptible poetry of today shall retreat, along with its exit, its gangs of followers shall proportionally decrease in numbers". ${ }^{46}$ Bandhopadhyay's critique drew from discussions in a meeting of the Bethune Society in 1852 about the backwardness of Bengali literature and rising concern about the need for a "national literature" in Bengali itself. These concerns were shared by the Odia intelligentsia even as it was increasingly concerned about the "backwardness" of Odia in relation to Bengali.

In 1891, the literary journal Utkal Prabha was published in Baripada and funded by Ramachandra Bhanja Deo, Prince of Mayurbhanj. In the inaugural introduction of the journal, the editor declared that the objective of the journal was to close a gap in Odia community life - the lack of actual literature in Odia. The introduction argued that actual literature was literature that consists of texts "on reading of which the common person comes to gain an individual sense of responsibility and which helps every one to learn about ethics, character building and socialization. ${ }^{47}$ In contrast, argued the editor, older literature by poets like Bhanja - though blessed with originality and gravitas - did not contribute to the development of the Odia community due to an excessive preponderance of obscene content.

In subsequent years, the debate on Bhanja came to dominate the Odia public sphere in Cuttack. The pro-Bhanja group published numerous articles and received letters in the Odia weekly Utkal Dipika and the antiBhanja camp published its opinions in another Odia weekly newspaper, Sambalpur Hiteisini. Eventually, as the sheer volume of the writing on the debate came to overwhelm the two newspapers, two separate journals were floated to carry on the debate. Utkal Dipika sponsored a new journal Indradhanu and Sambalpur Hiteisini supported the publication of Bijuli.

\footnotetext{
${ }^{45}$ Purnachandra Mishra (ed.), Utkal Dipikare Bhanja Prasanga (Barhampur: Royal Book House, 1996), p. 2.

${ }^{46}$ Roshinka Choudhury, "Cutlets or Fish Curry: Debating Authenticity in Late Nineteenth-Century Bengal", Modern Asian Studies 40 (2006): 265.

47 "Suchana", Utkal Prabha, April 1891.
} 
Indradhanu was published for almost four years from 1893 to 1897 and carried articles from a steady group of writers who wrote under various pseudonyms. Bijuli became defunct in two short years. However, in this short period, anxieties about the appropriateness of Odia literature to the contemporary desa-kala-patra induced the Odia literati to raise some essential questions about the nature and function of literature and literary criticism. These concerns were centered on two major issues - the question of literary heritage and the need to ascertain the function of literature in contemporary Odia society.

Literature was repeatedly alluded to as "jatiya sampatti" or community patrimony in the rhetoric on both sides of the debate. In this context, critique of Bhanja's poetry posed an untenable dilemma - what were they to do with an inheritance that did not cater to their contemporary needs? The paradox of inheritance, as Jacques Derrida reminds us, is that it is property that one does not entirely own; it is simply held in trust and cannot be disposed of as though it were one's own thing. ${ }^{48}$ As such then could Odia literary heritage be maligned or even denied? Was it subject to nineteenth-century tenets of literary criticism or beyond it? In this vein, defenders of Bhanja countered arguments that the antiquity of a text does not necessarily require affective attachment by calling for greater attention to the ethics of reading and judging the value of literature with its own historical context in mind. ${ }^{49}$ Many of the pro-Bhanja essays in Utkal Dipika and Indradhanu reveal that this defence of literary inheritance was based on a mandate to establish an ancient literary canon in Odia. A common feature in these essays is a recurring refrain where the author asks the critics of Bhanja whether they should apply the same dismissive criticism to older English literary figures such as Dante, Milton, and Shakespeare. ${ }^{50}$ If there is space within the English canon for such figures, then why does the Odia canon have to deny representation to poets like Bhanja? These essays rarely argued that contemporary literary production

${ }^{48}$ Quoted in Anne E. Berger, "Politics of Mother-Tongue", Parallax 18, no.3 (2012): 15.

${ }^{49}$ For details, see essays in Sudershan Acharya (ed.), Indradhanu: Unabinsa Satabdira Eka Bismruta Patrika (Berhampur: Berhampur Biswabidyalaya, 1991). For instance, in an itemized response to a published critique of Bhanja's poetry, one of the contributors to Indradhanu asked: "As literary critics should we analyse a poet's work within the context of this time, place and character or by basing our reading on contemporary tastes?" Acharjya, Indradhanu, p. 14.

${ }^{50}$ See articles reprinted in Purnachandra Mishra (ed.), Utkala Dipikare Bhanja Prasanga (Berhampur: Royal Book House, 1996), pp. 16, 20, 23, 43-8. For instance, in a received letter published in Utkal Dipika in April 1893, a contributor queries: "Is giving a realistic description a matter of important literary flaw. If so, then Ramnarayan Babu would consider Milton's description of the embrace between Adam and Eve in Paradise lost to be the most egregious violation of good taste?"; Mishra, Utkal Bidipikare Bhanja Prasanga, p. 23. 
should emulate Bhanja or that his literary oeuvre should be used in school textbooks. Rather, their contention was that despite the fact that earlier Odia literature is not appropriate for modern times, it was the predecessors of contemporary poets and should not be dismissed as irrelevant to the literary life of modern Odisha. Its canonization was essential to the project of forming a national literature or "jatiya sahitya" in Odia that would enable the advancement of the Odia-speaking people.

Such apprehension about the loss of heritage was coupled with serious disagreements about the function of literature and whether early Odia poetry was true poetry. One critic of Bhanja's work, B. C. Mazumdar, argued that while his poetry entertains the reader, it does not perform the critical explicatory functions that are an essential feature of true poetry. Drawing heavily on tenets of English Romantic literary criticism, Mazumdar defined true poetry to be:

In that which has new-ness of description; that is, it has a clear description of the complexity of human nature, an efflorescence of profound joy as well as despair and an inviting explication of psychology, only that deserves to be called poetry. The unnecessary effort to describe the beauty of a beautiful woman through sentences filled with words like sakachanchunasi, Indibaranayan or Maralagamana is simply disingenuous. ${ }^{51}$

Implicit in Mazumdar's description of actual poetry and his charge against Bhanja that he befuddled his readers was an assumption that literature should perform a function beyond entertainment. Drawing on Romantic literary criticism, Majumdar's notion of true poetry had to use unadorned common speech to describe emotions that would then allow the reader to human psychology. ${ }^{52}$ Literature of this kind has a social function as it helps the community delineate human subjectivity and, by extension, some notion of a collective modern Odia subjectivity. Within this Romantic framework, Bhanja's poetry fails to do so. Furthermore, as Ramnarayan Lala's critique of Bhanja's epic Vaidehisa Bilasa illustrates, the critics of Bhanja found his work wanting when judged by Western standards of rhyming, rhetoric, sentiment, taste, imagination, poetics, and sentence structure. Based on these criteria, Rai had found Bhanja's poems to be difficult to understand, lyrically harsh, grammatically incorrect, and obscene. As a response to Majumdar and Rai, an article published under a pseudonym in Utkal Dipika said of Bhanja and other poets like him:

51 Ibid, p. 10.

52 The connection between emotion and human psychology in Romantic poetry has been extensively explored. See Alan Richardson, British Romanticism and the Science of the Mind (Cambridge: Cambridge University Press, 2001). 
In their writing there is hidden an eternal, indescribable, wonderful and unparalleled captivating force and it is precisely this force that attracts the human heart like a glittering jewel. It is in them that there is the actual essence of poetry or even a tiny speck of this essence; they are actual poets. ${ }^{53}$

Two very different notions of literature and its function in human life emerge here. This anonymous defender of Bhanja drew on the prevailing understanding of Bhanja's poetry as some of the finest examples of Sringara Rasa poetry. ${ }^{54}$ Rasa in Sanskrit means juice or sap and has been defined as that element in literature that raises the reader or viewer from the realm of their ordinary lives and feeling (bhava) to a higher plane of "ordered" and "depersonalized" emotion. ${ }^{55}$ Sringara Rasa in Indian literature appeared as depictions of scenes that evoked sexual desire in the reader or viewer. However, in Indian aesthetics, this desire is not a profane emotion. In his book on the making of romantic love, William Reddy has shown how in the tradition of Indian literary criticism, Sringara Rasa allowed the reader to experience transcendental emotion that, in turn, gave them access to association with the heroic and the divine. A. K. Ramanujam has argued that this association with the divine through Sringara Rasa is always as a result of collective effort rather than an individual effort of reading. Therefore, while Majumdar asserts that poetry should have an explicatory function, the author of the article here bases his claims about the nature of actual poetry in something far more nebulous, in its ability to captivate the human heart. It is disagreement between two visions of literature - literature as social instruction versus literature as an incitement to emotion - that spawned the debate on Bhanja and informed later discussions of literary production.

It should be noted here that even though this disagreement about the true nature of poetry appears to be based on an attempt to determine the limits of the genre of poetry, the terms of the debate - especially the invocation of the function of literature - points to a different reading. At issue here is not poetry or literature in itself. Rather, what is being contested here is a notion of Odia culture even though it is not named explicitly. The linking of literature to development and progress in the framing of the question of literature within anxieties about the backwardness of the Odia-speaking community in relation to other cultural groups, national and international, suggests that the anxiety here is about whether

${ }^{53}$ Hitabadi (pseudonym), "Received Letter", Utkal Dipika, May 28, 1891, reprinted in Mishra, (ed.), Utkala Dipikare Bhanja Prasanga, pp. 14-20.

${ }^{54}$ On Rasa literature, see Sheldon Pollock, A Rasa Reader: Classical Indian Aesthetics, (New York: Columbia University Press, 2016).

55 William Reddy, Navigation of Feeling: A Framework for the History of Emotions (Cambridge: Cambridge University Press, 2001), p. 57. 
there is a viable Odia culture that could serve as a rallying banner for the Odia-speaking people. The concern with development in a number of articles published during the debate on both sides suggests that this anxiety about culture assumes an Arnoldian understanding of the concept where it is not something that "we have" but something that "we become." ${ }^{56}$ The culture in these terms is fundamentally tied to an educational imperative aimed at the community rather than the individual. It is this desire for cultural transformation that the two sides of the debate were trying to apprehend in diametrically opposite ways.

This issue of literature driven by an educational imperative was finally resolved by Biswanath Kara. In the years following the debate, Biswanath Kara became one of the most influential literary figures of the twentieth century in his role as the editor of the Utkal Sahitya journal. In 1896, as the debate on precolonial Odia literature was winding down, Kara published a collection of his essays on literature. Entitled Vividha Prabhanda, this book explored the connections between literature and life, community, civilization, and development. ${ }^{57}$ Frankly didactic and programmatic, these essays were aimed at the literate Odia population and called for an active program of reading, discussion, and production of literature in Odisha. Bypassing the anxieties of literary modernity and tradition prevalent in the Bhanja debate, Kara recognized that literature served two functions - as symbolic capital and as an engine for social change. Therefore, both traditional Odia literature and modern Odia literature that broke with traditional modes of expression served as symbolic capital by establishing ancient literary heritage and a lively modern engagement with contemporary realities. According to Kara, good literature was fibanta Sahitya or living literature which was life like because it represented the aspirations and development of human life. To this end he called for the formulation of a new literary tradition informed by "new ideals." ${ }^{58}$ Concomitant with this proposal for a more socioculturally productive literature was Kara's arguments about literary discussions and the role of the literary critic. Commenting upon the emerging literary

56 The theme of development or unnati and regression or abanati crops up in many of the articles written by proponents on both sides of the debate. See Suchana, Sahitya Charcha, Utkal Sahitya in Utkal Prabha, 1891. See, also, articles entitled Samay, Paribartan, Utkal Sahitya in Sudershan Acharya (ed.), Indradhanu: Unabinsa Satabdira Eka Bismruta Patrika. For a discussion of Arnold's ideas about culture, see Collini, Arnold, p. xxvii.

${ }^{57}$ Archana Naik (ed.), Nirbachita Rachanabali: Biswanath Kara (Bhubaneswar: Sahitya Academy, 1999).

${ }^{58}$ As the question of tradition in Odia literature was not resolved, the discussion on the merits of older literature in Odia remained a matter of debate and anxiety among the Odia literati until as late as the 1920 s when Patna University decided to remove the works of Upendra Bhanja from the curriculum. 
activism among the Odia elite to work for the advancement of their mother tongue, Kara argued that the literary critic was an essential guide in this process.

In his essay titled "Sahitya O Samalochana" (Literature and Criticism), Kara extended the field for this community activism for the enhancement of Odia literature by introducing and centering the reader in the economy of textual production. In this essay about the function of literary criticism, Kara discussed the rights of the reader, duties of the authors and the function of the critic:

It is true, literary criticism is useful for both the writer as well as the reader. Whether a particular piece of literature is good enough to occupy a permanent place in society, literary criticism can show it by examining every nook and corner of the literary piece. Literary criticism reveals the value of literature to readers. Writers have freedom; they can freely express their opinion. However, just because they have written something does not mean that the people have to accept it meekly. If it is based on mis-information or is harmful, then the individual has the right to reveal that. ... All writers should remember that - just as they have freedom (of expression), so too do others have freedom. There is one writer, there are many readers. Not everyone's vision is equally sharp, not everyone has finely tuned taste; therefore, not everybody is capable of good literary criticism. A civic literary critic performs this function as a representative of the people ... Whatever it may be, the chief task of literary criticism is to apprise the writer of his responsibilities. ${ }^{59}$

By tempering artistic freedom with responsibility, Kara effectively staged the reader as a consumer who was central to the process of literary production as his needs directed the efforts of authors. The critic in this economy was the representative of the readers and was bound to regulate literary production by critically engaging with the author's work and demanding he heed the needs of the reader. This formulation of the literary world has three important implications. First, it gave the critic almost unlimited power to police and regulate future Odia literature. Second, by centering the reader, Kara finally established the importance of the utility of literature as being the chief criterion for good literature. Finally, by centering the reader and shifting the focus of literature from entertainment to education, Kara mitigated the eliteness of this move towards greater production of Odia literature and made it a much more populist activity involving the author, the critic, and the reader. While we know that the term "populism" invokes many contradictory meanings, I use the term here to mean political activism that takes the masses as its constituency. ${ }^{60}$

${ }^{59}$ Naik, p. 34.

${ }^{60}$ See Ernesto Laclau, On Populist Reason (London: Verso, 2005) on the contradictory forms of populism. 
Even as this is a problematic definition of the term as populism because politics of the masses is often a matter of rhetoric rather than fact, Kara's understanding of the term espouses both the proffered meaning of the term as well as its undiagnosed exclusions.

It should be noted that this literary populism proposed by Kara was more aspirational than actual. While constraints of literacy and economic access limited the number of readers who could participate in this new literary world to the educated elite, Kara envisaged a reading public consisting of all Odia-speaking people. In using the language of political representation and citizenship, Kara conjured up an Odia republic of letters in which each corner of this literary triangle has rights and obligations towards the development of Odia literature and community life. Reminiscent of Wordsworth's vision of literary production and consumption as a contract between the poet and the reader that had as its ultimate objective a political imperative of representation, Kara's argument seems to be more political than literary. ${ }^{61}$ In the absence of actual political citizenship, the new Odia literary public sphere was to encompass all of the Odia-speaking people into a literary-political community of shared expression.

However, Kara did not perceive the function of Odia literature as narrow provincialism. In a speech at the Utkal Sahitya Samaj entitled "Jatiya Jibanare Sahityara Stana" (The Place of Literature in the Life of the Community), Kara explained what was at stake in the creation of an Odia "literature of the community" (Jatiya Sahitya) for the constitution of the Odia as well as pan-Indian community:

It should always be remembered that literature of the community is a method of creation of community life. I have said it before, at present the objective of all of India is to build a mega-community and because of it the creation of provincial literature is considered meaning-less and detrimental. However, it is important to think about one thing properly. It is not wise to throw away what we have and build community life based on artifacts produced somewhere else. In different places, among small communities, those thoughts that have been expressed and collected can never be overlooked. The community's self-hood easily touches that community's innermost heart and its lowest rungs. Also the way various provincial literatures in India are being developed, common similarities between these literatures are gradually increasing - it is no longer difficult for various communities to understand each other. ${ }^{62}$

Kara's cosmopolitan justification of "provincial" literature points to the broader political atmosphere in India. The emphasis on unity and

${ }^{61}$ See Paul Keen, The Crisis of Literature in the 1790s: Print Culture and the Public Sphere (Cambridge: Cambridge University Press, 1999).

${ }^{62}$ Naik, p. 37. 
commonality of expression at the national level continued to make it necessary for leaders like Biswanath Kara to negotiate the demands of pan-Indian nationalism even as they argued for using Odia cultural artifacts to cultivate a sense of community in Odisha ${ }^{63}$ In the late nineteenth century, Kara was not alone in making the case for the constitutive relationship between Odisha and India. Often, poetry that elaborated on Odia selfhood would also mention the relationship of this emergent region with the broader nation. The most consistent poetic engagement with this theme can be found in the work of Madhusudan Rao. For instance, in his poem Navyuga or New Age, Rao called for the integration of Odisha not only into India but into broader humanity. The poem equated insularity with the defunct past and an expansive openness to the world with the "new age" of Odia community life.

References to India were not simply about the need for a greater openness in the Odia mind-set. Odisha was imagined as an essential part of the larger Indian whole. In his poem Bharath Bhavana, Rao gave an account on the history of the making of India and posed Odisha as essential to the making of the nation. Even in its earliest moment of conceptualization, the region had to think itself as part of the broader nation. However, it should be noted that this acknowledgement of the metonymic relationship between the region and the nation was not based on a disavowal of regional particularity, because to do so would be impractical. As can be inferred from Kara's statement, only the literature written in the language of the people could possibly unite them. This Herderian assertion of a provincial volkgeist would eventually determine the Indian National Congress's attitude towards linguistic diversity in India when, in 1931, Gandhi would uphold both the need to use the vernacular and to use Hindi as a cosmopolitan means of communication. ${ }^{64}$

Furthermore, Kara's comment about the power of vernacular literature to move people reveals a new element in the understanding of language in Odisha. In fact, the debate of the 1890s about literature, tradition, and community hinged on this new element. As the functional and political qualities of literature came to be foregrounded in the debate, it became apparent that regional languages that spawned such literature were something more than just objects of affect or mother tongues. Regional languages housed (through an evergrowing body of literature) and enabled (through discussion and propagation of literature) a continuous articulation of shared everyday life of the people who spoke such languages.

${ }^{63}$ At this point, the Indian National Congress used English in its communication to facilitate conversations across regional boundaries.

${ }^{64}$ For a detailed exposition of Gandhi's position, see M. K. Gandhi, Thoughts on National Language (Ahmedabad: Navajivan Publishers, 1956). 
Kara's reference to the "community's self-hood" that "easily touches that community's innermost heart and its lowest rungs" is a case in point. Here language, through literature written in it, expresses the community's selfhood. And this expression is unprecedented in its reach, to both the inner life of the speakers of the language as well as the lowest classes among these speakers.

\section{Vernacularity of Modern Odia Literature}

Perhaps the best example of literature that represented the inner lives of the lowest class of Odia speakers were Fakir Mohan Senapati's novels and short stories published from 1898 until his death in 1911. In his most well-known novel, Chcha Mana Atha Guntha (Six and a Third Acres), Senapati portrays Odia village life in rural vernacular through the voice of a narrator who maintains an explicit conversation with the reader. This narrative voice draws from Odia traditions of street theatre as well as from a caricature of a common figure in colonial Odisha - the touter who inhabited multiple locales of power and powerlessness from official colonial spaces to rural Odisha. ${ }^{65}$ Through this quasi-educated narrator who made jeering references to traditional Odia literary tropes as well as to important English political and intellectual traditions, Senapati traced a story of peasant indebtedness, the fallacies of the colonial legal system and land ownership patterns. ${ }^{66}$ In his conversations with the reader, the

65 Fakir Mohan Senapati and Rabi Shankar Mishra, Six Acres and a Third: The Classic Nineteenth-Century Novel about Colonial India (Berkeley, CA: University of California Press, 2005), p. 6.

66 The narrator's satirical references to traditional Oriya literary tropes and equally problematic Western literary ones allowed Senapati to directly reference the canon debate of the 1890s. When he introduced of the central female protagonists of Senapati, a jeering narrator asked:

"At this point we should tell our readers that they will meet Champa often in the course of this tale, since she was very closely connected to Mangaraj's household. And so it is important for us to describe her person and her character carefully. The most revered and classical rules of literature require writers to draw the portrait of their heroes and heroines in traditionally prescribed ways. We are not in a position to violate these divinely sanctioned principles.

But our writers have a major weakness. When it comes to talking about the heroine of their tales, they behave as though they have chanced upon something very delectable and do nothing but describe her beauty, forgetting everything else about her. As for us, it is not that we do not know how to describe the beauty of a heroine. Consider how ridiculously easy it is. According to classical literary techniques, all one has to do is to find parallels between specific attributes of our heroine Champa and different fruits, such as bananas, jack-fruits, or mangoes, and common trees, leaves, and flowers. But such oldfashioned methods are no longer suitable; for our English-educated babus we now have to adopt an English style. Classical Indian poets compare the gait of a beautiful woman to that of an elephant. The babus frown on such a comparison; they would rather the heroine 'galloped like a horse'. The way English culture is rushing in like the first floods 
narrator elaborated a fundamentally Odia critique of colonial power and that of the new Odia elite. ${ }^{67}$

Senapati's literary world populated by jeering narrators, active readers, dispossessed but morally superior peasants, pretentious babus, and irrelevant traditions (both Indian and Western) was echoed in later texts produced in subsequent years, such as Gopal Chandra Praharaj's Bhagbata Tungire Sandhya. In his work, Praharaj also portrayed a critique of both the educated and uneducated elements of Odia society as being implicated in a modern malaise of oppression, double standards, and social absurdity. The radical realism of Senapati's fiction owes much to the canon debate of the 1890 s. In struggling to configure a literary canon that would cater to contemporary necessity to carve out a separate Odia political identity in relation to both the colonial state and their more influential Bengali neighbors, the literary elite was faced with a dilemma between the need to uphold community patrimony and the need to display a more buoyant modern literary culture. Kara's resolution of this dilemma inaugurated a new literary republic of letters in which the imagined community of Odia readers were not simply passive consumers of tales but formed the fundamental rationale for literary production.

Of course, we should read this move with some caution as not all popular literature in Odia fit neatly into the elite expectations of "proper" Odia literature. As the anxious discussions about the need to reform fatra or Street Theatre literature between the 1890s and the 1910s reveals, popular literature produced outside elite institutions like the Utkal Sahitya Samaj often displayed a messy combination of Bhanja-like references to sexuality with more modern political critique of the dire economic and social conditions in colonial Odisha. ${ }^{68}$ Much more widely consumed than the more highbrow literature of Senapati and Praharaj, the Odia Jatra had attracted criticism from the literary elite as early as the 1870s. In 1873, a call for the reform of Jatras was published in a major newspaper where the author described the contemporary Jatra as: "Some rogues come to villages, sing in unparliamentary language, present some hysteric dance with naked and half naked costume on the stage, put on the costume masks of beasts and birds, excreted and defacated in front of

of the River Mahanadi, we suspect that our newly educated and civilized babus will soon appoint whip-cracking trainers to teach their gentle female companions to gallop." Senapati, pp. 56-7.

${ }^{67}$ Satya P. Mohanty, Colonialism, Modernity, and Literature: A View from India (New York: Palgrave Macmillan, 2011), p. 158.

${ }^{68}$ Hemant Kumar Das, Odia Natakara Eitihasika Bibartana (Cuttack: S. Publications, 2003), pp. 96-126. Ramesh Prasada Panigrahi, Signboard on the Marquee: Physiognomy, Cultural Rhetorics, and the Trajectory of Odia Fatra Theatre (Bhubaneswar: Odisha Sahitya Akademi, 2010), pp. 93-5. 
poor men's cottages." ${ }^{99}$ By 1895 as the debate on the status of Odia literature raged in towns of Odisha, calls for public opinion on the reform of Jatras were being published in newspapers. In an article published in Sambalpur Hiteisini in October 1895, the author argued that the contemporary Odia Jatra can be considered as the most clear barometer of popular taste. And that the civility of popular taste demonstrates the level of advancement of the community. By linking the rise of Western knowledge with the eradication of obscenity in popular literature, the author firmly situated the much desired advancement within a Western notion of civility and proper behavior. Using the more favorable example of Jatra in Bengali, the author lamented that unlike Bengali Jatra, that of Odia had not been transformed from its traditional obscenity to a more decent literary representation. The solution, he argued, was in a systematic reform of the Jatra tradition in Odisha that had to draw on the support of the educated elite. ${ }^{70}$ Such calls for reform often ignored the fundamentally popular nature of the Jatra tradition and argued for a Westernization of the Odia public tastes that had to be effected from the top down. In an article published in 1918 in Utkal Sahitya, the same author narrated twenty years of his efforts to reform the Odia Jatra. In the intervening years, he wrote, the educated literary elite of Odisha were encouraged to write Jatras in Odia. However, these pieces did not appeal to the popular audience as Jatras would. Keeping the "social backwardness and conservatism" in mind, efforts at reform were focused on coupling narratives of religious myths with modern dramatic literature. According to the author this was somewhat more successful.

These efforts at reforming Odia Jatra were successful from the Odia literati's perspective. As revealed in the work of Baisnab Pani, the most prolific Jatra writer of the twentieth century, Jatra literature underwent a radical transformation in the early 1900s. Pani did precisely what the elite critic of Jatra was hoping for - he coupled traditional Jatra narratives of religious myths with critiques of rural indebtedness, enforced migration, and other adverse effects of colonialism in Odisha. However, this reform came from within the Jatra tradition rather than from above. Pani himself was an impoverished school dropout and was trained in the religious environment of a Puri Mutt. His reformed Jatra did not do away with the elements of traditional Jatras that made elite critics uncomfortable. Rather, it supplemented them with the emergent popular discontent with the contemporary economic, social, and political problems

${ }^{69}$ Quoted in Panigrahi, Signboard on the Marquee, p. 94.

${ }^{70}$ Krushna Prasada Choudhury, "Ruchi Paribartana", Sambalpur Hiteisini, dated October 13, 1895, reprinted in Labanya Naik (ed.), Krushnaprashada Prabandhamala (Bhubaneswar: Orissa Sahitya Academy, 1992), pp. 175-7. 
in colonial Odisha. Pani's incorporation to the Odia canon remained peripheral because even when our elite critic lamented about the lack of proper Odia Jatra in 1918, Pani had been producing his reformed Jatra for more than fifteen years. Utkal Sahitya Samaj named him Ganakabi only ten years after his death in 1956. Pani provided a resolutely nonmodern, nonliberal mode of literary discourse that despite being celebrated by the Utkal Sahitya Samaj could only serve as a peripheral part of the mainstream Odia literary canon.

This elite discomfort with nonmodern literary engagement with Odia life at the turn of the nineteenth century is more starkly evident in the Odia literati's response to another popular literary corpus - the writing of Bhima Bhoi. Born blind to adivasi Khond parents and introduced to a millenarian cult called Mahima Dharma at an early age, Bhima Bhoi's literary oeuvre was extensive. ${ }^{71}$ The Mahima Dharma cult enjoyed a widespread following among adivasis and poorer Hindus of western Orissa. Much of Bhoi's oeuvre was written between the mid-1860s and the mid-1890s when he died. ${ }^{72}$ Bhima Bhoi had become the most influential leader of the Mahima Dharma by the early 1880s and, in 1881, Bhoi's followers stormed the Jaganath Temple at Puri and protested against idolatry. ${ }^{73}$ In the flurry of administrative accounts that emerged in the immediate aftermath of the 1881 temple entry protest, Bhoi was cited as the chief instigator of the event. The storming of the temple was received by the upper classes with much consternation and gave rise to an antagonistic relationship between the Oriya literati and the Mahima Dharma. An article published in Utkal Dipika dismissively referenced as "extreme mlechhas [outcastes]" who belonged to "wild" and "uncivilized" tribes and had been misled by their leader. ${ }^{74}$

What the elite failed to account for was that this forced entry into the Jaganath Temple was a result of complex critique of mainstream Hindu religiosity, caste discrimination, and social oppression of the adivasis and

${ }^{71}$ His most well-known works are his autobiographical epic, Stutichintamani and his collection of devotional poems Bhajnamala. See Bettina Baumer and Johannes Beltz, Bhima Bhoi: Verses from the Void: Mystic Poetry of an Oriya Saint (New Delhi: Manohar, 2010). See, also, Ishita Banerjee-Dube, Religion, Law and Power: Tales of Time in Eastern India 1860-2000 (London: Anthem Press, 2007); Ishita Banerjee-Dube and Johannes Beltz, Popular Religion and Ascetic Practices: New Studies on Mahima Dharma (New Delhi: Manohar Publishers \& Distributors, 2008).

72 The exact dating of Bhima Bhoi's life and work is shrouded in legend. Anncharlott Eschmann estimated that he joined the Mahima Dharma in 1862. Cited in Baumer and Beltz, Verses from the Void, p. 25. His death is clearly dated at 1895. See BanerjeeDube, Religion, Law and Power, p. 75.

${ }^{73}$ It was reported that the Dharmis threw cooked rice around the temple and desecrated the bhog of the temple. They even threatened to burn the idol of Jaganath. Ibid, pp. 49-50.

${ }^{74}$ Ibid, p. 51. 
lower castes. ${ }^{75}$ Bhoi drew heavily from Hindu, Christian, and Islamic theology to argue for a radical secular universalism, which produced, as Mukti Makhi Mangharam argues: "[A] universalist idea of rationality (that) would recognise that other cultures have forms of thought which are just as rational as Western forms of thought, even if they are not scientific." ${ }^{76}$ Bhima Bhoi's poems served to combine a modern critique of Western intellectual dominance with everyday forms of speech and writing for the uneducated reader.

Effectively, Bhoi's poetry did exactly what Biswanath Kara was arguing for - it produced a literature that spoke to the innermost hearts of the people. However, we find very few references to Bhoi's poetry in the Odia press of the time. The first reference to Bhoi appeared in 1908 in the monthly journal Mukura, as a bid to introduce readers to Bhima Bhoi and his work. There were no ongoing discussions about him after this time. If Kara's desired literature was to represent the life of the readers and engage their interests then the neglect of Bhoi's oeuvre or Pani's Jatra are quite revealing in their omission. The emergent Odia canon could not comfortably house these resolutely nonmodern and subaltern literary works because of the foundational political economy between the author, critic, and reader that thinkers like Kara were proposing. This representational political economy, which claimed that regional language was the only language through which the people could be reached because it was vernacular to them, was always steeped in a liberal framework of political representation. The democratization of literary production with the increasing effort to bring the Odia reading public into the cycle of literary production always assumed a liberal citizen subject who would engage in this cycle. The consumers of the literature produced by Pani and Bhoi were deemed as unsuited to this task due to their "backwardness," "conservatism," and "wildness." Effectively what was being avoided was not just the inclusion of

${ }^{75}$ For instance, in Stutichintamani, Bhoi extensively critiqued caste prejudice:

"Their minds are steeped in ignorance

And wicked are the high-born

When I speak of you as without desire,

O Swami, they just their moustaches in pride"

And later in the same poem:

" 'Give them no shelter, they are sinners and fools!

If you see them, drive them out!'

I preach the initiation of equality

And so they call us dogs."

Baumer and Beltz, Verses from the Void, pp. 125-31.

${ }^{76}$ Mukti Lakhi Mangaram, "Radical Religious Poetry in Colonial Orissa", Economic and Political Weekly XLVI (2011): 82-94. 
subaltern literature but also the subaltern people who created and consumed this literature. The vernacularity of modern Odia literature depended on the participation of the Odia public but the Odia public was imagined as a body of liberal individuals. Thus the vernacularity of modern Odia literature had written into it the exclusion of those groups that sought to destabilize the emerging Odia liberal middle class. 
The early life of Indian nationalism was inaugurated by local cultural politics. Histories of Indian politics have often seen this early phase as a precursor to more political and populist anticolonial nationalism of the twentieth century. ${ }^{2}$ However, this taxonomy of Indian nationalism into early culturalism and later political agitation can sometimes be overdetermined. ${ }^{3}$ When we look at the history of cultural politics of the late nineteenth and early twentieth centuries, we see that the argument for political rights was already immanent in demands posed by social organizations seeking to represent the interests of their constituencies. What is lost in the separation of early culturalism and later political activism is a denser history of transition in the development of politics in India. How does the cultural subject of early Indian nationalism turn into the political subject at stake in later agitational populism in India? If we accept that there are continuities between these two phases then we need to acknowledge that cultural identities fostered in the early phase do linger in the later definition of the uniform Indian citizen subject. This is particularly true of regional linguistic politics and its resolution with all-India nationalism in the 1920s. The subject at stake in movements for linguistic rights was turned into the Indian political subject during the 1910s and 1920s as discussions about regional boundaries, linguistic identity, and political franchise came to figure prominently in Indian national politics.

This chapter tracks how the emergent Odia public imagined by the anti-Bengali agitation of the 1860 s and 70 s and the literary canon debate

${ }^{1}$ An early article containing some parts of this chapter was published in Pritipuspa Mishra, "Practicing Prajaniti: The Odia Political Subject and the Rise of the Odia Movement", in Madhava Prasad and Veena Naregal (eds.), Language Movements and the Democratic Imagination in India (Hyderabad: Orient Blackswan, forthcoming).

${ }^{2}$ See, for instance, Ranajit Guha's argument about Bengali language and the roots of nationalism in nineteenth-century Bengal, in Ranajit Guha, An Indian Historiography of India: Nineteenth Century Agendas and its Implications (Calcutta: K. P. Bagchi, 1987), pp. 41-3.

3 Andrew Sartori, Bengal in Global Concept History: Culturalism in the age of Capital (Chicago, IL: University of Chicago Press, 2008). 
of the 1890s is transformed into a recognizable political constituency in the early twentieth century. This does not mean that the actual Odia public was politicized into an agitational community that self-identified as exclusively Odia. Rather, this transformation is the history of the formation of a category - the Odia electorate - who would form the basis for the demand for a separate administrative province of Odisha. The life of this category was mainly institutional and came to be very influential in the 1920 s and 1930s as the colonial state set about reformulating regional boundaries to create one of the first linguistic regions in India.

This transition occurs due to a set of unrelated but crucial shifts in Indian politics. First, the demand for linguistic and administrative rights for an Odia-speaking constituency in Odia organizations inadvertently produced an image of a cohesive Odia political constituency. Second, this surreptitious emergence of the notion of an Odia political constituency became entangled in the events leading to the introduction of wider franchise in India during the 1910s. As officials and the Indian political elite around the nation argued about the basis of constituencies of political representation, claims for territorial franchise based on language gained ground. Finally, these moves towards territorial franchise shifted the policy of the Indian National Congress from a reluctance to recognize regional linguistic politics to a linguistic classification of the Indian public based on the formation of Provincial Congress Committees constituted on the basis of common language. As a result of these shifts, a curiously paradoxical notion of regional and national political community emerged in Odia discussions about self-representation. While leaders argued for a separate Odia political constituency by citing that other linguistic communities like Bengalis or Biharis were "intermediary ruling races," the Indian nation came to be defined as a sisterhood of different linguistic groups. ${ }^{4}$

At the center of these changes was the rise and fall of the Utkal Union Conference or the Utkal Sammillani, as it was known in the vernacular. A pan-Odia organization set up in 1903 to represent Odia interests to the colonial state and the Indian political elite, the Sammillani served as one of the earliest sites for a systematic articulation of a cohesive Odia community. We can trace the shifts that led to the gradual transformation of the Odia public of the 1890s into a political constituency of the $1910 \mathrm{~s}$ through a history of the changing meaning of politics or rajaniti in the Utkal Sammillani - from an early denial of politics to the eventual acceptance of it as central to the organization's praxis. By 1920, as the Utkal

${ }^{4}$ This phrase enjoyed surprising valency in Odia claims for regional unity. First introduced by M. S. Das in 1918, it was deployed in arguments for the separation of Odia-speaking areas from other regions in the early 1930s. See Memoranda to the Orissa Boundary Commission. 
Sammillani was no longer able to sustain its apolitical stance, it became increasingly clear that the nature of the negotiations between the Sammillani and the colonial state had undergone fundamental changes. The social and the political could no longer be isolated. The inability of the Sammillani to maintain its apolitical stance illustrates how the Odia political community emerged. Its ultimate espousal of politics was due to broader changes in Indian politics as much as it drew from the fallacy of the organization's original rationale that social and economic rights could be earned without political representation. This fallacy lay in the very terms that they invoked to justify their stance - rajaniti and praja. The leaders of the organization argued that politics was beyond the realm of its activities by defining politics as rajaniti or the ethics of rule. By posing themselves as praja or subjects, leaders had suggested that Odia subject by virtue of their subjecthood had no access to rajaniti as this was the ruler's domain. Paradoxically, as I will illustrate, these terms that were used to exclude the Odia public from politics escaped their narrow conservative definitions as younger, more radical politicians argued that there could be a rajaniti (politics) of the colonized praja (subject). ${ }^{5}$

\section{Utkal Sammillani}

The conditions of its inception as well as its largely elite membership, which included many of the historically loyal Odia native princes, made the Utkal Sammillani both fiercely loyal to British rule as well as the most significant site for the articulation of pan-Odia nationalism. These dual fulcra of the Sammillani created profound tensions in its self-image as a public organization. On the one hand, leaders of the organization safeguarded their loyalist stand by using language such as British raja and Odia praja and by limiting rajaniti or politics to British raja's ethics of governance. On the other hand, the very act of arguing for the Odia community's rights to state resources and representation as a discrete community with specific interests opened up the possibility of the very anticolonial nationalist politics that they were seeking to avoid.

The Sammillani's agenda drew from earlier nineteenth-century cultural politics in urban Odisha. Beginning with Odia responses to the British management of the Odisha famine of 1866 as well as critiques of colonial salt and pilgrim tax policies, the demands made by the Odia intelligentsia posed linguistic rights as a means for the economic and

${ }^{5}$ Even as this chapter traces the emergence of the Odia electorate as a category, it is also a narrative about the changing meaning of politics in India. 
social development of the individual and the community, ${ }^{6}$ thus producing a community whose interests were at stake in the interests of language. Often in these discussions, language and development were linked as leaders argued that as the community's language developed the community would be better able to participate in the emerging Indian modernity. Not necessarily framed as a demand for regional autonomy, nineteenth-century public debates centered on two important objectives - the need for a more dedicated state machinery to cater to Odia interests by amalgamating all Odia-speaking areas under a single administration and the need to ensure that the Odia language, literature, and textual production kept pace with the other advanced languages of India.

This linking of language and development produced a liberal rhetoric that hinged on an educational imperative. As a result of the public discussion about the need for Odia textbooks on which depended the possibility of retaining the use of Odia language in schools, a connection between the development of the Odia language and that of the individual Odia was forged. During the 1860s and 1870s newspaper articles and speeches often featured claims that linked the underdevelopment and economic backwardness of the community with the "impoverished condition" of the language. ${ }^{7}$ It was often argued that better educational resources in Odia would enable more Odias to become educated and to participate in governance and administration. This, in turn, would allow for better economic and social circumstances in Odia-speaking areas as they would be administered by Odias themselves. This liberal aspiration for social and economic progress that would result in a more responsible

${ }^{6}$ For instance, in 1866 , a serialized article entitled "'Odiyamane Swabhavataha Nirbodha' Ehi Prabada Jatharta Ki Na" (“'Odias are naturally stupid' Is this argument right?”), the author argued that even though it appears that Odias are less advanced than Bengali, this is not the result of Odia ineptitude, but the direct result of the underdevelopment of the Odia languages. The author posed: "The foundation of the land's civilization is language. What was the English language in the past and what is it now? If we compare the English language from before the Saxon invasion with the ancient Odia language we see that there is a difference of day and night. Again, see that the development of the Bengali language is the result of concerted effort." Utkal Dipika, March 25,1866, in Sudhakar Pattnaik (ed.), Sambadapatrare Odisara Katha Part 1 (1865-1882) (Cuttack: Grantha Mandir, 1972), p. 11.

${ }^{7}$ For instance, the debate of replacement of Odia with Bengali in schools of the Odisha division raised the question of language and its relationship with the community's development. The argument for Bengali often made the case that Odia did not have enough speakers, school textbooks, and other resources. Hence, committing to education in Odia would limit the Odia speaker's access to modern advances introduced through colonialism. The counterargument was that, rather than abandoning Odia, the government should contribute to its development just as it has for Bengali. See "Utkal Bhasara Unnati Prati Byaghata" (Attack on the Development of the Odia Language), in ibid, pp. 531-6. 
class of British subjects pivoted on the development of Odia language. ${ }^{8}$ The linking of language and individual development in nineteenthcentury Odia cultural politics tied the first knot in the linking of language and citizenship in India.

Even as language and progress came to be linked in liberal Odia aspirations, the Odia praja in nineteenth-century rhetoric was often referred to as a political community still early in its development. For instance, in an 1868 article explaining the need for greater participation in public associations, the author argued that:

Some people think that as India has been ruled by various rajas since the beginning, the need for public associations has never been felt. To such people we would only say that during the rule of Hindu rajas, the praja were in their infancy - rajas like Ramachandra and Yudhistira nurtured them with parental love and praja lived happily. After that, during the rule of Mussalmans, the praja entered a phase of early education because Mussalman kings ruled the praja with an oppressive discipline of a strict teacher. In both these conditions the praja were unaware of their own wants. In their infancy, they had no wants. Whatever the strict teacher-like raja stipulated they did. These days, under the rule of the English, the praja have attained their youth. Now, if they do not work themselves then they cannot survive. Therefore, the praja have to consider their interests as they work, if they do not then there is no doubt that they will suffer. ${ }^{9}$

Like many of its contemporaries, this narrative of the praja's development situates British rule in an oft-cited history of changing forms of rule in India - Hindu, Muslim, British. ${ }^{10}$ While the characterization of Hindu

${ }^{8}$ In cautioning the government against introducing Bengali in Odia schools, newspaper articles often argued that this would dissuade people from sending their children to school. For instance, in an article titled "Utkal Bhasare Banga Bhasara Sikhya" (Education in the Bengali Language in Odisha), this anxiety about possible loss of students was posed as a foil to the colonial state's liberal mandate to educate as many people as possible - "Since the establishment of their rule, the British have educated people in a number of things by employing good governance practices. And they have expended resources in establishing schools in areas where even a single person was not educated so that they could incorporate the praja into their rule. However, those who are charged with education are attempting to make the language of the land extinct .... The government's desire is to educate all those who are under their rule and to remove all obstacles to this end. Only those who are charged with this task are unable to carry it out and are trying to save their jobs at all costs." Utkal Dipika, January 4, 1868, reprinted in Bansidhar Mahanty, Odiya Bhasa Andolana (Cuttack: Friends Publishers, 1989), pp. 225-8. Clearly, these loyalist claims are couched as liberal aspirations for progress which are seen as the remit of colonial government. See also "Ganjamara Odiya Manankara Unnati Nahebara Dayee Kiye?" (Who Is Responsible for the Lack of Progress of the Ganjam Odias?) Utkal Dipika, March 4, 1881, in Ibid, pp. 433-6.

9 Anonymous, "Samaj Unnatira Chesta", Utkal Dipika, November 14, 1868, reprinted in Sudhakar Pattnaik (ed.), Sambadapatrare Odisara Katha (Cuttack: Grantha Mandir, 1972), pp. 97-8.

${ }^{10}$ Partha Chatterjee illustrated how this narrative of rule was implicated in the nineteenthcentury nationalization of Hinduism. See his account of school textbooks on Indian history 
kings as kind fathers and Muslim kings as oppressive teachers is familiar, the discussion about British rule is striking. The only feature that seems to characterize British rule is one of happenstance. The British have come to rule India when the Indian praja happens to have come of age. This carefully loyalist narrative that is just shy of arguing that the Indian praja can no longer depend on a paternal state implies a progressive alienation between raja and praja in India - from father to teacher to outsider. While the narrative of the praja's development from children to engaged subjects sounds distinctly liberal, the article's silence on whether there is something about British rule that necessitates this engagement underlines its loyalism. This concurrence of loyalism and liberal aspirations was one of the hallmarks of moderate politics of the nineteenth century. In his reading of moderate politics in the Indian National Congress, Sanjay Seth has argued that loyalism was not simply a tactical choice that limited criticism of colonial rule. Rather, it "provided the very ground from which criticism became possible." 11 That is, moderate criticism was possible because the moderates could argue that the British rule was failing to live up to its own promise. Clearly, such a claim was founded on a loyalist commitment to British rule. We need to see Odia demands for unification within the context of loyalist liberalism.

The moderate demands for the union of Odia-speaking areas became increasingly insistent towards the end of the nineteenth century as proposals to change the official language of the Odia-speaking Sambalpur district of the Central Provinces from Odia to Hindi were posed in government circles in $1895 .{ }^{12}$ In the face of vocal opposition to the change amongst the Odia intelligentsia in the Odisha division of the Bengal Presidency, Sambalpur district in Central Provinces as well as the Odia-speaking Ganjam district of the Madras Presidency, the government decided to retain Odia as the official language of Sambalpur. The Sambalpur language agitation set in motion a process that would eventually lead to the partition of Bengal. As a result of the initial Sambalpur language agitation, the question of territorial redistribution of the massive Bengal Presidency was raised in colonial circles. In 1903, the Risley Circular, detailing the plans for the breakup of the Bengal Presidency,

from nineteenth-century Bengal from Mrityunjay Vidyalankar in Partha Chatterjee, Empire and Nation: Selected Essays (New York: Columbia University Press, 2010).

11 Sanjay Seth, "Rewriting Histories of Nationalism: The Politics of 'Moderate' Nationalism in India, 1870-1905”, American Historical Review 104, no.1 (1999), 95-116.

12 See S. C. Patra for an account of demands for the unification of Odia-speaking areas between the 1870s and 1900. The demand for amalgamation was particularly intense in outlying areas such as Ganjam in the Madras Presidency, and Sambalpur and Sareikela in the Central Provinces. S. C. Patra, Formation of the Province of Orissa: The Success of the First Linguistic Movement in India (Calcutta: Punthi Pustak, 1979). 
was published. While the plans for partitioning Bengal included the controversial issue of East and West Bengal, they also suggested that all Odia-speaking areas be brought together under a single province.

The push towards territorial reorganization by the government also received some impetus from Odia local organizations such as the Utkal Sabha and the Ganjam Hiteisini Sabha. The Utkal Sabha, set up in 1882 under the auspices of Madhusudan Das, allied with colleagues in Calcutta to organize a Bengal Provincial Conference, which was to discuss issues of provincial importance as opposed to issues of national importance that were discussed in the Indian National Congress. However, the Bengal Provincial Conference was unable to include Odia representatives from other British provinces. Hence, it could not serve as a pan-Odia organization. In early 1903, an organization called the Ganjam Jatiya Samiti met for the first time in the Odia-speaking Ganjam district of the Madras Presidency and called for the need of a pan-Odia organization. As a result of this meeting, it was decided to establish a public organization representing Odias from various British provinces. While the preparations for the Utkal Sammillani were underway, the Indian National Congress met in Madras to discuss the proposed partition of Bengal. While the partition of Bengal was severely critiqued, the delegates of the Congress also resolved that the proposed transfer of the Odia-speaking Ganjam district from the Madras to the Bengal Presidency was unnecessary as the Odias were given special consideration as backward classes. ${ }^{13}$ With scant support from the Indian National Congress, the establishment of a loyalist pan-Odia organization that would lobby for the amalgamation of Odia-speaking tracts seemed to be the only viable choice left for the Odia leaders such as M. S. Das.

In December 1903, the first session of the Utkal Sammillani met in Cuttack. Almost half of the founding members of the Utkal Sammillani were princes of the Odisha princely states. For instance, the thirty-two out of sixty-two members of the 1903 Standing Committee in charge of social reforms among the Odia-speaking people were native princes. A large number of the remaining thirty members were university-educated government employees. The demographic of the other standing committees was very similar. ${ }^{14}$ Closely reflecting the demographic of the erstwhile leadership in the Odia public sphere, this membership was fundamentally loyal to the colonial state. In the case of educated-government employees, this loyalty was enforced. Days before the first meeting of the Sammillani,

13 Pritish Acharya, National Movement and Politics in Odisha (New Delhi: Sage, 2008), p. 28.

${ }^{14}$ The resolutions of the first meeting of the Utkal Sammillani, including the record of founding members, is reproduced in Debendra Kumar Das (ed.), Utkal Sammillani (1903-1936) (Rourkela: Pragati Utkal Sangha, 2005), pp. 29-38. 
government employees were barred from participating in the proceedings and some of the members on the organizing committee had to resign. The order was rescinded when the Sammillani assured the Commissioner of the Orissa division that there would be no political agitation on the Sammillani platform. Only matters of social, educational, and industrial development were to be discussed. ${ }^{15}$

Under these circumstances, at its very inception, the organization declared that "all discussions on Political and Religious subjects and criticisms of the actions of Government and Government Officials are strictly prohibited." ${ }^{16}$ In its published statement on the objectives of the Sammillani, the organization declared that the Odia people were not ready for political revolution, being less developed than other communities in India. The statement argued that:

Before committing to political agitation, we need to find out if the Oriya people are ready for political discussion. In order to have political discussion we will have to think about the inadequacies of others or of the colonial State. However, if we pause to think about the present circumstances of the Oriya people then we see that before stepping out to reveal other people's inadequacies, we have to resolve our own inadequacies and learn to develop self-reliantly. ${ }^{17}$

In this vein, religious discussion was to be avoided as this would cause discord among the diverse groups of people who identify as Odia. The function of the Sammillani was to be able to achieve its social and economic ends without engaging in political or religious discussion. While subsequent politics of the Sammillani reveals that religious discussion did slip into the Sammillani's activities, politics in its very disavowal continued to haunt the organization until the fateful split in its ranks in 1920 when politics was included in the organization's praxis.

While religion and politics were barred from the Sammillani, it repeatedly addressed questions about popular education, female education, industry in Odisha, and social reform. Madhusudan Das, the founder of the organization established two firms that would help develop native crafts - a silverworks and Utkal Tanneries. Utkal Tanneries was a commercial as well as a social experiment. The company offered employment to lower-caste workers who were traditionally involved in leatherwork due to taboos against their involvement in "cleaner" professions. Das' aspiration was to engage the lower-caste groups in the commercial mainstream and, consequently, assimilate them into the liberal economy of colonial India.

15 Ibid, p. $27 .{ }^{16}$ Ibid, p. 29. ${ }^{17}$ Ibid, p. 43. 
The Sammillani's abstinence from politics (which, in this context, meant any critique of the colonial government), based as it was on a rhetoric of the unpreparedness of a young underdeveloped praja, allowed the organization to pose itself as a symptom of a preparatory phase in the development of Odia political subjecthood, thus also making a claim that it was contributing to the colonial civilizing mission. Its narrative of loyalism required both an insistence on loyalty to the crown and a commitment to the purported social aspirations of the colonial state - the commitment to the liberal progress of the individual and the community and the possibility of greater Odia access to modes of production and circulation of colonial capital. Odisha literally needed to be brought into the time of colonial capital before it could be politically engaged. The organization's attention to female education, industrial and commercial growth, alleviation of poverty, popular education, and social reform all tended towards creating a better Odia liberal subject who would remain just shy of citizenship as the organization situated itself in a time of preparation rather than action.

\section{Raja, Praja, and Rajaniti}

Despite explicit loyalism and a categorical denial of politics, the Sammillani inadvertently served as a site for the emergence of the Odia political subject. Throughout its career as the premier Odia public association, the Sammillani was plagued by criticism of its apolitical loyalist stance. Barely five years after its establishment, it was publicly attacked by younger radical leaders for banning the use of Vande Mataram on its platform. ${ }^{18}$ These debates, in and around the organization, raised some crucial questions about the nature of political activity, Indian subjecthood, the role of the colonial state, that of the Indian National Congress, and the relationship between the region and the nation in Odisha. In its denial of politics, the Sammillani used terms that eventually escaped the narrow conservative definitions ascribed to them and came to be redeployed by opponents of the organization to signify citizenship and politics. In this section, I will explore the discussions about the nature of the political within the organization by tracking the use of two key terms in the Sammillani's rhetoric - rajaniti and praja. In doing so, I explore the roots of their elision of conservative meanings.

In 1903, at the first annual meeting of the association, the President of the session, Ramchandra Bhanja Deo, Raja of Mayurbhanj, justified the

${ }^{18}$ Acharya, National Movement, pp. 33-4. 
organization's decision to avoid politics by pointing out the particular politics or rajaniti that was being debarred from discussion in the Sammillani. He argued:

What is said to be Rajaniti? Why will we boycott discussions of Rajaniti in the Sammillani? [We reject it] by saying it is a science of governance: by saying it is any effort by human kind for the governance of the country or community or for the protection of its peace and prosperity or for the protection of the inhabitants from external attacks. ${ }^{19}$ (emphasis added)

Bhanja Deo proceeded to argue that, as rajaniti was about governance, it was the prerogative of the colonial state. By comparing colonial rule with what he claimed was misrule by earlier rulers such as the Maratha and the Muslim monarchs, he contended that the Utkal Sammillani need not engage with questions of governance as the new British rajas lived up to their responsibilities as rulers. In fact, he argued that the primary aim of the Utkal Sammillani should be to help the Odia community recuperate from the ill effects of centuries of Muslim and Maratha misrule through social, economic, and cultural reform. At stake in this formulation of colonial rule as good rule was Bhanja Deo's effort to ensure that the Utkal Sammillani did not participate in any opposition to the colonial state, even as it ventured to carve out for itself a public domain where it could represent the social, cultural, and economic interests of the Odia-speaking people. Ostensibly, by asking what is "said to be rajaniti", Bhanja Deo claimed to be invoking a commonsensical notion of politics. In such a commonsensical notion, the raja would be king and the praja would be subject. And yet, smuggled in here, perhaps entirely against his explicit desires and arguments, is also another notion of raja and praja.

This slippage was due to the fact that Bhanja Deo's "commonsensical" understanding of rajaniti was not the only understanding of politics and its constituent concepts, such as raja and praja in Odisha during the early twentieth century. Bhanja Deo's definition of rajaniti as the ethics of rule that precluded subject participation was an overly simplified rendering of deeply nuanced traditions of sovereignty and subjecthood. To begin with, praja was a rather slippery term. ${ }^{20}$ With no etymological connection with

19 Ibid, p. 65.

${ }^{20}$ In colonial usage, the term praja has carried many different valences. Often used to mean subject, it was usually deployed to signify the peasant classes in the East Indian zamindaries. In Gandhi, praja is used to denote the nation or, sometimes, that the nation is the proper destination of the praja. In such a usage praja could be mean "public" and it does not always carry with it a suggestion of being ruled. See Ajay Skaria, "One Word Properly Altered: Gandhi and the Question of the Prostitute", Postcolonial Studies 10, no. 2 (2007), 219-37. 
raja or ruler, praja literally means progeny. ${ }^{21}$ While commonly used to denote subject, in Odisha this subjecthood did not constitute a lack of agency in matters of state. ${ }^{22}$ Much of the scholarship on precolonial kingship in Odisha concurs that kingly sovereignty in early modern Odisha was shared. ${ }^{23}$ By the time the Marathas gained control over Odisha from the Mughal Empire in the eighteenth century, the area was ruled by a two-tier political system consisting of the ritually central Gajapati state of Khurda, which controlled the Jaganath Temple at Puri and the, feudatory hill states or Garjat kingdoms of the Eastern Ghats. With the Marathas gaining control, the political power of the Gajapati king waned and the Garjat kingdoms became increasingly independent. These precursors of the British princely states managed to maintain a fragile sovereignty over their fiefdoms through a complex ritual economy of rule that involved the Jaganath Temple through the Puri Gajapati rulers of Khurda, the princes and the local adivasi populations of the feudatory states. ${ }^{24}$

Akio Tanabe has argued that the impact of growing market forces of the early modern period coupled with the rise of vaishnava Bhakti in Khurda produced a system of entitlements that resulted in the deepening of the state's reach into the local economy and society through a sharing of sovereignty between the king and the locality. ${ }^{25}$ This deepening of state control was unlike that of the modern state as it did not involve the intervention of a centralized bureaucracy and military power in the locality. Rather, what made this balance of power possible was the popular commitment to elements of Vaishnav Bhakti, particularly Karma Bhakti, which linked day-to-day service in the locality with service to the king as

${ }^{21}$ Arthur Anthony Macdonell, A Practical Sanskrit Dictionary with Transliteration, Accentuation, and Etymological Analysis Throughout (London: Oxford University Press, 1929). http://dsal .uchicago.edu/cgibin $/$ romadict.pl?page $=100 \&$ table $=$ macdonell\&display $=$ simple

${ }^{22}$ The term praja is discussed by a colonial official, D. F. Carmichael, as he attempted to understand the roots of the name paraja (this is the name of a tribe in southern Odisha). Carmichael argued that paraja drew from the Sanskrit praja and denoted a "class of ryots" or "commoners." Raphael Rousseleau has argued that the meaning is more specific - "subjects or clients" to the "patron king." Furthermore, these subjects are peasant subjects as opposed to residents of the city. See Raphael Rousseleau, "The King's Elder Brother: Forest King and the 'Political Imagination' in Southern Orissa", Rivista Di Studi Sudasiatici 4 (2009), 39-62.

${ }^{23}$ See Georg Berkemer, and Margret Frenz, Sharing Sovereignty: The Little Kingdom in South Asia (Berlin: K. Schwarz, 2003).

${ }^{24}$ By the beginning of the twentieth century, there were twenty-six Odia-speaking princely states. See Chakrapani Pradhan and Niranjan Pattnaik, The Odia Movement; Being a Demand for a United Orissa by Two Bachelors of Arts (Aska: H. H. Panda, 1919), p. 75.

25 Akio Tanabe, "Early Modernity and Colonial Transformation: Rethinking the Role of the King in Eighteenth and Nineteenth Century Odisha, India", in Masaaki Kimura and Akio Tanabe (eds.), The State In India: Past and Present (New Delhi: Oxford University Press, 2006), pp. 203-28. 
service to the divine. The ritualization of kingship in early modern Odisha was essential to the day-to-day secular functioning of the state at the center as well as the periphery. This ritualization of kingship became even more complex in the feudatory states that have traditionally struggled to maintain control by balancing sovereignty between Puri, themselves, and the adivasi communities under their rule. ${ }^{26}$ The feudatory princes maintained their control over adivasi communities either by claiming lineage from important tribal deities ${ }^{27}$ or by appropriating the worship of tribal deities and situating such local worship in an economy of piety that involved Jaganath in Puri, other Hindu deities, and tribal deities. ${ }^{28}$ At stake in this inclusion was a politics of conciliation that allowed Hindu rulers who were outsiders in the Gadajat areas to legitimize their rule. In some cases, adivasi legitimization had been incorporated into rituals of consecration. For instance, even in the mid-nineteenth century, royal succession in the princely state of Keonjhar had to be ratified, at least ritually, by leaders of the Bhuiyan community. The adivasi rebellion in 1868 in the Keonjhar princely state took place because a new successor had been announced without the approval of the Buiyan leaders. All this suggests that, in the day-to-day operation of state, sovereignty and the distinction between the religious and the political was often blurred. Sovereignty did not simply reside in the singular body of the king. Rather, the raja maintained his kingship through delicate networks of shared power and subjecthood.

However, Bhanja's oversimplification of systems of sovereignty was itself a product of colonial intervention into native kingship and religious structures. Bhanja's narrow notion of rajaniti as kingly ethics of rule was as much a product of Odia traditions of kingship as it was a consequence of the invention of Indian tradition due to the introduction of indirect rule by the postmutiny colonial state. As the policy of indirect rule of Indian princely states was introduced after the mutiny of 1857 , the colonial state decided to minimize its intervention in to what it saw as "native political and social order." ${ }^{29}$ The politics of indirect rule was based on a protectionist approach

${ }^{26}$ Traditionally, since the sixth century, the feudatory states were constituted by the establishment of foreign upper caste authority on the hinterlands. Often the origins of the ruling dynasty could be traced back to tribal origins but sovereignty was maintained through the establishment of Brahmanical authority on these areas. See Yaaminey Mubayi, Altar of Power: The Temple and the State in the Land of Faganath (New Delhi: Manohar, 2005), pp. 35-77.

${ }^{27}$ Rousseleau, "The King's Elder Brother", pp. 39-62.

${ }^{28}$ Burkhard Schnepel, "Durga and the King: Ethnohistorical Aspects of Politico-Ritual Life in a South Odishan Jungle Kingdom", fournal of the Royal Anthropological Institute 1, no. 1.(1995), pp. 145-66.

${ }^{29}$ For a discussion of the transition from the early liberalism of the East India Company to postmutiny traditionalism in the ideology of the colonial state, see Karuna Mantena, 
to "traditional" Indian political systems where Indian custom and tradition determined colonial interaction with princely states and other native political structures. While this was accompanied by essentialized notions of Indian rural life, it also produced efforts to define Indian customs of rule.

In Odisha, this resulted in two crucial moves by the colonial state. First, the princely states were notionally turned into states of exception with partial sovereignty over their domain and little intervention from the administrators of British Odisha. Second, it also resulted in the separation of the Puri Temple as well as the Gajapati King of Khurda from political power. ${ }^{30}$ Divine kingship became iconic rather than actual and was consigned to the private-religious experience of Odia Hindus while the political realm came to be inhabited exclusively by the British administrators and the native princes. No longer subjects of a religiopolitical hierarchy based on secular service to the divine, the Odia praja of the princely states as well as of British Odisha became private individuals with no access to the realm of the State.

Bhanja's statement that rajaniti consisted of governmental maintenance of law and order drew on this invention of tradition and was a direct product of the colonial state's policy towards the princely states of Odisha. In 1814, shortly after their conquest of Odisha, the colonial concerns about the administration of Princely states were guided by a liberal discomfort with princely misrule. To ensure the imperial mandate for good rule, a British official was appointed to each state who "unfettered by any precise rules might serve as a useful check on their conduct, and by obtaining a more accurate knowledge of the state of the country lay the foundations of an improved system of administration in the places in question." ${ }^{31}$ This interventionist attitude was considerably qualified by the late nineteenth century, when the British government granted new sanads to the Princely states to clarify the relationship between them. In a 1875 memorandum laying out the relationship between the British government and the princely states, we see that the remit of the British official posted in a princely state remained fairly wide but the status of the prince as the ruler came to be more rigorously protected. For instance, on the question of whether subjects of the princely states could sue their rulers, the memorandum was explicit that this should not be allowed as it would put the princes and their subjects on equal footing legally. According to the memoranda such a move ran

Alibis of Empire: Henry Maine and the Ends of Liberal Imperialism (Princeton, NJ: Princeton University Press, 2010).

${ }^{30}$ See Mubayi, Altar of Power.

${ }^{31}$ Extract of Judicial Letter from Bengal, dated November 29, 1814, in India Office Records, Board's Collections F/4/494/11899. 
counter to "the theory on which the sanads were based, namely, that he is the ruler of the state." "As the "chief is (within his powers) supreme," his authority "from the point of view of the subjects" should be "maintained intact." "33 The only caveat to this authority was the maintenance of just rule. To this end, the memorandum noted: "In maintaining in this way the dignity of the chief the principle must be recognized that the chief's dignity and privileges were dependent on this just, impartial and right administration of his state."

The resonances between these colonial stipulations of the rights and duties of the king and Bhanja's definition of rajaniti, the function of the raja and rights of the praja are clear. When Bhanja defined the limits of the Sammillani's activities he was drawing from his own experience of kingship and its remit. ${ }^{34}$ However, not only is his definition a very simplified version of Odia traditions of kingship, it did not account for contemporary discussions on sovereignty taking place outside colonial circles. For instance, we see that just a few years before Bhanja's speech, in 1897-98, articles on the meaning of rajaniti appeared in the Utkal Sahitya journal. In an essay titled "Rajaniti," Sadhucharan Rai unthreaded the relationship between raja and praja and, in this unthreading, endowed upon the praja a more modern characteristic of individual sovereignty. ${ }^{35}$ Rai's

${ }^{32}$ A memorandum prepared in 1875 , embodying a general sketch of the relations of the British government with the tributary mahals of Odisha, India Office Records R/2/286/ 8, p. 4

33 Ibid, p. 5.

${ }^{34}$ Bhanja Deo was the raja of the princely state of Mayurbhanj. The colonial career of this princely state as it transformed from a problem kingdom to a model one from the early to late nineteenth century illustrates the impact of colonialism on princely Odisha. Early nineteenth-century government reports commenting on mismanagement and exploitation of subjects illustrate that Mayurbhanj served as an important site for colonial intervention. However, by the late nineteenth century, we see that Mayurbhanj came to serve as important site for Odia literary and cultural activism, the state of Mayurbhanj was poised as a "model" kingdom complete with a monarchical constitutions, printing press, weekly newspapers, schools, and public works. See Ramaprasad Chanda, Selections from Official Letters and Records Relating to the History of Mayurbhanj (London: British Library, India Office Records, Board's Collections, IOR/F/4/494/11900, 1942). (Selected by Mr. Chanda. Synopsis prepared by Dr. Achyuta Kumar Mitra.) State Council (MAYURBHANJ), 1896. Regulations of the Mourbhanj State Council. [Compiled by Mohinimohana Dhara.] (Calcutta: Caledonian Steam Printing Works). "Oppressive and Violent Conduct by Several of the Rulers of the Orissa Tributary Mahals - Allegations against the Rajas of Mayurbhanj and Dhenkanal, etc., Vol . 2" (London: British Library, India Office Records, Board's Collections IOR/F/4/494/ 11900). Hence, when, at the turn of the twentieth century, the king of this kingdom describes rajaniti as ethics of rule and the praja as private individuals with access to the realm of the state, he was representing what was presented to him as the rites of good rule.

35 Sadhucharan Rai, "Rajaniti", Utkal Sahitya 1, no. 8 (1897): 193. Rai wrote regularly for the Utkal Sahitya in the early decades of the twentieth century. Not much is known about the particulars of his life because the journal did not introduce its contributors to its readers. 
formulation oscillated between a monarchical model and a model of politics resting on the balance between the sovereignty of the raja and that of the praja.

Building upon the notion of praja as progeny rather than subject, he suggested that rajaniti was based on a homology between the sovereign/ subject relationship and familial relationships. ${ }^{36}$ This formulation of rajaniti as management of family fits well into the Sammillani's understanding of rajaniti as governance. Rai wrote: "Raja is father, raja is mother, raja is brother, raja is teacher, and he is your closest friend. ${ }^{37} \mathrm{He}$ postulated that while the raja, like a father, could exercise his powers to discipline the praja, he should never abuse his powers. Furthermore, just as the mother comforted the child when he was punished, the raja, too, should protect the praja from excessive punishment. ${ }^{38}$ By enacting various familial and social relationships, the raja had to ensure that peace, brotherhood, and freedom among the praja was maintained. The raja here was more than just a figure of order, he was also a figure of conscience.

In this context, while the praja/subject depended on the raja for familial and social support, raja also required the support of the praja. In another essay entitled "Rajashakti O Prajashakti," Rai expanded on this interdependence between the raja and praja based on an economy of rajashakti (power of the raja) and prajashakti (power of the praja). ${ }^{39}$ Prajashakti, according to Rai, was the sum of all power that resides in all human beings. Rajashakti was the amalgam of all prajashakti. In an ideal situation, rajashakti and prajashakti would balance one another. A decrease in rajashakti could result in a people's revolution. An increase in prajashakti could lead to the establishment of democracy or prajatantra.

It could be inferred from Rai's discussion that neither revolution nor democracy was the ideal condition. In the ideal condition, the praja would be content with the regime of the raja. However, Rai's formulation of an ideal situation did account for the individual agency of the praja. He held that "every praja was a miniature raja." Thus, Rai argued, as long as the raja recognized this individual sovereignty, his sovereignty would remain unmolested. Clearly, for Rai the raja/praja relationship was based on a balance between individual sovereignty and the sovereignty of the ruler.

Two things should be noted about the "praja" in Rai's discussion. First, the praja here was understood as a subject under the protection of the raja.

${ }^{36}$ By subject in this case, I mean subject to the sovereign, As such, this understanding of subject is not the same as the subject as a being with consciousness and the ability to act. This is not to say that the subject-as-subject-to-sovereign is devoid of consciousness or action. Rather, that his/her very ability to act is limited by the terms of his/her subjection.

${ }^{37}$ Rai, "Rajaniti", $193 . \quad{ }^{38}$ Ibid.

39 Sadhucharan Rai, "Rajashakti O Prajashakti”, Utkal Sahitya 1, no. 10 (1897). 
By implicating the praja in a filial relationship with the raja, Rai invoked a traditional monarchical understanding of subjecthood where the praja's relationship with the state placed definite limits on his/her individual sovereignty; just as a child is free and self-determining only to the extent that the parent deems it fit. Paradoxically, and this is the second thing to be noted about Rai's praja: the praja also has individual sovereignty that is of fundamental importance to the stability of the raja/praja relationship and even rajaniti itself. When Rai argued that the each praja was a "small raja," the praja appeared in a completely different light. The argument that the raja/praja relationship depends on the balance between the sovereignty of the praja and that of the raja undermined the unquestionable control of the raja over the praja's destiny implied in the earlier idea of subjecthood. Even though this allusion to individual sovereignty does not invoke democracy, or at least the praja's participation in political activities, it opens the door to such possibilities. That is, the logic of individual sovereignty of the praja would ultimately lead to democracy or prajatantra. It is this ultimate possibility that Rai recoiled from when he wrote that in the ideal condition there should be neither rebellion nor democracy.

In both Bhanja's and Rai's framework, the praja's participation in governance remained suspect even as it repeatedly emerged as a possibility. It is in the limited case of their argument-the idea of rebellion-that this reluctance to envisage a politics of the praja emerges most clearly. Bhanja justifies the avoidance of politics within the Sammillani by arguing that good governance by the new English rajas makes the intervention of the praja into the affairs of state unnecessary. With this elaboration of the merits of the English raja, Bhanja Deo slips back into the language of the monarchical state in which the praja could only be a subject. For instance, he defined bad governance as rule where "the Rajas are selfish, and exploit their praja or are unable to protect their life and property." ${ }^{40}$ Bhanja Deo used instances from the Odia past, such as the period of Muslim and Maratha rule, to illustrate bad governance. By juxtaposing the establishment of rule of law and social stability during the British rule of Odisha, against his view of the political, social, and economic chaos of the Muslim and Maratha rule over Odisha, Bhanja Deo situated colonial rule within the matrix of existing political networks. ${ }^{41}$ The British colonial government could be seen as just another player in an already existing hierarchical political field and not necessarily an alien or colonial force. As rajaniti was defined as the ethics of governance, the changing identity of the ruler did not affect the concept of the political. Thus, this ambivalence about the identity of the ruler in

${ }^{40}$ Ibid, $65 . \quad{ }^{41}$ Ibid, 66. 
Bhanja Deo's definition of rajaniti allowed the leadership of the Utkal Sammillani to accommodate colonial rule in an existing political matrix.

Bhanja Deo's attempt to avoid politics by arguing that the British are good rajas, involves a double move that subverts the very purpose that it attempts to accomplish. On the one hand, there is an attempt to see the British as just another raja. On the other hand, in insisting that the praja stay out of politics, he uses a novel argument: that the praja can stay out of the political sphere because the government is being run properly. It is the converse of this statement that threatens to subvert his effort to foreclose on popular politics. The converse of his argument is that the praja need not stay out if the government is not running properly. By arguing that as long as the raja was fulfilling his responsibilities, the praja can abstain from politics, Bhanja Deo was providing for a possibility that a situation may arise when the praja could be a political actor. Thus, even as he asserted the older notion of raja and rajaniti, he smuggled in new notions of rule despite himself.

After establishing the efficacy of British rule over Odisha, Bhanja Deo argued that since peace and stability had been instituted by the British, it was time to "repair the losses suffered by the country due to many centuries of misrule." This was the function of an organization like the Utkal Sammillani. He proclaimed that the primary aims of the Utkal Sammillani would be to provide a common platform for the Odiaspeaking people living in different British provinces, to increase national wealth through supporting industrial growth, to promote the spread of education among the people, to support development of Odia language and literature, and to bring about social reform. Thus, the Utkal Sammillani was imagined as a social, economic, and cultural organization that represented all the Odia-speaking people.

In Bhanja Deo's explicit formulations, the constituency of the Utkal Sammillani was the Odia praja of the English rajas. The creation of the category of the Odia-speaking people as a distinct community was a necessary precondition for the institution of the Utkal Sammillani. As the last two chapters have illustrated, such an Odia public had already been imagined in the emergent but limited urban Odia public sphere and this imagined category carried within it the rudiments of a political community. The Odia praja that the Sammillani represented was already marked by a shared culture and language. This community based on language and culture was very different from Bhanja's formulation of a raja-praja relationship where all that defined the praja was that it was the subject. Here, ironically, the praja was more than a subject. The praja, while being bound together as a community by its subjection to colonial rule, was also interconnected by a preexisting cultural movement. 
By juxtaposing the Odia community and praja as subject, the Utkal Sammillani leadership redefined the "praja" as more than subject to a royal king. Praja now was marked by linguistic and cultural interests that were not within the governing responsibilities of the English raja. This community of interests bound the praja in connections that were not entirely mediated by the colonial state. Consequently, the very presence of Utkal Sammillani as a sociocultural organization outside the influence of the colonial state provided a possibility for the praja to explore his/her individual potential without limits posed by the colonial state. Furthermore, once the existence of such as praja was conceived, the possibility arose that this praja could practice a politics through a disagreement with the raja over questions of rule. This, in turn, could lead to a scenario where the praja could claim as praja some authority in the system of governance. It is this possibility that made Bhanja Deo anxious because by invoking the praja, the Sammillani was already laying claim to politics. Even though Bhanja Deo used the term praja to ensure that the constituency of the Utkal Sammillani remained apolitical and loyal to the colonial state, his very justification for the distancing of the praja from politics smuggled in the possibility of political activity by the praja.

\section{A New Politics: Prajaniti for the Praja (1903-1918)}

Even as the denial of politics in early Sammillani rhetoric raised the specter of a politics for the colonized in spite of its explicit efforts, the question of politics remained a highly contentious issue in the Odia public sphere. At every annual meeting of the organization, political activism was consistently disavowed. ${ }^{42}$ However, as the Swadeshi agitation against the partition of Bengal gained ground in the first decade of the twentieth century, the Sammillani's apolitical stand became increasingly untenable. As the Swadeshi movement linked political opposition to colonial rule with economic self-sufficiency and boycott of British goods in the interest of fostering Indian industry, the Sammillani's neat separation of the political and the socioeconomic threatened to break down. In this section, I will explore the public discussions surrounding the Sammillani's disavowal of politics, the attempts by the leaders of the organization to resolve the ensuing crisis by proposing an alternative politics of the colonized called prajaniti and the eventual critique of the separation of the political and social that led to the fall of the organization.

In its initial years as a pan-Odia organization, the Sammillani's decision to focus on the social and economic development of the community

${ }^{42}$ Das, Utkal Sammillani, pp. 121, 135, 160. 
without participating in political activity was celebrated by the Odia as well as Bengali press. In May 1904, an Odia newspaper carried an editorial in which the author congratulated the Odia leadership for pursuing "such a noble cause instead of clamouring in impotence for political privileges." "43 This positive view of the Sammillani was strengthened by the efforts of the organization to deepen its reach into Odia-speaking areas in British Odisha as well as the princely states. By January 1905, little over a year after its establishment, the organization had 381 branches in Odiaspeaking areas. ${ }^{44}$ By the time the antipartition movement began in Bengal in 1905, the Sammillani was seen as the primary representative association of all Odia people. The 1908, the Swadeshi movement's critique of colonial government threw the Sammillani's apolitical stance into question. Newspaper reports reveal that, initially, Odia community organizations everywhere supported the Swadeshi movement. Even the Jaganath Temple chose to boycott foreign cloth and other goods in its ritual practices. The Puri branch of the Sammillani convinced the local marwari traders to carry locally produced goods. ${ }^{45}$ However, in a few months, we see an increasing disaffection towards the antipartition movement in the Odia media. Loyalist newspapers, including the Star of Utkal, exhorted readers to distinguish between the antipartition movement and the Swadeshi movement. While the Swadeshi movement was "against the laws of political economy and would not survive for long," the antipartition politics was a legitimate grievance of the "civilized Bengalis" who should be given the same consideration as the "kols," the "Santhals" and the "negroes" by the British government. ${ }^{46}$ In the more liberal newspapers, this attitude is reversed. For instance, the Sambalpur Hiteisini argued that the Odias should support the Swadeshi movement but avoid the antipartition aspect of the movement because Odia activism "should be positive and not anti-British." 47 Meanwhile, the Sammillani leadership supported the boycott of foreign goods and campaigned for it in various places. However, by 1908, we see a stark change in the

${ }^{43}$ Udia O Navasambada, May 4, 1904, in Bengal (India). "Report on Native Papers in Bengal for the Week Ending 8th May 1904" (Calcutta): Bengali Translator's Office, 1904).

${ }^{44}$ Udia O Navasambada, January 25, 1904, in Bengal (India). "Report on Native Papers in Bengal for the Week Ending 30th January 1905" (Calcutta: Bengali Translator's Office. 1905).

${ }^{45}$ Utkal Dipika, October 8, 1904, in Bengal (India). "Report on Native Papers in Bengal for the Week Ending 2nd November 1904" (Calcutta: Bengali Translator's Office, 1904).

46 September 9, 1905, in Bengal (India), "Report on Native Papers in Bengal for the Week Ending 5th October 1905" (Calcutta: Bengali Translator's Office, 1905).

47 Sambalpur Hiteisini, February 10, 1906, in Bengal (India), "Report on Native Papers in Bengal for the Week Ending 27th February 1906" (Calcutta: Bengali Translator's Office, 1905). 
organization's attitude towards the movement. As mentioned earlier, the most ubiquitous feature of the movement, the nationalist song - Vande Mataram - was banned from the Sammillani platform. This move opened the leadership of the organization to criticism as they were called a "handful of sycophants" who had shown no solidarity with the Indian National Congress. ${ }^{48}$ The liberal leadership of the organization, headed by Madhusudan Das, responded by arguing that political reform should be gained by "moral not physical force." 49

While the banning of Vande Mataram caused controversy, the Odisha famine of 1908 coupled with the government's plans to conduct survey exercises for revenue settlement at a time of scarcity forced the organization into an untenable position. Newspapers of both loyalist and liberal bend such as Nilachal Samachar, Sambada Vahika, Gadajat Basini, and Utkal Dipika exhorted the Sammillani to "show their practical usefulness as a representative organization by doing something substantial to relieve the distress in Odisha." "These arguments were often linked with an economic critique of colonial rule. ${ }^{51} \mathrm{Within}$ the context of the antipartition Swadeshi movement that conflated economic concerns with radical anticolonial politics, it became impossible for the Sammillani to pose demands for economic support while still sustaining its apolitical stance.

This conundrum led the founding member of the Sammillani, Madhusudan Das, to propose an alternative politics that would enable the Odia people to ask for economic rights without demanding political rights. Madhusudan Das (1848-1934) was one of the most influential figures in the Odia public sphere of the late nineteenth and early twentieth centuries. Educated as a lawyer in Calcutta, he served as the Odia translator to the government of India, a member of the legislative council, as member of the Odisha Association (established 1882) and a founding member of the Utkal Sammillani. Das rose to fame early in his career when he successfully represented the Queen of Puri in her lawsuit

${ }^{48}$ Acharya, National Movement, pp. 33-4.

${ }^{49}$ Utkal Dipika, January 18, 1908, in Bengal (India), "Report on Native Papers in Bengal for the Week Ending 22nd February 1908” (Calcutta: Bengali Translator's Office, 1908).

50 Gadajat Basini, February 8, 1908, in Bengal (India), "Report on Native Papers in Bengal for the Week Ending 21st March 1908" (Calcutta: Bengali Translator's Office, 1908).

${ }^{51}$ For instance, Sambad Vahika noted that "notwithstanding the many blessings which the British rule in India have conferred on the Indians, they are growing poorer day by day, their resources are being more and more exhausted and they are falling victims to malaria, cholera, famine and plague, which are decimating people by the thousands. The Indian has to pay a heavy tax which leaves nothing for him to eat. Indigenous industries have been destroyed by foreign competition while famine has become chronic."Sambad Vahika, February 20, 1908, in Bengal (India), "Report on Native Papers in Bengal for the Week Ending 21st March 1908” (Calcutta: Bengali Translator's Office,1908). 
opposing the implementation of the Puri Temple Act of 1880 . He dominated the Utkal Sammillani platform for most of the organization's active life.

In his essay, "Utkal Sammillani", published in the Utkal Sahitya journal in 1908, Das argued that politics was not necessary for the development of the community because:

What would a conquered jati achieve by discussing rajaniti? ... Why will the conquerors listen to us if, as has been noticed elsewhere, we go around critiquing them $?^{52}$

Implicit here is an echo of Bhanja Deo's argument that the praja have no say in the realm of governance. However, while Bhanja Deo had suggested that the British were just another ruler in a long list of rulers, Das' use of the term "conquered" gestures at a departure from the Sammillani's notion of rajaniti as an economy of rule between the raja and the praja. This recognition that British rule was not simply any rule but a colonial rule also changed the nature of praja - not simply praja but a colonized praja. However, despite this nod to contemporary critiques of colonial rule in Odisha and elsewhere, Das' subsequent discussion shies away from any radical anticolonial propositions.

He conceded to the critics of the Sammillani that the exclusion of politics limited the organization's effectiveness. By breaking down the community's development or unnati into the unnati of dharma (ethical goodness), mokhsha (spiritual transcendence), kama (pleasure) and artha (wealth and power), Das argued that the exclusion of religious and political discussion resulted in an inability to develop fully on any of these registers. This reference to the four purushrathas is revealing. In classical Indian political tradition, the objective of the science of politics or Danda niti was to "create the cultural conditions necessary for the pursuit of the four great ends of life: the purushrathas." ${ }^{53}$ By invoking this, Das effectively marked the parameters of his intervention as squarely within the science of politics. This again is a departure from the early Sammillani discussion. While Bhanja Deo's definition of rajaniti as ethics of rule effectively precluded any discussion of politics, thinking about the science of politics and the attainment of purushrathas opened the door to alternative definitions of rajaniti. In his pursuit of the four purusharthas, Das suggested that the Sammillani should allow for a partial inclusion of politics. He defined this partial politics as follows:

52 M. S. Das, "Utkal Sammillani”, Utkal Sahitya 11, no. 3 (1908): 63.

53 Anthony J. Parel, "Gandhi and the Emergence of the Modern Indian Political Canon", Review of Politics 70 (2008): 41. 
Praising and pointing out our problems rather than critiquing is our need of the hour ... Such praxis is part of Rajaniti and it would be more appropriate to call it Prajaniti. The Sammillani often neglects this prajaniti because it confuses prajaniti with rajaniti. ${ }^{54}$

This prajaniti belonged to an entirely different sphere of activity than that of rajaniti. Das argued that it was crucial for the interest of the raja as well as the praja to make this distinction clear and avoid any encroachment of one on the other. Not simply limited to praising the government, the rest of Das' essay laid out a manifesto for a praxis of prajaniti. This praxis was centered on community education. According to Das, the Sammillani had to identify and educate the Odia people about:

What self-interest is not at odds with the community's interest and that, whatever is against the interests of the community is not in the interest of the individual. We should identify the tasks that are in the interest of this province of India, but not against the interests of India and how are they to be achieved. In the present condition which of these tasks can be counted among our commonly held desires and which of these is it within our powers to achieve. Basically, what is the identity and responsibility of every individual, every family, every village and the whole Odia province ${ }^{55}$ (emphasis added)

Thus the function of the Sammillani, according to Das, was to educate the Odia people in the ethics of communal life. The Sammillani had to identify and balance the interests of the individual, Odia community, and the Indian nation. In balancing these interests, Das posed a regional politics that was informed by both local and national concerns.

In this economy of interests, Das ascribed to the Sammillani a conceptual task. The actual task of development of the Odia condition, such as the establishment of schools, local hospitals, or cooperative banks was to be carried out by the rural organizations or Gramya Samitis set up by the Utkal Sammillani. The Sammillani itself was to clarify conceptual issues about community building and ensure that the Gramya Samitis acted in accordance with the interests of the Odia region and the Indian nation. Since Das argued that the activity of the Utkal Sammillani as well as that of the Gramya Samitis was prajaniti, two types of praja emerge here. The Utkal Sammillani as praja ascribed to itself the position of the vanguard while the Gramya Samitis as praja were to be instructed by this vanguard in the rites of citizenship.

In Das' rejection and refiguration of Rajaniti, the stakes of rajaniti emerged clearly. In accommodating critiques of the Utkal Sammillani's political standing while maintaining the Sammillani's distance from politics, Das' formulation of a politics of the colonized praja proposed

${ }^{54}$ Das, p. $63 . \quad{ }^{55}$ Das, Utkal Sammillani, p. 65. 
a number of radical shifts in the understanding of subjecthood. While arguing the separation of the praja from rajaniti be maintained, his invocation of purusharthas as development towards the four crucial ends of life and insistence on education as the centre of community activism suggests a fundamentally liberal understanding of subjecthood - liberal but Indian. This avowal of partial citizenship and politics despite profound discomfort with the idea of popular politics was due to Das' realization that acting in the interests of a community essentially involved political activity. What Das failed to address is how the Odia community could be emancipated without opposition to the colonial state whose interests did not coincide with that of the Odia community.

This question of the opposition between the interests of the colonial state and that of the colonized animated the activism of younger members of the Sammillani. For instance, in an essay entitled "Samaja Sanskara o Rajaniti", an anonymous author argued that "a community's politics influences and constitutes its social life in as much as it is influenced and constituted by the community's social life." ${ }^{56}$ From 1908 onwards, the primary critics of the Sammillani were members of student organizations like Bharati Mandir and the younger members of the Sammillani itself. Young students and lawyers such as Gopabandhu Das, Harekrushna Mahtab, Nabakrushna Chaoudhury, Nilakantha Das, Godavarish Mishra, Lakhshminarayan Sahu, and Jagabandhu Singh disagreed with the Sammillani's positive attitude towards the colonial state. Over the next two decades, many of these men came to play a significant role in anticolonial politics in Odisha. Prominent among the opponents of the Utkal Sammillani were Gopabandhu Das, Nilakantha Das, Godavaris Mishra, Krupasindhu Mishra, and Harihara Mishra. Together they came to be called the Satyabadi group named after the Satyabadi School set up by Gopabandhu Das in 1909. This school came to symbolize anticolonial nationalism in Odisha. Through their educational activities, the Satyabadi group was engaged in social reform projects that exposed them to the day-to-day realities of the common Odia people. The politics of the Satyabadi group emerged from an understanding of the people as oppressed and disenfranchised under colonial rule. The Utkal Sammillani's formulation of "praja" as passive receptors of good governance did not speak to the ground realities as witnessed by the Satyabadi group. ${ }^{57}$

56 Anonymous, "Samaja Sanskara O Rajaniti”, Utkal Sahitya 11, no. 4 (1908), 14.

57 For more details, see Nivedita Mohanty, Odia Nationalism: Quest for a United Odisha, 1866-1936, pp. 85-93. 
By the end of the first decade of the twentieth century, two perspectives on political participation by the colonized circulated in Odisha. In arguments for the Sammillani's apolitical stance we see that any participation in politics is seen as "impotent" and sometimes as a self-indulgent, elite pastime. ${ }^{58}$ In arguments against the Sammillani's stance, politics is seen as essential to the amelioration of economic problems that plagued common Odias. As such antipolitical arguments saw the practice of politics as a betrayal of popular interests that could only be served by an elite alliance with the colonial state. In contrast, propolitical arguments during the Swadeshi movement held that without political rights for the colonized, popular economic interests could never be met. ${ }^{59}$ Despite this opposition, both sides shared a common understanding that proper politics was possible only if the colonized shared equal political rights as the colonizers. Therefore, political agitation was impotent because the Odias were not on a par with the British. And yet, it was necessary precisely because equal political rights had to be gained by the colonized. In this framework, the leaders of the Sammillani as well as the emerging radical leadership had to engage with the conflict between regional and national interests. Much like other minority politics, regional agendas worked on a principle of colonial appeasement and a need to seek state protection against more dominant national interests. Both these concerns, about the lack of political sovereignty and the anxiety about balancing the interests of the region and the nation, became much more significant with the introduction of a wider franchise in 1918 through the Montagu-Chelmsford reforms.

\section{A Magna Carta for India: Constitutional Reforms of 1918-19 and the Emergence of Liberal Citizenship in India}

The introduction of a wider franchise in 1918 precipitated a rethinking of the relationship between the ruler and ruled in India. It also resulted in what I would call the "regionalization" of Indian national politics. The system of diarchy instituted by the Government of India Act of 1919 involved the introduction of wider elections, which established a system

${ }^{58}$ For instance, in a 1914 article published in the weekly $A s h a$, the editor noted: "But if educated men sit down and simply make a spectral analysis of politics then they will be possessed by the devilish politics ever more." In Unknown, "Politics and the Uriyas", Asha, March 13, 1914.

59 See for instance, Anonymous, "Bharatare Rajanitik Andolana", Utkal Sahitya 9, no. 3 (1905). Invoking the examples of Britain, Germany, and Japan, the author argued that these nations are advanced because: "Rajashakti was allied with the prajashakti." In India, on the contrary, the British raja's interests were diametrically opposed to those of the praja. 
of dual governmental responsibility between a popularly elected provincial government and the central government under the Governor General of India. The need to demarcate constituencies and assign representation to various elements of Indian society required the colonial government to take regional public opinion into account. Consequently, the reforms involved a systematic accounting of linguistic communities in India and language became one of the most important factors in determining representation in future elections. As regional identity movements had come to be based on language by the early twentieth century, the idea of Indian franchise and representation came to be informed by a system of classification that was based on linguistic regions.

With the emergence of a more popular franchise and increased awareness of the need for a broader popular base in both regional and national organizations, the colonial government, Indian National Congress, and the Utkal Sammillani had to conceptualize subaltern political participation. The argument here is about neither elite politics nor subaltern politics. Rather, it is an attempt to elaborate on the way in which the elite thought about the absorption of the non-elite into the realm of the political. Appealing to regional linguistic interests and using regional languages in all-India nationalist political praxis was the most effective means of enabling a broader base for both the regional and national political organizations. Hence, I argue that this need to create a political community that would reach beyond the elite produced the paradoxical concept of the Indian citizen who was marked by particular regional linguistic identities.

The emergence of colonial citizenship required a reformulation of the notion of rule or rajya in colonial India, which would make way for the participation of Indian subjects in British reign in matters of government. Thus, this section traces changes in the understanding of "rule" or rajya through a reading of political discussions both within and outside Odisha that argued for a broadening of politics and the inclusion of the "masses" in political agitation in India. It is in this shift in the meaning of rule in 1918-1919 that the roots of the change in the attitude of the Utkal Sammillani's politics lay.

In the years preceding the 1918 reforms, Indian leadership as well as the colonial government in India became increasingly entangled in the ongoing global move towards self-determination. The growing emphasis on the "consent of the governed" in the Wilsonian moment in world politics coupled with the commitments made by the colonial government to the Indian leadership in return for native support in the Great War compelled the British government to "endow India ... with the largest measure of self-government compatible with the maintenance of the 
supremacy of British rule." 60 In their response to Wilson's arguments for self-determination of races, the Indian political leadership came to deploy Wilson and his speeches as a propaganda tool against the colonial government. For instance, shortly before her arrest for sedition in 1917, Annie Besant distributed copies of Wilson's war message in aid of the Indian Home Rule movement. ${ }^{61}$ The impact of World War I on Indian politics also produced profound changes in the attitude of the Indian leadership. Their excitement about Indian participation in the war effort as a means to achieve parity of citizenship with European British subjects as well as the rapid growth of Indian manufacturing to make up for British goods that had disappeared from local markets encouraged a reappraisal of the relationship between the British and their Indian subjects. In 1916, the Indian Home Rule league led by Annie Besant and Bal Gangadhar Tilak elaborated a detailed argument for self-governance that fell just shy of a demand for complete independence.

Tilak's home rule speeches from 1916 to 1918 reveal how the demand for home rule was founded on a careful reinterpretation of rajya or rule as it shifted away from the domain of the raja and was transformed into a category tenuously linked to popular will. By translating home rule as swarajya, Tilak argued that, rather than demanding the removal of British sovereignty, the demand for swaraj was seeking to achieve the right of Indians to govern their home. ${ }^{62}$ Taking care not to argue against the continuance of colonial rule, Tilak suggested that swarajya entailed a qualified idea of self-rule. Hence, even though the utterance of swarajya invokes the existence of "some kind of rule opposed to swa, i.e. our," this opposition is not necessarily about the alienness of the ruler's race. ${ }^{63}$ That is, he argued elsewhere, the contemporary government of India was not alien because it was British but because the British colonial government did not do its duty as King:

The King's duty is to do all things whereby the nation may become eminent, be benefited, rise and become the equal of other nations. That King who does this duty is not alien. He is to be considered alien, who does not do this duty, but looks

60 This language was included in a proposal introduced in the Executive Council of the Colonial government in 1916. Richard Danzing, "The Announcement of August 20th, 1917", Fournal of Asian Studies 28, no. 1 (1968), 20.

${ }^{61}$ Erez Manela, Wilsonian Moment: Self Determination and the International Origins of Anticolonial Nationalism (New York: Oxford University Press, 2007), p. 78.

${ }^{62}$ By invoking "home" as self (the swa of swarjya), Tilak also invoked the "world." As Partha Chatterjee has established, the late nineteenth and early twentieth centuries' Indian political and social rhetoric made use of the tropes of home and the world to establish boundaries between the domain of activity of the Indian people and that of the British government.

${ }^{63}$ B. G. Tilak, Lok Tilak's Speeches on Home Rule (Banares: Yoda Press, 1917), p. 3. 
only to his own benefit, to the benefit of his own race and to the benefit of his own country. ${ }^{64}$

By avoiding the question of the alienness of British rule, Tilak posed an idea of self-rule that was divorced from any implication of nativist Indian sovereignty. To underline this separation, he punctuated the rest of his speech with the refrain "the question of swarajya is not about the emperor." Swarajya was not about the emperor because the emperor represented an "invisible sentiment" that was different from the "visible administrative arm of the state." 65 As such, demanding swarajya by questioning the right of the visible administration to "manage" India was not sedition or rajyadroha. In the era of swarajya, he argued:

The Emperor still remains. The difference would be that the white servant who was with him would be replaced by a black servant. [Cheers] From whom then does this opposition come from? This opposition comes from those people who are in power. It does not come from the Emperor. From the Emperor's point of view there is neither anarchy not want of loyalty, no sedition in this. What does Rajadroha (sedition) mean? Hatred of the King. Does the King mean a police sepoy? ... you will see that the demand made by us is right, proper, just and comfortable to human nature. ${ }^{66}$

While it can argued that Tilak's care to illustrate that the demand for swarajya was not sedition was a strategic move to avoid prosecution by the colonial government and to assure his listeners that their support of the movement could not be seditious. By arguing that the demand for swarajya was proper to human nature, Tilak envisioned an Indian subject who was not only entitled to express dissent but this expression was essential to proper rule. This was clearly a radical departure from existing loyalist perspectives on popular dissent like those prevailing in elite organizations in Odisha where any opposition to the colonial state was seen as an illicit encroachment into the realm of the political.

This changing relationship between the subject and the sovereign in British India was also a major concern for the planners of the constitutional reforms of 1918-1919. The Montague Declaration of August 1917 proclaimed the intention of the government to work towards "the increasing association of Indians in every branch of the administration and the gradual development of self-governing institutions with a view to the progressive realization of responsible government in India as an integral part of the British empire." 67 The reforms of 1919 were the enactment of

${ }^{64}$ Ibid, p. $6 . \quad{ }^{65}$ Ibid, p. $4 . \quad{ }^{66}$ Ibid, p. 21.

${ }^{67}$ Great Britain India Office and India Governor-General (1916-1921: Chelmsford), Report on Indian Constitutional Reforms (Calcutta: Superintendent's Government Printing, 1918). 
this governmental policy to institute responsible government based on popular elections. In keeping with the spirit of the declaration, the reforms introduced two major changes to the existing form of government in India. First, the reforms introduced the idea of direct election that was based on limited popular franchise. Hitherto, a system of indirect elections was used to enable Indian representatives to be members of the Indian Legislative Council and the Provincial Legislative councils based on a very narrow franchise. ${ }^{68}$ Second, a system of diarchy where the responsibility for the governance of British India was shared between a partially elected central government and the provincial government was introduced. The Southborough committee set up to investigate the eligibility criteria for franchise and categorization of the Indian electorate into constituencies suggested that franchise be based on territorial constituencies within each province. This provincial and territorial classification of the new Indian electorate created a new citizen who was not simply a potential voter but who was also a subject marked by regional or provincial identity.

The report on the Indian constitutional reforms suggests that the drafters of the reforms were chiefly concerned with the need to educate the rural Indian masses in a "sense of citizenship" as the proposed changes threatened to cause "the most radical revolution in the people's traditional ideas in India." ${ }^{\circ 9}$ The report noted that unlike in the past, when the Indian peasant placed his "faith" in the government official to represent his interests, he now had to be much more actively involved in governance as he had the "power to compel" the attention of the person he chose as his representative. ${ }^{70}$ Coupled with this language of radical

68 The preexisting system of indirect elections is explained in the Report on Constitutional Reforms in a discussion about the limitations of the existing system. The report notes: "The chief of these are the very restricted nature of the present franchise, and except in the constituencies composed on the member of some special class or community, the lack of any real connection between the primary voter and the member who sits in the councils. In the Indian Legislative Council there are eighteen members who are elected to speak for sectional interests, and nine who may be said to represent, however remotely, the views of the people as a whole. So far as can be stated the largest constituency which returns a member directly to the Indian Legislative Council does not exceed 650 persons; and most of the constituencies are decidedly smaller. The constituencies which return the nine representatives of the people at large are composed of the nonofficial members of the various provincial legislative councils, and the average number of voters in these electoral bodies is only twenty two, while in one case the actual number is nine. In the case of the provincial councils themselves there is the same division of members between those who are directly elected to represent special interests and those who are elected indirectly as the representatives of the general population. For the latter the members of the municipal and local boards either acted as electors or chose electoral delegates to make the election; but in neither cases do the constituencies exceed a few hundred persons”, in ibid, p. 53.

${ }^{69}$ Ibid, p. $87 .{ }^{70}$ Ibid, p. 87. 
change was a language of protection in relation to the Indian rural population. As the report discussed the political preparedness of the Indian population, concerns about the possible exploitation of the "Indian ryots" by "people who are stronger and cleverer that he is" served as ground for the colonial state to "retain power to protect him." ${ }^{71}$ While these concerns about political unfitness and its associated dangers can rightly be read as a means to halt Indian progression towards complete self-governance, the report reveals (along with Tilak's notion of swarajya) a moment of profound rupture in the way both the colonial officials and the Indian political elite read the relationship between the sovereign British government and its colonized Indian subjects.

This moment of rupture is particularly important because it was the beginning of one of the most enduring preoccupations of Indian nationalist as well as postcolonial politics - the politicization of the Indian masses. It is in this context that the use of the vernacular also became important in politics for both the colonial government that was trying to introduce representative government and the Indian political elite of the Indian National Congress that was trying to rouse the masses to join the struggle for self-determination. Later in the chapter, I will be illustrating how there was an increasing realization within the ranks of the Indian National Congress that a common national political agenda could not be propagated throughout India without recourse to vernacular languages. While English served as a lingua franca for the urban English educated elite of the Indian provinces, the majority of the Indian population used the local vernacular for public communication. As was illustrated in Chapter 2, the vernacular public sphere was fairly well developed by the 1920s and could effectively serve the interests of panIndian nationalism.

In Odisha, these shifts occasioned a break from the earlier avoidance of political discussion within the Utkal Sammillani. A special session of the Sammillani met in August 1918 with the express objective of critiquing the proposed constitutional reforms. As president of the session, Madhusudan Das made a speech on Odia objections to the proposed reforms. Even as he set out to critique the government, Das placed his discussion squarely within the earlier economy of rule between the British raja and the Odia praja, by posing the August 1917 Montagu declaration as an Indian Magna Carta. What distinguished the 1917 declaration from its medieval English predecessor was that while the latter was introduced by a king "who had no sympathy with the aspirations of the people," the former was the "free gift of a constitutional monarch" to protect the "just

${ }^{71}$ Ibid, p. 99. 
and legitimate rights of the people." 72 By framing the reforms as an Indian Magna Carta, Das was able to sustain an idea of sovereignty rooted in the British emperor and account for the emergence of a new kind of politics in India where the Indian people were laying stake on governance.

Das' speech also reveals the impact of the reforms on the manner in which the political geography of India came to be envisioned in the subsequent years. Much of his speech was devoted to the implications of the suggestions for the reorganization of the provinces on linguistic grounds in the report on the constitutional reforms. ${ }^{73}$ In discussing these suggestions, M. S. Das addressed the report's concerns about the need to gradually politicize the rural Indian population by underlining the importance of linguistically homogenous provinces for the effective politicization of the people. He explicitly linked the question of redistribution of British Indian territories on linguistic lines with the reform objectives by connecting language with access to citizenship. While Das applauded the report's allusion to the need for reorganization of provincial boundaries, he took issue with the implicit deferral of any actual state action to that end. In the rest of his speech he made a forceful argument for the reorganization of Indian provinces on linguistic lines based on the claim that the government's efforts to institute political reforms would come to naught if provinces were not linguistically homogenous.

By introducing the idea of "intermediary ruling classes," Das attempted to prove that in linguistically heterogeneous provinces such as Bihar and Odisha and the Bengal Presidency, the speakers of minority language were at a great disadvantage in the new atmosphere of representative government. Instead of introducing limited self-governance through the institution of provincial autonomy, the reforms would put in place an intermediary ruling class of Biharis and Bengali who were in a majority in the aforementioned provinces. As Odias were a minority in both provinces, they would be assigned a fewer number of representatives to both the Bihar and Odisha and Bengal provincial legislatures. This, in turn, would mean that the Odia would not have an equal say in matters of government and hence would not enjoy a true measure of self-rule. Das emphasized that this lack of self-rule for the Odias and the institution of "intermediary ruling classes" would both mar the "sisterhood of Indian states in the future" and jeopardize Odia loyalty to the British Empire.

National consciousness and self-esteem ought to develop into national pride and sustain the spirit of sacrifice. Realization of the responsibilities, which the new

${ }^{72}$ Reprinted in Debendra Kumar Das, Utkal Sammillani (1903-1936), p. 423.

${ }^{73}$ Report on Indian Constitutional Reforms, pp. 148-9, 158-9. 
atmosphere has given birth to, is an impossibility without the growth of the national consciousness. Allow a group of people to occupy the position of an intermediary ruling race and you store up trouble for the future from the dominant race and deprive the empire of loyal support from another race. Allow one race to exercise a dominant influence over another and you mar the glorious picture of a sister-hood of states in India of the future. ${ }^{74}$

By entangling national consciousness, responsibility and the notion of intermediary ruling races, Das made a case for the recognition of Odias as a separate political constituency that could only have representation through the formation of a linguistically organized Odia province. This recognition, Das argued was crucial for the life of the Empire as well as that of the emerging Indian nation as a sisterhood of states. By stressing the link between language and access to self-rule, Das was arguing for the recognition of the regional nature of the emergent citizen in India. Hence, for both the framers of the constitutional reforms of 1918 and the Utkal Sammillani, the reforms were about the introduction of a new kind of relationship between the colonial state and the Indian people. Furthermore, this relationship was marked by an idea of a regional citizen based on a regional electoral constituency. This is particularly reflected in M. S. Das' formulation of "intermediary ruling races," which emphasized self-rule through a demarcation of distinct "racially" differentiated regions.

\section{Speaking to the Heart of the People: Indian National Congress Policy on Regional Languages and Linguistic Politics}

The introduction of constitutional reforms coincided with a shift in the policy of the Indian National Congress towards linguistic politics in India. At the national level, this acknowledgement of regional linguistic politics occasioned a reimagining of the Indian nation as a conglomeration of linguistically diverse regions. It was in this period (1918-1920) that the metonymic relationship between linguistically diverse regions and the unified Indian nation was established. This section will trace the prehistory of this moment and also illustrate how this new idea of the Indian nation enabled an elision of other more pressing registers of difference particularly the Hindu/Muslim question. Two important themes will be dealt with in this section - the curious relationship between the Congress attitude towards language and the organization's engagement with the problem of Hindu/Muslim communalism and the realization within

${ }^{74}$ Ibid, p. 433. 
Congress that its objective of the politicization of the Indian masses was impossible without the use of vernacular languages.

Language became an important issue on the Congress platform in 1903 when the British government published plans to partition the massive Bengal Presidency into two halves. Bengali Muslims were a majority in the proposed East Bengal province and Bengali Hindus were a majority in the new western half. The proposals for the partition of Bengal led to the first mass-based public demonstrations against the policies of the colonial government - the Swadeshi movement of 1908. While the Swadeshi movement figures as a major landmark in the history of anticolonial nationalism in India, the partition of Bengal played a pivotal role in two other histories in early Indian nationalism in the history of communalism in India and that of the Congress attitude towards language in national politics. In 1903, after the plans for the partition of Bengal were made public, the Congress met for its major annual meeting in Madras and severely criticized what its leaders saw as the government's efforts to create dissention among the "Bengali speaking brethren" on religious grounds. ${ }^{75}$ Here, the linguistic community of the Bengali-speaking people was privileged over the actual religious communities that the Bengali-speaking people belonged to. Paradoxically, this acknowledgement of the linguistic identity of the Bengali people involved an argument for the retention of existing political boundaries of British Indian provinces in general. This argument entailed an opposition to other plans for rearranging regional boundaries that would unite other linguistic communities in India. In particular, the Congress resolutions in Madras criticized not only the partition of Bengal but also the proposals of the Risley circular, which called for the amalgamation of the Odia-speaking tracts including the Ganjam district of the Madras Presidency under a single administration. ${ }^{76}$ Criticizing all government efforts to rearrange provincial boundaries the Congress in Madras stated:

Resolved that the Congress views with deep concern the present policy of the Government of India in breaking up territorial divisions which have been of long standing and are closely united by ethnological, legislative, social and administrative regulations and deprecates the separation from Bengal of Dacca, Mymensingh, Chittagong Divisions and portions of Chotanagpur Division, and

75 This language of "Bengali speaking brethren" recurs in the Congress discourse about the partition of Bengal. See A. M. Zaidi and S. G. Zaidi, "On the Road to Self-Government", in Encyclopaedia of the Indian National Congress, Vol. 4: 1901-1905 (New Delhi: S. Chand \& Company Ltd, 1978).

${ }^{76}$ For an account of the Risley circular see Pradhan and Pattnaik, The Odia Movement. 
also the separation of the district of Ganjam and the agency tracts of the Ganjam and Vizagapatnam Districts from the Madras Presidency. ${ }^{77}$

This contradictory resolution that questioned both the government's efforts to divide the Bengali linguistic community and unite the Odia linguistic community alienated the Odia political elite. It appeared that the Congress would not support Odia efforts for the amalgamation of all Odia-speaking areas under a single administration.

The 1903 Congress recourse to claims about the interests of regional linguistic community in its opposition to the partition of Bengal compounded a curious conflation of the question of religious difference and the idea of a linguistic community. The argument that linguistic community produced a shared everyday life that trumped the demands of religious separatism recurred in the early twentieth-century Congress rhetoric about the Hindu-Muslim relationships. For instance, the 1906 annual presidential address by Dadabhai Naoroji spoke about the need to inculcate a "thorough political union among the Indian people of all creeds and classes" by emphasizing the linguistic commonality between people of various religious groups:

In this appeal for a thorough union for political purposes among all the people, I make a particular one to my friends, the Mohammadens ... All the people in their political position are in one boat. They must sink or swim together. Without this union all efforts will be in vain. There is the common saying - but also the best commonsense - "United we stand - divided we fall." There is one another circumstance, I may mention here, If I am right, I am under the impression that the bulk of the Bengalee Mohammadens were Hindus by race and blood only a few generations ago. They have the tie of blood and kingship. Even now a great mass of the Bengalee Mohammadens are not to be easily distinguished from their Hindu Brothers. In many places they join together in their social joys and sorrows. They cannot divest themselves from the natural affinity of common blood. On the Bombay side, the Hindus and Mohammadens of Gujarat all speak the same language, Gujarati, and are of the same stock, and all the Hindus and Mohammadens of Maharastric Annan - all speak the same language, Marathi and are of the same stock - and so I think it is all over India, excepting in North India where there are the descendants of the original Mohammaden invaders, but they are now also the people of India. ${ }^{78}$

While this passage raises many interesting questions about race, religion, and historical memory, let us focus on how language is used to trump

77 A. M. Zaidi (ed.), In the Glorious Tradition -Vol. 1: 1885-1920 (New Delhi: Indian Institute of Applied Political Research, 1987), p. 238.

78 A. M Zaidi and S. G. Zaidi, "The Surat Embroglio", in Encyclopaedia of the Indian National Congress, Vol. 5 (1906-1911) (New Delhi: S. Chand \& Company Ltd, 1978), pp. 136-7. 
religious difference in Naoroji's call for the thorough unification of all classes and creeds in India. In his formulation, the difference between Hindus and Muslims is an artificial and historically contingent difference. Religious identity by definition is also a historically contingent form of identification that cannot enable Hindus and Muslims of various regions of India to "divest themselves from the natural affinity of common blood." By moving immediately to the assertion that the Hindus and Muslims of Maharastra and Gujarat share a common language and racial origin, Naoroji afforded linguistic community a primordial status in the organization of the people of India. It was a marker of difference far older and influential than religious difference that was threatening to disrupt his dream of a united India.

It is evident from the language of first Indian constitution to be prepared by Indians in 1928 that this use of linguistic affinity to trump religious difference had come to dominate the way in which constituents of the Indian nation were being categorized and enumerated. The Nehru Report written under the presidentship of Motilal Nehru was published as the first native constitution for India . After expending a lot of ink on the question of communalism and communal representation in the future Indian electorate, the Report turned to the question of linguistic reorganization of states. The Nehru Report deemed the question of linguistic reorganization of the states as an issue that was "more germane to the Constitution of India." ${ }^{79}$ Focused mainly on the question of the creation of a new Sindh province, the Report's discussion of the details of the proposed reforms in the boundaries of the Indian provinces called for a deliberation on the issue which considered "the general question on the merits apart from its communal bearings." Implicit in the Nehru Report's efforts to set aside the question of religious difference and focus on the question of linguistic regions was the imagining of the Indian nation on linguistic terms. It is evident that, by 1928, the dominant way of thinking about difference in India was through language rather than through religion. Congress rhetoric often presented political debates based on religious issue as illegitimate and harmful to the interests of the Indian nation. However, by 1928, the idea of a differentiated India seemed to be acceptable to the Congress leadership. This was because in place of religion language had become the dominant and most acceptable register of difference for the Congress platform.

${ }^{79}$ Conference All Parties and Motilal Nehru, Report of the Committee Appointed by the Conference to Determine the Principles of the Constitution for India: Together with a Summary of the Proceedings of the Conference Held at Lucknow, 3rd ed. (Allahabad: General Secretary, All India Congress Committee, 1928), p. 44. 
How did this come about? The roots of this resolution of difference lie in the late 1910s when the Congress leadership attempted to broaden its popular base through local propaganda. In conjunction with the increased governmental attention to the politicization of the Indian masses as the result of the constitutional reforms of 1918-19, the new impetus within the Indian National Congress to "broaden its base" made the question of language of popular political discussion very important. In 1920, Annie Besant, the President of the Indian National Congress Session at Lahore noted:

In many parts of the country, where Conference are carried in the vernacular, the raiyat attend in large numbers, and often take part in the practical discussions on local affairs. They have begun to hope and to feel that they are a part of the great National Movement, and that for them also a better day is dawning. ${ }^{80}$

Besant saw the use of the vernacular languages as a way to include in the "great National Movement," the hitherto excluded sections of the Indian population - the raiyat or peasants. In Congress, the raiyat had frequently come to stand in for the lower classes of rural India. Hence, like the framers of the report on the constitutional reforms of 1918, Besant and her colleagues at the Congress had come to realize that popular participation in "practical discussions on local affairs" was impossible without the use of the vernacular languages in political and public forums. What should be noted here is the emergence of more general concern with the local and the implications of greater attention to "local affairs" on the growing constituency of the "National Movement." The realization that the awareness of a membership in the Congress-led "National Movement" had to come via a greater involvement in discussions about local affairs points to the ways in which the emergence of the need to increase popular participation in political affairs led to the rethinking of the relationship between the national and the local. Hence, apart from the efficacy of using the vernacular in public political discussions, the Congress leadership at the center was also coming to realize that the incorporation of local affairs within the concerns of the day-to-day activities of the Congress was essential to broadening the reach of its politics.

Of course, local issues had been espoused by the Congress leadership in the past. For instance, Gandhi's support of the peasants in Champaran in 1916 was definitely based on an attempt to draw on local politics to make the case for a wider political demand for reforms in colonial governance. However, these early efforts at involvement in local affairs were meant to

${ }^{80}$ A. M. Zaidi and S. G. Zaidi, "Emergence of Gandhi", in Encyclopaedia of the Indian National Congress, Vol. 7 (1916-1920) (New Delhi: S. Chand \& Company Ltd, 1978), p. 202. 
serve as exemplars. They were meant to be spectacles that would reveal the problems with colonial governance. Besant's invocation of local affairs was motivated by an entirely different need - to involve a greater number of people in Congress practices through a greater attention to particularities of their daily lives: to bring the nation home to the local. Hence, the local came to be constitutive of the national in this period.

This concern with language and the local was echoed in Gandhi's discussions about language in the early 1920 s when he centered language as matter of great importance to the fight for Swaraj. It is through his rhetorical intervention that the question of language became of the most prominent issue with the ranks of the Congress in the 1920s. By the time both Annie Besant and Gandhi were talking about the question of language, Congress had called for the establishment of new provincial branches called the Provincial Congress Committees (PCCs). The constituency of these PCCs was based on linguistic lines rather than the existing provincial boundaries. Once Congress had recognized linguistic politics through the establishment of PCCs along these linguistic lines, it adopted the demand for the redistribution of British Indian territories on linguistic lines as one of its foremost demands in the early 1920s. Even though the politics of Congress and its attitude towards the constitutional reforms of this period underwent significant changes in this period, its attitude towards vernacular languages and linguistic politics remained constant.

In his advocacy of vernacular languages in the 1920s, Gandhi made the use of Indian languages central to anticolonial praxis. He did this in two ways: first, his critique of the use of English as the lingua franca of India was based on the need to use the language of the people in popular propaganda and, second, he made the demand for linguistic reorganization of Indian provinces central to demand for self-rule in the Congress politics of the 1920s.

In his 1920 article entitled "An Appeal to Madras," Gandhi argued that the use of English in popular propaganda undermined the ability of political speakers to reach their audience. He noted that in all the years since the establishment of the Congress party, English had been useful only as a "spectacle but never for its real educative value." 81 That is, political speeches in English may have drawn the crowds to experience Congress politics only as passive spectators. Such a popular experience of Congress where the common people did not participate as thinking citizens, rather as devotees following the example of the spectacular

${ }^{81}$ Gandhi, Collected Works of Mahatma Gandhi, Vol. 19 (Delhi: Publications Division, Ministry of Information and Broadcasting, 1958), p. 332. 
English-speaking political leader was no longer desirable by 1920. Given the increasing attention to the political education of the common people due to the constitutional reforms, Congress was beginning to adopt a policy of increasing popular awareness of the people's role in a democratic political set up. Gandhi's discussion of popular politics and the relationship between the leaders and the people is symptomatic of this shift. In an article titled "About leaders and Public," he noted:

There is a new awakening in the country. The common people now want to play their part, are ready for self-sacrifice, but do not know the way. And so long as we do not speak to the people in their own language, what can they understand? How can they understand? ${ }^{82}$

Regional vernaculars became central to the project of building a new mass-based political movement where every individual understood his role in the movement and "was ready for self-sacrifice."

As the Congress leadership came to realize the importance of vernacular languages to their political project, they espoused the demand for the linguistic reorganization of the Indian provinces as a central political aim. In 1920, immediately after the declaration of the constitutional reforms while the Congress was still prepared to participate in the provincial elections, Gandhi wrote an article titled "What Should the Voter Do?" ${ }^{83} \mathrm{He}$ suggested the voters ask their prospective representative the following questions:

2. Do you hold that all the affairs of a province should be conducted in its own vernacular and that the affairs of the nation should be conducted in Hindustani-a combination of Hindu and Urdu? If you do will you endeavor incessantly to introduce the use of vernaculars in the administration of the respective provinces, and the national language in imperial administration?

3. Do you hold that the present division of the provinces of India was made for administration and political purposes and that no regard was paid to the wishes of the people? And do you hold that this division had done much harm to the national growth? ${ }^{84}$

These questions reveal the growing importance given to linguistic reorganization of the provinces during this period. By posing the lack of linguistically organized provinces as an impediment to national growth, Gandhi shifted the emphasis of regional linguistic movements from regional interests to Indian national interests. That is, the demand for linguistically organized states was no longer required merely to safeguard

82 Ibid, pp. 179-80.

${ }^{83}$ Collected Works of Mahatma Gandhi, Vol. 20 (Delhi: Publications Division, Ministry of Information and Broadcasting, 1958), p. 319.

84 Ibid. 
the interests of particular linguistic groups. Rather, linguistic reorganization of Indian provinces was central to the interests of the Indian nation as such reorganization would lead to national growth. Hence, Gandhi made regional linguistic politics cosmopolitan and nationally relevant.

\section{Thinking the Region Within the Nation: Changing Attitude of the Utkal Sammillani Towards Anticolonial Politics}

[T] hose who say that a colonized community has no politics, do not see human life in its entirety. Whether free or subjugated a community which lives within a kingdom and accepts the reign of a well structured State governed by the rule of law, has a politics in some form or other. The politics of a self-governing people will be different from that of a colonized people. However, it cannot be said the colonized have no politics. ${ }^{85}$

Gopabandhu Das, Presidential Speech at the Utkal Sammillani, December 1919

This speech by Gopabandhu Das, who later served as the president of the Utkal Provincial Congress Committee, marks the final radical change in the praxis of the Utkal Sammillani. In its annual session in January 1920, the Sammillani decided to espouse Congress politics and participate in the emerging Non-Cooperation Movement. As the prevailing understanding of rule based on the relationship between the British sovereign and the Indian colonized subject was changing due to the introduction of electoral franchise in 1919-20 and the Indian nation came to be understood as a conglomeration of linguistically distinct regions, Odia attitudes towards anticolonial, nationalist political agitation also radically changed. This nationalization of regional politics could not have been brought about without the intervention of a younger generation of Odia political activists led by Gopabandhu Das. These activists attempted to rethink crucial relationships that were the basis of the Sammillani's attitude towards political activism - the relationship between the British raja and the Odia praja, the relationship between the interests of the region Odisha and the Indian nation and, finally, the relationship between the elite of public organizations and the people they seek to represent. It is this rethinking that produced a new notion of citizenship in Odisha articulated through terms such as praja-sadharana (ordinary-subject) often used by Gopabandhu Das in his writing. Central to this rethinking was the privileging of those who constituted the "silent masses of India" in definitions

85 Gopabandhu Das, Desa Misrana Andolana, Vol. 3, Gopabandhu Rachanabali (Collected Works of Gopabandhu Das) (Cuttack: Gopabandhu Janma Satabarshika Samiti, 1976), p. 14 . 
of community and politics. This section treats Gopabandhu's speech and traces his ideas about politics, citizenship, region, and nation to illustrate how the emerging ideas of representative government, on the one hand, and a nation constituted of linguistic difference, on the other, enabled a regional understanding of citizenship and the region's role in the future of the Indian nation.

Gopabandhu's speech was not only the harbinger of the changes in Odisha politics but also the most sustained and representative statement of the changing attitude towards political activism, the colonial government, and the Indian National Congress in Odisha. In his speeches and writings, Gopabandhu, like Gandhi, called for mass participation in political activism and made the individual Odia central to both regional and national politics. His definition of the relationship between the region and the nation was founded on the primacy of the needs, interests, and potential of every Odia individual.

In order to make his point, Das used both rhetorical strategies and conceptual intervention into the way community was thought about in Odisha. Through rhetorical strategies such as discursive structures of past presidential speeches to introduce new concerns into the Sammillani platform, Das attempted to reformulate the very meaning and symbolism of the Sammillani as a community organization. While he called for a reformulation of the prevailing understanding of the Utkal Sammillani to include more populist ideas and imperatives, Das also introduced a new way of thinking about community itself by arguing that the ultimate objective of the Utkal Sammillani should be the establishment of udaar manabikata or "expansive humanism." This informed the way he reconceptualized the constituents of the Odia community and located the Odia region within the Indian nation. More significantly, the notion of expansive humanism informed his eventual construction of the identity of the Odia/Indian citizen.

Mimicking presidential speeches of earlier years, which began with obituaries to notable members of the Odia community, Gopabandhu commenced his speech with a reference to the dead of Odisha. However, he departed from this earlier rhetoric by also calling attention to even greater losses to Odia population due to the ongoing famine and floods in Odisha. The significance of this departure was not simply because of the mention of the Odia masses in the same register as the members of the Odia elite but also due the tone of this invocation of the Odia people:

If they had lived a long life with healthy and strong bodies they could have added great strength to this country. Who knows what talents lay hidden in them? Who can say what they could have contributed to society if these talents were given time 
to develop? ... It is superfluous to say that their deaths have weakened Odisha. Each one of them, either in a big way or a small way, were the strength of this community union of ours. ${ }^{86}$

This mention of the dying millions of Odisha was doing something more than bringing public attention to their plight. Das was attempting to engage with the earlier tendency of the Utkal Sammillani to see itself as a vanguard class that spoke for the interests of the "silent long suffering Odia people." While refraining from demonizing something that was essentially a product of the movement's early efforts to build a public notion of a political community that did not preexist the organization, Das was arguing that it was time to see both the organization and the Odia people differently.

Signaled here is the emerging notion of the Odia praja as something more than subjects of the colonial state. By thinking of them as potential contributors to the Odia community rather than the consumers of the boons begotten by the Utkal Sammillani from the colonial state (as the earlier use of the term praja seemed to suggest), Das centered the role and interests of the Odia people in the development of a community project like Utkal Sammillani. This shift reveals the earliest move within the Utkal Sammillani from the elitist civic activities based on the management of the Odia people to a more populist political agenda wherein the people themselves had a direct stake.

Apart from this radical reconfiguration of the organization, Das proceeded to argue for a more expansive understanding of both the Sammillani and the Odia community. Calling for a more inclusive association that would make it more than a "mere Conference ... a meeting of knowledgeable Odia people aimed at discussing the interests of Odisha or that of Odia people." 87

This speech featured an entirely new construction of the Odia community, which was no longer founded merely on the Odia language. Rather, Das' new Odia community was based on the place known as Odisha.

Who is Odia community? It is seen around the world that communities are named after places. A feeling of affinity develops naturally among those who inhabit the same place. Their hope, purpose, fate and future is confined to a singular interest for welfare. Their land of action is the same and undifferentiated. For them that very land is a pure and lovable space. It is their birth place. In their view it is equal to heaven. Therefore, those who live in such a defined tract of land - they are one community and they are named according to the name of that land. According to this natural law those who have been born and have died with the same hopes and

${ }^{86}$ Das, Desa Misrana Andolana, p. $10 .{ }^{87}$ Ibid, p. 10. 
desires, and have been imbued with the same interests - they are all Odia community. ${ }^{88}$

This definition of the Odia community signaled a significant shift in the understanding of community in Odisha as the fundamental basis of the Odia community shifted from language to place. Definitions of community in Odisha, both before and after the formation of the Utkal Sammillani had always been based on language. As Chapter 1 illustrates, the efforts by the colonial state to replace Odia with Bengali first occasioned public articulations of the interests of the "Odia community." Since then community came to be defined as a group of people speaking the same language. Occasional efforts to broaden this understanding to include non-Odia-speaking communities who resided in the Odisha division were made by the domiciled Bengalis of Odisha division. The domiciled Bengalis were an influential group within the Odia literati of Cuttack and played an important role in the Odia language movement of the nineteenth century. In 1905, the Star of Utkal, an English-language paper published by a member of the domiciled Bengali community, featured an article that introduced the term utkaliya to denote members of the Odia community. Utkaliyas were people who lived in the Odiaspeaking area but did not use Odia in their day-to-day lives. ${ }^{89}$ However, it was with Gopabandhu's speech that the dominant understanding of the Odia community went through its first divorce from language.

By founding his understanding of community on spatial categories like stana (place), sketra (area), and bhumi (land), Gopabandhu called for a shift in focus from a linguistically based community to one that was geographically organized. In his speech, Das managed this shift by calling into question the distinction between Utkal and Odia. The common understanding of Utkal - due to its links with the term utkaliya - invoked the idea of the inhabitants of Odisha. The appellation Odia denoted the speakers of the Odia language. Das posed the question: Is there a distinction between those who inhabit Odisha and those who speak Odia?

Some people even see a difference between Utkal and Oriya. In fact there is no difference between these two and there should not be any. Whether they are from Bengal or Punjab, from Marwar or Madras, Hindu or Muslim, Aryan or Aboriginal, those who have assimilated their selfhood and interest with Orissa Orissa is theirs and they are of Orissa. These days it is impossible for a place to be inhabited by the same kind of people. There is almost no place on earth where different communities or societies are not living together. Only, the focus of their interests is one. It is natural and acceptable that over time they become united as

${ }^{88}$ Ibid, p. 12. $\quad{ }^{89}$ Anonymous, "Utkaliya”, Star of Utkal, 1905. 
a community. The United States of America is an exemplar of such a formation of community affiliation. ${ }^{90}$ (emphasis added)

This move proposed to shift the locus of Odia regional politics from an exclusive community based on linguistic identity to a more inclusive constituency based on a shared everyday life in a common place. However, the argument for a community based on adjacency and commonality of interests did not necessarily involve a disavowal of the Odia community as a linguistic unit. Rather the very invocation of other such linguistic identities such as Bengali, Punjabi, Marwari etc. reveals Gopabandhu's investment in the distinctiveness of these identities. In fact, he was calling for a cosmopolitan idea of community where shared interests, common historical experience and future aspirations transcended rather than effaced particular linguistic identities. Furthermore, by calling for transcendence of linguistic identities, he did not forsake the idea of a distinct region of Odisha. In fact, for Das, the transcendence of particular linguistic, religious, or caste identity was possible precisely because the geographical category Odisha was assumed as an irrevocable reality. Hence, his call for the inclusion of other linguistic groups in the Odia community did not threaten to demolish the long-cherished vision of a separate region of Odisha.

The geography of the proposed province of Odisha became central to the objectives of the Sammillani as a consequence of Das' privileging of a spatial definition of the Odia community. Hence, in this session a new constitution of the Utkal Sammillani was drafted where the concept of "natural Odisha" as a geographical category was defined. ${ }^{91}$ In the new constitution, natural Odisha was opposed to the existing "artificial" or political Odisha that did not include all Odia-speaking areas.

As the definition of regional community came to be founded on a commonality of interests and shared everyday life rather than exclusively on language, Gopabandhu was able to argue for a new set of objectives for the Utkal Sammillani that were aimed at fostering an inclusive politics based on expansive humanism. He listed three main objectives of the Utkal Sammillani: fostering kinship among the various communities within Odisha their home, participation in politics because as a well-rounded community organization all interests and concerns of the community fall within the purview of the Sammillani, and the establishment of liberal humanism.

${ }^{90}$ Utkal is a term used both to denote the Odia language and the place Odisha as a geographical category. In this particular instance, Gopabandhu is using Utkal to denote both and here Odia denotes simply the language. Das, Desa Misrana Andolana, p. 12.

91 Ibid, Utkal Sammillani (1903-1936), Part 1. 
At the root of his revisioning of community was his use of expansive humanism that enabled him to forge an intrinsic connection between the interests of the Odia community and that of the Indian nation. Approaching the question of the relationship between the region and the nation from the perspective of the interests of the Odia community, Das argued that expansive humanism could be possible only through espousing broader Indian objectives:

Indian feeling will definitely help us in our journey towards gaining expansive humanism. We have to remember that we are part of the Indian community. India is a mega-nation, hence over time many small communities marked by provincial differences have emerged in India; only all their fates are encompassed in the fate of India. Whether we are connected with Indian institutions or not, we have to more or less participate in the trials and tribulations of India. ... We have to remember that we are human first, then Indian and finally Oriya. If we do not keep this thought in mind then the development of our community is impossible. Every individual has freedom, only without social foundation this freedom cannot emerge. Just like that, the freedom of Orissa will blossom on the firm ground of strong Indian nationalism and all-inclusive expansive humanism. ${ }^{92}$

Unlike Madhusudan Das' sisterhood of provinces organized by a common allegiance to the British Empire, Gopabandhu Das' India remains unmarked by Indian subjecthood to the British. While M. S. Das' organizing principle for the making of the Indian nation was a shared bond with the British Empire, for Gopabandhu Das, it was a social kinship of common interests. The Indian nation in Gopabandhu Das' formulation was a society of linguistic provinces in which the freedom of each province was ensured by the establishment of the strong national civil society. Hence, Das posed Odisha as something akin to a citizen in the Indian social world populated by other such communities. Also the emphasis on India as a liberal civil society allowed him to reimagine the relationship between other communities residing in Odisha - Biharis and Bengalis.

The earlier Utkal Sammillani attitude towards these groups is best exemplified by Madhusudan Das' description of the Bengalis and Biharis as "intermediary ruling races." M. S. Das argued that being majority linguistic groups in their respective provinces, these groups of people occupied a more dominant position in the colonial hierarchy of influence. They acted as intermediaries between the colonial rulers and the Odia people. Such a reading of the relationship between these communities and the Odia community implied unequal and oppressive transactions between Bengalis and Biharis and the Odia community. Through his

92 Ibid, Desa Misrana Andolana, p.15. 
discussion of liberal humanism and a national civil society, Gopabandhu Das attempted to reimagine this relationship as equal.

Having established Odisha's place within the Indian nation, Gopabandhu Das moved to establish the particular characteristic of the Odia community that made it most adept at imagining a liberal and inclusive community. Das argued that historically only the Odias have been able to recognize the importance of expansive humanism and lead an inclusive social and spiritual life. He based his argument on the Odia community's allegiance to the Cult of Jaganath. He notes:

The history of the Oriya community clearly reveals that the Oriyas have forever been proficient at this expansive Humanist ethic and have experienced an everyday connection with India ... Even though Orissa is bounded by rivers and mountains, they (the Oriya community) have transcended these boundaries and moved towards greatness. At the focus of nationalism is liberal humanism, in all of India it was the Oriya people who understood this.... Among the Oriya this nationalism and love for the country could never be rigid, lifeless, barren and selfish. It was never founded on the desire to gain ruling power or violence. It was based on profound religiosity and firm faith. Peace, friendship and freedom are its symptoms. In Orissa this thought is materialized in Nilachal Dham [Puri- the seat of the Jaganath cult]; hence Jaganath is the national deity of Orissa.... In the ethic of Nilachal there is no distinction between big and small, raja and praja, Brahmin and Chandal, friend and foe or even Hindu and Buddhist. In the later Chaitanya age even the distinction between Muslim and Hindu was obscured. Because this seed of expansive humanism and pan Indian nationalism lies in Nilachal, over the ages devotees and great men have been attracted to Nilachal. ${ }^{93}$

Through this discussion of the Jaganath cult, Das is able to both establish the exceptional and exemplary nature of Odia community and make an argument for equality within the Odia community by drawing on the notion of equality before God. Making such a case for expansive humanism allowed Das to describe an Odia community that transcended race, religion, and caste. As more and more concrete decisions about the new province were made in the next two decades, this description of Odia community that transcended difference and was held together by allegiance to common land and religion would be put in service of the movement for the formation of the new province.

\section{Conclusion}

Gopabandhu's humanist definition of the Utkal Sammillani, the Odia community, and the relationship between the region Odisha and the Indian nation established the basic structures and ideas that were

93 Ibid, p. 15. 
fundamental to the foundation of liberal democracy in India. His redefinition of both the Utkal Sammillani and the Odia community enabled him to posit a new idea of liberal community that was not based on any exclusive marker of identity. Rather, it was based on a shared everyday life that, in turn, enabled him to see members of both the Odia and the Indian community as mutually interchangeable and fundamentally equal.

This was clearly a departure from Madhusudan Das' understanding of the non-Odia-speaking people such as Bengalis and Biharis as "intermediary ruling races" whose control over the fortunes of the Odia-speaking people, in the Bengal Presidency and the province of Bihar and Odisha, threatened to negate the colonial government's efforts to introduce representative government based on franchise. Gopabandhu Das's concern about the creation of a community based on the homogenizing potential of expansive humanism was informed by his desire to think the relationship between the Odias, Bengalis, and Biharis differently.

A stake in this rethinking was an argument for a national community that allowed for both Indian nationalism and Odia regional affiliation. The shift in the understanding of community represented by the difference between Madhusudan Das and Gopabandhu Das' approach to Bengalis and Biharis illustrates the gradual expansion of the limits of regional and national allegiances. That is, the move from an idea of regional community based on exclusive interests to an idea of regional community predicated on expansive humanism enabled the imagination of an Indian citizen who could be simultaneously loyal to both India and Odisha.

At the root of this shift and the creation of this doubly marked Indian citizen is Gopandhu's astute sublimation of language as the basis of regional community. Gopabandhu effected the resolution of the contradiction between an exclusively language-based regional identity and the increasingly urgent need to imagine an inclusive Indian national identity by founding his definition of Odia identity on the notion of the shared space of Odisha. As the rhetoric within the Indian National Congress illustrates, language as the basis of regional community sat uncomfortably within the Congress's political agenda of unification. Even when it was acknowledged, linguistic identity of the Indian peoples was seen as an irrevocable fact of Indian life that needed to be harnessed to further the project of Indian nationalism. Within this context, the Odia drive to define regional community on exclusively linguistic lines could possibly disrupt the nationalist agenda. Therefore, the linguistic identity drive had to be sublimated into something a bit more acceptable within the nationalist framework. However, as I have illustrated in the discussion of my use of the term sublimation in the introduction, this sublimation of regional 
exclusivity is always inherently reversible. It is wrought by the pressure to fit into a broader Indian federation of linguistic communities and to account for uncomfortable minorities like Muslims, domiciled Bengalis, and, most importantly, adivasis within the territory being claimed as Odisha.

In his 1920 speech, Gopabandhu was able to achieve this by shifting the basis of Odia regional community from language to shared space. This space, "Natural Orissa" was already a discrete space in the Odia imagination but not yet an officially defined territory. As Gopabandhu's speech suggests, this imagined shared space of natural Odisha was also marked by specific qualities of sacredness and religious inclusivity. With the Indian National Congress' establishment of Provincial Congress Committees on linguistic lines, the demand for a separate territory contiguous with natural Odisha could be made in earnest. From this moment on, Odisha as a spatial and territorial category came to be central to Odia politics of the 1920s and 1930s. In the next half of the book, we will see how this spatial and territorial idea of Odisha is elaborated through the use of the discourse of inclusive humanism that was at the root of the sublimation of exclusive language politics in Odia regional politics and eventually in debates about regional territory at the national level. We will see how this sublimation of language and its attendant discourse of shared everyday life was employed to claim areas inhabited by adivasi communities as part of Odisha in Chapter 5. But in the next chapter, I will illustrate how the foundations of this discourse of shared everyday life were established in spatial imaginaries of Odisha that were elaborated as part of colonial, regional, and national descriptions of Odisha. This spatial imaginary of Odisha as a sacred, inclusive land is what legitimized Odia claims to adivasi areas during the formation of the new province in 1936. 


\section{$4 \quad$ Odisha as Vernacular Homeland}

This country is not made for conquests nor for the design of human ambitions, it belongs to the Gods.

Abul Fazal

Abul Fazal's sixteenth-century remark about Odisha has been echoed numerous times in the ensuing centuries. This view of Odisha remains in play even today. A recent textbook on the history of India titled its chapter on Odisha as "Odisha: The Land of the Gods." And yet, Odisha today is also known for conflagrations between the state government and the minority adivasi communities of the province. Even the question of religion has become a fundamentally contentious issue with the increasing establishment of polarizing Hindutva politics and violence against Odia Christian communities. In spite of the evidence of intercommunity violence and consistent state neglect of its minority communities, Odisha continues to stand as an enchanted, godly place. As Gopabandhu's early twentieth-century claim about the inclusive humanism of Odisha suggests, this reading of Odisha as a religious space performed very vital political labors during the early nationalist movement. It situated particular Odia political aspirations within the broader logic of Indian nationalism. In this chapter, I present a modern history of the idea of Odisha as a religious space and illustrate how this reading of the province enabled the colonial state, early Odia political leadership, and even major nationalist leaders like Gandhi to simultaneously highlight and elide fundamental differences within the Odia community.

This modern history of Odisha as a concept is part of a larger history of how regional space was imagined, demarcated, and configured in the late nineteenth and early twentieth centuries. Regional space, no matter how porous or fuzzy, was already a social reality by the beginning of colonial rule. Acts of pilgrimage, interactions between centers and peripheries and popular literary accounts that situated themselves in recognizably local places had already enabled a sense of shared space that was distinct from 
other regional places. ${ }^{1}$ For instance, in Odisha the relationship between the ritual center of Puri and small kingdoms in the distant areas in the Eastern Ghats was rehearsed in the origin myths of both the adivasi communities and princely states long before the colonial state established regional administrative zones. ${ }^{2}$ While the connections between centers and peripheries were already established, the distinction between outside and inside the regional zone was also somewhat clarified in the precolonial period. When the British took over the administration of the Jaganath Temple at Puri they found that the "outsider" pilgrims have to pay a pilgrimage tax to enter the sacred complex that was not levied on "local" people. ${ }^{3}$ The process of colonial accounting of India set in motion a more systematic and connected imagination of region in India. ${ }^{4}$ Massive ethnographic projects such as W. W. Hunter's Imperial Gazetteer of India and Statistical Account of Bengal not only produced discrete regions such

${ }^{1}$ See for instance, Anne Feldhaus' work on Maharastra in Anne Feldhaus, Connected Places: Region, Pilgrimage and Geographical Imagination in India (New York: Palgrave Macmillan, 2003). Here, Feldhaus shows how narratives about and acts of pilgrimage already produced a geographical imaginary of regional cohesion that predated colonial rule. C. A. Bayly's famous work on imperial information networks has shown how pilgrimages formed a preexisting network of communication that served the emergent empire to fathom Indian geography. See Christopher A. Bayly, "Knowing the Country: Empire and Information in India", Modern Asian Studies 27, no. 01 (1993): 3-43. For discussions about regional connections in Odisha, see Akio Tanabe, "Indigenous Power, Hierarchy and Dominance: State Formation in Odisha, India", in Ideology and the Formation of Early States (Leiden: Brill, 1996): pp. 154-65; Georg Pfeffer, Periphery and Center: Studies in Odishan History, Religion and Anthropology, Vol. 7. (New Delhi: Manohar Publishers, 2007). See, also, Raphael Rousseleau, "Village Festival and Kingdom Frame: Center and Periphery from a Poroja Village Point of View", in Marine Carrin and Lidia Guzy, Voices from the Periphery: Subalternity and Empowerment in India (New Delhi: Routledge, 2012). For a sense of how another region thought through its spatial imaginary, see Chitralekha Zutshi's essay about early Kashmiri spatial imaginary in her book Languages of Belonging: Islam, Regional Identity and the Making of Kashmir (New Delhi: Permanent Black, 2003).

${ }^{2}$ Early colonial accounts of this connection can be seen in texts such as J.P. Frye's essay "On the Uriya and Kondh Populations of Odisha", Fournal of the Royal Asiatic Society of Great Britain and Ireland 17 (1860): 1-38. These colonial narratives about connection have been extensively interrogated in more recent scholarship. See, for example, Felix Padel, The Sacrifice of Human Beings: British Rule and the Konds of Odisha (New Delhi: Oxford University Press, 1995); and Jaganath Pathy, "Colonial Ethnography of the Kandha: 'White Man's Burden' or Political Expediency?”, Economic and Political Weekly 30, no. 4 (1995): 220-8. As this trend makes taking the colonial narratives at face value, we can draw on more recent scholarship on center periphery studies of Odisha. For instance, Raphael Rousseleau, "The King's Elder Brother: Forest King and Political Imagination in Southern Odisha", Rivista di Studi Sudasiatici: RiSS 4 (2009): 39-62, in which Rousseleau looks at how poroja origin myths are used in establishing kingship in southern Odisha.

${ }^{3}$ Nancy Gardner Cassels, Religion and Pilgrim Tax under the Company Raj (New Delhi: Manohar Publishers, 1988); and Yaaminey Mubayi, Altar of Power: The Temple and the State in the Land of Faganath (New Delhi: Manohar, 2005).

${ }^{4}$ Bernard Cohn, Colonialism and its Forms of Knowledge: The British in India (Princeton, NJ: Princeton University Press, 1996). 
as Bengal, Odisha division, or Assam, they also marked them as specific sorts of place. Each region came to have special characteristics that would later be amplified by twentieth-century regional nationalist rhetoric in order to establish connections between regions and the Indian nation. These regional imaginaries were not simply a product of colonial knowledge but were heavily inflected by native spatial imaginaries. In her book, Jayita Sharma has illustrated how Assam came to be described as the "garden of India." Such a description performed complex explicatory labors. As a garden, Assam was a place where British enterprise had tamed the wildness of nature to produce an ordered, productive landscape that housed a recalcitrant and "indolent" population, which could not be trained into the rigors required of a modern workforce. Thus the tea industry had to look elsewhere for labor. Being deemed the Empire's Garden not only valorized the unique and productive ecology of Assam but also surreptitiously signaled the purported weakness of the Assamese community. ${ }^{5}$ Like Assam, Bihar and Uttar Pradesh came to acquire unique reputations as the birthplace of Indian civilization and culture. ${ }^{6}$ Prachi Deshpande has shown how regional cultural politics in Maharastra presented the province as the quintessence of the Indian nation. ${ }^{7}$

In the case of Odisha, the pilgrimage center of Puri served as the core of the regional spatial imaginary. Puri, the seat of the Jaganath cult and one of the four most important sites of Hindu pilgrimage in India, is central to this project of defining Odisha as a religious space. Situated on the coast, Puri is the site of the annual Rath Yatra which attracts pilgrims from various parts of India. Scholars studying the Jaganath cult have traced how Puri and its ruling deity have come to represent a universal religiosity that bears devotion from all classes of people from the "Aryan" caste Hindus and the "non-Aryan" adivasis of Odisha. Even as scholars have argued that such a claim is interrupted by a counternarrative of Hindu appropriation of a tribal deity, the force of this inclusive religiosity continues to draw people to Puri all around the year. ${ }^{8}$ During the late nineteenth and early twentieth centuries, the

${ }^{5}$ Jayeeta Sharma, Empire's Garden: Assam and the Making of Modern India (Durham, NC: Duke University Press, 2011).

${ }^{6}$ Gyanesh Kudaisya, Region, Nation, "Heartland": Uttar Pradesh in India's Body-Politic (New Delhi: Sage, 2006).

${ }^{7}$ Prachi Deshpande, Creative Pasts: Historical Memory and Identity in Western India (New York: Columbia University Press, 2007).

${ }^{8}$ For an interrogation of the universality of Jagannath and an account of the various arguments about the legends that illustrate how the notion of Jaganath as a universal deity is historically constructed, see Ishita Banerjee-Dube, Divine Affairs: Religion, Pilgrimage and the State in Colonial and Post-Colonial India (Shimla: Indian Institute of Advanced Study, 2001), pp. 31-6. 
spatial imaginaries of the Odia regional movement repeatedly referenced Puri and its associated legends as a central feature of the Odia community. As we will see later in the chapter, the colonial official account of Odisha also focused on how Puri was the key to understanding the culture, politics, and general ethos of Odisha. Gopabandhu's call for a regional community based on shared space and expansive humanism that was particular to this shared space could not have held meaning for his audience had there not been a commonly held understanding of Odisha as a sacred and inclusive space. This chapter seeks to unpack this orthodoxy about the centrality of Puri to Odia regional identity by tracking the history of how this centrality is established in colonial and regional narratives of Odisha.

Puri serves as such an important feature of the Odia spatial imaginary because it performs two crucial but contradictory labors in Odia rhetoric about regional space and community. As we will see in the chapter, it served as a site of exception to caste and religious exclusion by allowing lower caste and adivasi communities to have access to the deity during the annual festival of Ratha Yatra. At the same time this single annual event came to serve as an example of enduring inclusion of religious and caste difference in Odisha as a region. In the manner in which the sacred space of Puri has come to represent the religious and inclusive ethos of all of modern Odisha, we find very clear resonances of Michel Foucault's much maligned notion of heterotopia. ${ }^{9}$ Heterotopia according to Foucault was a hyperreal space unlike an imaginary Utopia. Its referential power was based on commonly held meaning that all of society invested in it. By virtue of being a space that was both marked out as a discrete separate site and was squarely placed within the realm of the community's spatial life, Foucault's heterotopias could serve as both an example and a place of exception.

Heterotopias were, according to Foucault, ''countersites,' a kind of effectively enacted Utopia in which the real sites, all the other real sites that can be found within the culture, are simultaneously represented, contested, and inverted." ${ }^{10}$ If we could borrow Foucault's idea that heterotopias worked as countersites to understand how Puri came to be deployed in narratives of Odia inclusion then we can see how the Jaganath Temple of Puri was often seen as a temple with an exception. Temple entry was restricted to the caste Hindu Odias in most of Odisha and was definitely

${ }^{9}$ Michel Foucault, "Of other Places", Diacritics 16 (1986): 22-7. For a critical reading of Foucault's concept of heterotopia, see Arun Saldanah, "Heterotopia and Structuralism", Environment and Planning A 40, no. 9 (2008): 2080-96; and Peter Johnson, "The Geographies of Heterotopia”, Geography Compass 7, no. 11 (2013): 790-803.

${ }^{10}$ Foucault, 1986, p. 24. 
restricted in Puri, too. ${ }^{11}$ However, as the ritual visit of the deity to meet his excluded followers stranded outside the temple has been institutionalized, the temple in Puri both sustained the idea of the ritually pure sacral space that denied entry to excluded populations while providing a regular exception to this exclusion. However, using Foucault's framework for understanding exceptional space also makes us susceptible to charges leveled against him for being too simplistic about the dualities posed by the idea of sites and countersites. Arun Saldanah has argued that in claiming that the countersite serves as an exception, Foucault was unwittingly producing a totalitarian vision of the concerned community. ${ }^{12}$ In the most ungenerous reading of Foucault, the resultant totality can be read as a homogenous community that understood the meaning of the heterotopia in monolithic and undifferentiated manner.

But when we attempt to understand Puri through Foucault's idea then we come upon this totalitarianism itself as an illuminating tool. It allows us to understand how taking the exemplary and the exceptional nature of Puri at face value could be problematic. Leaders like Gopabandhu Das claimed that the people and the land of Odisha are particularly adept at inclusion of difference by citing the example of Puri. This claim could only work because Das had already assumed a uniformity of intention and belief among the people of Odisha. Das' claim eclipsed the reality of socioeconomic differences between caste Odia people and adivasis outside Puri. The narrative about the practice of inclusion in Puri came to stand in for the practice of inclusion in the region beyond Puri. However, we know that in the region beyond Puri, Odisha was not always as inclusive and egalitarian as the practices in Puri implied. In the nineteenth and twentieth centuries, adivasi revolts against overtaxation by princely state rulers recurred across the Odia-speaking areas. ${ }^{13}$ Even in the early 1920s when Gopabandhu Das was describing Odisha as an inclusive

${ }^{11}$ There is evidence that restrictions in temple had been in place even in the sixteenth century and ways to work around these restrictions had already been practiced since then. See G. N. Dash's work on Hindu and tribal negotiations about access and ownership on the deity of Jaganath. Gaganendranath Dash, Hindus and Tribals: Quest for a Co-Existence (Social Dynamics in Medieval Odisha) (New Delhi:Decent Books, 1998); and Anncharlott Eschmann, "Hinduization of Tribal Deities in Odisha: The Sakta and Saiva Typology" and "Prototypes of the Navakalevara Ritual and Their Relation to the Jagannatha Cult", in Anncharlott Eschmann (ed.), The Cult of Faganath and the Regional Tradition of Odisha (New Delhi: Manohar, 1978), pp. 79-98, 265-84.

12 Saldanah, "Heterotopia and Structuralism", 2085.

${ }^{13}$ For a history of princely state overtaxation, see Biswamoy Pati, "Interrogating Stereotypes: Exploring the Odisha Princely States", in South Asia from the Margins: Echoes of Odisha, 1800-2000 (Manchester: Manchester University Press, 2012), pp. 97-115. 
land, the subjects of the princely state of Kanika had broken out in revolt against their ruler due to concerns about overtaxation.

As my discussion of the colonial rhetoric on Odisha will reveal, the colonial government's engagement with what was for all intents and purposes a massive financial operation spanning Odia-speaking areas and beyond, had a significant impact on the way that they read Odisha as a space in the nineteenth and twentieth centuries. The subsequent Odia and nationalist accounts of Puri both borrowed from and reconfigured the colonial reading of Odisha. In what follows, I will illustrate how the colonial, Odia, and nationalist reading of Odisha exhibit as shared rhetoric of Odia religiosity and inclusiveness. In particular, I trace the account of Odisha in the writings of three emblematic figures in colonial Odia and nationalist rhetoric on Odisha - W. W. Hunter, Madhusudan Rao and, very briefly, Gandhi. I argue that in defining natural Odisha as a religious space marked by absolute difference, the Odia political elite was able to both make an argument for a unified Odia-speaking province and illustrate how the demand for such a province was not at odds with all-India nationalism.

\section{Fanatic Land: Hunter's Odisha}

In my exploration of the colonial account of Odisha I use as my central text, W. W. Hunter's two-volume history of Odisha, which was published in 1872. Hunter's account was one of the last among a long series of colonial reports on the region. ${ }^{14}$ However, it is probably the most selfconscious accounting of Odisha as a category as this text served as the first two volumes of his monumental Statistical Survey and the Survey of India. In the preface of the piece, he claimed that this account of Odisha was to "exhibit my conception of a statistical and general account of an Indian province." ${ }^{15}$ As an exemplary account of an Indian province, Hunter's history was to provide adequate information about the region for purposes of administration and travel. In his preface, he acknowledges that

${ }^{14}$ Apart from reports collected in various parts of Odisha (see Yaaminey Mubayi, Altar of Power: The Temple and the State in the Land of Jagannatha (New Delhi: Manohar, 2005), few books on Odisha were published by colonial commentators. Andrew Stirling, Odisha: Its Geography, Statistics, History, Religion and Antiquities (London: John Snow, 1846); William F. B. Laurie, Odisha: The Garden of Superstition and Idolatry (London: Johnstone \& Hunter, 1850); and J. Peggs, Pilgrim Tax in India: Facts and Observations Relating to the Practice of Taxing Pilgrims in Some Parts of India and Paying a Premium to Those Who Collect Them for the Worship of fuggernaut at the Great Temple in Odisha (London: Seeley, 1830). A year after Hunter published his book, George Toynbee published his history of the conquest of Odisha: George Toynbee, The History of Odisha from 1803-1823 (Calcutta: Bengal Secretariat Press, 1873).

${ }^{15}$ W. W. Hunter, Odisha: Vol. 1 (London: Smith, Elder \& Co., 1872), p. 13. 
the nature of British interaction with India had changed by the 1870s and a new account of India and its provinces had to be framed that could respond to the new needs of the British visitors to the inner reaches of the country. ${ }^{16}$

In writing his new sort of regional history, Hunter sought to cater to the needs of the emergent British colonial official who had to engage with new regions of India every four years. His book was also provoked by the end of the East India Company monopoly over Indian trade. Hunter wrote in his preface that with the end of company monopoly more English capital would be flowing in to fund Indian industry. Using the example of the tea industry in Assam, Hunter warned against the hasty application of capital to India "without sufficient knowledge being accessible to ensure its safe and intelligent application." 17 The book was meant to serve as an introduction to Odisha for the uninformed British investor. Consequently, the book had to serve as a history of Odisha that would not "trouble the reader" with "confused dynastic changes." ${ }^{18}$ Rather by dispensing with "the plots and scenic effects of history," Hunter's history would introduce the reader to the "essential" features of Odia society and land. ${ }^{19}$

The volumes consist of detailed accounts of various aspects of social, political, and fiscal life in Odisha that served to illustrate his key arguments about the nature of Odisha as a space and the Odia people. Overarching these descriptions were two central arguments about the region - that the history of Odisha was driven by religion above all other factors and that despite what appeared to be a fairly long tradition of Hindu social customs, Odisha was still the site of primitive "land making" - that in Odisha history is still unfolding.

For Hunter, religion was a primary vector in Indian history. The case of Odisha was a particular example of this primacy. In his preface, Hunter apologizes to his reader for giving "to frequent prominence to the religious side of Odisha history" and claims that he has done so "from a firm belief that it forms the key to the right understanding of the people." ${ }^{20} \mathrm{He}$ argued that religion rather than ethnicity drove revolutionary changes in the history of Odisha as "each line of new kings represents a new era of worship and of spiritual belief." Hunter's focus on religion comes from an impulse towards writing a people's history of Odisha rather than tracking the high politics of the Odia past. This was no nationalist history that recounted ancient glories to instill communal pride. Rather, as this history was to inform the colonial official and the British capitalist with proper knowledge about the people and the land. A history of popular belief and an exploration of the history of state practices framed by

\footnotetext{
${ }^{16}$ Ibid, pp. 13-15. ${ }^{17}$ Ibid, p. $15 .{ }^{18}$ Ibid, p. $169 .{ }^{19}$ Ibid, p. $1 .{ }^{20}$ Ibid, p. 5.
} 
religious policies allowed Hunter to have a better sense of how the modern Odia populace have come to take its contemporary shape. In a chapter entitled "The Essentials of History," Hunter suggested that the central arguments of the book was to show the impact of larger political changes on human existence and beliefs and how they brought upon shift:

[T] he people, and the revolutions they have wrought in human existence and human beliefs; the struggles by which a race, buried in its primitive jungle, has from time to time painfully cast its skin and assumed new forms of life; above all, the stages by diverse ethnical elements have grown together into the composite rural communities of the present day. ${ }^{21}$

Therefore, by writing his detailed history of Odia religious and political past, Hunter hoped to draw out how the community of Odiaspeaking people came to be constituted of "diverse ethnical elements." This treatment of the Odia past was driven by a need to provide a distilled understanding of the essential nature of the Odia population while being challenged by the apparent diversity of the Odia population. By constructing a common history of the adivasi- and Odia-speaking communities, Hunter sought to produce a category of "Odia" people out of a diversity that was not necessarily amenable to this unification. Therefore, the first rationalist argument about a common history of the people of Odisha was borne out of Hunter's need to populate the modern category of "Odia people" and to render this knowledge useful for imperial governance and the spread of colonial capital into the as yet untouched Odisha. The need to produce neat regional categories what was at the foundation of Hunter's efforts was what forced the first move towards effacing difference among the population of the Odisha division. The populist impulses of his narrative, which at first glance would appeal to the modern social historian, were not necessarily populist but imperialist. Therefore, our project should not simply be about bringing the adivasi communities into the history of Odisha or India as has been attempted in the history of women or the working classes. Rather, it is more crucial to acknowledge that the process of incorporation of the adivasi into the history of Odisha has always been implicated in the operations of imperial and subsequently nationalist power.

This argument emerges from a curious juxtaposition of two parallel histories of Odisha in Hunter's text: one, the unprepossessing history of the upper-caste Odia population and, two, the history of the primeval tribal population caught in an equally primeval landscape:

${ }^{21}$ Ibid, p. 169. 
Nature, long grown cold and inert in Europe, here toils as wildly at her primeval labor, as if the work of Creation still lay before her. She discloses her ancient secrets of land making and admits us as spectators to the miracle of the Third day. We see the dry earth ... Within the single province of Odisha she has brought together, as in a great museum, specimens of all her handicrafts, from the half formed amphibious regions around the river mouths, to the chaos of primitive rock which walls out the seaboard from the inner table land. ${ }^{22}$

In another curious turn, immediately after expressing his wonder at the untimely primeval antics of nature in Odisha, he mentioned the inhabitants of Odisha in archaeological terms - as organic remains - as sediments of times past, present only to illustrate their own impotence.

Nor is the province less rich in organic remains. Upon the delta, and among the mountains which rise behind it, we come upon endless strata of races, dynasties, and creeds, from the latest alluvial deposit of Bengalis, with their soft Hinduism, to the aboriginal peoples and their hard angular faith. In Europe, the primeval tribes have disappeared from the range of observation into the twilight of hypothesis. Scholars have stood like Hamlet in the Elsinore graveyard, and see the bones of forgotten nations thrown up at their feet ... Odisha exhibits a profusion of such primitive races not in a fossil state, but warm and breathing, living apart in their own communities, amid a world of suggestive types and links that elsewhere disappeared. ${ }^{23}$

By mentioning the endless strata of races, dynasties, and creeds, Hunter acknowledges the diversity of the Odia people. However, through the use of the term "strata," he imposed a civilizational and temporal hierarchy within the various "races" in Odisha with the Bengalis as the topmost alluvial layer. However, his subsequent emphasis on the aboriginal peoples to the exclusion of all other "races" and "creeds" seems to justify his initial claim about the lack of cultural achievement in Odisha. Through the use of metaphor of museums and archaeological soil sediments, Hunter portrayed the people of Odisha as a class of people stuck in the past. He saw the aboriginal inhabitants of Odisha as the remnants of an earlier stage of human development that has long since disappeared in Europe.

This juxtaposition of races between the Odias of the Odisha plains and the adivasis of the hilly regions of Odisha is echoed in early reports by administrators writing back to the central government as they came to encounter the newly acquired province in $1803 .^{24}$ When the British

${ }^{22}$ W. W. Hunter, Odisha: Or the Vicissitudes of an Indian Province under Native and British Rule ... Being the Second and Third Volumes of the Annals of Rural Bengal (London: Smith, Elder \& Co., 1872), p. 3.

${ }^{23}$ Ibid, p. 4.

${ }^{24}$ See for instance, report by John Richardson on the geography, and land tenure for the Cuttack Division, 1817, British Library, IOR F/4/505. 
acquired most of the Odia-speaking areas they came to take on existing spatial divisions as their framework for understanding their new acquisition. The fertile coastal belt of present-day Odisha was called Mughalbandi as it used to be Mughal crown land. Areas covering the Odisha Eastern Ghats were called Garjat and consisted of the princely states. Early accounts of Odisha underlined the differences between the Mughalbandi and the Garjat by drawing attention to contrast between the relatively "civilized" and affluent population of the Mughalbandi and the "uncivilized," poverty-stricken, and politically oppressed adivasi population of the Garjat. $^{25}$

Accounts of the Mughalbandi areas were dominated by narratives of Puri and its centrality in the revenue and political structures in Odisha. ${ }^{26}$ Hunter's vision of Odisha as a land driven by religious changes drew from this colonial preoccupation with Puri. In both administrative and missionary circles, Puri came to serve as an exemplary heterotopia of "native idolatrous fanaticism." As the colonial government came to be more and more embroiled in the administration of massive temple complexes, the annual influx of pilgrims into Odisha from other parts of India and the institution of pilgrim taxes, they came to be faced with a growing anxiety in England and among colonial officials about how this fanaticism could mark an otherwise secular colonial state. ${ }^{27}$ Within missionary discourse

${ }^{25}$ In his report on the geography of the province in 1817, John Richardson made a clear distinction between the two parts of Odisha. Of Mughalbandi, he said that these areas were "plain, fertile but not well cultivated and possessing of a numerous population," Richardson, IOR F/4/505. 8. And that: "With all these advantages and a full enjoyment of security with the additional blessings of a mild and tolerating Government, we are naturally led to conclude and expect that the resources of this province are improving but that the inhabitants themselves through ignorant to the cause, are approaching towards a state of greater civilization," Ibid, p. 11. However the Garjat area had an entirely different complexion. About these areas, Richardson noted that: "[T]here, little is to be seen but wretchedness and poverty. The great surface of the country is unfit for culture and the small portion cultivated produces a scanty subsistence," Ibid, p. 12. Therefore, the Garjat area required a more assertive intervention from the colonial government. $\mathrm{He}$ observed that: "I have reason to believe that the connections which have existed between this portion of the District and the British government, has already tended greatly towards its improvement, still the baneful counteraction which this benign influence must constantly meet with, in depraved Government of its arbitrary Chiefs, whose cruelty and avarice, equal their ignorance and barbarity will long prove a bar to the introduction of a better order of things, so greatly to be desired, and so conformable in the views of British policy - As long as the inhabitants continue under the Iron rod of their present cruel and rapacious masters, any great amelioration of their situation is impossible, nor is it reasonable to suppose that any great change for the better will take place amongst them, until they are better protected from the arbitrary power of their chiefs," Ibid, p. 13.

${ }^{26}$ See Yaaminey Mubayi on the relationship between temple and state in Odisha.

${ }^{27}$ For colonial as well as metropolitan debates about the involvement of the colonial state in the administration of the temple, see Nancy Gardner Cassels, Religion and Pilgrim Tax 
both in India and in England, the annual Rath Yatra came to serve as an exemplar of unbridled, irrational, and fatal religious fanaticism in India. ${ }^{28}$ Finally, the institutional preoccupation with the religious nature of Odisha also drew from the incipient colonial state's engagement with a very complex political and revenue structure that was grounded in Puri through unique networks of ritual, fiscal, and symbolic power that bound together the princely states with the temple establishment.

In colonial accounts, Puri came to serve as what Michel Foucault has termed a colonial heterotopia of compensation. Even as these accounts were products of the everyday experience of rule, they also served to justify colonial rule in Odisha. As Odisha came to be defined as a religious land consisting of the fanatically religious coastal belt or the Mughalbandhi and the civilizationally backward and politically oppressed Garjat, the civilizational mission of British imperialism came to be clarified into a two-part program of disciplining Jagannath-centered Hinduism in the coastal areas and modernizing the Garjat areas. As a tourist guide book on Odisha published in 1900 argues that two kinds of people would find Odisha of particular interest - anyone interested in popular Hinduism and ethnographers interested in studying primitive tribes. ${ }^{29}$

\section{Divine Native Land}

The centrality of Puri and the Jagannath cult in the rhetoric of Odia linguistic politics has long been established. ${ }^{30}$ By the late nineteenth century, Odia poets had begun depicting Utkal or Odisha as a region that was "eternally victorious in the field of religion," as it was able to accommodate multiple streams of Hindu faith. ${ }^{31}$ Where the colonial accounts saw Odia religiosity as an instance of fanaticism, Odia nationalist

Under the Company Raj (New Delhi: Manohar Publishers, 1988). One such observer, William F. B. Lauri, wrote: "Orissa may be compared to a huge caldron, which has been boiling for many hundreds of years, into which ignorance stupidity, and bigotry, have cast so many poisonous ingredients, that it is difficult to say when the contents will become purified and good." Lauri, Orissa: The Garden of Superstition and Idolatry, p. 5.

${ }^{28}$ For details, see Subhakanta Behera, Construction of an Identity Discourse: Odia Literature and the Fagannath Cult (New Delhi: Munshiram Manoharlal, 2002). Also see Geoffrey Oddie's reading of how Claudius Buchanan's account of the Rath Yatra contributed to a colonial construction of Hinduism as a "heathen" and "idolatrous" religion; Geoffrey Oddie, "Missions and Museums: Hindu Gods and other 'Abominations' 1820-1860", in Indra Sengupta and Daud Ali (eds.), Knowledge Production, Pedagogy and Institutions in Colonial India (New York: Palgrave Macmillan, 2011), pp. 66-8.

${ }^{29}$ W. B. Brown, A Guide to the Principal Places of Interest in Orissa (Cuttack: Cuttack Mission Press, 1900), p. 5.

${ }^{30}$ G. N. Dash, "Jagannath and Odia Nationalism", in A. Eschmann (ed.), The Cult of faganath, op cit, pp. 359-74.

31 The best instance of this would be Madhusudan Rao's Utkal Sangeet. See Behera, p. 80. 
readings of the status of religion are much more positive - it serves as marker of identity and an essential nationalist myth. This nationalist myth performed a number of political labors. It served as an instance of historical pride in Odia traditions and as well as a means to illustrate how Odisha was a microcosmic version of the larger Indian nation.

At the end of Chapter 3, I discussed how the movement for a separate province of Odisha had to base their territorial arguments on the assumption that colonial Odisha was a product of artificial boundaries. According to such claims, colonial Odisha was artificial Odisha. Leaders argued that the colonial state needed to reform boundaries to bring together the area that was natural Odisha. One of the most sustained efforts to define and justify the existence of natural Odisha was written in 1919 by Niranajan Pattnaik and Chakradhar Pradhan in a book entitled The Oriya Movement: Being a Demand for a United Orissa. ${ }^{32}$ Written with the explicit purpose of making the case for Odisha for the colonial government, this book drew on the reigning definitions of Odia community that were being put forward in the Odia public sphere of the time. The authors argued that, in spite of apparent differences among people within the projected province (which included districts from the Madras Presidency, the Bengal Presidency and the Central Provinces), they shared "social manners and customs peculiar to themselves." 33 Unsurprisingly, the foundation for this claim came from Hunter's discussion of the Odia character. Writing almost fifty years after Hunter had penned his history, Pattnaik and Pradhan argued that:

The Oriya is constitutionally religious. Dr. Hunter is his "Orissa” Vol. I., pp. 315 et seq., says rightly to understand the intensely religious, or as some might call it, the superstitious nature of the Orissa peasant, we must remember that his sole monuments of the past are the edifices of his deities and the whole background of time is for him filled up with dim August revolutions of creeds. No comment is necessary." 34

This description of the Odia character accounted for the common identity of the Odia people despite the administrative divisions among them. However, in taking on Hunter's account of the fundamentally religious nature of the Odia-speaking people, the authors also had to acknowledge Hunter's ascriptions of abject, superstitious natures to the Odia people. As per Hunter's description, popular memory of the Odia past is populated by shifts in religious beliefs of the community rather than political revolutions. This makes the Odia community seem like an apolitical and

\footnotetext{
32 Two Bachelors of Arts (Niranajan Patnaik and Chakradhar Pradhan) The Oriya Movement: Being a Demand for a United Orissa (Aska: H. H. Panda, 1919).

${ }^{33}$ Ibid, p. $91 .{ }^{34}$ Ibid, p. 91.
} 
insular lot. While this insularity and apathy to political movements could curry favor with the colonial demands in the service of the movement for the formation of a separate province of Odisha, it also meant that the claim to a separate province was based on the separation between the Odia community and the people of the rest of India. Furthermore, in the subsequent discussion, the authors argued that the Odia people were different from the neighboring Telegu-speaking people because the Odias were Vaishnav and the Telegus were Shaivas. ${ }^{35}$ This proposition assumes that all the people being claimed as Odia were Hindu and Vaisnav. It assumes that the adivasi communities of Odisha who constituted almost a fourth of this population were also part of this Hindu/ Vaishnav faith community.

To counter this problem of insularity and the internal difference within the Odia community, the authors sought to focus on the religious landscape of Odisha:

Orissa had been all along known as the Punya Bhumi of India; and the Oriyas feel that the sacredness and sanctity attaching to their country has been defiled by the administrative vivisection which it has suffered at the hands of the British conquerors. In spite of the disintegrating forces, which have been at work as a result of this dismemberment, a living fundamental sense of unity has been fostered by all the hallowed spots and shrines scattered through the length and breadth of the country. As distinct from the other parts of Bharatvarsha the land of the Oriyas presents a spectacle of a marked religious entity. ${ }^{36}$

This focus on the sacred geography of Odisha allowed the authors to situate the province within the broader fabric of the Indian national community without undermining the distinctiveness of the Odia community. The experience of "vivisection" was portrayed as a positive force that trained Odias in espousing a "living fundamental sense of Unity," which could encompass religious and caste difference within the community, and serve as the foundation for a much stronger claim for separate statehood.

This narrative of punya bhumi and Odia religious exceptionalism was not novel in the 1910s and 20s. Narratives centering Odia religiosity had featured in Odia poetry of the nineteenth century. In the late nineteenth century, poets such as Radhanath Rai and Phakirmohan Senapati wrote about the geography of the province and imbued their descriptions with religious motifs and ascriptions. In his travelogue Utkal Bhramanam, Rai

35 Ibid, p. 91. "The Telegus of the presidencies are mainly Saivites, while the majority of the Oriyas are Vaishnavaites. The Madras Oriyas like the people of Orissa follow the Vaisnavism of Chaitanya, the great Hindu Reformer of Northern India.”

36 Ibid, p. 117. 
described Odisha as a "holy land" and a "gateway to heaven." ${ }^{37}$ For Rai, the holiness was an essential feature of the land of Odisha. ${ }^{38} \mathrm{~A}$ succinct example of such poetry is Madhusudan Rao's Utkal Sangeet.

Madhusudan Rao, often celebrated as one of the founders of modern Odia literature, wrote a number of poems that described Odisha or Utkal as a land of religious syncretism. The poem exhorts the readers to remember "mother Utkal" and her glories. The reason for this remembering is to push Odias to work towards the regeneration of the impoverished state of Odisha. While this narrative arc is a rather common nationalist trope, the means through which Rao makes his case is quite inspired. The poem begins with an attempt to make the abstract notion of the region real to the readership. Unlike other such poems that were published later, this concretization of the abstract notion of Odisha is not done through a description of the Odia landscape. ${ }^{39}$ In the absence of an actual province, which covered the areas that Rao would have liked to be included in the province of Odisha, Rao had to resort to a different way to make Odisha real to his readership. Therefore, the first section of the poem had a description of Odisha that provided a religious narrative about the land. Odisha is described as a land "victorious in the field of religion." Rao lists all the different religious sects that congregate in Odisha and describes how this congregation is sanctified during the annual pilgrimage to Puri. This reference to Puri is part of a nationalist narrative trope that recurs in definitions of the Odia community for the next sixty years. Rao's discussion of Odia dharma allows him to enter into a more urgent discussion about the underdeveloped state of the Odia people and their economic deprivation. Towards the end of the poem, Rao inverts the discussion of dharma in to a discussion of karma or labor in the interests of mother Utkal. By beginning with the centrality of dharma to the imagination of mother Utkal and ending the need for karma for the development of mother Utkal, Rao is arguing that in this moment, the importance given to religion needs to be applied to labor for the province of Odisha.

Gopabandhu Das' famous 1920 speech, which insisted that the Odia community be defined in terms of a shared sacred land rather than a shared language, needs to be read within the context of this conflation of religion and Odia geography during the late nineteenth century. Das argued that the instance of the annual pilgrimage to Puri illustrated the unity of the Odia-speaking people as all differences of religion, caste,

${ }^{37}$ Quoted in Behera, p. 82.

${ }^{38}$ Ibid, p. 82. He repeatedly connected Odia land with sacredness in his kavyas such as Chilika and Mahayatra.

39 An example of this would be Laxmikanta Mahapatra's Bande Utkala fanani, which has been adopted as the state anthem in the postcolonial period. 
language, and regional belonging fell away in the act of pilgrimage. The pilgrimage of Puri and inclusion of adivasis in the religious praxis of Jaganath cult illustrated the ethic of "expansive humanism" of the Odia people. This expansive humanism both indexed the particularity of the "Odia" people and allowed them to transcend their particular regional identity and embrace the broader national community.

Das' reference to Puri works for him on two registers: Puri as a regional heterotopia that incites the Odia people to buy into an ethic of inclusive humanism that will transcend social differences and Puri as a national heterotopia in which pilgrimage to Puri allows the individual visitors to transcend national differences in general. In his formulation, Puri becomes a local space where one's place in the nation could be affirmed. It worked both as an ideological beacon as well as an actual space of national pilgrimage. Das' cosmopolitanism is hard to pin down. While it can be said that it seems to pivot on liberal transcendence of particular identities, it is not based on a liberal critique of actual social difference within the Odia community. The absolute social difference between the Odias and the adivasis is never disavowed. While the colonial rhetoric on Odisha underlined fanatic religiosity as well as a civilizational paradox of the coexistence of classical Hinduism with "primitive" adivasis, Das' formulation overturns both these claims into an exemplary social praxis that should be emulated by the rest of India. The underlying assumptions about Odia exceptionalism, however, are carried over from the colonial discourse on Odisha.

\section{Eternal Holy Land: Gandhi's Odisha}

Perhaps it could be possible to label Das' cosmopolitanism as a Gandhian cosmopolitanism that was based on a commitment to absolute difference and a commitment to the local. Das' cosmopolitanism is possible not only because of the inclusive ideological imperative of the cult of Jaganath that could be exported out into the Indian nation but also because of the actual place of Puri, which serves as a transformative space in which all distinctions are lost - a place to be travelled to for this transformation. A place of pilgrimage.

In Gandhi's writings on Odisha and Puri, this transformative possibility of Puri recurs.

For instance, in an article in Indian Opinion written in 1903 where he argued for a better sense of community among Indians in South Africa, Gandhi noted:

There are in India sharp divisions between the different races inhabiting it; for instance, Tamil, the Calcutta men, as the inhabitants of the upper provinces are 
called here, the Punjabis, the Gujaratis, etc. There are also Mohamaddens, the Hindus, the Parsis and others according to religions. Then among the Hindus there are the Brahmins, the Kshatriyas, the Banniyas and others. Now to our mind, if we have brought from India these divisions and differences as very valuable cargo to be treasured up all this distance, then there is no doubt that it would clog us at every slip and hinder our progress. South Africa ought to be to the British Indians a great Puri where all divisions are abolished and levelled up. We are not, and ought not to be Tamils or Calcutta Men, Mohammaden or Hindus, Brahmans or Baniyas, but simple and solely British Indians, and as such we must sink or swim together. ${ }^{40}$

We know from Gandhi's other writing not to confuse this argument for a more cosmopolitan political ethic with a Nehruvian argument for denial of particular identities. But then, what work does "we are not, and ought not to be" doing in this claim. I would argue that there the "ought not to be" emerges from the diasporic status of the South African Indians. If South Africa has to be considered a "great Puri," then travel to South Africa effaces difference amongst the Indians. By corollary then, Puri, in Gandhi's reading, can transform its visitors precisely because they visit. In some ways, it can be read as a philosopher's stone of equality. The act of pilgrimage to Puri is transformative. It is a local place that enables Indian cosmopolitanism.

While it is clear that Puri served as an idealized cosmopolitan space in Gandhi's thought, other readings of Puri as well as Odisha interrupt this reading of the place. Most prominent of these is the question of poverty and famine in Odisha. Many of Gandhi's visits to Odisha coincided with some of the worst famines of the twentieth century. Hence, the recurring reference to the inescapable "shadow of Odisha" that "haunts" him points us to a different reading of the exemplary status of Odisha and its place in the Indian nation. In many of his references to Odisha, Gandhi comments on how the poverty in Odisha is emblematic of Indian poverty in general even as it remains the most spectacular form of this poverty, with his references to starving bodies, orphans and destitution. In his requests for financial support for the Odisha public, Gandhi's use of the term daridranarayan points to his alternative reading of the relationship between Odisha and India. It has been argued that Gandhi's understanding of the nation pivoted on a political praxis of seva to the daridranarayan, as Ajay Skaria has argued, "through the weaving of Khadi, a darshan of the daridranarayan was instituted as constitutive of the Gandhian nation." 41 In his definition of the darshan of God, Gandhi suggests that

${ }^{40}$ CWMG, Vol. 3, 1903, pp. 205-206.

41 Ajay Skaria, "Gandhi's Politics: Liberalism and the Question of the Ashram", South Atlantic Quarterly 101, no. 4 (2002): 968. 
such a darshan is possible only when we look into the hearts of the people: "The darshan of God is fraught with difficulties. He dwells in the hearts of thirty crores of people. If you wish a glimpse of him there then you should merge yourself with their hearts. These thirty crores include all the skeletons of Odisha, Christians, Muslims, Parsis, Sikhs, men, and women." 42 This juxtaposition of the "skeletons of Odisha," with other groups that are defined on entirely different registers, suggests the centrality of a certain reading of poverty and its locus in Odisha to the Gandhian logic of the nation.

\section{Conclusion}

I would like to conclude with two issues that this chapter incites. First, what happened to the inclusive promise of Puri? As the events of the 1930s with the failure of Gandhi's temple entry program in Puri suggests the inclusive ability of the Jaganath cult had some real limits. ${ }^{43}$ The question of dalit temple entry in Puri continues to be a point of contention even today. Furthermore, even within Odia definitions of Odisha, while elite claims for the horizontal brother hood of the Jaganath cult enabled them to claim adivasi areas as part of the new province of Odisha, critiques of the provincial state's treatment of the adivasis in the past sixty years suggests that such claims could just be read as the basis for elite hegemony in Odisha.

Second, what does this discussion reveal regarding the early twentiethcentury ideas about national cosmopolitanism in India? Puri as a site of pilgrimage enabled the imagination of a nation of multiregional people who were transformed into national subjects on their arrival in Puri. The subsequent linguistic organization of the India where regional linguistic interests were avowed allowed the imagination of Puri as a shared religious space that undoes regional differences to endure. However, what were unable to endure were the utopian claims of Gopabandhu Das, Madhusudan Rao, and Gandhi that Puri as well as Odisha was a space in which caste Hindus, Muslims, and adivasis were equal. While we can argue that this was due to the fact the claims themselves were fallacious at their inception, perhaps it should also be noted that the conduct of the

42 Ibid.

43 A 2012 article on NDTV news illustrates how the question of inclusive temple entry still remains fraught. The assault on an American citizen for attempting to climb the chariot of the deity during Ratha Yatra again brought up the question of temple entry and the inclusive ideals of Jaganath. http://www.ndtv.com/bhubaneshwar-news/controversiesover-jagannath-temples-entry-rules-495314 (accessed July 12, 2016). For a historical account of denials of temple entry, see R. Khuntia and B. Bhatta, "Entry of Non- Hindus in to the Jaganath Temple, Puri: A Study, Odisha Review 6 (2012): 107-12. 
postcolonial Odia regional state also contributed to the failure of Puri's inclusive promise. The endurance of a multiregional/multilingual notion of Indian cosmopolitanism at the expense of the figure of the adivasi does demand that we investigate the roots of this endurance and its price more carefully. The next two chapters of this book attend to this investigation of how the figure of the Adivasi was incorporated into the Odia community and, subsequently, into the Indian community during the reorganization of Indian provinces. 


\section{The Invisible Minority: History and the Problem of the Adivasi}

[O]rthodox historians would limit themselves to telling only "what really happened" on the basis of what could be justified by appeal to the (official) "historical record". They would deal in proper language and tell proper stories about the proper actions of proper persons in the past, Thus, insofar as history would be called a science, it was a discipline of "propriety."

Hayden White ${ }^{1}$

White's claim that history was a discipline of propriety is particularly apt in the context of nationalist historiography that often seeks to produce a historical orthodoxy, which laid out a proper record of the community's past. $^{2}$ This chapter is about the creation and impact of an Odia historical orthodoxy. If the first three decades of the twentieth century saw the articulation of an Odia selfhood that came to be increasingly divorced from exclusive definitions of linguistic identity and came to be associated with a more inclusive idea of belonging to a common land then the 1930s saw a concerted effort to produce a historical record of this common land and its inhabitants. However, the need to create a "proper" narrative of Odia past meant that the emerging historiography of the Odisha had to deliberately render invisible a sizable minority of the province: the adivasi communities.

As the notion of linguistic provinces gained support from both the colonial state and the leadership of the Indian National Congress, the idea of a linguistic region of Odisha had to be coupled with concrete definition of and justification for an Odia regional space. We have seen in Chapter 3 that, by the mid-1920s, talk of regional boundaries that would divide existing provinces such as Bihar and Odisha, the Bengal Presidency,

${ }^{1}$ Hayden White, "Preface", in Jacques Rancière, The Names of History: On the Poetics of Knowledge (Minneapolis: University of Minnesota Press, 1994), p. x.

${ }^{2}$ Some parts of this chapter appeared in an article in Indian Economic and Social History Review in 2011. See Pritipuspa Mishra, "Beyond Powerlessness: Institutional Life of the Vernacular in the Making of Modern Orissa (1866-1931)", Indian Economic E Social History Review 48, no. 4 (2011): 531-70. 
and the Madras Presidency into new linguistic provinces had already begun to appear in government deliberations. The Phillip Duff Committee, setup in 1924, was tasked with clarifying the linguistic nature of the Ganjam district of the Madras Presidency and exploring the possible inclusion of this district in the future province of Odisha. As the newspaper coverage of the committee suggests, the Odia political leadership had become increasingly entangled in discussions about the affinity of communities occupying the border regions and the majority populations of the proposed province of Odisha.

By the 1930s, this need to clarify the linguistic nature of the inhabitants of border zones had become crucial because of the institution of the Orissa Boundary Commission. Tasked with the job of drawing the boundaries of the new province, the commission received memoranda from a variety of associations and communities about whether the inhabitants of border districts like the Ganjam district were Odia or Telegu. The need to claim territory as an "Odia-speaking area" became one of the more urgent impulses in Odia historiography of the 1930s. However, this raised a fundamental contradiction. To write a history of Odisha was to write a history of Odia. And as we saw in Chapter 1 , the effort to establish linguistic singularity of the language posed the fraught question of the adivasi. To recap, late nineteenth-century Odia intellectuals claimed that Odia was different from Bengali because of the intermingling of the regional prakrit with the indigenous adivasi languages prevalent in ancient Odisha. The adivasi formed an uncomfortable element in the narrative of Odia origins. In what follows, I will show why the figure of the adivasi was such a fraught presence in the Odia past and present and how efforts were made to incorporate them into the regional community by rendering them into an invisible minority. This chapter illustrates how the adivasi as a historiographical problem was resolved in both histories of Odisha written in the early twentieth century and the regional movement for the formation of the province of Odisha.

\section{The Adivasi Conundrum}

For early twentieth-century Odia historians, the adivasi presence in the Odiaspeaking areas posed a historiographical problem. The need to counter W. W. Hunter's aspersion that the ancient Odias lacked historical achievement required a progressive historical narrative of the Odia past that presented the present-day Odias as most modern editions of a historically illustrious people. However, historians of Odisha were faced with a dilemma. On the one hand, the contemporaneous presence of the "primeval tribal" in the early twentieth century threatened to disrupt this new Odia historicism. On the other hand, it was essential for Odia historians to incorporate the adivasi into 


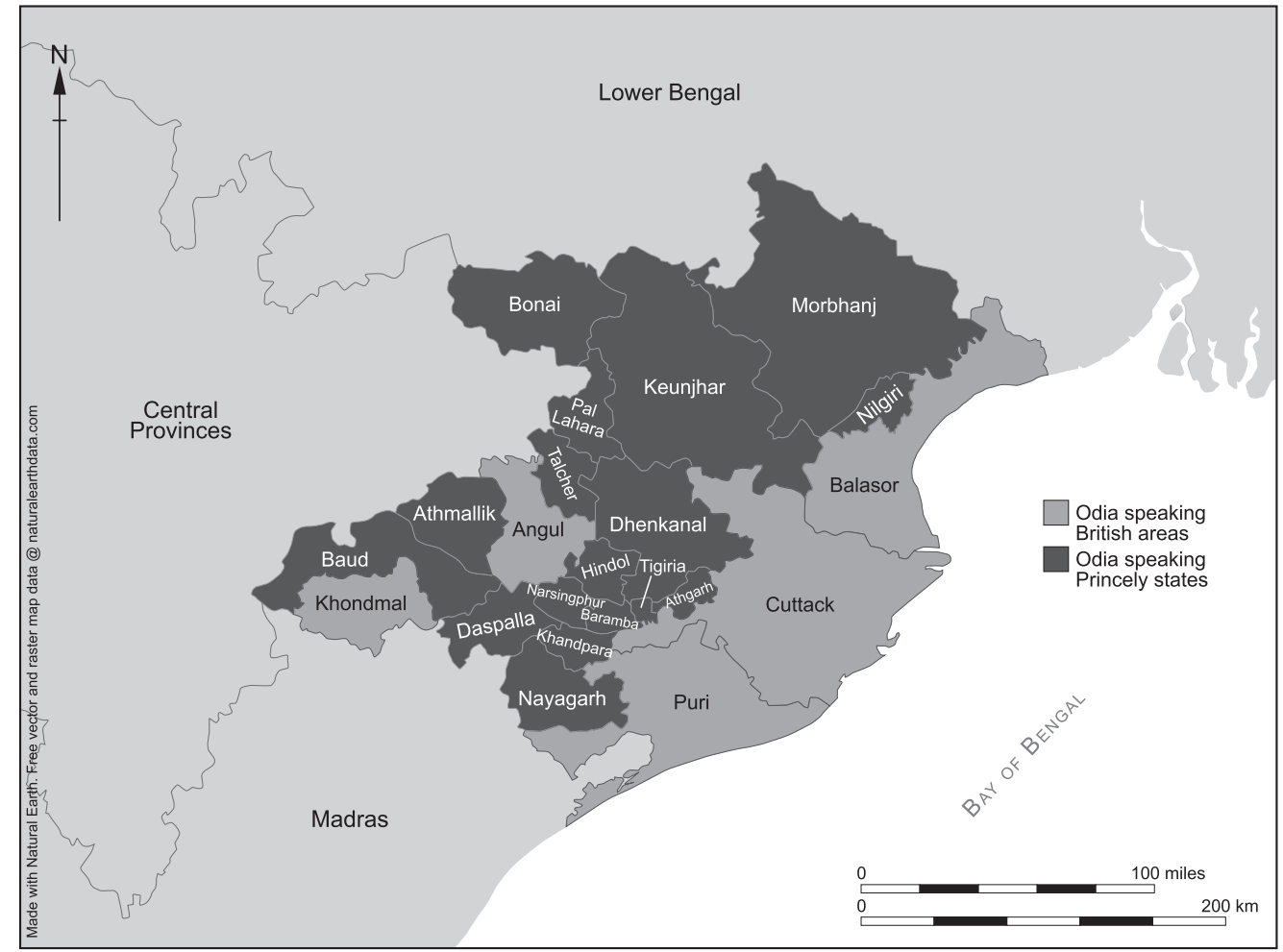

Map 4. 1870 map of Orissa Division of Bengal Presidency and associated princely states. 


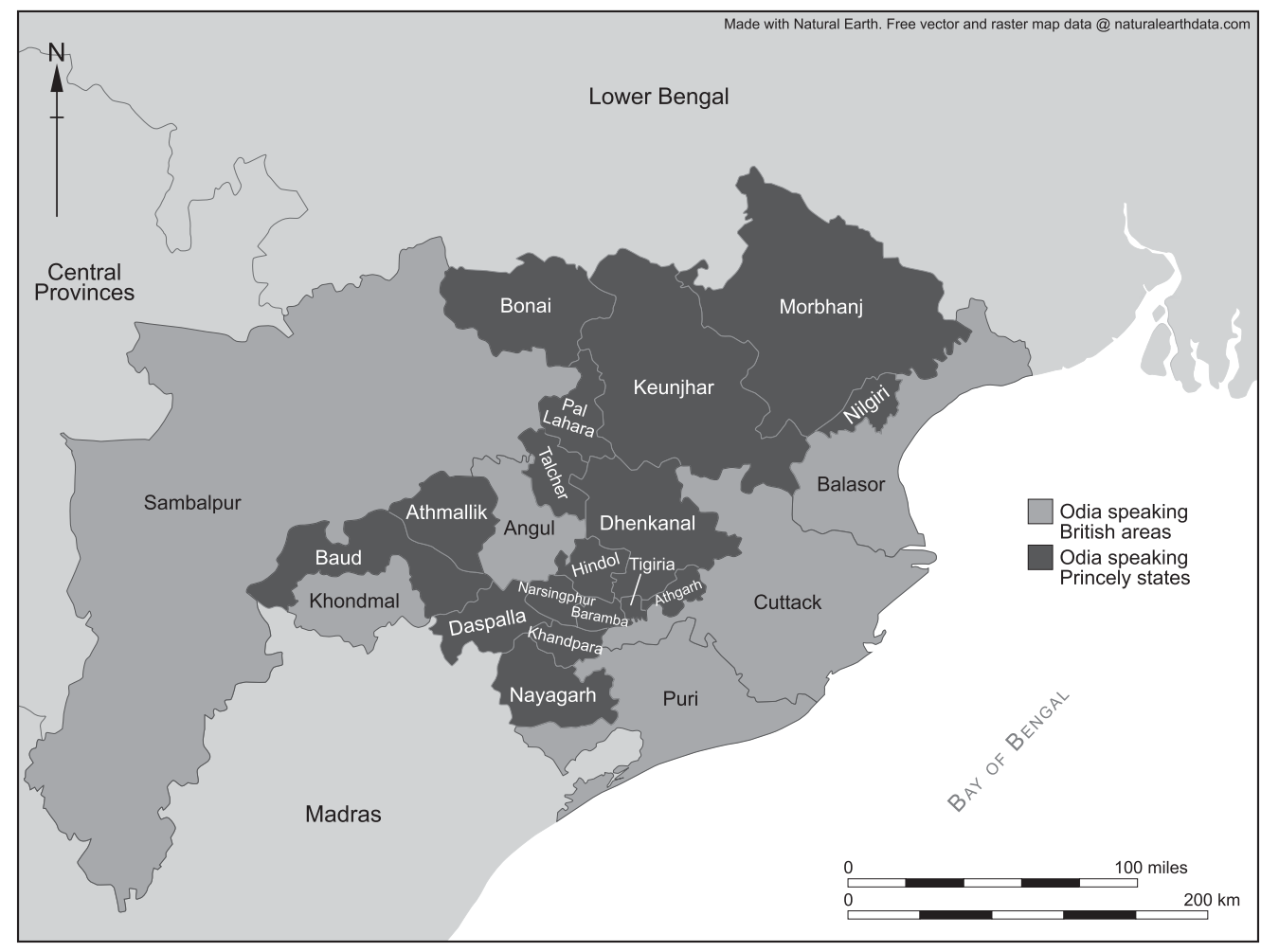

Map 5. 1905 map of Orissa Division of the Bengal Presidency. In 1905, the Odia-speaking areas of the Central Provinces along with associated princely states were attached to the Orissa Division. 


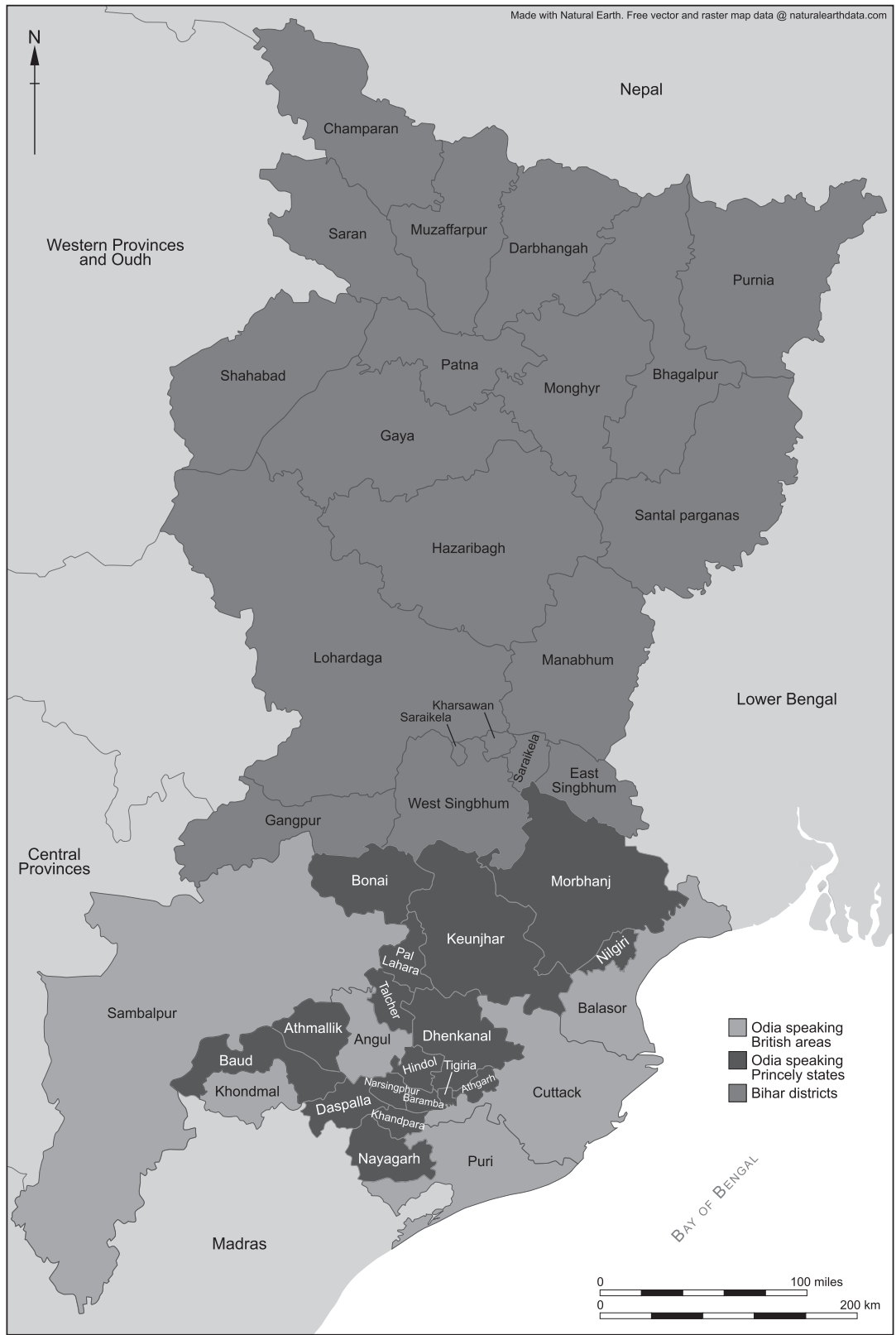

Map 6. 1912 map of the new province of Bihar and Orissa. The province was constituted by excising Bihar and Orissa Division from the Bengal Presidency. 


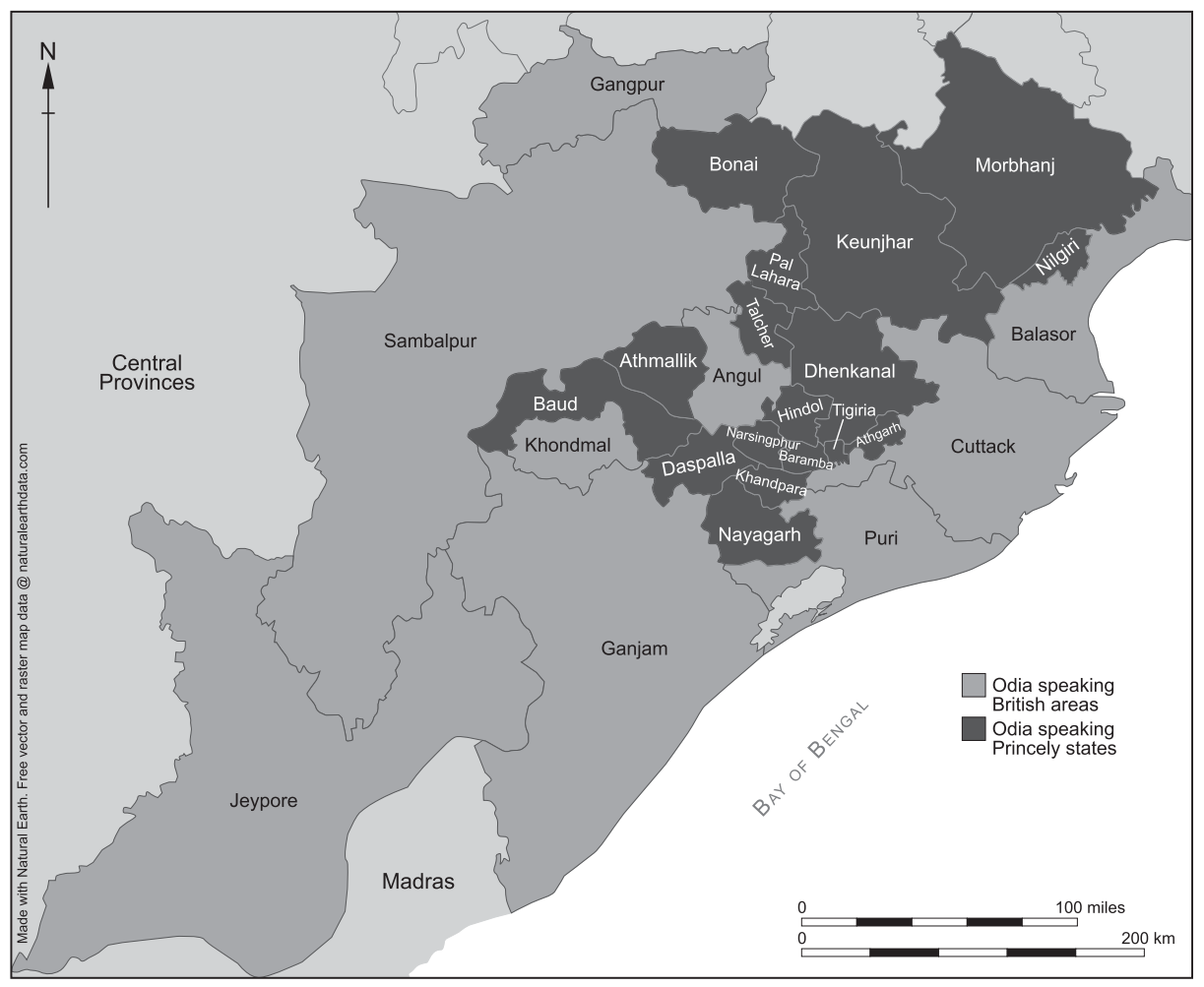

Map 7. 1936 map of the newly formed Orissa Province where the Odia-speaking areas of Bihar and Orissa and such areas from the Madras Presidency (including Ganjam) were brought together to make the new province. 
both the past and present of the Odia community, even as their presence put in question the emergent Odia claims to a higher civilizational status based on an illustrious historical tradition. This was because the movement for the formation of a new province of Odisha through the amalgamation of the Odia-speaking areas required histories that not only illustrated to the colonial government a shared historical past for all such areas but also made a case for the incorporation of the adivasi population (non-Odia speakers) of these areas into the Odia community. Therefore, Odia historians of the early twentieth century were challenged with a three-pronged task: the need for a history that established Odia civilizational and historical bona fides that conclusively proved that the Odia-speaking areas belonged to a single historical past and that incorporated both the mainstream Odia population and the non-Odia adivasi population into a single historical community. This project, both cultural and geographical, faced its greatest challenge in the figure of the adivasi. As she/he was considered neither historically civilized nor linguistically Odia, the adivasi became a sticking point in the histories of Odisha written in the early twentieth century.

In the areas that the Odias claimed as part of the proposed province of Odisha, the adivasi population was sizable. Just the northern and southern part of the proposed province, excluding the western area, contained 230,7144 adivasis of various communities such as Khondh, Savara, Godaba, Poroja, Munda, Oraon, Kharia, Hos, and Bhumij. ${ }^{3}$ This was roughly a fourth of the total population of the areas being claimed as Odisha. Most of these communities were not primarily Odia speaking or Hindu. In fact, quite a few of the adivasis communities spoke their own languages and the tribes were named after the language they spoke. ${ }^{4}$

Theoretically, this problem of the adivasi could have been resolved by what Johannes Fabian calls the "denial of coevalness," where the adivasi is simply seen as an anachronistic presence who could be dismissed as an exception. ${ }^{5}$ Such a case has already been made in the Indian context. In her insightful treatment of adivasi pasts in Bengal, Prathama Banerjee argues that Bengali modernity was "centrally defined by the dominance of the historical." ${ }^{\circ}$ She suggests that the production and sustenance of this modernity required the marking out of a "primitive" within the community. The Santhals of Bengali came to serve as this "primitive within." The Odia case

3 "Memoranda to the Odisha Boundary Commission", in Private Papers (Bhubaneswar: Odisha State Archives, 1931), Appendix B, "The Problem of the Aboriginal Tracts."

${ }^{4}$ Details on the linguistic otherness of adivasis is discussed in Chapter 1.

${ }^{5}$ Johannes Fabian, Time and the Other: How Anthropology makes its Object (New York: Columbia University Press, 1983), p. 32.

${ }^{6}$ Prathama Banerjee, Politics of Time: Primitive and History-Writing in a Colonial Society (New Delhi: Oxford University Press, 2006). 
is slightly different. The Odia primitive is much more intimate than the Santhal is. Therefore, in Odia historiography the adivasi could not be so easily dismissed. The adivasi population played a peculiar role in the constitution of the proposed province of Odisha. The demand for a separate province of Odisha required historical proof of the incorporation of areas where a majority of the population was adivasi. Hence, rather than viewing them as inconsequential temporal exceptions, the Odia historians of this period had to provide a theory that would explain the relationship between the mainstream Odia-speaking population and the adivasi population. Yet this relationship could not undermine the existing hierarchies within Odia society. Therefore, the Odia elite anxiety about the adivasi was based on a paradox. While Odisha as geographical category could not be imagined without incorporating the adivasi into the Odia community, the imagination of the Odia community could not include the adivasi due to his perceived historical backwardness.

The question of the adivasi was not simply an academic conundrum. In this period, history writing was important to anyone involved in the Odia regional political project - the amalgamation of all Odia-speaking tracts under a single administration. Essential to this project was a justificatory historical narrative that produced the "place" Odisha as a long-standing historical and geographical entity. This was especially challenging because a historical Odisha that would be contiguous with the boundaries of the desired province of Odisha had never existed in ancient times. Natural Odisha, as the projected province came to be called, had been four different kingdoms in the ancient times - Kalinga, Utkala, Odra, and Kosala. Present-day historians of ancient Odisha have gleaned from ancient sources like the Mahabharata and the Manusamhita that "these areas were inhabited by the [sic] different stocks of people, but in the course of time they gradually became amalgamated, though the distinct nomenclatures of their territories continued to exist." 7 The modern name Odisha is a tenth-century AD bastardization of the name Odra and its other derivatives such as Udra and Odraka. A geopolitical Odisha akin to the projected "Natural Odisha" came to be established only in the eleventh century AD under the Imperial Ganga Dynasty that ruled Odisha for almost three and a half centuries.

It could be argued that the case for natural Odisha could have been made by referencing the historical Odisha of the Ganga Dynasty. However, the discursive privileging of ancient Indian history as the justificatory marker for early twentieth-century political demands made it essential for the

${ }^{7}$ K. C. Panigrahi, History of Odisha (Hindu Period), 3rd ed. (Cuttack: Kitab Mahal, 1995), p. 4. 
proponents of a separate province of Odisha to prove that Odisha was an ancient geopolitical entity. ${ }^{8} \mathrm{Hence}$, in this period the production of an ancient historical Odisha became one of the more significant projects of Odia regional politics. The effort was to ensure that the emergent histories of ancient Odisha established that the four kingdoms of Kalinga, Utkala, Odra, and Kosala were integrally tied together by cultural and political bonds. Furthermore, the Odia nationalist historians were invested in proving that these kingdoms were inhabited by both the original aboriginal inhabitants of the areas (understood as the ancestors of the adivasis) and the "civilized" Aryan immigrants from northern India.

While Odia historians were engaged in an effort to produce a unified, ancient, cultural, political, and linguistic heritage for the Odia people, the particular political ends served by these narratives defined the limits of what was acceptable as a story of the Odia past. Not just any narrative would do. Odia history writing in this period was a site where the very nature of the modern Odia linguistic community was being produced. The Odia elite's anxiety about incorporating a sizable number of "aboriginal" adivasi groups of the Odia-speaking areas into the Odia community was resolved through specific iterations of origin myths linked with the Odia linguistic community. These myths centered on the Jaganath cult. By implicating both the adivasi people and the Odia-speaking people in a legendary narrative, these legends of the cult of Jaganath served as a bridge between these two groups. Through a reading of the historiographical use of these origin myths, this chapter traces the actual political stakes in producing narratives of the Odia past that would both establish the unity of the adivasi and non-adivasi elements of Odia society and maintain existing social hierarchies between the two groups.

\section{Early History Writing in Odisha and the Need for a Patriotic History of Odisha}

Early histories of Odisha were written by colonial officials in the nineteenth century. These colonial histories of the Odia speaking tracts, like

\footnotetext{
${ }^{8}$ Historians Gyan Prakash, Javeed Alam, and Sumit Guha have illustrated how ancient history is used in India as a justicatory basic of Indian nationalist political rhetoric. See Gyan Prakash, Another Reason: Science and the Imagination of Modern India (Princeton, NJ: Princeton University Press, 1999); Javeed Alam, India: Living with Modernity (Delhi: Oxford University Press, 1999). Also Partha Chatterjee and Lata Mani have shown how the production of orthodox tradition during the early colonial period drew heavily of colonial studies of Indian scriptures rather than from everyday custom. Therefore a reading of ancient texts became central to understand the Indian past. See Partha Chatterjee, The Nation and Its Fragments: Colonial and Postcolonial Histories, Princeton Studies in Culture/Power/History (Princeton, NJ: Princeton University Press, 1993); Lata Mani, Contentious Traditions: The Debate on Sati in Colonial India (Berkeley, CA: University of California Press, 1998).
} 
histories of other regions in early colonial India, were written as guides for colonial administrators. History writing was a colonial exercise in as much as it produced useful colonial knowledge as it created a particular reality for the colonized people. Bernard Cohn points to the ontological power of history written by colonial officials in the nineteenth and early twentieth century. The ontological power of these histories resided in the effects of the knowledge produced on the actual administration of Indian provinces. Cohn argued here that the study of Indian history allowed the Colonial officials to apprehend Indian customs and traditions. This in turn enabled them to effectively rule and administer India. ${ }^{9}$ On the other hand by producing and perpetuating colonial knowledge these histories ossified particular interpretations of Indian society and its past. In so doing they produced a new self-image of the subjects they were seeking to represent. ${ }^{10}$

Similarly, colonial histories of Odisha outlined the nature, of the land, people and culture of the region. These histories were necessarily essentializing and produced a distilled vision of the colonial apprehension of the native Odia. We saw in Chapter 4 that W.W. Hunter described Odisha as a primitive land of no historical glory. Hunter's history serves as an instance of the colonial portrayal of Odisha that provoked the twentieth century native re-elaboration of the Odia past. ${ }^{11}$

Hunter's reading of the history of Odisha was representative of the Orientalist essentialization of the non-Western life. Anouar Abdel-Malek has argued that this effort to essentialize the Orient reads it as both historical and ahistorical. ${ }^{12}$ Hence, the essentialization inherent in Orientalist scholarship involved the production of two parallel readings of the object of study: first, a reading that establishes the object's

${ }^{9}$ See Bernard S. Cohn, Colonialism and Its Forms of Knowledge: The British in India, Princeton Studies in Culture/Power/History (Princeton, NJ: Princeton University Press, 1996).

${ }^{10}$ For instance, Nickolas Dirks illustrates how caste emerged as a colonial construction and became one of the more important factors in postcolonial Indian politics. See Nicholas B. Dirks, Castes of Mind: Colonialism and the Making of Modern India (Princeton, N.J.; Chichester: Princeton University Press, 2001).

${ }^{11}$ W. W. Hunter, Odisha: Or the Vicissitudes of an Indian Province under Native and British Rule ... Being the Second and Third Volumes of the Annals of Rural Bengal \& ... (London: Smith, Elder \& Co., 1872), p. 3.

12 Anouar Abdel-Malek, "Orientalism in Crisis", Diogenes 44, no. Winter (1963). He notes that: "According to the traditional Orientalists, an essence should exist-sometimes even clearly described in metaphysical terms - which constitutes the inalienable and common basis of all the beings considered; this essence is both 'historical', since it goes back to the dawn of history, and fundamentally ahistorical, since it transfixed the being, 'the object' of study, within its inalienable and nonevolutive specificity, instead of defining as all other beings, state, nations, peoples, and cultures - as a product, a resultant of the vection of the forces operating in the field of historical evolution." 
changeless historical essence and, second, a reading that underlines this changelessness by posing it in a historical narrative where everything but the essence changes.

In Hunter's history of Odisha, this dual reading appears in two parallel histories of Odisha: one, the unprepossessing history of the upper-caste Odia population and, two, the history of the primeval adivasi population caught in an equally primeval landscape. Here, the unchanging adivasi and his inability to tame the Odia landscape serve as the essence of Odisha even as Hunter clearly does not equate the adivasi with the rest of Odia's population. Hence, despite the absence of any apparent arguments about the linkages between the upper-caste Odias and the adivasis, Hunter attempted to substantiate his reading of ancient Odisha as a singularly uneventful place with the example of the primevalness of the adivasi.

Even though we have discussed Hunter in the previous chapter, his description of adivasis in Odisha bears further attention. In the body of his book, while Hunter foregrounded the lack of civilization and advancement in his contemporary Odisha, he traced the ancestry of modern Odias to pre-Aryan "aboriginal people." He argued that the earliest inhabitants of Odisha were "hill tribes and fishing settlements belonging to nonAryan stock." ${ }^{13} \mathrm{He}$ saw the modern-day Savara and Khonds as the descendants of these "aboriginal inhabitants" of ancient Odisha. Hunter quotes ancient texts to illustrate the disdainful attitude of the Aryan Sanskrit writers towards these tribes. In such texts, they had been described as cannibalistic people who were a "dwarfish race, with flat noses and a skin the color of charred stake. ${ }^{114}$ However, Hunter argues that these hill tribes were not the only inhabitants of ancient Odisha. They coexisted with other communities "belonging to another stock and representing a very different stage of civilization." 15

Hunter's acknowledgement of the presence of diverse "races" in Odisha coupled with this narrative privileging of the adivasi section of the population enabled him to essentialize Odisha as a land of primeval unhappening. This portrayal of Odisha, particularly the marginalization of the "Aryan" element of the Odia population would potentially undermine later Odia efforts to claim a higher civilizational status through an Aryan kinship with their European masters. ${ }^{16}$

13 B. C. Mazumdar, Odisha in the Making (Calcutta: University of Calcutta, 1925), p. 52.

${ }^{14}$ Ibid, p. $52 .{ }^{15}$ Hunter, Odisha, p. 3.

16 To illustrate the stakes of Hunter's allusion to "Aryans," I must introduce the concept of Aryan and its implications for Indian nationalist historiography. As Tapan Raychaudhury so succinctly put it:

The Hindu self-image has received a moral boost from ... the writings of Professor Max Meuller. His linguistic studies stressed the common origins of Indo-European languages and the Aryan languages. These theories, transported into popular idiom, 
It is against this backdrop that the search for a more flattering history of Odisha took place. Various writers as early as 1907 drew attention to the need for a history of Odisha written by Odias themselves. Odia leaders argued that colonial and Bengali historians had failed to write an adequate history of Odisha that would foreground the cultural heritage of the ancient ancestors of the Odia people. For instance, in 1917, in his article "Prachin Utkal," Jagabandhu Singha critiqued histories written by Hunter and some unnamed Bengali scholars and argued that: "In these times those who can advertise their accomplishments emerge victorious. Those, who remain silent have their ancient heritage appropriated by others." 17

Here, Singha made a veiled reference to the prevailing apprehension among the Odia elite that the Bengalis and the Telegus were attempting to appropriate elements of the Odia historical past. For instance, Singha devoted an entire chapter in his book Prachin Utkal to prove that Jayadev, the renowned author of Geeta Govinda, was Odia and the text was originally written in Odia. ${ }^{18}$ In this chapter, he refuted the contentions of a number of Bengali writers who had claimed Jayadev as a Bengali figure. ${ }^{19}$ Thus, in this period, history writing was a site of cultural contestation between various regions in India. Claims about a glorious historical tradition were not only a response to colonial official narratives about the primitiveness of Odias but also an engagement with neighboring communities like the Bengalis and the Telegus in order to lay stake on the past. This perception of the usurpation of Odia past contributed to the creation of defensive historiography that strove to reclaim the aspects of the Odia past that had generally been ascribed to other regions.

Essays on history published in the Utkal Sahitya reveal that throughout the early decades of the twentieth century, Odia intellectuals were making

were taken to mean that the master race and the subject population were descended from the same Aryan ancestors. The result was a spate of Aryanism. Books, journals, societies rejoiced in Aryan identity ... Educated young men in large numbers affected a demonstrative reversion to the ways of their forefathers ...With fasts, pig-tails, well displayed sacred threads, and other stigmata of Hindu orthodoxy. The name "Aryan" appeared in every possible and impossible context - in the titles of books as much as in the names of drugstores.

Edwin Bryant, The Quest for the Origins of Vedic Culture: The Indo-Aryan Migration Debate (New York: Oxford University Press, 2001), p. 47.

17 Jagabandhu Singha, "Prachin Utkal, Part 1", Mukura 11, no. 9 (1917).

18 Singha, Prachin Utkal (Ancient Odisha) (Bhubaneshwar: Utkal Sahitya Academy, 1964 (1st edition 1929)).

19 The Bengali historian of Odisha was a common figure. Apart from the colonial officials a number of historians from Bengal wrote histories of Odisha. See, for instance, Mitra, The Antiquities of Odisha. By Rajendralala Mitra ... These Are Some of the Relics of the Past, Weeping over a Lost Civilisation and an Extinguished Grandeur ... Published under Orders of the Government of India (Calcutta: Wyman \& Co., 1875). 
an effort to define clearly the project of history writing. Their primary preoccupation was the introduction of a "Western" concept of history into Odia discussions of the past. Therefore, many such essays began with clarifications about the meaning of the term itihasa or history. Contrary to claims by historians that colonial histories written by Indians were driven by traditional Indian understandings of itihasa, these essays explicitly modeled their discussions on a Western understanding of historical writing based on evidence, observation, and a rational search for a past reality.

For instance, in the essay titled "Itihasa," written in 1906 by Chandramohan Rana, the author proposed a new understanding of the traditional term itihasa. He argued that, although the term came from a Sanskrit root, its meaning had changed. Rana claimed that, in its new sense, history meant "a description of some person, community or country informed by its function, origin/cause and future/consequences." 20 Such an articulation of the understanding of history based on functions and consequences reveals the emergence of a functional attitude towards history writing in the early twentieth century.

Interestingly, Rana made no effort to explain the original meaning of itihasa. It appears that the essayist's primary concern was to make a case for the new itihasa. For Rana, the new itihasa was to be modeled after histories written by major classical Western historians like Herodotus. Even as Rana conceded that the histories of Herodotus contained a liberal sprinkling of fiction, he insisted that these histories were the urtexts of a new kind of history writing. Rana pointed out that as such histories did not exist in Odisha. Hence, the task before the intellectuals in Odisha was to write new histories of Odisha modeled on those of the West.

Intellectuals such as Rana applied themselves to the explication of the process of writing such histories. Fundamental to this process was the identification of dependable sources that would serve as evidence. In an article titled "Itihasara Krama" (The Course of History) by Jogesh Chandra Rai, read at the April 1915 Session of the Utkal Sahitya Samaj, the question of historical evidence was raised. Rai called for a concerted effort within the Utkal Sahitya Samaj to collect historical source material on the history of Odisha. He lists five important categories of texts: Madalapanji Temple records of the Jaganath Temple at Puri, genealogical histories collected by the rulers of the princely states, village records preserved in palm leaf manuscripts, minor temple records, and copper plate inscriptions. In spite of this call for attention to such a wide variety of sources, new historians of the early twentieth century depended heavily on the Jaganath Temple record - the Madalapanji papers.

${ }^{20}$ Chandramohan Maharana, "Itihas", Utkal Sahitya 9, no. 2 (1906). 
Consequently, products of such research remained deeply mired in the narrative strategies and evidentiary information provided in the temple records. The result was a deeply Hindu, upper-caste telling of the history of Odisha. ${ }^{21}$

As a result of such discussions about the need to write a new, more scientific history of Odisha, the Prachi Samiti was formed in 1930. Also, a history wing of the Utkal Sahitya Samaj, exclusively devoted to the investigation of the history of Odisha, had been set up in 1915. Most histories written in this period were fostered in these two forums of historical writing.

Even though these two groups covered a variety of historical topics, they were both informed by a common discursive interest in the historical construction of the Odia community. Within the historical construction of the Odia community, there were two main concerns. First among them was the need to create a historical geography of Odisha that would incorporate all the areas being claimed as part of the proposed province of Odisha. Second, historians needed to counter claims like Hunter's primeval description of Odisha by establishing a glorious historical past for Odisha. This project of writing a glorious past for Odisha was threatened by the presence of the "uncivilized" adivasi in the imagined community of Odisha. Hence, historians of this period had to perform a dual task of proving that Odisha was a product of an ancient civilization while accounting for the adivasi presence within the Odia community without undermining their project of giving Odisha a glorious past. For this reason, the figure of the adivasi became one of the most enduring preoccupations in the history writing in Odisha. The rest of the chapter investigates the implications of this anxiety for regional politics in Odisha.

\section{Anxious Origins: Majumdar's Odisha in the Making and the Problem of the Adivasi Origin of the Modern Odia Community}

Odia anxiety about the adivasi reached a flashpoint in 1926 when B. C. Majumdar wrote that not only were there adivasis in ancient Odisha, they were also the ancestors of modern-day Odia people - even those who claimed Aryan heritage. Majumdar, a professor at Calcutta University,

${ }^{21}$ For an assessment of these records, see Kulke, Hermann, "The Chronicles and the Temple Records of the Madala Panji of Puri: A Reassessment of the Evidence", Indian Archives 36 (1987): 1-24. And, more recently, Hermann Kulke, "The Katakarajavamsavali: The Colonial Biography of Puri's Sanskrit Chronicle of the Year 1820," Indian Historical Review 38, no. 1 (2011): 65-75; and Hermann Kulke "Historiography and Regional Identity: The Case of the Temple Chronicles of Puri", faganatha Revisited: Studying Society, Religion and the State in Orissa, New Delhi (2001): 211-25. 
argued in his book Odisha in the Making that "the history of Odisha begins where the history of Kalinga Empire ends." An established and wellregarded scholar of Odia history and literature, Majumdar was tracing the process by which a unified linguistic Odia community came into being. The cornerstone of his argument was that the ancestors of modern-day Odias had no links with the Kalinga Empire and, in fact, came to be identified as Odias as a consequence of the processes set in motion by the fall of the empire.

To illustrate the significance of Majumdar's claim about Odisha and Kalinga, I should introduce the Kalinga Empire. References to the Kalinga Empire abound in ancient Hindu scripture. These texts refer to a very powerful, cultured and prosperous kingdom covering an area roughly contiguous with the proposed province of natural Odisha. By claiming descent from the Kalinga Empire, Odia historians of the period could claim a glorious historical heritage that had been denied to them by historians such as Hunter.

Majumdar's claim and the unfavorable response it provoked among contemporary Odia historians reveals the significance of history writing in early twentieth-century Odia political life. For example, Odia nationalist historians such as Jagabandhu Singh posited alternative linguistic and racial pedigrees for the Odia-speaking people. Singh argued that ancient Odisha, commonly called ancient Utkal, had always been linked with the Kalinga and the two names Utkal and Kalinga were often used interchangeably in the past. Sinha took particular offence at Majumdar's claim that the ancestors of modern-day Odias were aboriginal, "uncivilized" Odra and Utkala races who were later Aryanized by people of Aryan stock and rendered itinerant due to the fall of the Kalinga Empire. Countering Majumdar's depiction of the origins of the Odia language and people, Sinha argued that the Odra and Utkalas were of Aryan descent. The points of contention in these two narratives of the Odia past hinged on the question of the provenance of the Odia language and, by extension, of the modern Odia people.

By the time Majumdar's Odisha in the Making was published in 1926, he was a well-known academic figure in Odisha. A professor at Calcutta University, Majumdar had published many influential texts on Odia literature. Most notably his three-volume Selections from Odia literature was a prescribed textbook for undergraduates in the Odia department of Calcutta University. Odisha in the Making was also designed as a scholarly text and, to this end, Majumdar prefaced his book by clarifying that it was "intended to constitute rather a sourcebook than a story of Odisha for popular readers." 22 The book was commissioned by Calcutta University

${ }^{22}$ Mazumdar, Odisha in the Making, p. i. 
but, due to its paucity of funds, it was finally funded by the Raja of Sonepur, an Odia-speaking princely state.

In this section, I argue that early twentieth-century histories of Odisha had much more than the delineation of an ancient place named Odisha at stake. As the disagreement between Majumdar and Odia nationalist historians such as Singh reveal, it is the question of the racial and linguistic pedigree of the modern-day Odias that is the central matter of contention. While both agree that the modern-day Odias are descendants of the inhabitants of Odra, Utkala, and Kosala, Majumdar's effort to delink the connection between ancient Kalinga and the history of modern Odisha raised an objection from Singh. Majumdar's claim was based on the argument that the ancestors of the modern-day Odias were, in fact, aboriginal tribes who were "civilized" by the invading Aryans and this history did not intersect with the history of the Kalinga Empire. Singh's discomfort with this claim, which established an aboriginal heritage for the modern Odia people, is revealing.

Majumdar's primary object was to investigate:

How and when several tracts of dissimilar ethnic character did come in to the composition of Odisha as it now stands by accepting an Aryan vernacular as the dominating speech for the whole province. ${ }^{23}$

Thus, his text described the process by which a historical Odisha came into being. He hoped to correct what he considered was a prevalent misconception about the historical antecedents of Odisha. He argued that, in writing the history of Odisha, historians should take into account the history of not merely the coastal tract of Odisha. Rather they should investigate how the hilly tracts of Odisha came to be linked in with the province of Odisha. He was seeking to do a holistic history of Odisha. Majumdar held that this exclusive emphasis on the history of the coastal Odisha, particularly Puri, was misleading. This was because rather than the whole of modern Odisha only the coastal tract was part of the ancient Kalinga Empire. Scholars had mistakenly associated Utkala or modern Odisha with the ancient Kalinga Empire. As a corrective measure, Majumdar argued that historians of Odisha should look at the history of the hilly tracts and not coastal areas of modern-day Odisha to trace the history of the land.

He focused on how racially disparate non-Aryan tribes named Odras and Utkalas came to constitute a linguistically homogenous group - the Odia-speaking people. Majumdar argued that the ancient kingdoms of Kalinga, Utkal, and Odra were three distinct but contemporary political

${ }^{23}$ Ibid, p. ii. 
entities before the fall of the Kalinga Empire in the seventh century BC. $\mathrm{He}$ quoted ancient texts such as the Mahabharata to prove that Kalinga was a mighty empire that stretched from the river Ganga in the north to the river Godavari in the south. A highly cultured and economically prosperous empire, Kalinga had actually been mentioned in the Mahabharata as racially akin to the Aryan Angas and Vangas. In contrast, the Utkala people are mentioned in his sources as "rude people of very early origin having no affinity with the races around them." They controlled a thin strip of land that ran contiguous to that of the Kalinga Empire. Similarly, the Odra people populated the northwestern part of present-day Odisha. Majumdar quotes extensively from Huen Tsang's travel accounts to prove that the general disorder and chaos that ensued after the fall of the Kalinga Empire in the seventh century BC was instrumental in the creation of Odisha. It is during this period of transition that the "rude tribes" of the Odras and the Utkalas "poured" into the coastal tract of the erstwhile Kalinga Empire. As this coastal tract was one of the primary centers of Hindu religion, contact with the religious institutions, resulted in the gradual Hinduization of the Odras and the Utkalas to produce the ancestors of present- day Odia people. The name Odisha therefore draws from the word Odra. And Utkal, the classical name for Odisha, draws from the Utkala, another ancient aboriginal people.

Majumdar's argument had two important implications for the study of history. First, by claiming that only the coastal tract of Puri was part of the Kalinga Empire and the Kalinga Empire was controlled by the ancestors of the Andhra people, Majumdar questioned the Odia nationalist effort to claim lineage from the Kalinga Empire. Furthermore, if Puri, the seat of the religious deity of Jaganath, were part of the empire controlled by the Andhra people, then the Odias could not lay claim to the Jaganath cult as a national cultural unifier. Second, the argument that the modern-day Odias, including the Odia upper-caste elite, are descended from the Hinduised aboriginal tribes of the Odras and the Utkalas threatened to muddle the differentiation between the caste known as the Odias and the "adivasis" of the hilly tracts of Odisha.

\section{Recuperating Odra-Rastra: Legend, History and Incorporation of Adivasi Heritage}

Odia nationalist response to Majumdar's thesis was focused on disproving his claim that the Odras and the Utkalas were uncivilized races who had no links with the Kalinga Empire. The Odia effort to establish the antiquity of Odia civilization was not merely a product of the response to 
Majumdar. Odia historians were countering Majumdar's claim as much as they were responding to Hunter's assertion that Odisha was a primeval land untouched by human endeavor. In the case of Utkala, the task was easy because of the Sanskrit roots of the very term "Utkala." Utkala was read as the conjunction of "ut" and "kala." This translated as "high art." That is, Utkala was the land of high art or high culture. In the case of "Odra," the task was not as easy, even as proving that Odra was the name of a civilized kingdom was crucial. This was because Odisha was drawn from "Odra Desa" or "Odra Rastra." Jagabandhu Singh mentioned in an article that the Bengali Vishwakosha defined the Odra as people who were weight bearers. In fact, there were many different iterations of the term Odra in this period. Such references to menial origins of the Odias forced the Odia elite to systematically recuperate Odra from its contemporary definitions in existing historiography.

Here, I will focus on an article written by Satya Nararyan Rajguru, a nationalist historian associated with the Prachi Samiti, titled "The Odras and their Predominancy," ${ }^{24}$ Rajguru was one of the founding members of the Prachi Samiti. Set up in 1931, the Prachi Samiti was intended to throw "light on the hitherto shrouded aspects of the great Kalinga civilization, which carried the arms of its cultural conquest far and wide, and made the 'Greater Utkal'." ${ }^{25}$ The founders believed that the ancient glory of Utkal was lost and with it was also lost the prosperity and pride of the people of Utkal. History was to provide an uplifting memory of a glorious past that would rouse the people of Utkal from the depths of degeneration and powerlessness. ${ }^{26}$ To this end, the Prachi Samiti was striving to bring about a revival of the Odia past through historical writings and republication of ancient Odia texts. ${ }^{27}$

Rajguru's essay was part of this mission to revive a glorious memory of ancient Odisha. In this essay, Rajguru attempted to advance an alternative narrative of the formation of Odisha, one that was based on the redefinition of the term Odra. He affirmed the prevalent understanding among Odia nationalists that modern-day natural Odisha covers the territories of the erstwhile Kalinga, Odra, and Utkala kingdoms. However, in contrast to Majumdar's thesis that Odisha was formed when the fall of the Kalinga Empire resulted in the Aryanization of the

${ }^{24}$ Satyanarayan Rajguru, "The Odras and Their Predominancy", The Prachi 1, no. 3 (1931).

25 “Ourselves", The Prachi 1, no. 1 (1931).

26 "People who made their land the cradle of all fine arts, whose maritime activities established an oversea empire and who kept burning the torch of independence when the same had been extinguished from the rest of India are today alas!, zealots abroad and hewers of wood and drawers of water in the land of their birth!", Ibid, p. 2.

${ }^{27}$ See "Ourselves", Ibid. 
uncivilized Odra and Utkala peoples, Rajguru argued that the Odra people were the first Aryans to come in from the north. Hence, he argued, present-day Odisha is the result of the intermingling of these Odras with preexisting aboriginal peoples of the land and the gradual spread of Odra influence over natural Odisha.

In Rajguru's thesis, the Odras were the fallen Kshatriyas mentioned in the Manu Samhita. He noted that some scholars have interpreted the term Odra as "one who flies." Thus, Rajguru argued that: "The word Odra as interpreted by some scholars is a synonym of a person who flies. Probably this is the first race to fly from the 'Aryavartta' or the northern part of India and settle in the south." 28 This reading allowed Rajguru to establish the Aryan heritage of the Odra people. As opposed to Majumdar's claim that the Odras were rude, uncivilized people who inhabited the fringes of the civilized Kalinga Empire, Rajaguru cited ancient texts, such as the Manusamhita and Bisnuparva, to claim that the Odras were a race of people with a separate spoken language OdraBibhasa. This language was broadly derived from Prakrit and Pali and later came to be known as Odia. The region in which it was spoken came to be called Odisa or, as the British called it, Orissa. The later influx of the Aryan Utkala people resulted in the Sanskritization of the Odia people.

While Rajguru established the Aryan heritage of the Odra and the Utkala people, he also attempted to establish the linkages between the adivasi population of natural Odisha and the Odra people. He focused on two tribes in particular, the Khonds and the Savaras. ${ }^{29} \mathrm{He}$ argued that both of these tribes were the products of the intermingling of the Odra people with the aboriginal people of Odisha. As proof of this, Rajguru took recourse to linguistic analysis of the adivasi languages such as Santhali and Ho. He illustrated the similarities between words in Odia and these languages to prove that languages like Ho are merely local dialects of Odia. This allowed Rajguru to claim that the tribes such as Santhals, Parajas, Hos, Bhils, etc. are part of the Odia-speaking

${ }^{28}$ Rajguru, "The Odras and Their Predominancy."

${ }^{29}$ Perhaps this is because the Khonds and the Savaras were the most widely known of the Odisha tribes. Colonel John Campbell documented his expedition in the Khondmals to eradicate human sacrifice and female infanticide. This text and other colonial recordings of instances of human sacrifice perpetuated the image of the adivasis of Odisha as savages. The Savaras were widely known in the colonial official circles because of their role in the functioning of the Jaganath Temple. From the onset of colonial rule in Odisha, the Jaganath Temple and the annual chariot festivals obsessed colonial administrative resources.

It appears, from Rajguru's choice of examples that his paper was intended partly for colonial officials. This resonates with efforts among Odia nationalist to write histories of Odisha that served as arguments for the amalgamation of the Odia-speaking tracts. See Pradhan and Pattnaik, The Odia Movement: Being a Demand for a United Orissa. 
community and that areas inhabited by them should be included in the amalgamated Odisha.

While linguistic similarities established the membership of the adivasis in the Odia community, the relationship between adivasis and the Odras had to be clarified. As has been discussed earlier, in existing historiography, the Odras themselves were portrayed as the aboriginal ancestors of the modern-day adivasis of Odisha. This coupled with the claim that the Odras were also the ancestors of the modern-day Odia elite who were the product of the Aryanization of the Odras and implied not only that the modern-day adivasis and the Odras are racially linked but also that the modern-day Odia caste elite and adivasis come from the same racial stock.

In order to maintain a clear distinction between the Odia caste elite and the adivasis of the hilly regions of Odisha, Rajguru turned to the originary myth of the Jaganath cult. As Jaganath was considered the most important deity of the Odia people, connecting adivasis to Jaganath legitimized their incorporation into the Odia community. In this myth found in the Madala Panji Temple records, the original devotee of Jaganath was a Savara man named Basu. Indradyumna, a kshatriya king of Malava, sent Vidyapati, a Brahmin priest to bring Basu's idol of the deity to his kingdom. Vidyapati visited Basu and married his daughter. In the course of time, Vidyapati was able to bring the deity to Indradyumna's kingdom. Rajguru argued that the offspring of the Brahmin and Savara Basu's daughter are the ancestors of the present-day Savara. The legend goes that, in recognition of Basu and his daughter's devotion to Jaganath, Jaganath himself decreed that the children of Basu's daughter be recognized as suddho Savara or pure Savara.

The use of the legend allowed Rajguru to make two claims. First, the Savaras were culturally integrated into the Hindu caste system and belonged to the Odia community. Rajguru noted that it is these suddho Savaras who functioned as cooks in the Temple of Jaganath. As any service in the temple was considered a marker of the great devotion and had immense pacificatory powers, the Savaras were assimilated into the mainstream Odia community. Interestingly, while the essay began with a reference to Khonds and Savaras, there was no discussion of the assimilation of Khonds into the Odia community towards the end of the essay. In fact, by the end of the essay, the Savaras had come to stand in for all the adivasis of Odisha. This shift, coupled with the use of the Madala Panji legend, allowed Rajguru to make a case for the cultural assimilation of the Odia adivasis into the mainstream Odia caste community.

Second, although the Savaras are adivasis, they are a fairly evolved race of people. To this end, he described the Savara system of administration and claimed that even that colonial state deferred to their code. 
Furthermore, the use of the legend allowed him to conclude that the "Savaras and the Odras were living side by side in Odisha." This emphasis on the "side-by-side" coexistence is very revealing. Even as the essay seems to be straining against claims about the common origins of the Odia-speaking elite and the adivasis, it is driven by the need to establish that both of them belong to the same community. The use of the expression "side-by-side" enabled Rajguru to claim that the Adivasis of Odisha and the caste Odias belong to the same community without having to accede to any racial commonalities. A common adjacency over a long period of time coupled with a common language was to Rajguru an adequate ground for community.

However, even as he emphasized the cultural advances of the adivasi elements in the Odia population, the use of the myth enabled him to maintain the hierarchies within modern Odia society. The legend of Jaganath implied that while the adivasis were assimilated into Aryanised Hindu Odia society, the terms of their coexistence was based on a clear distinction between the adivasis and the caste Hindu Odia elite.

\section{Naturalizing Adivasi Odisha: Memoranda to the Odisha Boundary Committee and the "Aboriginal Problem"}

These efforts to produce a normative Odia past in which the ancestors of aboriginal tribes and caste Hindus of the Odia-speaking areas lived "side by side" had more than just Odia community pride at stake. The production of these histories was informed by the ongoing discussions within the colonial government to inscribe the limits of the proposed province of Odisha. By 1924, the colonial government had decided to act upon the recommendations of the Montague-Chelmsford Report of 1918-1919 that argued for the reorganization of the British provinces in India on linguistic lines. To that end, the government had instituted the PhillipDuff Committee to investigate the possibility of the transfer of the Ganjam district from the Madras Presidency to the new Odisha province. Similar efforts on a smaller scale were in process in other Odia-speaking areas located in other provinces. This atmosphere of the administrative reform of the political geography of British India was the context for efforts by historians such as Satyanarayan Rajguru in Odisha to construct a unified and glorious past for all the Odia-speaking areas scattered in various British provinces. Such histories produced an Odia historiographical orthodoxy that was put in service of the movement for the creation of a separate province of Odisha.

In 1931, the Odisha Boundary Commission was set up to define the boundaries of the proposed province. The commission received a number 
of memoranda that made the case for the inclusion of various outlying areas in the province. The language of these memoranda, drafted by leading advocates for the formation of a separate province of Odisha, reveals the stakes of history writing in Odisha during this period. History was the means of producing a historical, "long-standing" regional culture that would inform the colonial production of a new geographical and administrative region in India. These histories were creating a concrete geographical region by arguing that in the past Odisha and its people were part of a common experience. Such claims to common history enabled the Odia elite to demonstrate that the Odia people met the basic criteria that the colonial state has set for an ideal provincial area.

The memoranda noted that the Indian Statutory Commission of 1930 had described these criteria as "(common) language, race, religion, economic interest, geographical contiguity." ${ }^{30}$ These criteria, particularly those of common language, race and religion, could be proved only through claims about a shared historical past that was based on a common development of language, race, and religion. As I illustrated in Chapter 1, colonial understanding of the development of language and race was entwined in the study of the origins of Indian languages. Hence to prove that a people shared the same language necessarily involved narratives of origin that established the commonality of race. In the case of Odisha, the effort to prove that all inhabitants of the Odiaspeaking areas belonged to the same community involved more complicated discursive strategies. Owing to the discomfort with claims to common racial and linguistic origins among the "non-Aryan" adivasis population of the Odia-speaking areas and the "Aryan" upper-caste Odia elite, historians such as Satya Narayan Rajguru drew on religious myths from the Jaganath cult to establish a different kind of commonality. However, this different commonality also had to be rooted in the past. This motivated the construction of histories such as Rajguru's treatment of the history of Odradesa.

Rajguru's argument reveals the incredibly productive nature of the Odia historiographical efforts to imagine the Odia community as one comprised of both the Aryan and non-Aryans elements of the population of the Odia-speaking areas. Even as his argument produced a community based on a shared everyday life, his use of the Jaganath origin myth is also indicative of how and why the Jaganath cult became the normative religion of modern Odisha. Thus, historians such as Rajguru and Jagabandhu Singh made the case for a common Odia culture through histories based on the fundamental unity of experience

30 "Memoranda to the Odisha Boundary Commission," 52. 
that belied racial difference. Such a reading of the past also enabled Odia claims to areas inhabited by aboriginal populations that interspersed areas where a majority spoke the Odia language. This was especially crucial because the Odia claims to these areas were threatened by the fact that the aboriginal peoples of these areas had their own languages such as Gond, Ho, Munda, Bhumij, Savara, etc. Hence, as claims to common linguistic identity could not be made in the face of such linguistic diversity, Odia historians and the political leaders had to argue for a community based on a shared historic-geographical space - ancient Odisha. Therefore, these histories written by the Odia historians of the early twentieth century were not only arguing for the recognition that all inhabitants of the Odia-speaking areas were part of one community, they were also attempting to validate the demand for a separate province of Odisha by creating a historical Odisha as a geographical region that may or may not have existed in reality. The importance of this claim to a common Odia past is revealed in the justificatory refrain "since time immemorial" that recurred in the 1931 memoranda sent to the Odisha Boundary Commission.

It is evident from the memoranda that the need to incorporate the adivasi populations into the proposed province remained one of the more anxious preoccupations for the advocates of the formation of the new province. Odia claims to particular districts in the Madras Presidency, Bihar and Odisha, Bengal Presidency, and Central Provinces greatly depended on proving that the sizable adivasi populations of the aboriginal tracts could be counted as part of the Odia community. For instance, one of the memoranda made a systematic analysis of the percentage of adivasis in the population of each district and how the coupling of this segment of the population with the Odiaspeaking nonaboriginal population would constitute a majority - thus justifying the incorporation of that district in the proposed province. This matter was particularly crucial in the case of the southern Odiaspeaking district of Ganjam in the Madras Presidency which has become a bone of contention between Odia and Telegu leaders. As both Odisha and Andhra Pradesh were provinces in the making, both proponents of both provinces laid claim to the Ganjam district, which had sizable populations of both Odia-and Telegu-speaking people. The adivasi people of this district formed the third major demographic of this district. Hence both the Odias and the Telegus argued for the incorporation of this group into their community in order to prove that their linguistic group was a majority in the district. In the discussion of Ganjam in the memoranda written by the Great Utkal League, the author noted: 
These parts are largely peopled by Khonds, Sabars, Porojas, Khondadoras and Godabas. There has always been a sinister insinuation on the part of our opponents to take these people almost as Telegus. To outnumber the Oriya population they are trying to hoodwink the simpler folk with this dilemmatic argument; nonOriyas versus Oriysa. Here they cleverly manage to add the aboriginals to the Telegus and thus to swell up the number of non-Oriyas. And thereby they discredit the Odia claim to these parts. But it is only just that the real issue should be Telegu vrs. Non-Telegu because there are very cogent grounds to take these aboriginals as castes of Oriyas for all practical purposes. The Savaras reside only in Oriya territories and therefore be taken as Oriyas. Gadavas are found only in the Vizag agency and their language was taken as a dialect of Oriya in the 1911 Census Report. Census Report of 1901 takes Poroja as a dialect of Oriya too ... The Indian Government Letter of 1903(No. 3678) rightly remarked "The majority of the people of Ganjam Agency tracts speak Khond which as education spreads is certain to give place to Oriya." 31

Two things emerge from this argument for the incorporation of the aboriginal or adivasi tracts of the Ganjam district in the proposed Odisha province. First, by introducing "cogent grounds to take these aboriginals as castes of the Oriyas for all practical purposes," this argument was attempting to do more than just lay claim to the areas inhabited by these aboriginals by recourse to colonial enumerative practices. The invocation of these grounds indicates an effort to understand the nature of the Odia relationship with the aboriginal people differently. In fact, the discussions in the memoranda about this relationship reveal the tendency among the Odia elite to think of the Odia community and its ability to include the aboriginal communities as an exception. Unlike other linguistic communities such as the Telegus, Biharis, and the Bengalis, which could lay claim to these areas on the grounds of linguistic commonalities, the Odia community, the framers of the memoranda argued, was best suited for the assimilation of these races without encroaching on the interests of the aboriginal peoples. As we saw in the last chapter, this was a common formulation.

Interestingly, this claim to an already present Odisha in the past did not suffice. The memoranda coupled these references to history with a more prescient argument about the need to link the areas inhabited by sizable adivasi populations with the proposed province. This argument was based on an upper-caste paternalistic attitude towards the adivasi populations of the Odia-speaking areas. While arguing for the incorporation of the aboriginal tracts of both Bihar and Odisha and the Bengal Presidency in the proposed Odisha province, one of the memoranda argued:

31 Ibid, 57. 
Be it noted here that the majority of the aboriginal people do not properly understand where their interests lie. We leave it entirely to the Government to judge for them to see if they should allow these people to be swamped by the "combatant Bihari" or the all-absorbing Bengalee. ${ }^{32}$

The protectionist language used to describe the adivasi populations of this area rendered the adivasi into silent nonactors in the rearrangement of the British provinces. While the adivasis were appropriated as members of the Odia community, their participation in the community was curtailed. The argument made by the memoranda was directed towards establishing Odisha's comparative suitability as the primary host for the aboriginal peoples of these areas. The opposition between the "combatant Bihari" or the "all-absorbing Bengali" and the more inclusive yet nonintrusive Odia was based on precisely the kind of historical community that Satya Narayan Rajguru's history of the adivasi relationship with caste Odias produced. However, as the language of the claim quoted above indicates, such a historical community is predicated upon a fundamentally unequal relationship of power between the caste Odias and the adivasi people.

This unequal relationship is explained away in the memoranda by further discussion about the particular adeptness of the Odia people at civilizing and assimilating the adivasi populations of the area. While these claims do not deny the prevalent exploitation of the adivasi people at the hands of the caste Hindus, they claimed that this exploitation was a necessary accompaniment to the gradual civilization of the adivasi population:

We admit that these people have been subject to Hindu exploitation to certain extent, we also hold that the exploitation has gone hand in hand with civilization we don't like to enter into the discussion of the comparative economic position of the Hinduized aborigines. But nobody can challenge that the Hindu culture played prominent part in raising the states of these people and engrafted their culture through the medium of their civilized tongue and if any race in India can claim to have civilized the aboriginal, the most, it is the Oriya, we don't like to travel into the regions of ethnology, but it is certain that Hindi has driven the aborigines to the south-east and Telegu to its north-west till pushed by the Oriya and it is the Oriya who has penetrated into the hilly regions [sic], lived amongst the rude tribe and made them absorb its culture and language and has been continuing as the functional caste among the thousands of aboriginal villages, and it is the Oriya rajas be they of Rajput origin or [sic] of Semi-aboriginal origin who have been so long lending special protection to these people. If any nation is India has ever cast his lot with the aborigines and lived its life with the aborigines it is the Oriya. $^{33}$

${ }^{32}$ Ibid, 83. ${ }^{33}$ Ibid, 95. 
While this statement reiterates the exceptional nature of the Odia community, it introduces a new element into the justification of the incorporation of the adivasi areas into the proposed province of Odisha - the civilizing role of the Odia language. When the argument that the civilizing influence of Hinduism, particularly through the medium of language, has succeeded in "engrafting" adivasi culture into the mainstream is coupled with emphasis on the Odia exceptional ability to incorporate the adivasi population, the claim about the ability of the Odia language to civilize the adivasi population is substantiated.

Considering the possibility discussed in B. C. Majumdar's history, that is, that both the Odia language and people descended from early aboriginal kingdoms of Utkala, Odra, and Kosala, the distancing of the Odia from the adivasi and the establishment of a liberal hierarchy between them reveals the mechanics of discrimination in the imagined Odia community. The statement quoted above not only denies the possibility of a racial kinship between the Odia and the adivasi, it also imitates the British liberal attitude towards the native Indian population in thinking a new kind of kinship. Hence, even as the Odia community is being imagined as a liberal, inclusive, and horizontal brotherhood, this reading of the relationship between the adivasi and the Odia effectively maintained existing hierarchies within the Odia-speaking community.

Interestingly, this argument about difference and hierarchy between the Odia and adivasi coexists with Odia arguments about Odia selfgovernance and the removal of the alien influence of the Bengali and Bihar "intermediary ruling races." Elsewhere in the memoranda, the authors argue that provincial governments in Odia-speaking areas are not truly representative of Odia interests.

On this point, authors of the Montague-Chelmsford reforms remark that:

[G]enerally speaking we may describe provincial patriotism as sensitively jealous of its territorial integrity. In an all India politician of the brightest luster be scratched, the provincial blood will flow in torrents. Even the Provincial Government betrays a mentality and an advocacy that could only be expected from the professional Advocate. The dispatches and letters of the Government of Madras and C.P. since the days of Lord Curzon right up to the time of Sir John Simon, betray an advocacy for the majority community and sensitiveness for territorial integrity which no government constituted for the good government of various peoples under their charge can ever resort to ... Again the "intermediary ruling power" i.e. the majority partners of the province who feed upon the minor partner and appropriate to themselves all the loaves and fishes of service and hold the string of commerce, trace and industry and who force the Oriyas to give up their mother tongue, can never tolerate to the rid of their prey. Under the circumstances mutual agreement can hardly be expected. All imaginable obstacles and pleas will be put forward by 
the people and the Governments to keep their territorial integrity intact. It is for the government to right the wrong they have so long permitted through their stolid callousness. If they fail the destruction nay annihilation of an ancient race, of an ancient language, of an ancient civilization will lie at their door. It must be remembered that it was not by mutual consent that the Oriyas preferred to remain under four different Governments, nor it was by common.

Taken together, the two statements quoted above illustrate the emergence of two ideas of community in Odisha. First, there is the kind of community based on shared everyday life of the Odia and the adivasi where, in spite of quotidian neighborliness, the community is marked by hierarchical divisions. Second, the critique of 'intermediary ruling power" and the oppression of the majority that would lead to the eventual annihilation of the entire Odia community, implies that the writers of the memoranda were invested in a community of equal rights - a liberal community. Interestingly the central argument of the above passage is the possibility of the extermination of the entire Odia community due to the imposition of a different language and culture is oddly reminiscent of the Odia claims about their suitability as "civilizers" of the adivasi people. Clearly, while there is an effort to avoid a destructive homogenization of culture at the national level, the only way the Adivasi question is resolved is through the same process of aggressive homogenization.

\section{Conclusion}

As these memoranda to the Odisha Boundary Commission of 1931 reveal, history writing in early twentieth-century Odisha was employed to produce the proposed province of Odisha as an area deserving of official recognition from the colonial state as a bona fide province. Central to this effort was the need to define the history and membership of the Odia community in a manner that was both conducive to an upper-caste Odia racial exclusivity based on claims to Aryan descent and the need to incorporate those inhabitants of the Odia-speaking areas who were not considered part of this exclusive community of the progeny of the Aryans - the aboriginal peoples or adivasi of Odisha. Although a discussion of the way the ancient name of the Odisha and its inhabitants was interpreted in the early twentieth century by the Odia elite, I have revealed that considerations of racial origin informed the production of a normative vision of the Odia past. In particular, both the discussion of early colonial historiographical portrayal of Odisha as a primeval and uncivilized space and Majumdar's 1926 claims that the Odias were descendants of ancient aboriginal communities such as Odras and the Utkalas illustrates the context for Odia elite anxiety about the need to produce a 
history that was proper to their aspirations for the formation of a strong modern Odia community with a separate province of its own. By the same token, the sizable presence of the adivasi population in the Odia-speaking areas necessitated the production of a historical past that would incorporate these communities in order to justify the inclusion of areas inhabited by them into the proposed province of Odisha.

The use of the expression "side by side" enabled the resolution of this dilemma. However, even as the effort of Odia historians such as Satya Narayan Rajguru was to provide a narrative of the Odia past that featured all members of the modern Odia community, such a history was invested in hierarchical divisions within modern Odia society. What is also being produced here through the incorporation of the adivasis into the Odia community is the idea of language as the primary marker of community. This, in turn, produces the Odia community as a category that can be used to define the particular identity of the Odia/Indian citizen. In Chapter 6, we will see how this move to create neat linguistic regions in which the adivasi elements are made invisible through their incorporation is then institutionalized in the imagination of an Indian federation of linguistic states. As this incorporation occurred to produce India as a collection of discrete linguistic provinces, the adivasis of India were rendered doubly invisible. 


\section{The Genius of India: Linguistic Difference, Regionalism, and the Indian Nation}

There will be people who would cite the cases of Canada, Switzerland and South Africa. It is true that these cases of bilingual States exist. But it must not be forgotten that the genius of India is quite different from the genius of Canada, Switzerland and South Africa. The genius of India is to divide - the genius of Switzerland, South Africa and Canada is to unite.

B. R. Ambedkar ${ }^{1}$

B. R. Ambedkar's claim that the "genius of India is to divide" was at once despondent and hopeful. If left unchecked, this division that was the genius of India could bring the nation to the precipice of yet another catastrophic rupture like the partition of $1947 .^{2}$ And yet, for India to have a genius at all, she would have to be a singular entity. Rupture was not inevitable. India's inherent ability to divide could be harnessed through proper divisions, as Ambedkar would proceed to outline in his 1955 Thoughts on Linguistic States. Also invoked in the idea of genius is a notion of a positive quality of remarkable ability. If the genius of India is to divide, then Ambedkar was claiming that India was remarkably adept at dividing. What an uncanny thought!

Perhaps this claim is not as uncanny when we read it beside claims made by his contemporary, Jawaharlal Nehru. Nehru's celebration of "unity in diversity" has a similar tenor. It is both a celebratory and a defensive phrase. It carried within it the dynamism of threatened rupture. Nehru's unity is always threatened by the specter of diversity. And yet unity thrives. Why? Precisely because the genius of India is to divide.

Read together, these two ways of celebrating the diversity of India betray a shared project among the Indian political elite to establish the terms for balancing cultural, religious, and linguistic difference with the

${ }^{1}$ B. R. Ambedkar, Thoughts on Linguistic States (New Delhi: Ramakrishna Printing Press, 1955), p. 11.

2 A very early version of the second section of this chapter was published in Parallax in (2012). See Pritipuspa Mishra, "The Mortality of Hindustani”, Parallax 18, no. 3 (2012): $71-83$. 
demands of unitary nationalism. In this particular instance, Ambedkar was talking about the linguistic division of India into provinces. By the mid-1950s, when this text is written, the question of linguistic provinces had become crucial to the Indian populace and the postcolonial Indian state.

Such a claim to genius allows us to think about how India is divided and how the anxieties provoked by multilingualism in India are resolved in nationalist thought of the early to mid-twentieth century. Crucial to this resolution is the idea of the linguistic region. While this idea is founded on language it also transcends discussions of linguistic identity onto debates about languaged place - the region.

This chapter shows how this sublimation of language into place or region is institutionalized into the very imagination of India and how this allows both regional and national elites to bypass the question of regional minorities - particularly adivasi or tribal minorities who belong neither to the reigning linguistic nor caste community of the emergent states. This sublimation of language results in the ways in which the limits of regional space and community come to be defined once the reign of one particular language on a region is established.

By making the conversation about place or region, the question of linguistic difference drew on many other questions including finance, boundaries, and natural resources. It also necessarily created monoliths that the state could see as its units. The singularity of Odisha, Bengal, or Assam was already always established when conversations about linguistic difference could take place. In doing so, the question of minority rights could only be dismissed as an intrastate problem. In what follows, I recapitulate how, in the instance of the province of Odisha, the region imagines its relationship with its compatriots who make up the nation, and how the nation imagines its linguistic fragments. This is a history of incorporations of parts coming together to make a whole and of parts being added on to an existing whole. And central to this history is a preoccupation with the detritus of this process of incorporation - the figure of the adivasi.

\section{Odisha Incorporated}

This section explores how the ideal and material life of the province was at play in the movement for the formation of Odisha. In the previous two chapters, I demonstrated how, in the period between 1920 and 1936, the proposed province came to be idealized as an inclusive regional space rather than an exclusive linguistic domain. However, after the province was incorporated in 1936 from various Odia-speaking districts of 
neighboring provinces, concerns about employment, franchise, property rights, and education provoked a return to a profoundly monolingual definition of the region where allegiance to the Odia language came to be the primary alibi for regional belonging.

In these two previous chapters, we saw how the rhetoric of the movement for the creation of a separate linguistic province of Odisha produced Odia as a landed vernacular. In Chapter 1, we saw how, like many community movements bent on producing a territorial base for the community in India, the early politics of Odia linguistic regionalism was marked by a discourse of victimhood that often focused on the threatened status of the Odia language. The Odia language came to be understood as a subaltern tongue, locked in a battle for survival with more dominant languages such as Bengali or English. Consequently, the leadership of the movement often described the Odia people as a besieged group subjected to governmental neglect and exploitation by the neighboring Bengalispeaking people. ${ }^{3}$

However, this imagination of a besieged, victimized but exclusive language community was interrupted by anxieties about the possible exclusion of non-Odia-speaking groups in the proposed province - the domiciled Bengali population, who formed an influential urban minority, and the adivasis communities, who constituted almost a fourth of the total population of the province. In addition, the growing influence of anticolonial politics in the 1910 s along with the Indian National Congress' support of regional aspirations for linguistic provinces meant that articulations of exclusive regional community identity had to be tempered with some commitment to national community building. ${ }^{4}$

\footnotetext{
${ }^{3}$ Such discussions about Odia backwardness abound both in the late nineteenth and the early twentieth centuries. For instance, as the proposals for the removal of Odia from schools in the Orissa division were floated in the 1860 s, a slew of articles on the topic were printed in the weekly newspaper, Utkal Dipika. In March 1869, Utkal Dipika published a two-part article entitled "Utkala Bhasara Unnati Prati Byaghata" or "An Attack on the Development of the Odia Language," which spoke of an assault on Odia culture by Bengali interest groups. See Sudhakar Pattnaik (ed.), Sambada Patraru Odisara Katha, Part 1 (1856-1881) (Cuttack: Grantha Mandir, 1972), pp. 531-6. Much later, as the colonial government invited memoranda and conducted interviews of influential Indians on the question of franchise and representation preceding the publication of the Montague-Chelmsford reforms, the founder of the Utkal Sammillani, Madhusudan Das, gave a speech at the Sammillani where he reiterated the Odia demand for a separate province by arguing that the Bengalis and Biharis were in fact "intermediary ruling races." See Debendra Kumar Das (ed.), Utkal Sammillani (Rourkela: Pragati Utkal Sangha, 2005), p. 423. Similar language was repeated in the various memoranda that were sent to the Orissa Boundary Commission in 1931.

${ }^{4}$ In 1919, the Indian National Congress decided to reorganize its provincial branches on linguistic lines.
} 
Concerns about the exclusive nature of the linguistic definition of community compelled the leaders of the organization to define the proposed province in historical and territorial terms rather than in linguistic terms. As the preceding discussion of the heterotopic production of Odia space and vernacular historical writing of the 1920s and 1930s illustrates, this new emphasis on shared space effected a sublimation of language as the basis of regional territory. As the discussion of my use of the term sublimation in the introduction established, there are two major features of this process. First, it is the sublimation of an unpopular drive to create a region based on exclusive ideas of linguistic community. This unpopular drive needed to be sublimated in order to facilitate the incorporation of Odisha in the larger community of Indian linguistic provinces. The sublimation of language as the basis of community was the price of incorporation. This leads to the second major feature of the process, that is, that the idea that sublimation was always inherently reversible as the drive towards an exclusive Odia identity is what founded the movement for the formation of Odisha. Hence when political conditions require it, the sublimation of language as the basis of regional community could be substantively undone even as the ostensive references to inclusivity remained in place.

Gopabandhu Das' pivotal speech at the 1919 Utkal Sammillani argued for a reinterpretation of contemporary understanding of regional community based on the acknowledgement of a unique ability of the Odia people to embrace religious, ethnic, and linguistic difference. ${ }^{5}$ Often called the "Odia Gandhi," Das argued that, due to their allegiance to the Hindu cult of Jaganath, the Odia people had an exceptional understanding that "at the focus of nationalism is liberal humanism." ${ }^{6}$ Das' claim that the Odia people have understood this observation because of their commitment to the Jaganath cult posed the province as exceptionally adept at being a national space. By alluding to the Jaganath cult and Puri, the site of one of the four most important places of Hindu pilgrimage in India, he was able to suggest that the region of Odisha was a space that allowed transcendence of cultural and ethnic difference. In Nilachal, the seat of the Jaganath cult, he argued: "[T] here is no distinction between big and small, raja and praja, Brahmin and Chandal, friend and foe or

${ }^{5}$ Utkal Sammillani was the primary Odia regional association that lobbied for the creation of a separate province of Odisha.

${ }^{6}$ Gopabandhu Das, Desa Misrana Andolana, Vol. 3, Gopabandhu Rachanabali (Collected Works of Gopabandhu Das) (Cuttack: Gopabandhu Janma Satabarshika Samiti, 1976), p. 16. In the explicit ideology of the cult (if not in its actual functioning), the deity Jaganath is considered to be the "master of the world" and hence accessible to people of all castes and creed. The cult is repeatedly used in Odia political rhetoric to symbolize a regional brotherhood borne out of a transcendence of social difference. 
even Hindu and Buddhist. In the later Chaitanya age even the distinction between Muslim and Hindu was obscured. Because this seed of expansive humanism and pan Indian nationalism lies in Nilachal, over the ages devotees and great men have been attracted to Nilachal." 7

Who, then, belonged in this inclusive nation-space? Das suggested that there should be no distinction between those who inhabit Orissa and those who speak Oriya: "Whether they are from Bengal or Punjab, from Marwar or Madras, Hindu or Muslim, Aryan or Aboriginal, those who have assimilated their selfhood and interest with Orissa - Orissa is theirs and they are of Orissa." ${ }^{8}$ Das' privileging of shared space over shared language underlined the centrality of the category of "Natural Orissa," as the proposed province had come to be named in the movement. In the next two decades of the 1920s and 1930s, a new Odia historicism emerged where scholars tracked the ancient origins of the Odiaspeaking people and marked out the boundaries of the kingdoms inhabited by them. ${ }^{9}$ Through the organization of historical associations, the more prominent Odia nationalists produced a historical orthodoxy about the ancient past of the province of Odisha.

It is in this move from language to space through the writing of history that the sublimation of language as the basis of regional territory took place. As various histories of ancient Odisha written in the early twentieth century attest, the central impulse of history writing in this time was focused on explaining how historical "Natural Odisha" came to be a discrete geographical unit in ancient times. Such a history necessarily involved reconstructing the past of the Odia-speaking people and their historical experience of migration and miscegenation. ${ }^{10}$ More than just narratives of the ancient Odia past, these histories were about the encounters between the Odia and the non-Odia. Who were the ancestors of the modern Odia-speaking people? Were they Aryan or non-Aryan? How do the modern Adivasi communities fit into the history of the Odia community? Historical orthodoxy of this period incorporated the twenty-six different adivasi communities of the area by recourse to the origin myth of the Jaganath cult. It is said that the original devotee of Jaganath was a Sabara tribal chieftain who hosted a traveling prince. The prince discovered the deity in the jungle and decided to settle with the Sabara

${ }^{7}$ Ibid, p. $15 . \quad{ }^{8}$ Ibid, p. 16

${ }^{9}$ For an exhaustive list of texts see Laxmikanta Mishra and Sitakanta Mishra, Historians and Historiography of Orissa: A Study in Perception and Appropriation of Orissan History (New Delhi: Kaveri Books, 2005).

${ }^{10}$ One of the most explicit, if problematic, treatments of ancient Odia migration and miscegenation can be found in B. C. Majumdar, Odisha in the Making (Calcutta: University of Calcutta, 1925), pp.16-18 
community for some time. He married the daughter of the chieftain. The children of this marriage are said to be the modern-day adivasi community and are ritually pure enough to serve in the temple of Jaganath. This origin narrative allowed the Odia elite to both incorporate the adivasi population and yet maintain social difference.

Therefore, the sublimation of language as the basis of regional territory came about through a paradoxical narrative move. The shift from language to place was effected by a historiographical conflation of language and place. In historicizing "Natural Odisha" back to the ancient times, the leaders of the Odia movement were effectively attempting to trace the ancient origins of a people who spoke the Odia language. In order to argue for the creation of Odisha as a geographical entity, they historicized the category that marked the ancestors of the Odia-speaking people as separate from other communities: the Odia language. To historicize Odisha was to historicize Odia.

The rhetoric of Das' iconic speech recurred in subsequent Odia political discourse of the 1930 s and 40 s. In the memoranda sent to the Orissa Boundary Commission in 1931 from various political, historical, and social associations of the Odia-speaking areas in Bengal, Bihar, and Madras, we find echoes and quotes from his discussion of shared space, unique Odia cosmopolitanism, and the shared history of Odias and adivasis. However, once the province was officially instituted in 1936, rhetorical borrowings from the speech shifted radically. Instead of the early emphasis on the inclusiveness of Das' narrative, what came to be foregrounded was his discussion of shared interests and assimilation: "[T] hose who have assimilated their selfhood and interests with Orissa - Orissa is theirs and they are of Orissa." Admission into Odisha required the immigrant to espouse the language and politicoeconomic interests of the province to the complete occlusion of her/his native language and community interests.

Discussions about domicile in the new province of Odisha provided an opportunity for the Odia political leadership to rethink the sublimation of language as the basis of regional community. Within debates about who could have access to resources provided by the Odisha state government, we find that the Odia leadership begin to qualify the narrative of inclusivity introduced by Gopabandhu Das. In the report of the Orissa Domicile Enquiry Committee of 1943, the president of the committee, Godavarish Misra, quoted Gobandhu's 1919 speech. While speaking of Gopabandhu's reference to "fellow countrymen from other parts of India who identify themselves with the prosperity of Orissa" could be considered as referring to Odias due to their allegiance to the state, Misra added a caveat to this inclusive claim by referencing the possibility of those who 
would see themselves as outsiders and seek to exploit the resources of the state. In this vein, Misra argued that:

Orissa is not, either politically or economically, a cosmopolitan province such as towns like Calcutta and Bombay are, though in the sphere of religion it has ever embraced spiritual enthusiasts from all parts of the country. ${ }^{11}$

Here, Misra posits a separation between religious cosmopolitanism and more practical issues of political and economic cosmopolitanism. While upholding Gopabandhu Das' narrative of inclusive humanism of the Jaganath cult, Misra suggests that when it comes to economic and political rights the "sons of the soil" and the "genuine residents" should have absolute rights in Odisha. The rest of the report suggests that this claim for Odia rights is founded on a narrative of Odia underdevelopment and neglect in the years before a separate province of Odisha was formed. The central claim of the report was that a protectionist attitude had to be adopted to undo the damage of a century and a half of neglect of Odia interests. A concomitant discussion about the distinction between immigrants and minorities in the report reveals the grounds for the granting of a domicile certificate are expressly focused on cultural assimilation. ${ }^{12}$ This shift undoes the careful cosmopolitanism of the 1920s where the Jaganath cult allowed for assimilation that enable the sustenance of cultural difference.

This is especially evident in the texts generated by the Orissa Domicile Certificate Enquiry Committee to figure out the requirements for granting the status of domicile to immigrants from other Indian provinces. Manned by prominent Odia politicians, the committee interviewed seventy-eight officials and representatives of political associations from different parts of Odisha and produced hundreds of pages of depositions. Respondents were often posed tough questions about what constituted assimilation and what level of language knowledge was mandatory. For instance, a Telegu-speaking official from the Ganjam district was interviewed in the following way.

Question: You have said that there should be no distinction between the domiciles and natives. It is also a fact that a domicile person is an emigrant. Now you say that there should be no distinction. Don't you think that the basic principle of emigration must be assimilation? Assimilation means he must march with the people of the province.

${ }^{11}$ Report of the Orissa Domicile Certificate Enquiry Committee, p. 7.

12 At one point, the report quotes Nehru's definition of successful immigration: "The very basis of immigration must be assimilation of the immigrants. If he remains alien and an outsider, he is a disruptive force in the body-politic”, Ibid, p. 17. 
Answer: I feel that the basic principle of emigration should be that the emigrant should feel the province his own.

Question: What circumstances should be fulfilled before he can be considered to be merged in the other community - making the province his home, uniting his interest with the interest of the province ... Merger in a major community making his interests equal in par with those of the majority.

Question: You should not claim the language to be recognized as the court language.

Answer: The economic interests of the majority of the people, the economic interests of the province being my interest does not mean that I should lose my language. ${ }^{13}$

Definitions of the Odia community had come full circle to the initial emphasis on language and community interests. While the requirement for assimilation into the language and political economic interests of the region were founded on a preexisting inclusive rhetoric, in reality, such questions could only alienate new entrants into the province.

\section{Incorporating India}

Even as the meaning of regional and national community continued to be debated in provincial India, nationalist leaders of the early twentieth century had to resolve the seeming conflict between unitary nationalism and multilingual diversity. In what follows, I track the history of this effort beginning with Mohandas Karamchand Gandhi's efforts to create a symbiotic linguistic economy of regional mother tongues and a common Indian national vehicular language. I then show how Jawaharlal Nehru, who was to become the first prime minister of India, builds upon this newfound resolution between regional linguistic difference and the need for a national language to produce a contained and domesticated portrait of language diversity in India. Finally, through discussions and critique of the official efforts to institutionalize this tamed linguistic difference onto Indian territory, I discuss the costs of this neat division of India into rationalized linguistic zones. To do this, I examine Bhimrao Ambedkar's analysis of the proposals for territorial reorganization put forward by the States Reorganization Commission. As the leader of the depressed classes movement, the first law minister of India and the chairman of the Constituent Assembly in

${ }^{13}$ Deposition to the Orissa Domicile Certificate Enquiry Committee, Orissa State Archives no. 562 , p. 168. 
charge of crafting the Indian constitution, Ambedkar was uniquely placed to provide a critique of the recommendations of the States Reorganization Commission from the perspective of the minorities. However, despite explicit efforts to make the minorities visible in the future linguistic state, Ambedkar is unable to expose the systematic incorporation of adivasi communities into large culturally dominant linguistic states.

\section{Bilingual Love: Gandhi's Linguistic Imaginary}

Long before he returned to India from South Africa, Gandhi spoke of a common language for the Indian people, a language of political community and populist agitation. Posed as an alternative to the "foreign" English, Hindustani was seen as an amalgam of the Hindu Hindi, Muslim Urdu, and much more. In his discussions about language, Gandhi proposed a new linguistic economy in India that would make English redundant. This economy of languages comprised regional mother tongues, which would form the basis of provincial politics, and a national language, which would allow regional parties to transcend the parochial. I explore Gandhi's dual commitment to what Anne Berger has called the "vernacular and the vehicular" in language. In doing so, I suggest that Gandhi's linguistic imaginary proposed an alternative relationship with regional mother tongues that allows for the simultaneous reign of the vernacular and vehicular.

In making my argument, I am drawing on Derrida's critique of monolingualism in the postcolonial world. In his Monolingualism of the Other, Derrida argues that all culture is essentially colonial. Language, therefore, is never natural property. The mastery of language or the having of language is in itself a colonizing act. Because the master:

[...] cannot maintain any relations of property that are natural, national, congenital, or ontological, with it, because he can give substance to and articulate [dire] this appropriation only in the course of an unnatural process of politicophantasmatic constructions, because language is not his natural possession, he can, thanks to that very fact, pretend historically, through the rape of a cultural usurpation, which means always essentially colonial, to appropriate it in order to impose it as "his own." "

And if language can never be natural property then inheritance of language is possible only by reappropriating it - an act that engenders "appropriative madness" or a "jealousy without appropriation." ${ }^{15}$ If we

${ }^{14}$ Jacques Derrida, Monolingualism of the Other or the Prosthesis of Origin, trans. Patrick Mensah (Stanford, CA: Stanford University Press, 1998), p. 23.

15 Derrida, Monolingualism of the Other, p. 24. 
consider the case of language politics in India from within this problematic then the cultural politics of multiple mother tongues appears to be colonial in two senses. First, it is colonial because of the redefinition of the major postprakrit languages as vernacular by the new colonial elite. I have illustrated how the term "vernacular" is not appropriate in the context of modern India as it invokes properties of indigeneity, locality, and powerlessness that these languages did not necessarily possess. ${ }^{16} \mathrm{In}$ framing these languages as vernacular, colonial Orientalists bestowed on them qualities and deficiencies that would later drive the colonized "masters" of these languages to political movements of "appropriative jealousy." And this is the second sense in which it is colonial.

In his dual commitment to the vernacular and the vehicular, Gandhi posed a radical critique of both colonial and Indian nationalist theories of language. Committed to producing a national economy of languages that would enable wider and more inclusive access to political activism in India, Gandhi eschewed language politics based on "appropriative jealousy." Rather, he suggested that the commitment to the mother tongue enabled the individual's access to other languages just as affect for the mother founds the self's relationships with others.

When Gandhi joined Indian politics in 1915, he entered into a linguistic landscape populated by embodied mother tongues, a chimeral "national" language (Hindustani) and a chauvinistic pretender to the status of national language (Hindi). As I illustrated in Chapter 1, through a century and half of colonial linguistic experimentation and native activism, the major regional vernaculars had come to achieve curiously contradictory qualities. Colonial officials described them as lacking in vocabulary and hence unable to perform modern functions of education and communication. And yet the colonial state saw these vernaculars as the only languages, apart from English, through which the Indian people could be ruled and educated. By the 1910s, Indian vernaculars had discrete demographic constituencies and increasingly more discrete territorial domains. The Indian elite represented these languages as gendered mother tongues that were related and yet parallel to one another. The very weakness that rendered these languages premodern in the state's eyes was also what called for nativist activism in the form of new literary production, lexical innovations, and standardization of vocabulary, grammar, and idiom. According to the native elite, even as these languages were weak, they were also the

${ }^{16}$ Pritipuspa Mishra, "Beyond Powerlessness: Institutional Life of the Vernacular in the Making of Modern Orissa", Indian Economic and Social History Review 48 (2011): 531-70. 
foundation of the modern regional community - the ground from which they could participate in the national community with dignity. In this economy of languages, India came to be constituted of monolingual subjects. On his entry into Indian politics, Gandhi had to contend with the jealously protected political domains of these languages.

Hindustani, in contrast, is a much harder language to pin down. Since the early years of British colonialism in India, Hindustani has had a variable existence. The earliest British mention of Hindustani can be found in George Hadley's grammar of the "vulgar dialect of the Indostan language" in 1772. In later years, the name came to signify a number of different linguistic realities that the new rulers encountered in their early years. ${ }^{17}$ The name "Hindustani" simply signified the language of Hindustan or India. ${ }^{18}$ By the 1930 s and early 40 s, the question of Hindustani animated nationalist discussions about the linguistic, legal, and educational future of India. Organizations like the Hindustani Prachar Sabha worked towards identifying Hindustani as the "largest common factor of languages spoken in Northern India" and attempted to build a compact vocabulary of the language by drawing on words from Hindi and Urdu. ${ }^{19}$ However, we see that this language-in-making gradually disappeared from official documents as it failed to appear in the list of official languages of the 8th Schedule in the Indian constitution in 1950 and was ultimately dropped from the Indian census in $1971 .^{20}$

Much of the blame for the disappearance of Hindustani could probably be laid at the door of lobbyists for Hindi. Posed as an alternative to Urdu and a solution for the anxiety of linguistic variety of India, the Hindi language was viewed by its supporters as a "robust" and masculine language that drew on "native" Sanskrit roots and Khari Boli, a language spoken in rural north India. By the 1910 s, the question of popular language was becoming increasingly important as proposals for the introduction of wider franchise cited the gulf between the Englishspeaking political elite and the rural peasantry as the chief impediment to the success of responsible government. Language and self-rule or

${ }^{17}$ John Gilchrist's $A$ Grammar of the Hindustani Language posed it as the language used all over India by both the literary elite and the illiterate masses. In 1800, he was appointed Professor of Hindustani at Fort William College in Calcutta where he worked towards establishing it as a "language of command." See Alok Rai, "The Persistence of Hindustani”, Annual of Urdu Studies 20 (2005): 135-44 for a history of the ghostly life of Hindustani.

${ }^{18}$ Alok Rai, "The Persistence of Hindustani", 140.

${ }^{19}$ Mentioned in a note by the Bihar Urdu Committee in 1937 in Mohandas Karamchand Gandhi, "A Welcome Move" [1937], in The Collected Works of Mahatma Gandhi, 95 Vols, Vol. 72 (New Delhi: Publications Division, Ministry of Information and Broadcasting Government of India, 1958-1982): p. 209. Henceforth CWMG.

20 David Lelyveld, "Colonial Knowledge", 679-80. 
swarajya became intrinsically linked in subsequent nationalist politics. Throughout his political life in India, Gandhi campaigned for the use of Indian languages in politics and education. Education, he argued, should be imparted in the regional mother tongues to avoid the unnecessary burden of English learning. And nationalist politics should be conducted in a common Indian language - Hindustani.

In the Constituent Assembly debates during the late 1940s, a delegate questioned the efficacy of such a dual commitment to regional languages and a national language. ${ }^{21} \mathrm{He}$ posited: "I cannot understand how these things can go together [...] we cannot hope to have one language for the whole country and at the same time work for the enrichment of the regional languages." 22 How did Gandhi resolve this contradiction in his thoughts? I suggest that the key to understanding how Gandhi sustained this commitment to the vernacular and the vehicular can be found in his approach to "mastery" and the "proper place" of language.

In his statements about the knowledge of and allegiance to languages, Gandhi displays a remarkably nonappropriative, unjealous approach. A few examples from his language statements:

I am interested in language as such. What I mean is that whatever language one may speak or write one's pronunciation should be clear and the grammar perfect. I have not been able to reach this ideal in the case of any language. Gujarati being my mother tongue, naturally, I have love for it. But everyone knows how imperfect my Gujarati is. My grammar is weak, my spelling indifferent. What need I say about my Hindi, Urdu and Hindustani? Yet I have allowed myself to be the president of the Hindustani Prachar Sabha. (June 3, 1946) ${ }^{23}$

In spite of my great love for the English tongue and English people, I have failed to master that language up to now. I commit mistakes in spelling the English words and my English idioms have often been inaccurate, the English words I use are not always appropriate. How can I do otherwise? I learnt the English language not to become a scholar but to convey my thoughts. (January 18, 1934) ${ }^{24}$

[P]lease pick up at least an elementary knowledge of the Hindi language so that you may be enabled to get into the hearts of twenty crores of your brethren in India. Maybe, it is not a substitute for either English or Malayalam. Malayalam is your mother tongue. It is a sin not to know it and not to know it well. Only, if you have an all-India heart or an all-India will, Hindi could be learnt. (January 18, $1934)^{25}$

21 The Constituent Assembly was responsible for the drafting of the Indian Constitution. It met for a little over three years from December 1946 to January 1950 and consisted of 207 delegates from different parts of India.

${ }^{22}$ Quoted in Granville Austin, 'Language and the Constitution: A Half-Hearted Compromise' in Asha Sarangi ed., Language and Politics in India, (New Delhi: Oxford University Press: 2009), p. 89.

${ }^{23} C W M G$, Vol. 91, p. $104 .{ }^{24} C W M G$, Vol. 63, p. 6.

${ }^{25} C W M G$, Vol. 63, p. 6. Here, by Hindi, Gandhi means Hindustani. 
Taken together, these statements about language mastery are a radical critique of the prevailing notions of monolingual affect among Gandhi's contemporaries. Unlike the participants in linguistic cultural politics across India who insisted on the mastery of proper language, Gandhi suggests that good knowledge of language - mother tongue or otherwise - is aspirational rather than essential. As his commitment to the Hindustani Prachar Sabha suggests, lack of felicity in a language does not preclude an investment in it. By being interested in "language as such," Gandhi sought to inhabit a tension between treating all languages as interchangeable ("whatever language one may speak ... should be clear") and the love for a specific language ("Gujarati being my mother tongue, naturally I have love for it"). However, as we see elsewhere in his oeuvre, some sort of love could also be extended to English, too. The only thing that sets Gujarati apart is its status as mother tongue - love for it is natural. Love for English or the commitment to learn Hindustani has to be an extension of this natural ability to love the mother tongue through the adoption of an "all-India heart or an all-India will." Ultimately, his argument for an investment in multiple languages produces a palimpsest of linguistic affect with the mother tongue as the foundation.

When it came to the mother tongue, Gandhi built upon contemporary Indian notions of language-as-mother even as he departed from the exclusivity of such a commitment. ${ }^{26}$ In one instance he argues that "disrespect to the mother tongue is as reprehensible as disrespect to one's mother." 27 This conflation of mother tongue and mother insists on an intimate relationship with the maternal language. As Anne Berger's discussion of Abdelkebir Khatibi's avowal of langage maternel reveals, such an investment in speech-as-maternal is inalienable because it carries in it "the trace of an initial, intimate, ineffaceable, and irreplaceable contact with the mother's body." 28 As in the case of Khatibi, this intimate connection remains intact despite spatial dislocation, as it is no longer linked to a land of origin. In Gandhi, such a connection allows him to carry his love for the mother tongue even as he transcends the region of Gujarat to inhabit the broader Indian nation. It also suggests the impossibility and undesirability of mastery over language as mother. Finally, it allows him to treat his commitment to his mother tongue as a foundational a priori that is not undermined by other linguistic investments. Just as the

${ }^{26}$ Language as mother is a formulation we find in the figure of Tamiltay or Mother Tamil. Also in Odia linguistic politics, the language is called "Utkal Janani." While janani means mother, it also makes specific reference to the act of giving birth. Janani literally means "the woman who gave birth to me."

${ }^{27} C W M G$, Vol. 16, p. 58.

28 Anne Berger, "Politics of Language", Parallax 18, no. 3 (2012): 25. 
relationship with the mother is both foundational and preparatory for all other human connections, the use of the mother tongue enables Gandhi to access other languages.

Hence, rather than a quest for appropriatory mastery, we find in Gandhi's discussions of mother tongue a recognition of the fundamental debt to her - or matririn as Gayatri Chakravorty Spivak puts it. ${ }^{29}$ Matririn - according to Spivak - is a gift that cannot be and is not to be repaid. It constitutes both a debt to the mother and a debt of child rearing owed by her. Unlike the discourse of debt that justified linguistic activism in the politics of Hindi or Tamil, Gandhi's idea of debt accounts for both the labour of the speaker and that of the language. For instance, in Gandhian thought, the task of building a modern vocabulary for Indian mother tongues involves both the labour of the modern speakers of the tongue and the labour of the language itself to represent the lives of its speakers. Speaking of Gujarati he said:

A language takes its form from the character and life of those who speak it. We can say without hesitation that the people whose language does not reflect the qualities of courage, truthfulness and compassion are deficient in those virtues. Importing words expressive of courage or compassion from other tongues will not enrich or widen the content of a language nor make its speakers brave or kind [...] In our own mother tongue, we find a large number of words denoting an excess of meekness, because we have lived under subjections for many years. Similarly, no other language in the world has as many nautical terms as English. Supposing that an enterprising Gujarati writer were to render books on the subject from English to Gujarati, it would not add one whit to the range and power of our language, nor would it in any way increase our knowledge of ships. But as soon as we start building ships and raise a navy, the necessary technical phraseology will automatically establish itself. ${ }^{30}$

Through a focus on the disruptive moment of translation, this passage suggests that the impossible repayment of debt is conducted not through linguistic work (such as new literature, grammars or lexicons) but by action beyond the world of language. However, the placement of life before language, suggested by the way Gandhi supposes language will catch up with changing realities, appears to disrupt the notion of language as the originary mother. Or does it? His commitment to action that would eventually lead to the modernization (but not Westernization) of language is possible because the mother tongue is always foundational, always available to adjust to life of the child-speaker.

This passage also illustrates Gandhi's departure from the Orientalist condemnation of Indian languages as being "unfit" for modernity.

${ }^{29}$ Gayatri Spivak, "Translation as Culture”, Parallax 16 (2000): 15.

${ }^{30}$ CWMG, Vol. 16, p. 73. 
Rather, Gandhi argued, the lack of vocabulary was a reflection of actual lacks in the Indian economy and society. By juxtaposing a vocabulary of colonized meekness and that of British naval power, this passage recuperates an older notion of Indian deshi language as languages that evolved to reflect a changing world. ${ }^{31}$ In doing so, Gandhi overturns the colonial narrative of linguistic lack even as he places the blame for this lack on the violence of colonialism.

Tied to his reluctance about mastery over language was Gandhi's insistence on the "proper place" of language. Speaking of the need to learn Hindi (Hindustani) along with one's own mother tongue, Gandhi said to his Malayalam-speaking audience: "Each is good in its own place and will serve its purpose accordingly. May I illustrate this point? Malayalam in the Punjab is useless, so is English for a Punjabi farmer. But if you speak to the Punjabi in Hindi, e.g., 'Salamalikum,' he will smile at you and he will say, 'I know him'." ${ }^{32}$ The notion of "proper place" recurs in much of Gandhi's writing. The Gujarati term often used in his writing on the "proper" was thekaana. Etymologically linked with staan or place, thekaana is a "place that is home or dwelling, including one within some hierarchy or order. A thekaana is not externally assigned; it is a destination that is a thing's or being's own. Objects cannot have a thekaana; only that can come home which has a proper." 33 Thus the proper place of language or its thekaana depends on what is home to it. The proper place of the mother tongue would be the home, school, the province, and the nation. However, even if it is at home in the nation, the mother tongue is implicated in a broader order of languages that the notion of thekaana implies - remember "Malayalam is useless in Punjab."

What then would be the proper place of Hindustani? As a language that shuttled between two languages, Hindi and Urdu, Hindustani was yet to be formed. To borrow a precolonial term, Gandhi's avowal of Hindustani posed it as a new marga language. ${ }^{34}$ A new language of the road constantly shuttling, binding, traversing between homes of various Indian mother tongues. Even if it would someday be a "stately language, which will serve the crores of India," Hindustani was emphatically no mother tongue. Rather, as Gandhi's repeated references to the birth of the language suggests, it was to be an offspring of the nation. Hence, its only proper place was the nation rather than the home or the school. Its very

${ }^{31}$ See Mishra, "The Mortality of Hindustani”, 73.

${ }^{32} C W M G$. In this instance, by Hindi Gandhi actually means Hindustani.

${ }^{33}$ Ajay Skaria, "Only One Word, Properly Altered: Gandhi and the Question of the Prostitute", Postcolonial Studies 10 (2007): 224.

${ }^{34}$ Marga in the precolonial period designated vehicular languages such as Sanskrit and prakrit. 
domestication was fundamentally nondomestic because it connected only public spaces. In doing so, Hindustani would replace English whose proper place was not the Indian nation. While this disavowal of English could be read as chauvinistic nativism, his treatment of the language suggests that in the orders of thekaana English simply belonged to a different home. It was, as Gandhi repeatedly called it, "an international language of commerce." Its home was beyond the Indian nation.

As we see, for Gandhi there was no conflict in investing in his mother tongue and working towards the development of Hindustani. Thinking of mother tongue as mother enabled Gandhi to undo the dually colonial nature of Indian linguistic politics. He neither bought into the colonial discourse of linguistic lack and servitude that the term "vernacular" invoked, nor participated in a colonizing appropriative linguistic jealously. By maneuvring out of the logic of colonialism, Gandhi was able, albeit for a short time, to imagine an Indian nation that was at once linguistically diverse and linguistically united without recourse to the language of colonialism itself: English.

Gandhi's engagement with linguistic difference and the search for a common national language is perhaps the most sustained discussion of this kind in India. Even as his Hindustani project does not survive in official circles past the first few years after independence, Gandhi's case for a palimpsest of linguistic affect for the vernacular as well as the vehicular provided a powerful alibi for the Indian National Congress to change its stance on linguistic provinces. In arguing that both the regional mother tongue and the national language have a proper place, Gandhi implicitly accepted the idea of linguistic regions and gave the demand for such regions some degree of legitimacy. To ask for a linguistic region was no longer an attack on the unity of the nation. Hence, in contrast to an earlier policy of noninterference in regional linguistic politics, Congress moved to enthusiastically support the regional movements for linguistic states from the 1920s onwards. Much of this enthusiasm was enabled by the vague and ideological nature of Gandhi's linguistic imaginary. Without concrete discussions about boundaries, domiciles, jobs, economic viability, or the status of minority populations, this new comfort with linguistic difference could easily support various regional movements for linguistic states that were often at odds with one another. ${ }^{35}$ Such fights, if acknowledged, would disrupt Indian unity.

${ }^{35}$ For instance, the fight between Andhra Pradesh and Odisha over the district of Ganjam or the fight between Bengal and Assam over Darjeeling. 


\section{Manageable Difference: Nehru and the Politics of Language}

These divisive possibilities, borne out of the concrete realities of regional linguistic politics, would eventually plague Jawaharlal Nehru at the moment of independence. However, in the two decades before independence, Nehru would build upon Gandhi's vague linguistic imaginary to resolve the question of language in Indian politics. His own insistence on treating the question as a very simple quest for a national language was founded on an assumption that the regional languages and their domains were not sites of contestation and struggle. Rather they served as the basis of popular access to democratic politics.

Sanjay Seth argues that the vagueness in Nehru's Discovery of India about the inherent Indianness or Indian geist enabled him to "avoid possibilities which he considers dangerous." " If at the end of his discovery of India, Nehru had described what he found in positive terms then it would have produced a nation that was too narrow to hold Indian diversity in it. Maintaining Indianness as a series of ahistorical and essential qualities - tolerance, inner urge or powerful impulse - allowed Nehru to craft a nation that would survive any particularity that could threaten its unity. This strategic deployment of vagueness is also evident in his take on the politics of language in India.

In his writing on the language issue, Nehru repeatedly denied that India had too many languages. In his 1937 essay, "The Question of Language," he contended that it is "the cry of the ignorant that India is a babel of tongues with hundreds and hundreds of languages." 37 In fact, he said, India has remarkably few languages considering her vast size. Later, in his 1944 Discovery of India, in an uncharacteristic indictment of scholarly consensus of his time, he argued that "the oft repeated story of India having five hundred or more languages, is a fiction of the mind of the philologist and the census commissioner who notes down every variation in dialect, and every petty hill-tongue on the Assam-Bengal border with Burma as a separate language, although sometime only a few hundred or a few thousand people speak it." ${ }^{38}$ Such a claim is surprising when we

${ }^{36}$ Sanjay Seth, "Nationalism, National Identity and 'History': Nehru's Search for India", Thesis Eleven 32 (1992): 37-54.

37 Jawaharlal Nehru, "The Question of Language" in The Unity of India (New York: J. Day, 1942), p. 241. This essay draws heavily on Gandhi's arguments about Hindustani. It was written at Gandhi's behest to shore up support for Hindustani from opposing Hindi and Urdu camps when communal tension reached a high point. Gandhi read and commented on it repeatedly. Subsequently, Nehru sent it to Jinnah as a means of addressing the Hindi-Urdu controversy. For a history of the text, see Robert King, Nehru and the Language Politics of India (New Delhi: Oxford University Press, 1999).

${ }^{38}$ Jawaharlal Nehru, The Discovery of India (New Delhi: Oxford University Press, 2004), p. 169. 
note that it was made almost three decades after Grierson's monumental Linguistic Survey of India was published. As his many references to philological concepts in the Discovery of India suggest, this charge of "fictional philology" could not really have been a product of his ignorance of contemporary scholarship on language. Rather, his comparison of the Indian case with the German one where the wily philologists had claimed that there were sixty languages suggests that something other than conservative ignorance is at play here.

As Partha Chatterjee has suggested, by the late 1930s, Nehru was already approaching questions of national unity as a future state leader. ${ }^{39}$ The idea of Germany having sixty languages was preposterous to Nehru because of the prevailing understanding of Germany as the quintessential monoglot nation-state. His use of the German example implies that his insistence on fewer Indian languages was informed by his need to see how the future Indian state could harness differences. At issue here is not what is correct philological knowledge, but what the emergent nation-state should see - to borrow James Scott's phrase - as the primary linguistic categories that constitute India. ${ }^{40}$ This explains his reluctance to acknowledge linguistic variety in India.

These debatable claims are then occluded by his repeated use of language lists that give the semblance of factuality and precision. Hence even as he appears to be wrong about the nature of linguistic diversity in India, he is emphatic in his claim that there are precisely fifteen languages in India. Not only this, his language lists are often posed within discussions about national unity:

It is fascinating to find how the Bengalis, the Marathas, the Gujaratis, the Tamils, the Andhras, the Oriyas, the Assamese, the Canarese, the Malayalis, the Sindhis, the Punjabis, the Pathans, the Kasmiris, the Rajputs and the great central block comprising of the Hindustani speaking people, have retained their peculiar characteristics for hundreds of years ... and yet have been throughout these ages distinctively Indian. ${ }^{41}$

The pictorial quality of this list is striking. It is not a list but a portrait or map of India - with a Hindustani heart surrounded by monolingual groups. Even though these language groups share an Indian quality, they are marked by their particularity. Despite his explicit liberal aspirations, such a list underlines the fact that the people of these language

39 Partha Chatterjee, Nationalist Thought and the Colonial World: A Derivative Discourse (Minneapolis: University of Minnesota Press, 1984).

40 James Scott, Seeing Like a State: How Certain Schemes to Improve the Human Condition Have Failed (New Haven, NJ: Yale University Press, 1998).

41 Nehru, The Discovery of India, p. 63. 
groups are not mutually interchangeable. The Indian citizen could not possibly be a universal liberal subject. She/he was always already languaged. However, by listing and linking these languages with each other and with national unity, Nehru was able to contain and domesticate linguistic difference. Not only were there strikingly few Indian languages, they were also no threat to national unity. Rather, they served as the basis of sociopolitical life in the regional India and were never at odds with allIndia nationalism. ${ }^{42}$

What was lost in this simplification and domestication of linguistic difference? Clearly, many languages were written out of the Indian community. But along with the languages, their people were also written out. Nehru's fifteen languages could now represent adivasi communities that did not belong to them. By dividing Indian territory into these neat and discrete linguistic domains without any reference to conflicts within these domains, Nehru produced linguistic regions as empty spaces that could hold all other registers of difference - religious, caste, or even class. These fifteen languages trumped all other difference within these communities. In the categorical logic of the emergent Indian state, linguistic divisions were the most effective and safe means to divide the population.

Despite his unrealistic understanding of language variety in India, Nehru saw knowledge of language as a crucial precondition to the success of the Indian democratic state. These languages, he argued:

[A]re ancient languages with a rich inheritance, each spoken by many millions of persons, each tied up inextricably with the life and the culture and ideas of the masses as well as of the upper classes. It is axiomatic that the masses can only grow educationally and culturally through the medium of their own language. Therefore it is inevitable that we lay stress on the provincial languages and carry on most of our work through them. The use of any other language would result in isolating the educated few from the masses and retard the growth of the people. ${ }^{43}$

This commitment to regional languages that connected the masses and the elite also shaped how Nehru envisioned his chosen national vehicular language - Hindustani. Ideally, Hindustani was to be a "living language," "a throbbing, vital thing" that has its "roots in the masses." The location of this language was in the home or the market place. ${ }^{44}$ If one looked for it in literary societies then one would find only Hindi and Urdu. A link language, Hindustani had to be founded on everyday experience because it had to "represent and mirror the life of the people as a whole and not that of a small group of people." To ensure that everyone had access to the language, Nehru suggested that it be simplified into Basic Hindustani.

42 Nehru, “The Question of Language”, p. 249. ${ }^{43}$ Ibid, p. $243 .{ }^{44}$ Ibid, p. 249. 
Much like Basic English, Basic Hindustani would have a really simple grammar and a very small vocabulary.

Ultimately, Nehru's thoughts on language hinged on his search for solutions to two fundamental problems in the building of the new nation. While he was concerned about domesticating potentially divisive linguistic difference, he was also addressing the problem of class difference- the distance between the masses and the elite. As I have shown in Chapter 3, the question of regional languages became important in the 1910s at the precise moment when the earliest efforts towards introducing popular franchise were being instituted. As the documents concerning the 1918 Montague-Chelmsford constitutional reforms illustrate, the colonial government posed the linguistic distance between the elite and the masses as a primary reason for limiting franchise to a smaller group of people. While doing so, the officials who put together the report on franchise argued that the Indian masses needed to be protected from the Indian elite precisely because the elite was out of touch with the masses. As I argued earlier, the decision to acknowledge provincial linguistic territorial demands within the Indian National Congress was compelled by this charge of elitism. Staking a selected number of regional vernaculars and a bizarre Hindustani as central to the praxis of democracy and development in India allowed Nehru to address both the problem of linguistic difference and the problem of class difference. Hence, for Nehru, both the regional vernaculars and Basic Hindustani were link languages essential to the Indian body politic. What is missing in Nehru's writings on language up to this point, however, is any acknowledgement that such linguistic populism is often implicated in operations of elite power. Such a critique of language would only come from B. R. Ambedkar in the 1950s.

Upon independence in 1947, Nehru retained his straightforward understanding of language politics in India. However, as the agitation for a linguistic state mounted and it became increasingly clear that language politics hid within it caste and class politics, Nehru was forced to reconsider his stand on regional languages. In his private correspondence of the 1950s, we see an acknowledgement that he was wrong to assume that language politics was simply about language. ${ }^{45}$ Immediately after independence, he set up the Dhar Committee to look into the question of linguistic reorganization of the Indian provinces. The committee recommended that the question be deferred, as the nation had many challenges to face before any careful reorganization could happen. However,

${ }^{45}$ For details, see Robert King, "The Private Nehru", Nehru and the Language Politics of India, pp. 140-86. 
agitation for provincial reorganization continued. In 1952, Potti Sriramalu, a leader of the Andhra movement, died while on hunger strike as he demanded a separate province of Andhra Pradesh. This forced Nehru's hand and he had to begin the process by setting up the State Reorganization Committee.

\section{The Problem of Minorities: Ambedkar and the Reorganization of the Indian Provinces}

As a response to the recommendations of the States Reorganization Commission, Ambedkar wrote what can only be called a "minority report." In his Thoughts on Linguistic Provinces, Ambedkar analyzed the plans for reorganization of the Indian states from a point of view that did not take the Nehruvian neatness of Indian difference for granted. As Anupama Rao has illustrated, his experience as the leader of the dalit movement made him uncomfortable with the nexus between language and caste power in regional India. ${ }^{46}$ In his essay on the formation of the separate state of Maharashtra, he even goes so far as to say that regional language should not be the official language of the linguistic states as this could privilege a regional caste elite. From this discomfort emerged his reluctance to allow the concentration of power in a few large Indian states. To this end, he argued for more division of Indian territory to break up such concentrations and enable minorities to have greater representation within the provinces.

Based on the resolution passed in the Indian parliament in 1952, the States Reorganization Commission (SRC) was asked to balance linguistic grounds for state creation with consideration of the ultimate unity and security of the nation, cultural homogeneity, and financial viability. ${ }^{47}$ The SRC recommended the formation of mostly monolingual states, which brought together all speakers of a language under a single administration one language, one state. The only exceptions to this rule were the many large Hindi-speaking states in the north and the bilingual state of Maharashtra and Gujarat. Ambedkar opposed both these exceptions and further suggested that any large unilingual states should be divided to make smaller monolingual states - one state, one language. In the case of large

${ }^{46}$ Anupama Rao, The Caste Question: Dalits and the Politics of Modern India (Berkeley, CA: University of California Press, 2009), p. 42. "Dalit" was a term coined in western India to denote the untouchable community. Literally, the term means the oppressed. In official language of the colonial state, they were called either the scheduled castes or oppressed peoples.

47 Government of India, Report of the States Reorganization Commission, (New Delhi: Government of India Press, 1955), p. 25. 
northern Indian Hindi-speaking province, he argued that the northern provinces were so large in comparison to the "balkanized" southern states that all governmental power could be concentrated in the north. ${ }^{48}$ By the same token, he warned that the mammoth size of the Maharashtra/Gujarat province would mean that the minorities in the provinces would either be "crushed" or "tyrannized and oppressed."

In sharp contrast to Nehru, Ambedkar insisted that there was no place for idealism in plans for linguistic provinces - "Politics is nothing if not realistic." The status of minorities in the Indian provinces had to be considered carefully and checks and balances had to be put in place to ensure that the tyranny of the majority was not encouraged. One of the checks would be to make the states smaller because this would decrease the magnitude of the numerical difference between the majority and minority populations. He argued that "a small stone of the consolidated majority placed on the chest of the minority may be borne. But the weight of a huge mountain it cannot bear. It will crush the minorities." 49 A second safeguard for minority rights could be special provisions for representation of minorities in the legislature. However, the Indian constitution did not allow separate electorates. Hence, Ambedkar noted with much pathos: "The lambs are shorn of the wool. They are feeling the intensity of the cold. Some tempering of the wool is necessary." ${ }^{50}$ This is where Ambedkar's optimistic understanding of India's divisive genius comes in. When separate electorates are not possible then, he suggests, we divide the constituency itself so that more than one member is returned from each constituency, thus giving the minority greater representation.

As the central preoccupation of this chapter is the figure of the adivasi, Ambedkar's use of the term "minority" is of particular interest to us. In his Thoughts on Linguistic States, Ambedkar uses this term to denote a specific minority group - the dalit. However, at no point in his minority critique of linguistic states does he mention the adivasi communities as minority. And, in doing so, he loses an opportunity to illustrate the dangers of forming linguistic provinces that would carry within them adivasi zones of exception. Why, unlike the dalit, could the adivasi not be described as a political minority within the context of the linguistic states?

In Anupama Rao's fascinating history of Ambedkar's formulation of dalit as a political minority, we see that he spent much of the 1930s in conceptualizing a unified dalit political identity and situating it within a discourse of minority rights that was hitherto only applied to religious

${ }^{48}$ Ibid, pp. 14-15. ${ }^{49}$ Ibid, p. $35 .{ }^{50}$ Ibid, p. 35. 
minorities. Ambedkar gave his constituency a "non-Hindu minority" status. This status drew not from an inherent feature of the untouchable community but from the everyday experience of being untouchable. Dalit came to signify the "existential horrors of stigmatized existence." 51 Ambedkar demanded that the dalits be treated as a distinct political minority because they were "educationally backward, ... economically very poor, socially enslaved. ${ }^{\circ 2} \mathrm{He}$ had to seek a redefinition of the notion of minority because if a religious community were the only form of political constituency, then the dalits would be included in the Hindu constituency - the very group that has degraded and enslaved them.

An important feature of dalit as political minority was the spatiality of dalit life. In his arguments, Ambedkar pointed to the contradictory nature of dalit emplacement in Hindu society. While "every village had a Dalit ghetto," they were also scattered across the country and could never hope to win political majority for themselves.

Perhaps this is where the life of the scheduled tribes differed. Defined by their historical emplacement in the hilly forest of India, which were consistently cordoned off from the plains by government decree, the adivasi could not be defined as a scattered minority population. ${ }^{53}$ In the areas they inhabited, they were a demographic majority. For instance, the Koraput district of southern Odisha had almost a sixty percent adivasi majority. Also, as both Prathama Banerjee and Uday Chandra have argued, the ascription of a quality of primitivism to the Adivasi meant that their disagreements with Hindu society were never acknowledged as "political diversity." ${ }^{54}$ Assertions of adivasi political difference could not be seen as such. Thus as a result of their putative primitivism and territorial emplacement, the adivasi communities of eastern India could not be imagined as a political minority.

For the States Reorganization Commission, the inclusion of such areas within linguistic states was a matter of territorial rather than demographic inclusion. This is particularly explicit in the case of Jharkhand, the only adivasi province that was proposed to the States Reorganization Commission. The proposed province comprised of the mineral-rich Chota Nagpur plateau in south Bihar. While denying the demand on the grounds that the adivasi population of the proposed area was only one third of the total, the Committee report noted that: "The separation of

${ }^{51}$ Anupama Rao, The Caste Question, p. $122 .{ }^{52}$ Ibid, p. 133.

${ }^{53}$ For a history of territorial exceptionalism of tribal India, see Uday Chandra, "Liberalism and its Other: The Politics of Primitivism in Colonial and Post-Colonial Law", Law and Society Review 47 (2013): 135-68.

${ }^{54}$ See Prathama Banerjee, "Culture/Politics: The Irresoluble Double-Bind of the Indian Adivasi”, Indian Historical Review 33 (2003): 99-126. 
South Bihar will affect the entire economy of the existing State. The plains are predominantly agricultural and Chota Nagpur Plateau provides as industrial balance. $" 55$

The example of Ambedkar's treatment of the question of linguistic states illustrates how even in a minority critique of the States Reorganization Commission, the adivasi could not figure. The incorporation of the adivasi into the India community via the linguistic states was rendered almost invisible. The preceding reading of Gandhi, Nehru and Ambedkar illustrate how linguistic division of India was made possible through resolution of any conflict between commitments to regional mother tongues and the national vehicular language, the domestication of a truncated notion of linguistic diversity into the biography of Indian democracy and finally the occlusion of the adivasis' incorporation into the linguistic states.

\section{The Unincorporated: Adivasis in Linguistic States}

At the beginning of the parliamentary debates on the recommendations of the States Reorganization Commission, the home minister of the Indian union made only a single veiled reference to the adivasi communities who were parceled in parts into various linguistic provinces:

There are I think 2 or 3 crores of people in our country who do not speak any of these 14 languages. Yet, they have a right to unfettered growth as much as those who have the privilege of belonging to these recognized linguistic groups. ${ }^{56}$

This enumeration rather than naming of adivasi communities, even as a category, is symptomatic of the broader discussion of adivasi areas within the debates pertaining to the States Reorganization Commission. By counting rather than describing them, this statement greatly simplifies the differences between the Adivasi and the caste populations of linguistic provinces. The only thing that distinguishes them from the more dominant communities around them is linguistic difference. Such sleight of hand veils the history of elite exploitation of adivasi communities and resources. It renders obscure histories of usury, overtaxation, land dispossession, forced migration, slavery, bodily, and sexual exploitation. ${ }^{57}$ It also denies the long history of adivasi dissent against the very populations

55 Government of India, Report of the States Reorganization Commission, p. 169.

${ }^{56}$ Government of India, Lok Sabha Debates on the Report of the States Reorganization Commission (14th December to 23rd December 1955), Vol. 1 (New Delhi: Lok Sabha Secretariat, 1956), p. 11.

${ }^{57}$ For a history of tribal exploitation in Odisha and the networks of power involving native elite, princely states rules, and the colonial government, see Biswamoy Pati, South Asia On the Margins (Manchester: Manchester University Press, 2012). 
that they are now placed adjacent to. This simplification is the key to understanding the mechanics of the inclusion of tribal communities into the linguistic provinces. Here, I treat selections from memoranda sent by various provincial governments and private lobbies to the States Reorganization Commission in order to illustrate how they made the case for the inclusion of adjacent adivasi areas into their own provinces.

Memoranda from the various regions with adivasi communities to the States Reorganization Commission illustrate how in claiming these areas the difference between the caste community and adivasi groups was simultaneously marked and obliterated. For instance, in a memorandum submitted by the Telegu-speaking Vishalandhra Mahasabha from Hyderabad, the claim to areas in southern Odisha inhabited by the "agency tribes" were made in the following terms: ${ }^{.8}$

The agency tribes that are in that area are Telegu in character, customs, traditions and beliefs though they may have their own primitive language. They understand Telegu better than Oriya. Ever since their inclusion in the Orissa state the Andhras have been agitating intensely for their coming to their Andhra homeland. ${ }^{59}$

While it is unclear what the Telegu character would be, the reference to customs, traditions, and beliefs suggests that they were arguing for a community based on shared everyday life. Of course, this would deny the reality of independent adivasi faith systems that were outside the Hindu pantheon. In the absence of any details about actual names of the adivasi groups, ethnographic counterarguments about the actual belief systems of these communities cannot be posed. Also, in invoking their primitiveness, the memorandum situated the adivasi as a figure of incommensurable difference, an anachronistic presence that shared their everyday life with the Telegu people. They were both insiders and outsiders.

Another strategy of inclusion was the rhetoric of interests. For instance, the member of parliament for the Khurda district in Odisha argued for the inclusion of the Singbhum district in the state on the grounds that state government has done a "great deal in ameliorating the condition of the adivasi people in the course of the last seven years ... This has naturally attracted the Hos and the Santhals of Singbhum district towards Odisha

58 The agency tribes refer to the communities living in the Meriah Agency areas. In the mid nineteenth century, the colonial state marked off a part of southern Odisha and Ganjam as the separate agency in an effort to curb what was rumored to be the practice of human sacrifice. For details, see Felix Padel, The Sacrifice of the Human Being: British Rule and the Khonds of Orissa (New Delhi: Oxford University Press, 2001).

59 The Vishalandhra Mahasabha, Demand for the Vishalandhra State (Vijayavada: Venkatrama \& Co., 1955), p. 40. 
and they confidently feel that their interests would be better looked after by the Government of Odisha than by any other province."60

Finally, at the root of many such contentions are claims that the mainstream community and the adivasi community share a common historical past. Both historical and philological arguments are deployed to make such a case. For instance, the memorandum submitted by the government of West Bengal makes such a case for the inclusion of the district of Darjeeling. Countering Bihar's claims to the district on the grounds that the majority language Nepali was a form of Hindi, the Bengal government's argument tracks a detailed philological account of the languages spoken by the communities of the area. By illustrating that two groups of languages are spoken among these communities - the formal language Khaskura, which is an Indo-Aryan language drawn from the Sauraseni prakrits, and the colloquial language, which was often one of the TibetoBurman languages - they disproved the Bihari claim that the people of the area spoke some form of Hindi. In terms of history, the memoranda argued "significant history of the district starts only from 1836 with the British acquisition of this area. From that time onwards, the district has always been an administrative limb of Bengal." 61

What all these strategies have in common is a meticulous balance between arguments for incorporation and suggestions of distance. While the adivasi communities shared everyday life, interests and a common history, they were also primitive, dependent on the mainstream population and ahistorical before the contact. The adivasi was also seen as less than equal to the mainstream population of the linguistic provinces. Often these claims amount to arguments for trusteeship over adivasi life.

There are very few instances of adivasi counternarratives to such majoritarian claims in the Lok Sabha debates. ${ }^{62}$ Jaipal Singh, the leader of the Adivasi Mahasabha and a strong proponent for the formation of the province to Jharkhand gave the most comprehensive statement at the Lok Sabha debates. In his statement he argued for consolidation of the Chota Nagpur plateau under a single administration as opposed to the area being scattered into "five giant" provinces that surround it. In making his argument, Singh attacked the discursive tools that had been deployed by neighboring states in their efforts to incorporate the adivasi population

${ }^{60}$ Government of India, Lok Sabha Debates on the Report of the States Reorganization Commission, Vol. 1, p. 843.

${ }^{61}$ Government of Bengal, Memorandum (Supplementary) Before States Reorganization Commission (Alipore: West Bengal Government Press, 1954), p. 29.

${ }^{62}$ I have not been able to find the memoranda submitted by those lobbying for Jharkhand. 
- historicity, enumeration, and development. Demanding that his colleagues not use "distorted history" to make their case, Singh exclaimed:

Do not vitiate historical facts. If you want to rewrite history you can do that; the history of the freedom movement is going to be written; you can make your own contribution to that.

But in independent India, the bluff of past history is not going to work. ${ }^{63}$

Here is an acknowledgment of the spurious historical narratives at play in the debate about adivasi regions. It could be argued that perhaps Singh was also pushing back against historiographical violence perpetrated on the Adivasi. Through a study of historical memory in the part of the Chota Nagpur plateau that was still part of Odisha, Ranabir Samaddar has shown how elite efforts to manage adivasi memory have wiped out histories of adivasi political self-determination. ${ }^{64}$

While history could not be trusted, neither could one depend on numbers gleaned from census reports:

[T] here has been this most undesirable endeavor by the political parties and various sections of communities to make the census reports not a mine of the most useful and scientific information but as something which will suit their own particular political requirements. ${ }^{65}$

This abuse of numbers compounded his charge against those who were opposing the formation of Jharkhand. Despite an investment in real historical facts and scientific census figures, Singh's distrust of the discursive framework within which claims of inclusion have been made meant that he steered clear of arguments involving past history and census figures. Instead, he argued for adivasi humanity as a disrupted humanity. That the vivisection of the Chota Nagpur plateau into many parts had violently disrupted the humanity of the adivasi population and that the bringing together of these peoples will make them "feel that one-ness which is necessary to enable them to regain their lost nerve." Furthermore, greater attention to the disruption of adivasi humanity is required in the face of the celebration of development that makes invisible the tragedy of Adivasi lives:

Whether you talk of the D.V.C. or the Hirakud Dam or anything like that, let us not merely talk of the engineering feats. I want to know what happened to my people in the Hirakud project. It may be a marvelous feat of engineering but that is

${ }^{63}$ Government of India, Lok Sabha Debates, p. 730.

${ }^{64}$ Ranabir Samaddar, "Territory and People: The Disciplining of Historical Memory", in Partha Chatterjee (ed.), Texts of Power: Emerging Disciplines in Colonial Bengal (Minneapolis: University of Minnesota Press, 1992), pp. 167-99.

65 Government of India, Lok Sabha Debates, p. $719 . \quad{ }^{66}$ Ibid, p. 721. 
not all for me. Similarly, the D.V.C. and the same also with the reorganization of States; and I maintain that nothing should be done to disrupt or disintegrate any of these areas, because, first of all, you are dealing with human beings and already the democratic process has expressed itself positively and unequivocally against any disintegration. ${ }^{67}$

By juxtaposing the large dams like the one built by the DVC (Damodar Valley Corporation) in Bengal and Hirakud Dam in northwestern Odisha with the States Reorganization Commission, Singh was demanding that the displacement and land dispossession of the adivasi communities be discussed in a unified and direct way. As the earlier discussions about the claims of incorporation illustrate, there was a consistent vagueness in the ways in which adivasi lives, customs, and interests were defined. We have learnt from our reading of Nehru that vagueness can be a powerful discursive tool. By asking his contemporaries to discuss his people as human beings and not as detritus of new Indian projects of unification and development, Singh was radically reformulating how adivasis could be talked about. He was rendering the invisible visible.

\section{Conclusion}

In conclusion, perhaps we should ponder on what is at stake in doing such a skeptical history of the mysterious workings of the divisive genius of India. Claims like "the genius of India is to divide" or that India is blessed with "unity in diversity" veil both the positive and the negative features of the Indian nationalist project. Gandhi's exciting plea for a palimpsest of linguistic affect is not the product of happy chance but the result of years of activism in the service of the ideal of multilingualism and a committed critique of monolingual jealousy. Nehru's crafty management of difference is what enables the conditions of possibility for multilingual democratic nation-state and not some vague notion of an essential spirit of India. And, as the critiques of both Ambedkar and Jaipal Singh illustrate, this successful multilingual democracy that confounded global expectations by surviving difference was founded on the effacement of difference in the form of adivasi languages and lives.

\footnotetext{
${ }^{67}$ Ibid, pp. $728-9$.
} 


\section{Postscript}

This book has attempted to discuss two crucial vectors in the history of the Indian nation-state - language and land. ${ }^{1}$ In tracking the history of the regional linguistic politics in Odisha, I have spoken of land as territory. This is how it has featured in geopolitical discussions in Odisha and at the center in the debates and memoranda related to the States Reorganization Committee. However, by bringing the history of the making of the Indian citizen into this context of apportioning territory to languages, I have sought to raise the figure of the adivasi as a means to disrupt this totalizing narrative of territorial division. In Chapter 6, we saw how claims to regional territory often employed a language of trusteeship when it came to arguing for the inclusion of areas inhabited by adivasi communities in provinces such as Odisha, Andhra Pradesh, or West Bengal. This language of trusteeship was then coupled with a claim that the adivasi communities had a long history of shared everyday life with the Odia, Telegu, or Bengali communities and, therefore, it was in their best interests to be coupled with these larger linguistic communities.

By the early 1940s, the notion that India was a composite of linguistic regions had come to serve as the orthodox understanding of the new nation. An article in the Amrita Bazar Patrika described the relationship between the region and nation in the following way:

Indian Nationalism is of a composite character, no useful purpose will be served by ignoring facts, or by trying to twist them to suit a particular theory, nor will it be helpful for us to import analogies from Europe and America for guidance of our conduct, as thousand years of eventful history have gone to the making of the different sub-nations that inhabit the Indian soil. The proper adjustment of our mutual relations demands that we should recognize our unity as well as our diversity. Any attempt to grind us into a dull, dead uniformity in the name of our common nationhood is bound to cause friction, and end in disruption. Provincialism, rightly understood and kept within proper limits, is quite a healthy phenomenon, and is nothing to be ashamed of. There is no disguising the fact that an Oriya, Bengali or a Gujarati feels his kinship with a fellow

\footnotetext{
${ }^{1}$ I use land here to reference two kinds of geographical category - space and territory.
} 
provincial much more keenly than he does with a Tamilian or a Panjabi, and this is true with rare exceptions of the members of every provincial group. To ignore this fact is simply to misunderstand the nature of Indian nationhood, and store up trouble for the future. It is time that the composite character of Indian nationhood were properly understood. India is not and never will be one uniform nation in the sense in which France and Germany are nations, and any attempt to cast the different peoples that inhabit this country into one uniform cultural and linguistic mould is sure to end in failure and possibly lead to disaster. We must recognize both unity and diversity and must not seek to justify any wrong step by importing false analogies from outside. ${ }^{2}$

This caution against the dangers of understanding India within the framework of European and American examples of "uniform nationhood" presents provincialism as both constitutive of and a threat to the Indian nation. The tone of the article suggests that provincial linguistic difference is an immutable feature of the Indian nation: "[A]thousand years of eventful history have gone to the making of the different subnations that inhabit the Indian soil." Presenting the provincial allegiances as subnationalism gives these provincial units a great degree of legitimacy in the political context of both anticolonial nationalism in India and the broader discussions of freedom and self-determination taking place around the world as World War II raged in Europe and Asia. Also, references to thousands of years of eventful history naturalizes provincialism in India. Provincialism is a fact of Indian life according to this article. Therefore, any nation-building strategy that denies this fact would necessarily run the risk of being undermined by the arguably legitimate force of these provincialisms. Hence, if not understood properly provincialism could disrupt the Indian nation. Here lies the threat of provincialism.

Therefore, provincialism had to be "rightly understood and kept within proper limits." Provincialism had to be managed properly for the Indian nation to thrive. The solution posed by the article to the conundrum of provincialism suggests that rather than thinking of provincialism as the disruptive force, provincialism is acknowledged as an important feature of Indian national life - it represented the diversity of India even as it mediated any discussion of the unity of India. Provincialism served as the quintessential diversity that is at the root of the unity of India. And, as Nehru argued, this unity is not simply based on a transcendence of diversity. Rather, the acknowledgement of diversity enables unity to survive.

So far, the idea of Indian nationalism posed by this article is very positive and difficult to take issue with. But, as the history of the shift in

${ }^{2}$ Quoted in Orissa Domicile Committee, Report of the Orissa Domicile Committee (Bhubaneswar: Government of Orissa, 1943), p. 22. 
Odia attitudes to anticolonial politics and Indian National Congress politics discussed in Chapter 3 suggests, the acknowledgement of provincialism appeases the proponents of provincial identity (the provincial elite) and this appeasement enabled the provinces to commit to participating in a collective idea of Indian nationalism. The question of appeasement only arises because of the hegemonic status enjoyed by the regional elite in provinces such as Odisha. In the case of Odisha, we have seen that in the sphere of linguistic activism (Chapter 1), literature (Chapter 2), politics (Chapter 3), and history (Chapters 4 and 5), the regional cultural politics systematically produced a regional orthodoxy that provided a very clear narrative of what it meant to be Odia.

At the center of this orthodoxy was the idea of an Odia citizen subject who was simultaneously and unequivocally Indian. This Odia citizen had to be distinct from other regional subjects. As the discussion of Odia language and history in Chapters 1 and 5 illustrate this distinctiveness of the Odia subject was maintained through a claim that the Odia language and people were different from their neighbors because of the shared early life of Odia and its close adivasi neighbors. Unlike other regional communities, the Odia language and people developed in close harmony with nearby adivasi communities - this early shared life is evident in the number of adivasi words that existed in the Odia language. While this distinctiveness enabled the Odia regional movement to respond to encroachment from Bengali and Telegu regional politics, it also produced an enduring anxiety about the ethnic and linguistic proximity of the adivasi. As we have seen in the book, the response to this anxiety was to simultaneously assimilate and render invisible the adivasi element in the population of the new Odisha province.

It is striking that, in the case of Odisha, the domiciled Bengalis and Telegus are described as minorities but the adivasi communities who constitute about a fourth of the population are never referred to as a minority. Their difference from the majority Odia community is obscured by narratives of shared everyday life and adjacent origins. This distinction is particularly stark in the treatment of the question of minorities within the report of the Orissa Domicile Committee. When discussing the need to introduce protective measures for minorities within Odisha, the members of the committee referenced the global guidelines on what constitutes a minority provided by the League of Nations. According to these guidelines, a distinct community had to constitute between five and twenty percent of the population to be acknowledged as a minority within the territory of the nation. The committee report used these guidelines to judge whether the domiciled Bengali and Domicile Telugu communities of Odisha qualified as minorities in the province and decided that they did 
not. This led them to claim that Odisha was a fairly homogenous region. However, when trying to isolate the presence of a minority community within the region, no mention of the collected adivasi communities is made even though they accounted for one fourth of the population of Odisha. The reason they could not be counted as a minority in 1943 is because they had already been claimed as essentially Odia in the 1930s when the boundaries of the new province of Orissa was formed. My discussion of the various memoranda submitted to the States Reorganization Commission reveals that a very similar process of assimilation and elision happened in other provinces with large communities of adivasis as claims were made that the adivasi populations of India would be best served by being coupled with neighboring non-adivasi linguistic groups.

I would like to end the book with a question: Was it really in the best interests of the adivasis of Odisha to be so "absorbed" into the Odia community? Since 1947, close to three million people have been displaced by development-related projects in Odisha. Almost half of this number belong to adivasi communities. ${ }^{3}$ It appears that Jaipal Singh's impassioned plea in the Lok Sabha in 1956 that the impact of postcolonial development projects on adivasis needs to be addressed as instances of "disrupted humanity" rather than remain unheard in the growing celebration of postindependence developmental projects, like the Hirakud Dam, as feats of engineering was quite astute. In the 1950s, the Hirakud Dam project displaced 325 villages with an estimated population of 100,000 people. ${ }^{4}$ Protests against the building of the dam did take place but were eventually drowned out by a competing statist narrative that framed the adivasi loss of land as their sacrifice in the interests of the nation. $^{5}$

This notion of sacrifice for the nation needs attention. It is based on the assumption that the adivasi communities do share the same destiny as the majority of the Indian population and that the sacrifice of land is in the interest of the greater good. It assumes that this sacrifice will effectively enhance the socioeconomic life of everyone in the national community. However, events since the 1950s illustrate that those who sacrificed their land have not been the beneficiaries of the decades of development policy in India. In fact, the alienation of adivasi land has had catastrophic consequences for the displaced people of Odisha. Felix Padel and Samarendra Das have characterized these consequences as cultural

${ }^{3}$ Felix Padel and Samarendra Das, "Cultural Genocide and the Rhetoric of Sustainable Mining in East India", Contemporary South Asia 18 (2010): 335-6.

4 Arun Kumar Nayak, "Big Dams and Protests in India: A Study of the Hirakud Dam", EPW 45 (2010): 72.

${ }^{5}$ Ibid, 70. 
genocide. While the early postcolonial state took over private land for development projects that were state funded, a more recent statesponsored land grab has been in the service of the growing private investment in the mineral rich parts of Odisha. ${ }^{6}$ Odisha, West Bengal, and Jharkhand have the largest number of people displaced due to new mining projects. ${ }^{7}$ Between 1960 and 1995, 300,000 people were displaced in Odisha and between 1980 and 1995, 402,282 people were displaced in Jharkhand. Padel and Das suggest that this displacement in the case of adivasi communities amounts to "cultural genocide" because the loss of land often means the disruption of their social structure, land ownership, economic self-sufficiency, and religious customs. They are forced into urban spaces as landless laborers or relocated into "colonies of alien design," which bear no resemblance to their erstwhile life. As the adivasis of Odisha became displaced from their land, they ended up dissolving into the majority population and lost their particular identity as Khond or Munda. ${ }^{8}$ As a leader of the Adivasi resistance to the Utkal Alumina project in Kashipur, Bhagaban Majhi argued:

Our fundamental question is: how can we survive if our lands are taken away from us? We are tribal farmers. We are earthworms [Matiro poko]. Like fishes that die when taken out of water a cultivator dies when his land is taken away from him. So, we won't leave our land. We want permanent development. ${ }^{9}$

The adivasi resistance to these projects has met with middleclass apathy and sometimes with state violence. The Kalinganagar police shootings of 2006, which killed thirteen adivasi protesters who were opposing the building of the Kalinganagar Tata steel plant, illustrated the Odisha state approach to this issue. Even though the alienation of adivasi land is unconstitutional, the Odisha state government has consistently made efforts to circumvent the dictates of the constitution to enable legalizing state-sponsored land grab. ${ }^{10}$ The Odia middleclass see the postcolonial

${ }^{6}$ Walter Fernandes, "Tribal or Indigenous? The Indian Dilemma”, Commonwealth fournal of International Affairs 102 (2013): 385. "Orissa had used 100,000 acres for industries in 1951-1995 but acquired 100,000 acres more in the succeeding decade."

${ }^{7}$ See Minati Sahoo, "Mining and Land Acquisition: An Analysis of Mineral Rich Tribal Regions in Odisha", Fournal of Third World Studies 32 (2015): 153-74. Between 1960 and 1995, 300,000 people were displaced in Odisha and between 1980 and 1995 402,282 people were displaced in Jharkhand.

8 Padel and Das, 336. See also Hari Mohan Mathur, "Investor-Friendly Development Policies: Unsettling Consequences for the Tribal People of Orissa", Asia Pacific Fournal of Anthropology 10 (2009): 318-28.

${ }^{9}$ Quoted in Padel and Das, ibid, 336.

${ }^{10}$ For a legal history of eminent domain in Odisha during the colonial period, see Sankaran Krishna, "Colonial Legacies and Contemporary Destitution: Law, Race and Human Security”, Alternatives: Global, Local, Political 40 (2015): 85-101. And for 
Odisha state government efforts to attract private investment as a means to make Odisha a "modern hub of prosperity." The protesters are called "antigovernment" and "antidevelopment." They have been accused of being "Maoists." Padel and Das have argued that this accusation is "for the most part quite false." 11

Socioanthropological research on the cultural framing of the protests against state neglect of the more vulnerable communities in Odisha has shown how the adivasi complaints about state neglect are framed as instances of regional embarrassment. Odia leaders display an anxiety about how Odisha is viewed in metropolitan circles as a "feudal" place that is overrun by "nange-bhuke [people, often tribal], nearly naked, hungry and eating only very basic food of rough rice." 12 They argue that public episodes undermine Odia prestige: "Orissa has great cultural riches and we do not want its prestige tarnished." Orissa's prestige is also presented as an essentially Hindu prestige: "Orissa has Lord Jaganath as Protector; he is guiding and watching." ${ }^{13}$ While Lord Jaganath is seen as the protector of the poor there are instances where religion is also used as a justification of the suffering of the adivasis. Sometimes, officials are found saying: " $[\mathrm{I}] \mathrm{t}$ is their Dharma - they are meant for it" and "it is not the government's job to heal and feed them, it is Lord Jaganath's will." 14

This displacement of responsibility from government to the regional deity echoes of early twentieth-century Odia nationalist definitions of regional community. In the 1920 s and 1930s nationalists and historians had argued that the Odia community was a single community in spite of adivasi/non-adivasi difference because of the uniting force of the Jaganath cult. This claim allowed the mainstream leaders to incorporate the sizable adivasi minority populations into the Odia regional community - thus justifying the Odia claims to border districts like Ganjam, Koraput, and Sambalpur. However, this incorporation was founded on what Gopabandhu Das called expansive humanism (udaar manabikata) of the Jaganath cult. This humanism, rather than common political and administrative unity, enabled adivasi/non-adivasi unity. By founding unity on extragovernmental force of religion, this claim to humanism served more as an abstract promise of protection rather than a concrete legislation of equity and protection. It allowed for the new Odisha state to

a postcolonial history, especially of the Samantha judgment, see Mathur, "InvestorFriendly Development Policies”, 318-9.

${ }^{11}$ Ibid, 335.

12 Alan Rew and Shahzad Khan, "The Moral Setting for Governance in Keonjhar: The Cultural Framing of Public Episodes and Development Processes in Northern Orissa, India", Oxford Development Studies 34 (2006): 107.

${ }^{13}$ Ibid, $107 .{ }^{14}$ Ibid, 108. 
claim the adivasis as Odia without empowering them as equal citizens of the province.

Effectively, the humanism of Gopabandhu Das has met its limit in the politics of postcolonial development. The divine humanism of Das that made adivasis into citizens through the act of pilgrimage to Puri or the socialism of Nehru that gave entry into the national community to adivasis through an act of sacrifice have both failed to fulfill their promise in postcolonial India. 


\section{Bibliography}

Aarsleff, Hans, The Study of Language in England, 1780-1860 (Princeton, NJ: Princeton University Press, 1967).

Aarsleff, Hans, "Wordsworth, Language and Romanticism", in From Locke to Sassure: Essays On the Study of Language and Intellectual History (Minneapolis: University of Minnesota Press, 1983), p. 375.

Abdel-Malek, Anouar, "Orientalism in Crisis", Diogenes 44, no. Winter) (1963). Acharya, Pritish, National Movement and Politics in Orissa, 1920-29, Sage Series in Modern Indian History 11 (New Delhi: Sage, 2008).

Alam, Javeed, India: Living with Modernity (New Delhi: Oxford University Press, 1999).

Ambedkar, B. R., Thoughts on Linguistic States (New Delhi: Ramakrishna Printing Press, 1955).

Anonymous, Star of Utkal, "Utkaliya", 1905.

Ansari, Sarah F. D., Sufi Saints and State Power : The Pirs of Sind, 1843-1947, Cambridge South Asian Studies 50 (Cambridge: Cambridge University Press, 1992).

Banerjee, Prathama, "Culture/Politics: The Irresoluble Double-Bind of the Indian Adivasi", Indian Historical Review 33 (2003): 99-126.

Banerjee, Prathama, Politics of Time: Primitive and History-Writing in a Colonial Society (New Delhi: Oxford University Press, 2006).

Banerjee-Dube, Ishita, Religion, Law, and Power: Tales of Time in Eastern India, 1860-2000 (London: Anthem Press, 2007).

Banerjee-Dube, Ishita and Beltz, Johannes Popular Religion and Ascetic Practices: New Studies on Mahimā Dharma (New Delhi: Manohar Publishers \& Distributors, 2008).

Barrell, John, Imagining the King's Death: Figurative Treason, Fantasies of Regicide, 1793-1796 (Oxford: Oxford University, 2000).

Baruah, Sanjib, India Against Itself : Assam and the Politics of Nationality, Critical Histories (Philadelphia: University of Pennsylvania Press, 1999).

Bauman, Richard and Briggs, Charles S., Language Ideologies and the Politics of Inequality (Cambridge: Cambridge University Press, 2002).

Bayly, Christopher A., "Knowing the Country: Empire and Information in India", Modern Asian Studies 27.01 (1993): 3-43.

Beames, John, A Comparative Grammar of the Modern Aryan Languages of India (New Delhi: Munshiram Manoharlal, 1966). 
Beames, John, "On the Distribution of Indian Languages", in John Beames, Suniti Kumar Chatterji, and George Abraham Grierson, Outlines of Indian Philology, and Other Philological Papers (Calcutta: Indian Studies: Past \& Present, 1971).

Beames, John, "On the Relation of the Uriyas to Other Modern Aryan Languages", Proceedings of the Asiatic Society of Bengal (1870), pp. 192-201.

Beames, John, Chatterji, Suniti Kumar, and Grierson, George Abraham, Outlines of Indian Philology, and Other Philological Papers (Calcutta: Indian Studies: Past \& Present, 1971).

Behera, Subhakanta, Construction of an Identity Discourse: Odia Literature and the Fagannath Cult (New Delhi: Munshiram Manoharlal, 2002).

Berger, Anne E., "Politics of Mother-Tongue", Parallax 18, no.3 (2012): 9-26.

Berkemer, Georg and Frenz, Margret, Sharing Sovereignty: The Little Kingdom in South Asia (Berlin: K. Schwarz, 2003).

Bhargava, Rajiv and Reifeld, Helmut (eds.) Civil Society, Public Sphere and Citizenship: Dialogues and Perceptions (New Delhi: Sage, 2005).

Bhattacharya, Kantichandra, "Odiya Swatantra Bhasa Nuhe", in Bansidhar Mohanty (ed.) Odiya Bhasa Andolana (Cuttack: Friends Publishers, 1989).

Bhoi,Bhima and Bäumer,Bettina Bhima Bhoi, Verses From the Void: Mystic Poetry of an Oriya Saint (New Delhi: Manohar Publishers \& Distributors, 2010).

Brown, W. B., A Guide to the Principal Places of Interest in Orissa (Cuttack: Cuttack Mission Press, 1900).

Bryant, Edwin, The Quest for the Origins of Vedic Culture: The Indo-Aryan Migration Debate (New York: Oxford University Press, 2001).

Casanova, Pascale, The World Republic of Letters (Cambridge, MA: Harvard University Press, 2004).

Cassels, Nancy Gardner, Religion and Pilgrim Tax Under the Company Raj (New Delhi: Manohar Publishers, 1988).

Chakravorty, Swapan and Gupta, Abhijit, Print Areas: Book History in India (New Delhi: Permanent Black, 2004).

Chand, Soma, Odisara Chitra (Cuttack: Arjya Prakashan, 2006).

Chanda, Ramaprasad, Selections from Official Letters and Records Relating to the History of Mayurbhanj (London: British Library, India Office Records, Board's Collections, IOR/F/4/494/11900, 1942).

Chandra, Shefali, The Sexual Life of English: Languages of Caste and Desire in Colonial India (Durham, NC: Duke University Press, 2012).

Chandra, Sudhir, The Oppressive Present: Literature and Social Consciousness in Colonial India (New Delhi: Oxford University Press, 1992).

Chandra, Uday, "Liberalism and its Other: The Politics of Primitivism in Colonial and Post-Colonial Law", Law and Society Review 47(2013): 135-68.

Chatterjee, Partha, The Nation and Its Fragments: Colonial and Postcolonial Histories, Princeton Studies in Culture/Power/History (Princeton, NJ: Princeton University Press, 1993).

Chatterjee, Partha, Nationalist Thought and the Colonial World: A Derivative Discourse (Minneapolis: University of Minnesota Press, 1984).

Choudhury, Roshinka, "Cutlets or Fish Curry: Debating Authenticity in Late Nineteenth-Century Bengal”, Modern Asian Studies 40(2006): 257-72. 
Cohn, Bernard S., Colonialism and its Forms of Knowledge: The British in India (Princeton, NJ: Princeton University Press, 1996).

Cole, Steven E., "Coleridge, Language and the Production of Agency", Modern Philology 88 (1990): 109-25.

Collini, Stephan. Arnold: Culture and Anarchy and Other Writings (Cambridge: Cambridge University Press, 2010).

Cooper, Andrew R., “'Monumental Inscriptions': Language, Rights, the Nation in Coleridge and Horne Tooke", ELH 66(1999): 87-110.

Crowley, Tony, Politics of Language in Ireland, 1366-1922: Source Book (London: Routledge, 2000).

Dalmia, Vasudha, The Nationalization of Hindu Traditions: Bharatendru Harischandra and Nineteenth Century Banares (New Delhi: Oxford University Press, 1996).

Danzing, Richard, "The Announcement of August 20th, 1917", fournal of Asian Studies 28, no. 1 (1968): 19-37

Das, Debendra Kumar (ed.), Utkal Sammillani (1903-1936) (Rourkela: Pragati Utkal Sangha, 2005).

Das, Gauranga Charan (ed.), Praharaj Granthabali: Ramya Rachana Prathama Khanda (Cuttack: Vidyapuri, 2005).

Das, Gopabandhu, Collected Works of Gopabandhu Das (Cuttack: Gopabandhu Janma Satabarshika Samiti, 1976).

Das, Gopabandhu, Desa Misrana Andolana, vol. 3, Gopabandhu Rachanabali (Collected Works of Gopabandhu Das) (Cuttack: Gopabandhu Janma Satabarshika Samiti, 1976).

Das, Hemant Kumar, Odia Natakara Eitihasika Bibartana (Cuttack: S. Publications, 2003).

Das, J. P., Palm- Leaf Miniatures: The Art of Raghunath Prusti of Odisha (New Delhi: Abhinav Publications, 1991).

Das, Madhusudan, "Utkal Sammillani", Utkal Sahitya 11, no. 3 (1908): 62-6.

Dash, Gaganendranath, Hindus and Tribals: Quest for a Co-Existence: Social Dynamics in Medieval Orissa (New Delhi: Decent Books, 1998).

Dash, Gaganendranath, "Jagannath and Oriya Nationalism", in Anncharlott Eschmann (ed.), The Cult of fagannath (New Delhi: Manohar, 1979).

Dash, Gauranga Charan (ed.), Praharaj Granthabali Vol. 1 (Cuttack: Vidyapuri, 2005).

De Schutter, Helder and Robichaud, David (eds.), Linguistic fustice: Van Parijs and His Critics (London: Routledge, 2017).

Department of Public Instruction Bengal, "General Report on Public Instruction in the Lower Provinces of the Bengal Presidency" (1869-1870).

Derrida, Jacques, Monolingualism of the Other or the Prosthesis of Origin, trans. Patrick Mensah (Stanford, CA: Stanford University Press, 1998).

Deshpande, Madhav M., Sanskrit and Prakrit: Sociolinguistic Issues (New Delhi: Motilal Banarasidass, 1993).

Deshpande, Prachi, Creative Pasts: Historical Memory and Identity in Western India (New York: Columbia University Press, 2007).

Dirks, Nicholas B., Castes of Mind: Colonialism and the Making of Modern India (Princeton, NJ: Princeton University Press, 2001). 
Dodson, Michael S., "Translating Science, Translating Empire: The Power of Language in Colonial North India", Comparative Studies in Society and History 47(2005): 809-35.

Dodson, Michael S. and Hatcher Brian A. (eds.), Trans-Colonial Modernities in South Asia (New Delhi: Routledge, 2012).

Dube, Ishita Banerjee, Divine Affairs: Religion, Pilgrimage and the State in Colonial and Post-Colonial India (Shimla: Indian Institute of Advanced Study, 2001).

Errington, Joseph, Linguistics In a Colonial World: A Story of Language, Meaning, and Power (Chichester: John Wiley \& Sons, 2008).

Eschmann, Anncharlott (ed.), The Cult of Fagannath and the Regional Tradition of Orissa (New Delhi: Manohar, 1978).

Fabian, Johannes, Time and the Other: How Anthropology Makes its Object (New York: Columbia University Press, 1983).

Feldhaus, Anne, Connected Places: Region, Pilgrimage and Geographical Imagination In India (New York: Palgrave Macmillan, 2003).

Fernandes, Walter, "Tribal or Indigenous? The Indian Dilemma", Commonwealth Fournal of International Affairs 102(2013): 385.

Franklin, Michael J., "Orientalist fones": Sir William fones, Poet, Lawyer, and Linguist, 1746-1794 (Oxford: Oxford University Press, 2011).

Fraser, Robert, Book History Through Post-Colonial Eyes: Rewriting the Script (London: Routledge, 2008).

Frye, J. P., "On the Uriya and Kondh Populations of Orissa", Fournal of the Royal Asiatic Society of Great Britain and Ireland 17 (1860): 1-38.

Furgusson, Margaret W. Dido's Daughters: Literacy, Gender and Empire in Early Modern England and France (Chicago, IL: University of Chicago Press, 2003).

Gambarota, Paola, Irresistible Signs: The Genius of Language and Italian National Identity (Toronto: University of Toronto Press, 2011).

Gandhi, Mahatma, The Collected Works of Mahatma Gandhi, 95 vols. (New Delhi: Indian Ministry of Information and Broadcasting, 1958).

Gandhi, Mahatma, Thoughts on National Language (Ahmedabad: Navajivan Publishing House, 1956).

General Report on Public Instruction in the Lower Provinces of the Bengal Presidency (1869-70).

Gigante, Denise, “Zeitgeist”, European Romantic Review 18 (2007): 265-72.

Gilchrist, John, A Grammar of the Hindustani Language (Menstone: Scolar, P., 1970).

Government of Bihar and Orissa, "Memoranda to the Odisha Boundary Commission".

Government of India, Report of the States Reorganization Commission (New Delhi: Government of India Press, 1955).

Guha, Ranajit, "The Authority of Vernacular Pasts”, Meanjin 51, no. 2 (1992): 299.

Guha, Ranajit, An Indian Historiography of India: Nineteenth Century Agenda and Its Implications (Calcutta: K. P. Bagchi, 1987).

Gupta, Abhijit and Chakravorty, Swapan, Moveable Type: Book History In India (Ranikhet: Permanent Black, 2008).

Gupta, Akhil, "The Song of the Non-Aligned World: Transnational Identities and Reinscription of Space in Late Capitalism", Cultural Anthropology 7, no. 1 (1992): 63-79. 
Habermas, Jurgen, The Structural Transformation of the Public Sphere: An Enquiry into the Category of Bourgeois Society (Cambridge: Polity Press, 1989).

Hakala, Walter N., Negotiating Languages: Urdu, Hindi, and the Definition of Modern South Asia (New York: Columbia University Press, 2016).

Hatcher, Brian A., Idioms of Improvement: Vidyasagar and the Cultural Encounter (New Delhi: Oxford University Press, 2000).

Heller, Monica and McElhinny, Bonnie, Language, Capitalism, Colonialism: Toward a Critical History (Toronto: University of Toronto Press, 2017).

Honourary Secretaries, "Remarks on Mr Beames' 'Notes on the Relation of the Uriya to the Other Modern Aryan Languages", in Proceedings of the Asiatic Society of Bengal (1870).

Hunter, W. W., Odisha: Or the Vicissitudes of an Indian Province under Native and British Rule ... Being the Second and Third Volumes of the Annals of Rural Bengal (London: Smith, Elder \& Co., 1872).

Irvine, Judith T., "Subjected Words: African Linguistics and the Colonial Encounter", Language and Communication 28, no. 4 (2008): 323-43.

Irvine, Judith T., "The Family Romance of Colonial Linguistics: Gender and Family in Nineteenth-Century Representations of African Languages", Pragmatics 5, no. 2 (2009).

Irvine, Judith T., "Language Fields: Robert Needham Cust's Language Map of South Asia, 1878", in Cynthia Talbot, Knowing India: Colonial and Modern Constructions of the Past (New Delhi: Yoda Press, 2011).

Ismail, Qadri, Abiding By Sri Lanka (Minneapolis: University of Minnesota Press, 2005).

Johnson, Gordon, Provincial Politics and Indian Nationalism: Bombay and the Indian National Congress, 1880 to 1915 (Cambridge: Cambridge University Press, 1973).

Johnson, Peter, "The Geographies of Heterotopia”, Geography Compass 7, no. 11 (2013): 790-803.

Jones, Allen Keith, Politics in Sindh, 1907-1940: Muslim Identity and the Demand for Pakistan (Karachi: Oxford University Press, 2002).

Jones, William, Principles of Government in a Dialogue between a Scholar and a Peasant (London: Society for Constitutional Information, 1783).

Keen, Paul, The Crisis of Literature in the 1790s: Print Culture and the Public Sphere (Cambridge: Cambridge University Press, 1999).

Khuntia, R. and Bhatta, B., "Entry of Non-Hindus into the Jaganath Temple, Puri: A Study, Odisha Review (6) (2012): 16.

King, Robert D., Nehru and the Language Politics of India (New Delhi: Oxford University Press, 1997).

Krishna, Sankaran, "Colonial Legacies and Contemporary Destitution: Law, Race and Human Security", Alternatives: Global, Local, Political 40(2015): 85-101.

Kudaisya, Gyanesh Region, Nation, "Heartland": Uttar Pradesh in India's BodyPolitic (New Delhi: Sage, 2006).

Laclau, Ernesto, On Populist Reason (London: Verso, 2005).

Lamarre, Paul, "John Horne Tooke and the Grammar of Political Experience", Philological Quarterly 77 (1998): 187-207. 
Lauri, William F. B, Orissa: The Garden of Superstition and Idolatry (London: Johnstone \& Hunter, 1848).

Mahanti, Bamsidhara, Odia Bhasha Andolana (Kataka: Phrendas Publishers, 1989).

Maharana, Chandramohan, "Itihas", Utkal Sahitya 9, no. 2 (1906).

Majeed, Javed, "Modernity's Script and a Tom Thumb Performance: English Linguistic Modernity and Persian/Urdu Lexicography in Nineteenth Century India", in Michael. S. Dodson and Brian A. Hatcher (eds.), Trans-Colonial Modernities in South Asia (New Delhi: Routledge, 2012).

Majeed, Javed, Colonialism and Knowledge in Grierson's Linguistic Survey of India (New Delhi: Routledge, 2018).

Majeed, Javed, Nation and Region in Grierson's Linguistic Survey of India (New Delhi: Routledge, 2018).

Majumdar, B. C., Orissa in the Making (Calcutta: University of Calcutta Press, 1925).

Manela, Erez, The Wilsonian Moment: Self-Determination and the International Origins of Anticolonial Nationalism (Oxford: Oxford University Press, 2007).

Mangaram, Mukti Lakhi, "Radical Religious Poetry in Colonial Orissa”, Economic and Political Weekly XLVI (2011): 82-94.

Mani, Lata, Contentious Traditions: The Debate on Sati in Colonial India (Berkeley, CA: University of California Press, 1998).

Manly, Susan, Language, Custom and Nation in the 1790s (Aldershot: Ashgate, 2007).

Mansingh, Mayadhar, History of Oriya Literature (New Delhi: Sahitya Academy, 1967).

Mantena, Karuna, Alibis of Empire: Henry Maine and the Ends of Liberal Imperialism (Princeton, NJ: Princeton University Press, 2010).

Mantena, Rama Sundari, "Vernacular Futures: Colonial Philology and the Idea of History in Nineteenth-Century South India", Indian Economic \& Social History Review 42, no. 4 (2005): 513-34.

Mathur, Hari Mohan, "Investor-Friendly Development Policies: Unsettling Consequences for the Tribal People of Orissa", Asia Pacific fournal of Anthropology 10 (2009): 318-28.

Mazumdar, B. C., Odisha in the Making (Calcutta: University of Calcutta Press, 1925).

Mazumdar, B.C., Typical Selections from Odia Literature, Vol. 2 (Calcutta: University of Calcutta Press, 1923).

McDonald, Christie and Suleiman, Susan Rubin, French Global: A New Approach to Literary History (New York: Columbia University Press, 2010).

Mir, Farina, "Imperial Policy, Provincial Practices: Colonial Language Policy in Nineteenth-Century India", Indian Economic \& Social History Review 43, no. 4 (2006): 395-427.

Mir, Farina, The Social Space of Language: Vernacular Culture in British Colonial Punjab (Berkeley, CA: University of California Press, 2010).

Mishra, Laxmikanta and Mishra, Sitakanta, Historians and Historiography of Orissa: A Study in Perception and Appropriation of Orissan History (New Delhi: Kaveri Books, 2005). 
Mishra, Pritipuspa, "Beyond Powerlessness: Institutional Life of the Vernacular in the Making of Modern Orissa", Indian Economic and Social History Review 48 (2011), 531-70.

Mishra, Pritipuspa, “The Mortality of Hindustani”, Parallax 18 (2012): 71-83.

Mishra, Purnachandra (ed.), Utkala Dipikare Bhanja Prasanga (Berhampur: Royal Book House, 1996).

Mitchell, Lisa, Language, Emotion and Politics in South India: The Making of a Mother-Tongue (Bloomington, IN: Indiana University Press, 2009).

Mitchell, Lisa, "Parallel Languages, Parallel Cultures: Language as a New Foundation for Reorganization of Knowledge and Practice in Southern India", Indian Economic and Social History Review 42, no. 4 (2005).

Mitra, Rajendralal, The Antiquities of Odisha. By Rajendralala Mitra . . . These Are Some of the Relics of the Past, Weeping over a Lost Civilisation and an Extinguished Grandeur... Published under Orders of the Government of India (Calcutta: Wyman \& Co., 1875).

Mohanty, Jatindra Mohan, Tradition and Creativity: Essays on Odia Literature (Bhubaneswar: Subarnarekha, 2003).

Mohanty, Nivedita, Oriya Nationalism: Quest for a United Odisha, 1866-1936 (Bhubaneswar: Prafulla, 2005).

Mohanty, Panchanan, "British Language Policy in Nineteenth Century India and the Odia Language Movement", Language Policy 1 (2002): 53-73.

Mohanty, Satya P., Colonialism, Modernity, and Literature: A View from India (New York: Palgrave Macmillan, 2011).

Mohapatra, Bharati, Going to School in the Raj: Primary Education in India (1803-1903) with Focus on Orissa (Bhubaneswar: V. B. Shastry, 2003).

Montagu, Edwin and 1st Viscount Chelmsford. Report on Indian Constitutional Reforms. Calcutta, Superintendent Government Printing, 1918. Available at http://archive.org/details/reportonindianco00greaiala (accessed April 2, 2012).

Moore, Robin James, "The Composition of 'Wood's Education Despatch", English Historical Review 80, no. 314 (1965): 70-85.

Mubayi, Yaaminey, Altar of Power: The Temple and the State in the Land of faganath (New Delhi: Manohar, 2005).

Mufti, Amir R., Enlightenment in the Colony (Princeton, NJ: Princeton University Press, 2007).

Mufti, Amir, "Orientalism and the Institution of World Literatures", Critical Enquiry 36 (2010): 458-93.

Naik, Archana (ed.), Nirbachita Rachanabali: Biswanath Kara (Bhubaneswar: Sahitya Academy, 1999).

Naregal, Veena, Language, Politics, Elite and the Public Sphere: Western India Under Colonialism (London: Anthem Press, 2002).

Nayak, Arun Kumar, "Big Dams and Protests in India: A Case of the Hirakud Dam", EPW 45,(2010).

Nehru, Jawaharlal The Discovery of India (New Delhi: Oxford University Press, 2004).

Nehru, Jawaharlal, "The Question of Language", in The Unity of India (New York: J. Day, 1942). 
Neiman, Frazer, "The Zeitgeist of Matthew Arnold", PMLA 72(1957): 977-96.

Padel, Felix, The Sacrifice of the Human Being: British Rule and the Khonds of Orissa (New Delhi: Oxford University Press, 2001).

Padel, Felix and Das, Samarendra, "Cultural Genocide and the Rhetoric of Sustainable Development Mining in East India", Contemporary South Asia 18 (2010): 333-41.

Panda, B. D., History of Library Development (New Delhi: Anmol Publications, 1992).

Panigrahi, K. C., History of Odisha (Hindu Period), 3rd ed. (Cuttack: Kitab Mahal, 1995).

Panigrahi, Ramesh Prasada, Signboard On the Marquee: Physiognomy, Cultural Rhetorics, and the Trajectory of Odia Fatra Theatre (Bhubaneswar: Odisha Sahitya Akademi, 2010).

Pathy, Jaganath, “Colonial Ethnography of the Kandha: 'White Man's Burden' or Political Expediency?", Economic and Political Weekly 30, no. 4 (1995): 220-28.

Pati, Biswamoy, "Interrogating Stereotypes: Exploring the Orissa Princely States", in South Asia On the Margins: Echoes of Orissa, 1800-2000 (Manchester: Manchester University Press, 2012), pp. 97-115.

Pati, Biswamoy, South Asia On the Margins: Echoes of Orissa, 1800-2000 (Manchester: Manchester University Press, 2012).

Patnaik, Bichhanda Charan, Kabisamrat Upendra Bhanja Souvenir (Cuttack: Chattrabandhu Pustakalaya, 1950).

Patnaik, Sudhakar, Sambadapatraru Odisara Katha, Vol. 1 (1856-1881) (Cuttack: Grantha Mandir, 1971).

Patra, S. C., Formation of the Province of Orissa: The Success of the First Linguistic Movement in India (Calcutta: Punthi Pustak, 1979).

Patten, Alan, "Political Theory and Language Policy", Political Theory 29 (2001): 691-715.

Pfeffer, Georg, Periphery and Center: Studies in Orissan History, Religion and Anthropology, Vol. 7 (New Delhi: Manohar Publishers, 2007).

Pollock, Sheldon I., Literary Cultures in History : Reconstructions from South Asia (Berkeley, CA: University of California Press, 2003).

Pollock, Sheldon I., The Language of the Gods in the World of Men: Sanskrit, Culture, and Power in Premodern India (Berkeley, CA: University of California Press, 2009).

Pollock, Sheldon, A Rasa Reader: Classical Indian Aesthetics (New York: Columbia University Press, 2016).

Pradhan, Chakrapani and Pattnaik, Niranjan, The Oriya Movement, Being a Demand for a United Orissa by Two Bachelors of Arts (Aska: H. H. Panda, 1919).

Praharaj, Gopal Chandra, Pūrnn achandra Ordiā Bhāshākosha (A Lexicon of the Oriya Language) (Cuttack: Utkal Sahitya Press, 1931).

Praharaj, Gopal Chandra, The Odia Language and Lexicon (Vizianagaram: International Faculty of Andhra Research University of India, 1937).

Prakash, Gyan, Another Reason: Science and the Imagination of Modern India (Princeton, NJ: Princeton University Press, 1999).

Pütz, Martin, Fishmann, Joshua, and Van Neff Aertselaer, Joanne, "Along the Routes to Power": Explorations of Empowerment through Language (Berlin: de Gruyter Mouton, 2006). 
Rai, Alok, “The Persistence of Hindustani”, Annual of Urdu Studies 20, (2005): 135-44.

Rai, Lala Ramnararyan. Kabi Upendra Bhanja. Utkal Prabha (Baripada: Baripada Printing Press, 1891).

Rai, Mridu, Hindu Rulers, Muslim Subjects : Islam, Community, and the History of Kashmir (London: C. Hurst, 2003).

Rai, Sadhucharan, "Rajaniti", Utkal Sahitya 1, no. 8 (1897): 193.

Rai, Sadhucharan, "Rajashakti, O Prajashakti", Utkal Sahitya 1, no. 10 (1897): 65-6.

Rajguru, Satyanarayan, "The Odras and Their Predominance", The Prachi 1, no. 3 (1931).

Rajguru, Satyanarayan, “Ourselves”, The Prachi (1) (1) (1931).

Ramaswamy, Sumathi, Passions of the Tongue : Language Devotion in Tamil India, 1891-1970, Studies on the History of Society and Culture 29 (Berkeley, CA: University of California Press, 1997).

Ramaswamy, Sumathi, "Sanskrit for the Nation", Modern Asian Studies 33, no. 2 (1999): 339-81.

Rao, Anupama, The Caste Question: Dalits and the Politics of Modern India (Berkeley, CA: University of California Press, 2009).

Reddy, William, Navigation of Feeling: A Framework for the History of Emotions (Cambridge: Cambridge University Press, 2001).

Rew, Alan and Khan, Shahzad, "The Moral Setting for Governance in Keonjhar: The Cultural Framing of Public Episodes and Development Processes in Northern Orissa, India", Oxford Development Studies 34 (2006): 99-115.

Rousseleau, Raphael, "The King's Elder Brother: Forest King and Political Imagination in Southern Orissa", Rivista di Studi Sudasiatici: RiSS 4 (2009): 39-62.

Rousseleau, Raphael, "Village Festival and Kingdom Frame: Center and Periphery From a Poroja Village Point of View", in Marine Carrin and Lidia Guzy, Voices from the Periphery: Subalternity and Empowerment in India (New Delhi: Routledge, 2012).

Roy, Anindyo, "Subject to Civility: The Story of the Indian Baboo", Colby Quaterly 37(2001): 113-24.

Sahoo, Minati, "Mining and Land Acquisition: An Analysis of Mineral Rich Tribal Regions in Odisha", fournal of Third World Studies 32 (2015): 153-74.

Saldanah, Arun, "Heterotopia and Structuralism", Environment and Planning A 40, no. 9 (2008): 2080-96.

Samaddar, Ranabir, "Territory and People: The Disciplining of Historical Memory", in Partha Chatterjee (ed.), Texts of Power: Emerging Disciplines in Colonial Bengal (Minneapolis: University of Minnesota Press, 1992), pp. 167-99.

Samantraya, Natabar, Odiya Sahityara Itihas (1803-1920) (Bhubaneswar: Granthalaya, 1974).

Sarangi Asha (ed.), Language and Politics in India (New Delhi: Oxford University Press, 2009).

Sarkar, Sumit, The Swadeshi Movement in Bengal, 1903-1908 (New Delhi: People's Publishing House, 1973).

Sartori, Andrew, Bengal in Global Concept History: Culturalism in the Age of Capital (Chicago, IL: University of Chicago Press, 2008). 
Sawhney, Simona, The Modernity of Sanskrit (Minneapolis: University of Minnesota Press, 2009).

Schnepel, Burkhard, "Durga and the King: Ethnohistorical Aspects of Politico-Ritual Life in a South Orissan Jungle Kingdom", fournal of the Royal Anthropological Institute 1, no. 1 (1995): 145-66.

Scott, James C., Seeing Like a State: How Certain Schemes to Improve the Human Condition Have Failed (New Haven, CT: Yale University Press, 1998).

Senapati, Fakir Mohan and Mishra, Rabi Shankar, Six Acres and a Third: The Classic Nineteenth-Century Novel About Colonial India (Berkeley: CA, University of California Press, 2005).

Sengupta Indra and Daud Ali (eds.), Knowledge Production, Pedagogy and Institutions in Colonial India (New York: Palgrave Macmillan, 2011).

Sengupta, Jayanta, At the Margins: Discourses of Development, Democracy and Regionalism in Orissa (New Delhi: Oxford University Press, 2015).

Seth, Sanjay, "Nationalism, National Identity and 'History': Nehru's Search for India", Thesis Eleven 32 (1992): 37-54.

Sharma, Jayeeta, Empire's Garden: Assam and the Making of Modern India (Durham, NC: Duke University Press, 2011).

Shaw, Graham W., "The Cuttack Mission Press and Early Oriya Printing” British Library fournal, 1977.

Shukla, Bana Bihari, Bhagabata Ghara and Village Panchayat in Mediaeval Orissa, 1510-1803 AD, 1st edn. (Cuttack: Bharati Publications, 1986).

Singha, Jagabandhu, "Prachin Utkal, Part 1", Mukura 11 no. 9 (1917).

Skaria, Ajay, "Gandhi's Politics: Liberalism and the Question of the Ashram", South Atlantic Quarterly 101, no. 4 (2002):955-86.

Skaria, Ajay, "Only One Word, Properly Altered: Gandhi and the Question of the Prostitute", Postcolonial Studies 10, no. 2(2007): 219-28.

Spivak, Gayatri, "Translation as Culture", Parallax 16 (2000): 13-24.

Subba Rao, G. V. and Movement Andhra Pradesh. Committee of History of Andhra, History of Andhra Movement (Hyderabad: Committee of History of Andhra Movement, 1982).

Tanabe, Akio, "Early Modernity and Colonial Transformation: Rethinking the Role of the King in Eighteenth and Nineteenth Century Orissa, India", in Masaaki Kimura and Akio Tanabe (eds.). The State In India: Past and Present (New Delhi: Oxford University Press, 2006), pp. 203-28.

Tanabe, Akio, "Indigenous Power, Hierarchy and Dominance: State Formation in Orissa, India", in Ideology and the Formation of Early States (Leiden: Brill, (1996), pp. 154-65.

Third Annual Report of the Cuttack Printing Company (Cuttack: Cuttack Printing Company, 1869).

Tilak, B. G., Lok. Tilak's Speeches on Home Rule, (Banares: Yoda Press, 1917).

Trautmann, Thomas R., The Aryan Debate, Oxford in India Readings. Debates in Indian History and Society (New Delhi: Oxford University Press, 2005).

Trautmann, Thomas R., Languages and Nations: The Dravidian Proof in Colonial Madras (New Delhi: Yoda Press, 2006).

Two Bachelors of Arts (Niranajan Patnaik and Chakradhar Pradhan), The Oriya Movement: Being a Demand for a United Orissa (Aska: H. H. Panda, 1919). 
Van Parijs, Philippe, Linguistic fustice for Europe and for the World (London: Oxford University Press, 2011).

Wakankar, Milind, "The Moment of Criticism in Nationalist Thought: Ramchandra Shukla and the Poetics of Hindu Responsibility", South Atlantic Quarterly 101 (2002): 987-1014.

Welter, Albert and Newmark, Jeffrey (eds), Religion, Culture and the Public Sphere in China and Fapan (London: Palgrave Macmillan, 2017).

Wogan-Browne, Jocelyn and Johnson, Ian Richard, The Idea of the Vernacular: An Anthology of Middle English Literary Theory, 1280-1520 (University Park, PA: Penn State University Press, 1999).

Yelle, Robert A., The Language of Disenchantment: Protestant Literalism and Colonial Discourse in British India (New York: Oxford University Press, 2012).

Zaidi, A. M. (ed.), In the Glorious Tradition - Vol. 1: 1885-1920, "Inc: The Glorious Tradition - Texts of the Resolutions Passed by the Inc, the Aicc and the Cwc" (New Delhi: Indian Institute of Applied Political Research, 1987).

Zaidi, A. M. and Zaidi, S. G. (ed.), Encyclopaedia of the Indian National Congress, XXVI vols (New Delhi: S. Chand, 1978).

Zastoupil, Lynn and Moir, Martin, The Great Indian Education Debate: Documents Relating to the Orientalist-Anglicist Controversy, 1781-1843, no. 18 (Hove: Psychology Press, 1999).

Zutshi, Chitralekha, Languages of Belonging: Islam, Regional Identity and the Making of Kashmir (New Delhi: Oxford University Press, 2004). 


\section{Index}

Aarsleff, Hans, 43, 233

Abul Fazal, 152

Acharya, Pyarimohan, 88

Act No 29 of 1837, 34-36, 44-45, 60

Adivasi

As Historiographical Problem, 171-78

As Incommensurable Difference, 222

As Minority, 170-71

As Unincorporated, 221-22

Adivasi Mahasabha, 223

Adivasi Resistance, 230

Affect, 4, 30, 36, 38, 48, 49, 79, 90, 99, 207, $210,213,221,225$

Ambedkar, B. R., 29, 205

Thoughts on Linguistic States, 218-21

Arnold, Matthew, 90, 91, 96, 235, 240

Artificial Orissa, 26, 147, 163

Asiatic Society of Bengal, 53, 54, 68, 69, 234,242

Balasore, 62, 83, 84, 85, 86

Balasore Sambadabahika, 84

Bandyopadhyay, Rangalal, 53, 92

Banerjee, Prathama, 176

Beames, John, 63-66, 67-70

Bengal Presidency, viii, 11, 13, 14, 17, 18, $26,34,35,36,44,48,50,51,52,55$, $57,58,59,61,68,79,81,86,111,112$, $135,137,150,170,172,173,174$, 192, 193, 236, 237

Berger, Anne, 210

Besant, Annie, 131, 140-41

Bethune Society, 92

Bhagabat Ghara, 82

Bhagabata Ghara, 49

Bhanja Deo, Ramachandra, 114

On Funding Utkal Prabha, 92

On Rajaniti, 114-15, 117-19, 121-23

Bhanja, Upendra, 87

Bharati Mandir, 128

Bhattacharya, Kantichandra, 62-71
Bhoi, Bhima, 103-5

Bijuli, 92

Calcutta School Book Society, 59, 86

Carey, William, 63

Central Provinces, viii, 2, 51, 55, 79, 111 , 163, 173, 192

Chittagong, 19, 45, 137

Citizen, 15

Indian, 110, 129-31, 216, 226

Marked by Language, 24, 133-34, 135, $141-42,150$

Odia, 78-80, 98, 104, 114, 127-28, 143-44, 197, 228

Cohn, Bernard, 179

Coleridge, Samuel Taylor, 37-38

Colonial Citizenship, 130

Colonial Philology, 9, 47, 62, 63, 67

Condillac, Etienne Bonnot de, 38, 39

Constituent Assembly, 14, 15, 16, 205, 209

Cult of Jaganath, 166, 178, 201

Cuttack Debating Society, 51, 53, 85

Cuttack Printing Company, 83-84, 85

Cuttack Young Men's Association, 85

Damodar Valley Corporation, 225

Das, Gopabandhu

UCC Presidencial Speech 1920, 144-49

Das, Jaganath, 83

Das, Madhusudan, 112, 113, 125, 134, $148,150,200$

Das, Nilakantha, 128

Das, Gopabandhu, 143

De, Baikuntha Nath, 86, 87

Denial of Coeval-ness, 176

Derrida, Jaques, 93, 206, 235

Monolingualism of the Other, 206-7

Desa-Kala-Patra, 90, 93

Development, 108-11, 114, 122

Dhar Committee, 217 
Diarchy, 129, 133

Domicile. See Orissa Domicile Enquiry Committee

English Charity School, 87

Fabian, Johannes, 176

Fallon, S.W., 73-74

Famine, 51, 54

Foucault, Michel, 155

Gajapati, 116, 118

Gandhi, Mohandas Karamchand

Linguistic Imaginary, 206-13

On Language Policy of INC, 140-43

On Puri, 166-68

Ganjam Hiteisini Sabha, 112

Garjat, 161, 162

General Baptist Society, 82

Government of India Act of 1919, 129

Gramya Samiti, 127-28

Greater Utkal, 187

Grierson, George Abraham, 50, 63, 64, 68, 215,234

Guha, Ranajit, 9-10, 33-34

Habermas, Jurgen, 78-80

Hadley, George, 208

Halhed, Nathaniel, 43

Hardinge Vernacular Schools, 50

Harris, James, 38, 41

Hayden White, 170

Herder, Johann Gottfried, 39

Heterotopia, 155-57, 161-62, 166 of Compensation, 155-57. See Puri as Regional and National Heterotopia, 166

Hindustani, 34, 73, 142 Gandhi On, 206-13

Nehru On, 215-17

Hindustani Prachar Sabha, 208

Hirakud Dam, 224

Humanism, 144, 147-51, 232

Humboldt, Alexander Von, 39

Hunter, 157-62, 163, 171, 179-81, 183, 184,187

Indian Home Rule, 131

Indian National Congress, 15-19, 26, 136-43, 170

Indian Opinion, 166

Indirect Rule, 117-18

Indradhanu, 85, 92, 93, 96

Intelligibility, 36, 64-65

Mutual Intelligibility, 64-65

Of Governmental Language, 36
Interchangeability of Languages, 56

Intermediary Ruling Races, 107, 135, 136, 148, 150, 195, 196, 200

Jaganath Cult, 70, 149, 178, 186, 189, 191, 201, 202

Jaganath Temple, 103, 153, 168, 182, 237

Jagannath Ballabh Press, 83

Jatra, 101-4

Jayadev, 181

Jharkhand, 223

Jones, William, x, 9, 16, 37, 38, 42, 43, 47, 237

Just Governance, 35-36, 60

Kabitabali, 87

Kalinga, 177, 184, 185, 186, 187, 188

Kangalinka fati Karana, 85

Kara, Biswanath, 96

Jatiya Jibanare Sahityara Stana, 98-99

Sahitya o Samalochana, 97-98

Vividha Prasanga, 96

Keonjhar, 117, 231, 241

Khurda, 116, 118, 222

Kosala, 177, 178, 185, 195

Language

Mother Tongue, 2, 27, 39, 42, 48, 99, 205-8, 209-14

Of Instruction, 48, 50-51, 52, 58-59

Romantic Notions Of, 38

Languages

Adivasi Languages: Munda, Ho, Chakma, and Gond, 46

Bengali, 45-46, 48, 50-57, 62-63, 68-70

Chakma, 46

English, 27, 31-32, 40-42

Greek, 41

Irish, 40-41

Italian, 39

Middle English, 39

Persian, 34-35, 42-44

Roman, 41

Tamil, 46

Telegu, 47

Vehicular, 31, 32, 40, 41, 46, 73, 205, 206, 207, 209, 212, 213, 216, 221

Liberal, 10, 27

Linguistic Identity Drive, 150

Linguistic Survey of India, 50, 215

Literary Criticism, 9, 27, 77, 78, 80, 90, 91, 93, 94, 95, 97

Literature

Community Patrimony, 93, 101

Function of, 78 
Literature (cont.)

Incitement to Emotion, 95

Literary Populism, 97

Obscene, 28, 73, 76, 88, 92, 94

Sringara Rasa, 95

Timeliness of, 78, 90

Utility of, 97

Locke, John, 38-39

Loyalism, 111, 114

Macaulay, Thomas Babbington, 41-42, 43

Madala Panji, 183, 189

Madras Presidency, viii, 13, 14, 17, 19, 51, 55, 79, 111, 112, 137, 138, 163, 171, $175,190,192$

Mahabharata, Odia, 49

Mahima Dharma, 103

Mahtab, Harekrushna, 128

Majumdar, B.C., 187

Orissa in the Making, 183-87

Maratha Empire, 1, 22, 49, 74, 115, 121

Matririn, 211

Mayurbhanj, 92, 114, 119, 234

Mill, John Stuart, 44

Minority, 218-21

Adivasi as, $170-71$

Odia as, 135

Mishra Godavaris, 128, 203

Mishra, Krupasindhu, 128

Mitra, Rajendralala, 53-57, 58-59, 69

Monolingualism, 47, 206

Montague-Chelmsford Report, 190

Mother Tongue, 6, 93, 234, 238

Abdelkebir Khatibi: "langage maternel", 210

Mughal Empire, 49, 74, 116, 161

Mughalbandi, 160-62

Mukura, 104, 181, 242

Nabakrushna Chaoudhury, 128

Naoroji, Dadabhai, 138-39

National Anthem, 1-2, 14-16

Natural Orissa, 29, 151, 202

Nehru Report, 139

Nehru, Jawaharlal, 20

On Language and Difference, 214-15

See also Hindustani, Nehru on

Nehru, Motilal, 33, 139, 238

Nietzsche, Friedrich, 12

Odra, 177-78, 184-91

Orientalist and Anglicist Debate, 43-44

Orissa Boundary Commission, 29, 171, 190-96, 203
Orissa Domicile Enquiry Committee, 203-5

Orissa Islamic Association, 85

Orissa Mission Press, 81

Orissa Tract Society, 82

Oriya Movement: Being a Demand for an United Orissa, The, 163

Oriya Swatantra Bhasa Nahe, 61-70

Palm Leaf Manuscripts, 82, 84, 182

Pani, Baisnab, 102-4

Peggs, J., 157

Phillip Duff Committee, 171

Pilgrim Tax, 108, 153, 162, 234

Place, 166, 167, 185, 199, 203, 212

Pollock, Shedon, 7-9, 47

On Mother Tongue, 47

On Vernacular, 7-9

Potti Sriramalu, 218

Prachi Samiti, 183

Praharaj, Gopal Candra, 31-33, 72-75, 101

Bhagawat Tungire Sandhya, 31

Purnachandra Bhasakosh, 72-75

Praja

As Projeny, 116

Prajaniti, 123-27

Prajashakti, 120

Prajatantra, 120-21

Provincial Congress Committee, 143

Public

Odia Public, 76, 78

Odia Public Sphere, 80, 85-88

Puri, 155-57, 161-62, 165-69

As a Problem for Colonial Governance, 161-62

As Heterotopia, 155-57

As Place of Pilgrimage, 165-69

Puri Temple Act of 1880, 126

Purusharthas, 126, 128

Rai, Gaurishankar, 83

Rai, Jogesh Chandra

Itihasara Krama, 182

Rai, Lala Ramnarayan, 76, 89, 90, 93, 94

Rai, Sadhucharan, 119-21

On Rajaniti, 119-20

On Rajashakti and Prajashakti, 120-21

Rajadroha, 132

Rajaniti

As Governance, 121-22

Odia Notions of Kingship, 115-20

Rajguru, Satya Narayan

On Odra-rastra, 187-90

Rana, Chandramohan

Itihas, 182 
Rao, Madhusudan, 86

Bharath Bhavana, 99

Navyuga, 99

Utkal Sangeet, 165

Rath, Gobinda Chandra, 86

Ratha Yatra, 155

Ray, Radhanath, 84, 86, 87, 164

Risley Circular, 18, 111, 137

Sacred Geography, 164

Sahu, Lakhshminarayan, 128

Samantaray, Natabar, 85, 87

Sambalpur Hiteisini, 84, 92, 102, 124

Sammillani, 107-8

Satyabadi Group, 128

Sedition, 132

Seditious Meetings and Treasonable Practices Bill, 37

Senapati, Fakir Mohan, 100-2, 164 Chcha Mana Atha Guntha, 100

Singh, Jaipal, 223-25

Singha, Jagabandhu, 128, 181, 184, 187, 191, 242

Prachin Utkal, 181

Sketra, 146

South Africa, 166

Space, 7, 13, 24-26, 29, 79, 100, 145, 150, 151

Odisha as Religious Space, 152-57

Stana, 146

States Reorganization Commission

Memoranda to, 221-23

Stirling, Andrew, 157

Sublimation, 5, 7, 11-13, 150-51, 201-4

Sutton, Amos, 87

Temple Entry, 155

Territorial Franchise, 107
Territory, 2, 3, 6, 7, 8, 10, 12, 13, 14, 24, $25,26,29,30,35,151,171,201,202$, 203, 205, 216, 226, 228

Tilak, Bal Gangadhar, 131-32

Swarajya, 131-32

Tooke, John Horne, 36-38

Toynbee, George, 157

Translation, 48-49, 62-63, 211

As Disruption, 211

Of Bengali Textbooks to Odia, 62-63

Of Epics to Odia, 48-49

Utkal Bhasha Uddhipani Sabha, 52, 81

Utkal Bhasha Unnati Bidhayini Sabha, 84

Utkal Dipika, 51, 69, 83-84, 92, 93, 94, 103, 125

Utkal Prabha, 76, 84, 89, 90, 92, 96, 241

Utkal Printing Company, 83, 84

Utkal Provincial Congress Committee, 143

Utkal Putra, 88

Utkal Sabha, 88, 112

Utkal Sahitya Samaj, ix, 98, 101, 103, 182,183

Utkal Sammillani, 121-30, 134, 136, 143-49

Utkal Tanneries, 113

Utkala, 184-89

Vaishnav Bhakti, 116

Vande Mataram, 114, 125

Vernacular

Authority of, 11

Paradigms of Understanding, 7-9

Powerlessness of, 10, 46-47

Vernacularization, 27, 33, 39, 47, 48

Wood's Despatch, 45, 50

Wordsworth, William, 38, 39, 41, 44, 98

Zeitgeist, 90, 91, 236, 240 
